\title{
Planejamento probabilístico usando programação dinâmica assíncrona e fatorada
}

\author{
Mijail Gamarra Holguin
}

\author{
DISSERTAÇÃO APRESENTADA \\ $\mathrm{AO}$ \\ Instituto De MATEMÁticA e EstatísticA \\ DA \\ Universidade De SÃo Paulo
}

\author{
Programa: Ciência da Computação \\ Orientadora: Profa. Dra. Leliane Nunes de Barros
}

Durante o desenvolvimento deste trabalho o autor recebeu auxílio financeiro da CAPES

São Paulo, abril de 2013 


\title{
Planejamento probabilístico usando programação dinâmica assíncrona e fatorada
}

\author{
Esta dissertação contém as correções e alterações \\ sugeridas pela Comissão Julgadora durante a defesa \\ realizada por Mijail Gamarra Holguin em 03/04/2013. \\ O original encontra-se disponível no Instituto de \\ Matemática e Estatística da Universidade de São Paulo.
}

Comissão Julgadora:

- Profa. Dra. Leliane Nunes de Barros (orientadora) - IME-USP

- Profa. Dra. Karina Valdivia Delgado - EACH-USP

- Prof. Dr. Carlos Henrique Costa Ribeiro - ITA 


\section{Agradecimentos}

À meu pai e minha mãe internos, que sempre estão junto comigo, só por causa deles que estou aqui. À meus pais que sempre estiveram me dando força e vontade de continuar com estes estudos, em especial à minha mãe, que me enviou para o Brasil. Às minhas irmãs e à Thani, que me deram apoio moral e emocional.

À professora Leliane Nunes, foi por ela que comecei pesquisar nesta área. Aos professores Karina Valdivia e Scott Sanner, que sempre estiveram me dando ideias para avançar na pesquisa.

Aos professores do Departamento de Computação do IME-USP, que contribuíram no crescimento do meu conhecimento. À CAPES pelo apoio financeiro para realização desta pesquisa.

Aos Professores Félix, Wilson, Jorge e Antonio pela força interna.

À meus colegas peruanos que me ensinaram todo o necessário para sobreviver na USP e em São Paulo.

À todos os meus colegas do laboratório, pela grata companhia e pela ajuda incondicional que permitiu o desenvolvimento deste trabalho.

E à toda minha torcida, que teve confiança e me deu o apoio suficiente para conseguir todo o que consegui e o que conseguirei. 


\section{Resumo}

Processos de Decisão Markovianos (Markov Decision Process - MDP) modelam problemas de tomada de decisão sequencial em que as possíveis ações de um agente possuem efeitos probabilísticos sobre os estados sucessores (que podem ser definidas por matrizes de transição de estados). Programação dinâmica em tempo real (Real-time dynamic programming - RTDP), é uma técnica usada para resolver MDPs quando existe informação sobre o estado inicial. Abordagens tradicionais apresentam melhor desempenho em problemas com matrizes esparsas de transição de estados porque podem alcançar eficientemente a convergência para a política ótima, sem ter que visitar todos os estados. Porém essa vantagem pode ser perdida em problemas com matrizes densas de transição, nos quais muitos estados podem ser alcançados em um passo (por exemplo, problemas de controle com eventos exógenos). Uma abordagem para superar essa limitação é explorar regularidades existentes na dinâmica do domínio através de uma representação fatorada, isto é, uma representação baseada em variáveis de estado. Nesse trabalho de mestrado, propomos um novo algoritmo chamado de FactRTDP (RTDP Fatorado), e sua versão aproximada aFactRTDP (RTDP Fatorado e Aproximado), que é a primeira versão eficiente fatorada do algoritmo clássico RTDP. Também propomos outras 2 extensões desses algoritmos, o FactLRTDP e aFactLRTDP, que rotulam estados cuja função valor convergiu para o ótimo. Os resultados experimentais mostram que estes novos algoritmos convergem mais rapidamente quando executados em domínios com matrizes de transição densa e tem bom comportamento online em domínios com matrizes de transição densa com pouca dependência entre as variáveis de estado. Palavras-chave: Planejamento Probabilístico, Processo de Decisão Markoviano, Programação Dinâmica em Tempo Real, Raciocínio Aproximado. 


\begin{abstract}
Markov Decision Process (MDP) model problems of sequential decision making, where the possible actions have probabilistic effects on the successor states (defined by state transition matrices). Real-time dynamic programming (RTDP), is a technique for solving MDPs when there exists information about the initial state. Traditional approaches show better performance in problems with sparse state transition matrices, because they can achieve the convergence to optimal policy efficiently, without visiting all states. But, this advantage can be lose in problems with dense state transition matrices, in which several states can be achieved in a step (for example, control problems with exogenous events). An approach to overcome this limitation is to explore regularities existing in the domain dynamics through a factored representation, i.e., a representation based on state variables. In this master thesis, we propose a new algorithm called FactRTDP (Factored RTDP), and its approximate version aFactRTDP (Approximate and Factored RTDP), that are the first factored efficient versions of the classical RTDP algorithm. We also propose two other extensions, FactLRTDP and aFactLRTDP, that label states for which the value function has converged to the optimal. The experimental results show that when these new algorithms are executed in domains with dense transition matrices, they converge faster. And they have a good online performance in domains with dense transition matrices and few dependencies among state variables.
\end{abstract}

Keywords: Probabilistic Planning, Markov Decision Process, Real-Time Dynamic Programming, Approximate Reasoning. 


\section{Sumário}

Lista de Abreviaturas $\quad$ xi

Lista de Símbolos $\quad$ xiii

Lista de Figuras $\quad$ Xv

Lista de Tabelas $\quad$ xvii

1 Introdução 1

1.1 Problemas e Domínios de Planejamento . . . . . . . . . . . . . . . . . 2

1.2 Soluções para Planejamento Probabilístico . . . . . . . . . . . . . . . . 3

1.3 Motivação . . . . . . . . . . . . . . . . . . . . . . . . 4

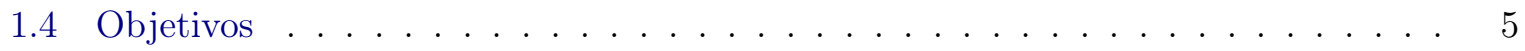

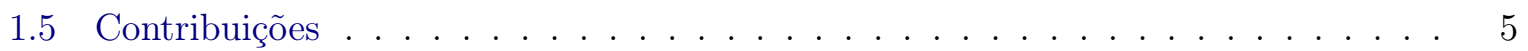

1.6 Organização do Trabalho . . . . . . . . . . . . . . . . . . . . 5

2 Processo de Decisão Markoviano: modelo enumerativo $\quad 7$

2.1 Processo de Decisão Markoviano _ . . . . . . . . . . . . . . . . . . . . . . . . 7

2.1.1 Avaliação de políticas: horizonte infinito . . . . . . . . . . . . . . . . . 10

2.1.2 Avaliação de políticas: horizonte finito . . . . . . . . . . . . . . . . . . . 11

2.2 Soluções para MDPs . . . . . . . . . . . . . . . . . . . . . . . . . 11

2.2 .1 Iteração de Valor . . . . . . . . . . . . . . . . . . . . . . . . . . . 12

2.2 .2 Iteração de Política . . . . . . . . . . . . . . . . . . . . . . . . . . 13

2.2.3 RTDP: Programação Dinâmica em Tempo Real . . . . . . . . . . . . . . . . 14

2.2.4 LRTDP: Programação Dinâmica em Tempo Real Rotulado . . . . . . . . 16

2.2.5 BRTDP: Programação Dinâmica em Tempo Real Limitado . . . . . . . . 20

3 Processo de Decisão Markoviano Fatorado $\quad 23$

3.1 Modelo fatorado . . . . . . . . . . . . . . . . . . . . . . . 23

3.1.1 Representação fatorada de estados . . . . . . . . . . . . . . . . 23

3.1.2 Transições e Recompensas Fatoradas . . . . . . . . . . . . . . . . . . . . 23

3.2 Diagramas de Decisão . . . . . . . . . . . . . . . . . . . 26

3.2 .1 Operações sobre conjuntos com BDDs . . . . . . . . . . . . . . 28

3.2 .2 Diagramas de Decisão Algébrico (ADD) . . . . . . . . . . . . . . . . . . 29

3.3 Construção e Manipulação de Diagramas de Decisão ........... 30 
3.3.1 Construção de Diagramas de Decisão reduzidos . . . . . . . . . . . . . . . 30

3.3.2 Operações sobre Diagramas de Decisão . . . . . . . . . . . . . . . . . . . . 32

4 Soluções Fatoradas para MDPs $\quad 37$

4.1 Soluções Síncronas para MDP Fatorado . . . . . . . . . . . . . . . . . . . 37

4.1.1 SPUDD: Iteração de Valor usando Diagramas de Decisão . . . . . . . . . 37

4.1 .2 APRICODD: Iteração de Valor Aproximada . . . . . . . . . . . . . . . 38

4.2 Soluções Assíncronas para MDPs fatorados . . . . . . . . . . . . . . . . 39

4.2.1 sRTDP: RTDP usando Diagramas de Decisão . . . . . . . . . . . . . . . 39

4.2 .2 sBRTDP: BRTDP usando Diagramas de Decisão . . . . . . . . . . . . . . 42

5 Programação Dinâmica Assíncrona e Fatorada: novos algoritmos 45

5.1 FactRTDP: RTDP Fatorado . . . . . . . . . . . . . . . . . . . 45

5.2 FactLRTDP: RTDP Fatorado e Rotulado . . . . . . . . . . . . . . . . . 48

5.3 aFactRTDP: RTDP Fatorado e Aproximado . . . . . . . . . . . . . . . 51

5.4 aFactLRTDP: LRTDP Fatorado e Aproximado . . . . . . . . . . . . 56

6 Linguagens de Definição de Domínios de Planejamento $\quad 57$

6.1 Linguagem de Definição de Domínios de Planejamento (PDDL) . . . . . . . . . . 58

6.1 .1 Extensões do PDDL . . . . . . . . . . . . . . . . . . . . 61

6.1 .2 PPDDL: PDDL com probabilidades . . . . . . . . . . . . . 62

6.2 Linguagem Relacional de Diagramas Dinâmicos de Influência . . . . . . . . . . . 64

7 Domínios de Planejamento Probabilístico $\quad 73$

7.1 Descrição dos domínios de teste . . . . . . . . . . . . . . . . . . . 74

7.1 .1 Crossing Traffic . . . . . . . . . . . . . . . . . . . . 74

7.1 .2 Elevators . . . . . . . . . . . . . . . . . . . 75

7.1 .3 Game of Life . . . . . . . . . . . . . . . . . . . . . . 76

7.1 .4 Navigation . . . . . . . . . . . . . . . . . . . . . . . . . 77

7.1 .5 Recon .............................. 78

$7.1 .6 \quad$ Skill Teaching . . . . . . . . . . . . . . . . . . . . . . . . . 79

7.1 .7 SysAdmin . . . . . . . . . . . . . . . . . . . . 80

7.1 .8 Traffic . . . . . . . . . . . . . . . . . . . 81

7.2 Resumo da complexidade dos domínios . . . . . . . . . . . . . . . . . 82

8 Resultados Experimentais $\quad \mathbf{8 5}$

8.1 Planejamento (online) na IPPC-2011 . . . . . . . . . . . . . . . 85

8.1 .1 Simulador rddlsim . . . . . . . . . . . . . . . . . . 85

8.1 .2 Execução dos algoritmos de modo online . . . . . . . . . . . . . . . . 87

8.1.3 Os planejadores vencedores da IPPC-2011: Prost e Glutton . . . . . . . . 88

8.2 Algoritmos usados nas Análises . . . . . . . . . . . . . . . . . . . . . . 89

8.3 Análise de Convergência . . . . . . . . . . . . . . . . . . . . . . . . . 90 
8.3.1 Domínio Denso: Game of Life . . . . . . . . . . . . . . . . . . . . . 92

8.3.2 Domínio Esparso: Navigation . . . . . . . . . . . . . . . . . . 92

8.4 Análise de desempenho online dos algoritmos . . . . . . . . . . . . . . . . . . . 95

8.4.1 Domínios Densos ........................ 95

8.4 Domínios Esparsos ....................... 97

$\begin{array}{lr}\text { Conclusões e Trabalhos Futuros } & 101\end{array}$

A Exemplo do funcionamento do algoritmo APLICA 105

B Cálculo fatorado das porcentagens de densidade e dependência 107

$\begin{array}{lr}\text { C Sistema rddlsim } & 109\end{array}$

D Descrição em RDDL dos domínios do IPPC 113

D.1 Descrição do domínio Crossing Traffic . . . . . . . . . . . . . . . . . . . . . . . 113

D.2 Descrição do domínio Elevators . . . . . . . . . . . . . . . . . . . . . . . . . . . . 114

D.3 Descrição do domínio Game of Life . . . . . . . . . . . . . . . . . . . . . . . . . . 117

D.4 Descrição do domínio Navigation . . . . . . . . . . . . . . . . . . . . . . . . . . . 118

D.5 Descrição do domínio Recon . . . . . . . . . . . . . . . . . . . . . . . . . 119

D.6 Descrição do domínio Skill Teaching . . . . . . . . . . . . . . . . . . . . . . . . . 121

D.7 Descrição do domínio SysAdmin . . . . . . . . . . . . . . . . . . . . . . . . . . . 123

D.8 Descrição do domínio Traffic . . . . . . . . . . . . . . . . . . . . . . . . . . . . . 123

$\begin{array}{lr}\text { Referências Bibliográficas } & 127\end{array}$ 
x SUMÁRIO 


\section{Lista de Abreviaturas}

$\begin{array}{ll}\text { ADD } & \text { Algebraic Decision Diagram. } \\ \text { ADL } & \text { Action Description Language. } \\ \text { aFactLRTDP } & \text { Approximate Factored Labeled Real-Time Dynamic Programming. } \\ \text { aFactRTDP } & \text { Approximate Factored Real-Time Dynamic Programming. } \\ \text { APRICODD } & \text { Approximate policy construction using decision diagrams. } \\ \text { BDD } & \text { Binary Decision Diagram. } \\ \text { BRTDP } & \text { Bounded Real-Time Dynamic Programming. } \\ \text { CSI } & \text { Context-Specific Independence. } \\ \text { CPT } & \text { Conditional Probability Table. } \\ \text { DBN } & \text { Dynamic Bayesian Network. } \\ \text { DD } & \text { Decision Diagram. } \\ \text { FactLRTDP } & \text { Factored Labeled Real-Time Dynamic Programming. } \\ \text { FactRTDP } & \text { Factored Real-Time Dynamic Programming. } \\ \text { IA } & \text { Inteligência Artificial. } \\ \text { MDP } & \text { Markov Decision Process. } \\ \text { PDDL } & \text { Planning Domain Definition Language. } \\ \text { PPDDL } & \text { Probabilistic Planning Domain Definition Language. } \\ \text { RDDL } & \text { Relational Dynamic Influence Diagram Language. } \\ \text { RTDP } & \text { Real-Time Dynamic Programming. } \\ \text { LRTDP } & \text { Labeled Real-Time Dynamic Programming. } \\ \text { SPUDD } & \text { Stochastic Planning using Decision Diagrams. } \\ \text { sBRTDP } & \text { Symbolic Bounded Real-Time Dynamic Programming. } \\ \text { sRTDP } & \text { Symbolic Real-Time Dynamic Programming. } \\ \text { SSP } & \text { Stochastic Shortest Path. } \\ \text { STRIPS } & \text { Stanford Research Institute Problem Solver. } \\ & \end{array}$


xii LISTA DE ABREVIATURAS 


\section{Lista de Símbolos}

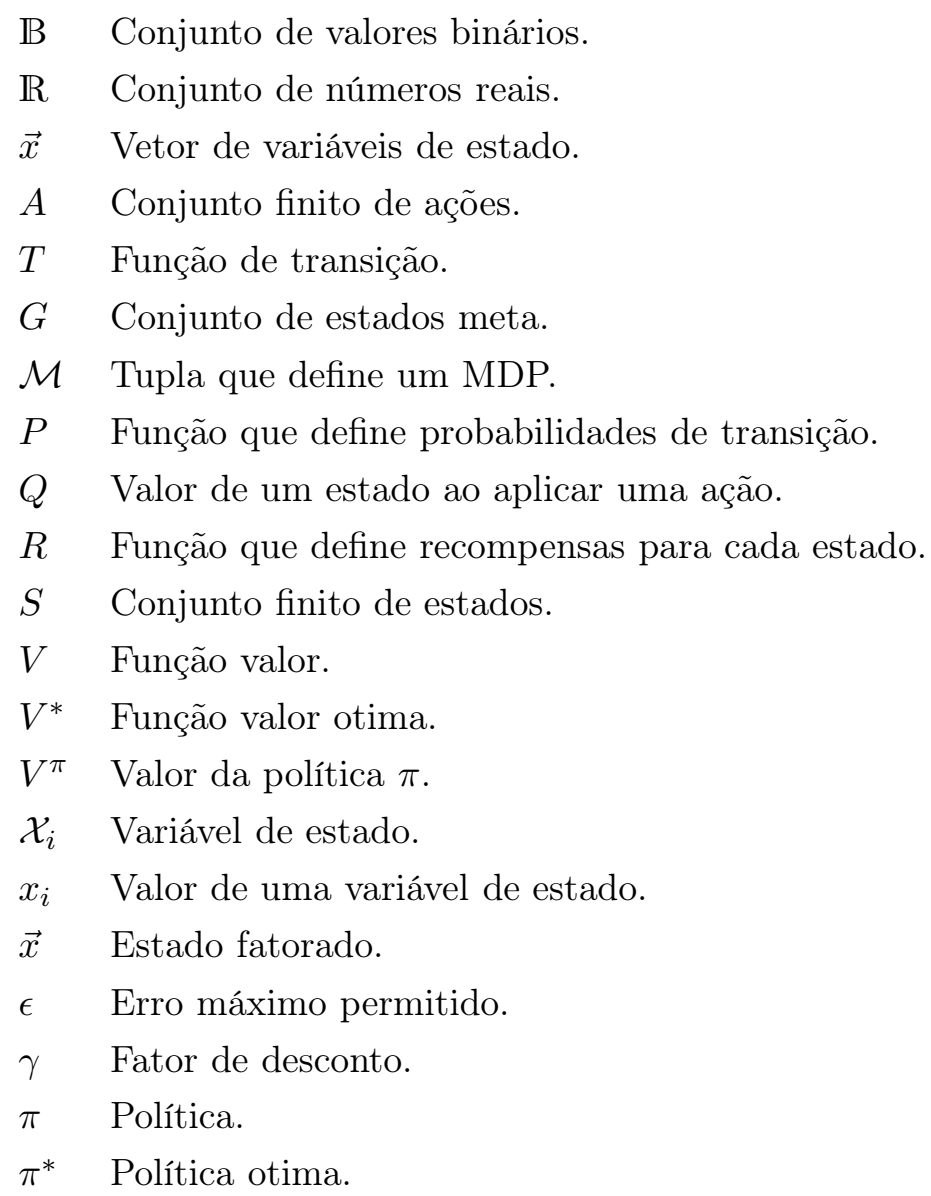




\section{Lista de Figuras}

1.1 Classificação dos domínios de planejamento probabilístico. . . . . . . . . . . . 3

2.1 Dinâmica de transição de estados de um MDP (Boutilier, 2002) . . . . . . . . . 8

2.2 Matriz de transição para o problema do SysAdmin com 3 computadores. . . . . . 9

2.3 Dinâmica de transição de estados. . . . . . . . . . . . . . . . . . . . . . . 13

2.4 Maximização da açao segundo o valor $Q^{t} \ldots \ldots \ldots \ldots \ldots \ldots$

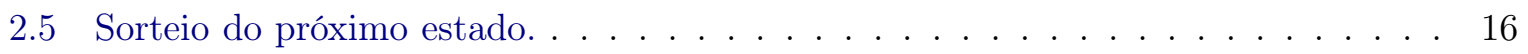

2.6 Exemplo de um trial de RTDP que terminou ao encontrar um estado meta. . . . 16

2.7 Exemplo de um trial de LRTDP. . . . . . . . . . . . . . . . . . . . . . . . . . . . 19

3.1 Topologia do exemplo de três computadores do SysAdmin. . . . . . . . . . . . . 24

3.2 Representação fatorada de um problema do domínio SysAdmin. . . . . . . . . . . 24

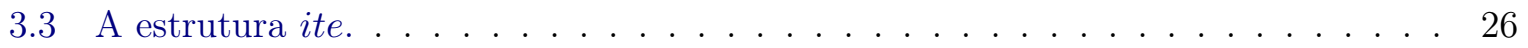

3.4 Árvore de decisão para a expressão $\left(\mathcal{X}_{1} \vee \mathcal{X}_{2}\right) \wedge\left(\mathcal{X}_{2} \vee \mathcal{X}_{3}\right) \ldots \ldots \ldots \ldots \ldots . \ldots 27$

3.5 Árvore de decisão para a expressão $\left(\mathcal{X}_{1} \leftrightarrow \mathcal{X}_{2}\right) \wedge\left(\mathcal{X}_{3} \leftrightarrow \mathcal{X}_{4}\right) \ldots \ldots \ldots \ldots \ldots . . \ldots 27$

3.6 Compartilhamento de grafos isomorfos na arvore de decisão da Figura 3.5. . . . . 28

3.7 Compartilhamento de grafos isomorfos e eliminação de testes redundantes. . . . . 28

3.8 Exemplo de representação de uma função $f: \mathbb{B}^{n} \rightarrow \mathbb{R}$ com um ADD. . . . . . . . 29

3.9 Exemplo de um CPT representado com um ADD . . . . . . . . . . . . . . . . 29

3.10 A estrutura nó, para um nó interno $F_{h}$ e $F_{l}$ são os ramos do nó (Sanner, 2008). . 30

3.11 Notação dos ADDs para a Recursão do algoritmo Aplica (Sanner, 2008). . . . . 33

3.12 Exemplo de marginalização de um ADD . . . . . . . . . . . . . . . . 35

4.1 Processo de generalização por valor para o estado abstrato $E$ no sRTDP. . . . . . 41

4.2 Cálculo da distribuição $b\left(x^{\prime}\right)$ para o sBRTDP (Delgado et al., 2010). . . . . . . . 43

5.1 Exemplo, passo a passo, do cálculo da máscara $\vec{x}_{D D} \ldots \ldots \ldots \ldots \ldots$. . . . 47

5.2 Exemplo de atualização do algoritmo FactRTDP. . . . . . . . . . . . . . . 47

5.3 Ilustração das pilhas closed e open. . . . . . . . . . . . . . . . . . . . 48

5.4 Forma de agrupar os nós terminais. . . . . . . . . . . . . . . 55

5.5 ADD com $4 \%$ de aproximação feito sobre o ADD da Figura 5.2d. . . . . . . . . 56

6.1 Código em PDDL do domínio Gripper. . . . . . . . . . . . . . . . . . . . . 59

6.2 Código em PDDL de um problema do domínio Gripper. . . . . . . . . . . . . 60

6.3 Parte do código em Linguagem PPDDL do domínio Delivery Coffee. . . . . . . . 63 
6.4 Exemplo de declaração de tipos. . . . . . . . . . . . . . . . . . . . . 65

6.5 Exemplo de declaração de pvariables. . . . . . . . . . . . . . . . 66

6.6 Exemplo de declaração de CPFs. . . . . . . . . . . . . . . . . . . . . . . 67

6.7 Tabela de probabilidade condicional para $P\left(p^{\prime} \mid p, r, a\right) \ldots \ldots \ldots \ldots$

6.8 Tabela de probabilidade condicional para $P\left(q^{\prime} \mid q, r, a\right) \ldots \ldots \ldots \ldots$

6.9 Tabela de probabilidade condicional para $P\left(r^{\prime} \mid r, q, a\right) \ldots \ldots \ldots \ldots$

6.10 Código em RDDL do domínio Game of Life. . . . . . . . . . . . . . . . . . . 69

6.11 Código em RDDL dos não-fluentes da instância 1 do domínio Game of Life. . . . 70

6.12 Código em RDDL da instância 1 do domínio Game of Life. . . . . . . . . . . . 70

7.1 Simulador do sistema rddlsim para o domínio Crossing Traffic. . . . . . . . . . 75

7.2 Simulador do sistema rddlsim para o domínio Navigation. . . . . . . . . . . . 77

7.3 Classificação dos domínios de planejamento probabilístico. . . . . . . . . . . 83

8.1 Divisão de tempos para a competição. . . . . . . . . . . . . . . . . 87

8.2 Convergência para o Game of Life . . . . . . . . . . . . . . . . . . . . . . . 91

8.3 Convergência para o Navigation. . . . . . . . . . . . . . . . . . 93

8.4 Convergência para o Navigation. . . . . . . . . . . . . . . . . . 94

8.5 Desempenho dos algoritmos nos domínios densos da IPPC 2011 . . . . . . . . . 96

8.6 Desempenho online nos domínios esparsos 1. . . . . . . . . . . . . . . . . 98

8.7 Desempenho online nos domínios esparsos 2. . . . . . . . . . . . . . . . . . 99

A.1 Um exemplo de funcionamento do algoritmo AplicA. . . . . . . . . . . . . . 105

C.1 Diagrama de Influência Gerado pelo simulador. . . . . . . . . . . . . . . . . . 109

C.2 Diagrama de Decisão Algébrico Gerado pelo simulador. . . . . . . . . . . . . . . . 110 


\section{Lista de Tabelas}

3.1 Equivalência entre as operações de BDDs e operações de conjuntos. . . . . . . . . 28

3.2 Entradas e saídas para CalcularResultado. . . . . . . . . . . . . . . 33

7.1 Características do domínio Crossing Traffic. . . . . . . . . . . . . 75

7.2 Características do domínio Elevators. . . . . . . . . . . . . . . . . 76

7.3 Características do domínio Game of Life. . . . . . . . . . . . . . . . 77

7.4 Características do domínio Navigation. . . . . . . . . . . . . . 78

7.5 Características do domínio Recon. . . . . . . . . . . . . . . . . . . . 79

7.6 Características do domínio Skill Teaching. . . . . . . . . . . . . . . . 80

7.7 Características do domínio SysAdmin. . . . . . . . . . . . . . . 81

7.8 Configuração do semáforo do domínio Traffic. . . . . . . . . . . . . . . . . 81

7.9 Características do domínio Traffic. . . . . . . . . . . . . . . . 82

7.10 Características dos domínios da IPPC 2011. . . . . . . . . . . . . . . . 82

8.1 Características dos domínios da IPPC 2011. . . . . . . . . . . . . . . . . . 90 
xviii

LISTA DE TABELAS 


\section{Lista de Algoritmos}

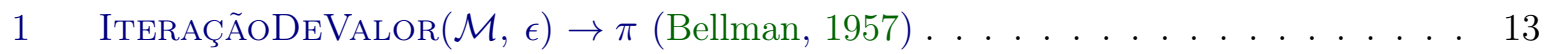

2 IteraçãoDePolítica $(\mathcal{M}) \rightarrow \pi($ Howard, 1960) $\ldots \ldots \ldots \ldots \ldots \ldots$

$3 \operatorname{RTDP}\left(\mathcal{M}, s_{0}, G, \Delta t, \max\right.$ Depth $) \rightarrow \pi$ (Barto et al., 1995) . . . . . . . 15

$4 \operatorname{LRTDP}\left(\mathcal{M}, s_{0}, G, \Delta t, \max\right.$ Depth,$\left.\epsilon\right) \rightarrow \pi$ (Bonet e Geffner, 2003) $\ldots \ldots \ldots$

$5 \quad \operatorname{CheckSolved}(s, \epsilon, V) \rightarrow r v($ Bonet e Geffner, 2003) . . . . . . . . . . 18

$6 \operatorname{BRTDP}\left(\mathcal{M}, s_{0}, G, \Delta t, \max\right.$ Depth,$\left.\epsilon\right) \rightarrow \pi$ (McMahan et al., 2005) $\ldots \ldots \ldots .21$

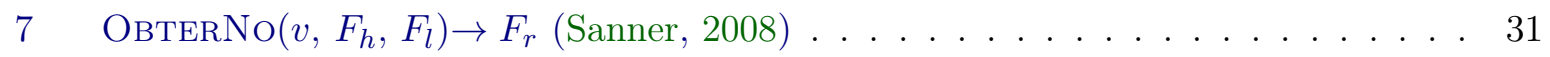

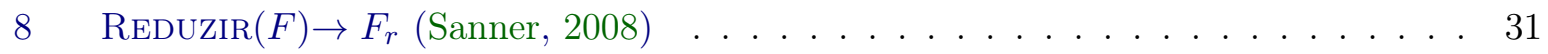

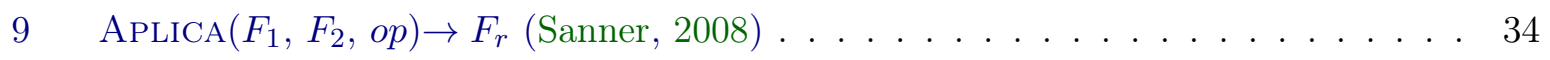

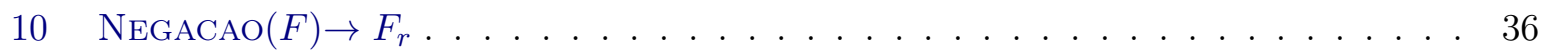

$11 \operatorname{sRTDP}\left(\mathcal{M}, V_{D D}^{0}, \vec{x}_{0}, G, \Delta t\right.$, maxDepth, $\left.\epsilon\right) \rightarrow \pi($ Feng et al., 2003) $\ldots \ldots . . \quad 40$

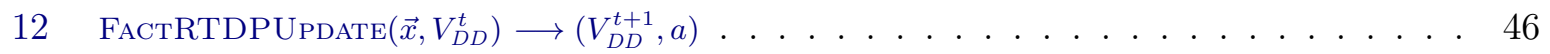

13 FactCheckSolved $\left(\vec{x}, \epsilon, V_{D D}^{t}\right) \rightarrow r v \ldots \ldots \ldots \ldots \ldots \ldots$

14 CalcularSucessores $(\vec{x}, a) \rightarrow{\text { successor } s_{D D} \ldots \ldots \ldots \ldots \ldots}_{\ldots} \ldots \ldots$

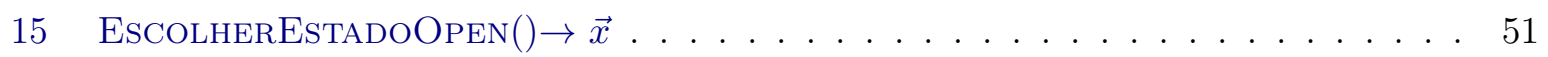

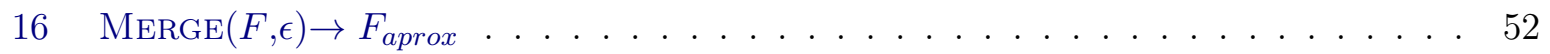

17 ColetanosTerminais $(F$, nosTerminais $) \ldots \ldots \ldots \ldots \ldots$

18 MapearNosMedia(nosTerminais, $\epsilon) \rightarrow$ MapaSubstituicao . . . . . . . . . . 54

19 MapearNosmax $($ nosTerminais, $\epsilon) \rightarrow$ MapaSubstituicao . . . . . . . . . . . 54

20 SubstituirNos $(F$, MapaSubstituicao $) \rightarrow F_{\text {sub }} \ldots \ldots \ldots \ldots \ldots \ldots$

21 ExecutarOnline $\left(s_{0}\right.$, base, Horizonte,$\left.V_{D D}^{0}\right) \ldots \ldots \ldots \ldots \ldots$ 


\section{Capítulo 1}

\section{Introdução}

Planejamento é o raciocínio necessário para a tomada de decisão. Todos os dias nos deparamos com a tarefa de planejar nossas ações para alcançar determinadas metas. De fato, a habilidade de planejar tarefas é um aspecto fundamental do comportamento inteligente e, já há mais de quarenta anos (McCarthy, 1963; Newell e Simon, 1963), sua automatização tem sido um dos principais tópicos de pesquisa da área de Inteligência Artificial (Russell e Norvig, 2010).

Planejamento é ainda mais importante em tarefas complexas que tenham requisitos de eficiência e segurança. Por exemplo, precisamos planejar para uma operação de resgate após a ocorrência de um desastre natural, como por exemplo, um terremoto ou uma inundação. Essa operação envolve muitos atores bem como a comunicação entre eles e seu transporte, requerendo assim um planejamento cuidadoso e uma avaliação de planos alternativos.

Em planejamento, a forma com que um sistema evolui a cada ação executada, chamada de dinâmica das ações, pode ser: determinística, não-determinística ou probabilística. Enquanto nos modelos determinísticos não há incerteza no efeito das ações (executar uma ação em um determinado estado sempre leva o agente a um único estado), nos modelos não-determinísticos e probabilísticos existem diferentes formas de incerteza.

A linha de planejamento que lida com a dinâmica de ações determinística é chamada de planejamento clássico. Um estado do mundo pode ser representado por um conjunto $\Sigma$ de átomos que denotam proposições verdadeiras nesse estado. Uma maneira simples de representar uma ação $\alpha$ é como uma tupla da forma $\langle\operatorname{pre}(\alpha), \operatorname{add}(\alpha), \operatorname{del}(\alpha)\rangle$, onde $\operatorname{pre}(\alpha)$ é um conjunto de átomos que denotam proposições que devem ser verdadeiras no estado em que a ação $\alpha$ é executada (ou seja, precondições da ação); add( $\alpha$ ) é um conjunto de átomos que denotam proposições que passam a ser verdadeiras, após a execução da ação $\alpha$ (ou seja, efeitos positivos da ação) e del $(\alpha)$ é um conjunto de átomos que denotam proposições que passam a ser falsas após a execução da ação $\alpha$ (ou seja, efeitos negativos da ação) (Pereira, 2003).

Dado um estado $\Sigma$ e uma ação $\alpha$, dizemos que $\alpha$ é aplicável em $\Sigma$ se e somente se $\operatorname{pre}(\alpha) \subseteq \Sigma$. Ademais, se uma ação $\alpha$ é aplicável em um estado $\Sigma$, então o estado resultante da execução dessa ação é representado pelo conjunto $\Sigma+\operatorname{add}(\alpha)-\operatorname{del}(\alpha)$, denotado por $\operatorname{res}(\alpha, \Sigma)$ (Pereira, 2003).

Um problema de planejamento é definido por uma tupla $\mathcal{P}$, da forma $\langle\mathcal{A}, \mathcal{I}, \mathcal{G}\rangle$, onde $\mathcal{A}$ é o conjunto de ações do domínio de planejamento considerado, $\mathcal{I}$ é uma estado inicial e $\mathcal{G}$ é um conjunto de estados meta.

Dado um problema de planejamento $\mathcal{P}=\langle\mathcal{A}, \mathcal{I}, \mathcal{G}\rangle$ e uma seqüência de ações $\Pi=\left\langle\alpha_{1}, \alpha_{2}, \cdots, \alpha_{n}\right\rangle$, 
dizemos que П é uma solução (ou seja, um plano solução) para o problema de planejamento $\mathcal{P}$, se contém apenas ações do domínio considerado e é executável, ou seja, $\left(\right.$ pre $\left(\alpha_{i}\right) \subseteq \mathcal{I}$ e para $\left.1<i \leq n, \operatorname{pre}\left(\alpha_{i}\right) \subseteq \operatorname{res}\left(\alpha_{i-1}, s\right)\right)$ tal que $s \in \mathcal{G}$.

A linha de planejamento que lida com a dinâmica probabilística de ações é chamada de planejamento probabilístico e está baseada em Processos de Decisão Markovianos (Markov Decision Process - MDPs) (Boutilier et al., 1999). Esta forma de planejamento é uma importante extensão de planejamento clássico, que nos permite tratar problemas em que as ações do agente têm efeitos incertos. A diferença para planejamento clássico é que as soluções do planejamento probabilístico não são seqüências de ações, mas são funções que mapeiam estados para ações, chamadas de políticas.

O desempenho de um algoritmo de planejamento probabilístico depende das características dos domínios de planejamento.

\subsection{Problemas e Domínios de Planejamento}

Exemplo 1.1.1. SysAdmin(Guestrin et al., 2003).

Este dominio descreve o problema em que um agente deve administrar um conjunto de $n$ computadores $c_{1}, c_{2}, \cdots, c_{n}$ conectados de acordo com alguma topologia. Em cada estágio os computadores podem estar funcionando ou não. Um estado para este dominio é definido através da configuração do estado (funcionando ou não) de cada computador, por exemplo, um possivel estado do domínio é a configuração em que todos os computadores estão funcionando e outro estado é a configuração em que só o computador $c_{n-1}$ está funcionando.

Em cada estágio do problema o agente pode não fazer nada ou reiniciar um computador. Um computador reiniciado tem $100 \%$ de probabilidade de funcionar no próximo passo. A probabilidade de que um computador em funcionamento continue funcionando no próximo passo depende do número de computadores aos quais ele está conectado e que estão em funcionamento. Este dominio também define uma probabilidade de que um computador que não funcione passe a funcionar no próximo passo. A recompensa de cada estado é o número de computadores que estão funcionando menos uma penalidade, caso o agente reinicie algum computador. Uma política ótima deveria reiniciar o computador que tem mais impacto na recompensa futura.

A complexidade dos domínios de planejamento probabilístico envolve três características importantes:

- a quantidade total de variáveis de estado e seus domínios de valores e consequentemente de estados,

- quantidade de estados sucessores nas transições e

- a dependência entre as variáveis do domínio nas transições.

Considerando o domínio do Exemplo 1.1.1, suponha que o estado $s$ é o estado em que todos os computadores não estão funcionando e a ação $a$ é não fazer nada. Assim, todos os computadores podem estar funcionando ou não no próximo passo, de acordo com uma distribuição de probabilidades. Portanto, neste exemplo, quando a ação $a$ é aplicada no estado $s$, o número de 
estados que pode ser atingido é o tamanho do espaço de estados (uma vez que todas as combinações dos computadores estarem funcionando ou não, são situações possíveis). Assim, dizemos que a ação a do domínio SysAdmin permite que o estado $s$ tenha $100 \%$ de estados sucessores com relação ao espaço de estados. Como esta porcentagem é a mesma para qualquer estado, então a ação a tem uma matriz de transição densa e por isso dizemos que o domínio SysAdmin é um domínio denso.

Considerando novamente o domínio SysAdmin, as variáveis deste domínio são: $c_{1}, c_{2}, \cdots, c_{n}$ e o valor de cada variável é o estado do computador, ou seja, se ele está funcionando ou não. Se uma ação reiniciar é aplicada ao computador $c_{2}$, a probabilidade dos outros computadores que estão em funcionamento continuarem funcionando no próximo estado, depende dos computadores aos quais eles estão conectados e se eles estão em funcionamento. Suponha que o computador $c_{3}$ está conectado aos computadores $c_{1}, c_{4}, c_{7}$ e $c_{8}$. Então, a transição do valor do computador $c_{3}$ depende desses quatro computadores, isto é, a variável $c_{3}$ depende do valor das variáveis $c_{1}$, $c_{4}, c_{7}$ e $c_{8}$. No caso do domínio SysAdmin, a dependência entre variáveis é diferente para cada topologia definida na instância do domínio. Se na topologia um computador está conectado a $10 \%$ do total de computadores, então dizemos que essa instância é uma instância com pouca dependência entre as variáveis de estado.

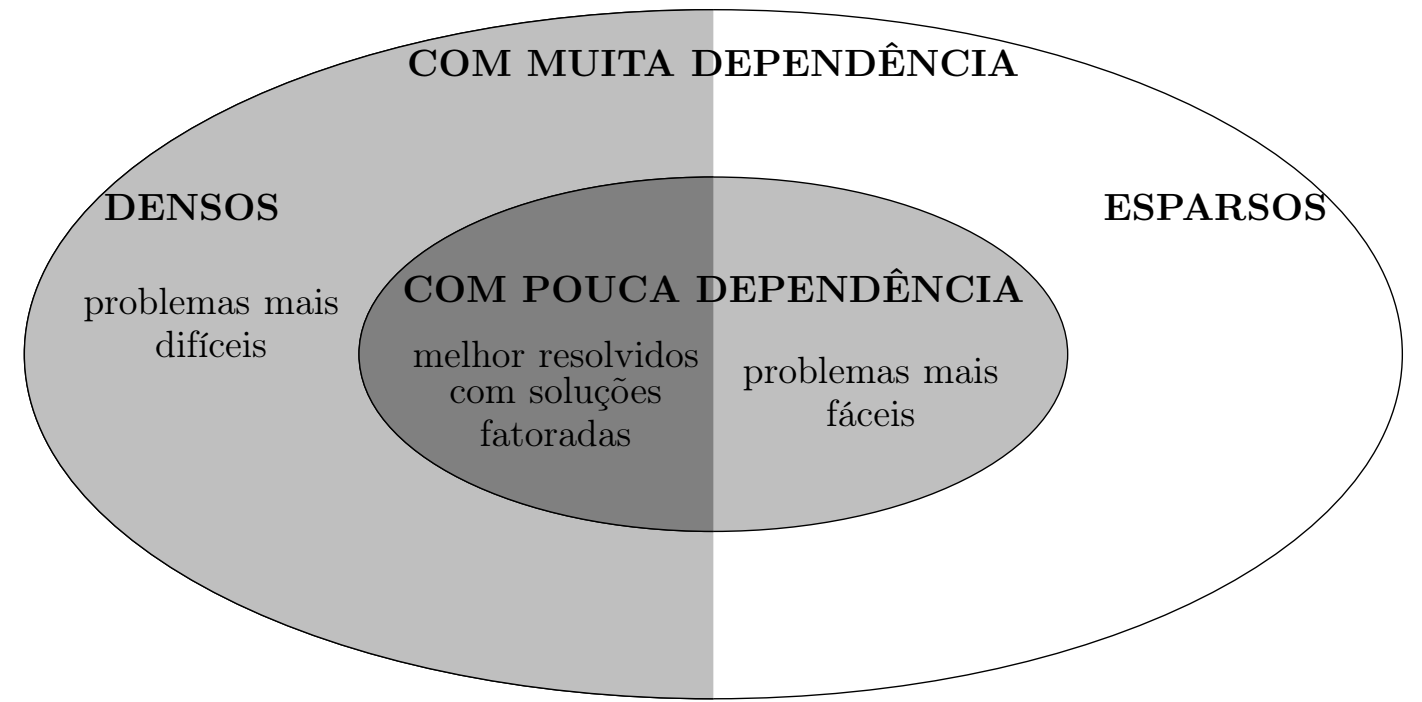

Figura 1.1: Classificação dos domínios de planejamento probabilístico.

Na Figura 1.1, a elipse maior representa todo o espaço de domínios de planejamento probabilístico. A parte esquerda da elipse representa os domínios densos e a parte direita representa os domínios esparsos. A elipse menor representa o subconjunto de domínios com pouca dependência nas variáveis de estado e o restante do conjunto representa os domínios com muita dependência nas variáveis de estado.

\subsection{Soluções para Planejamento Probabilístico}

As soluções mais conhecidas para MDPs assumem uma representação enumerativa de todos os estados, entre elas pode-se destacar: Iteração de Valor (Bellman, 1957), Iteração de Política 
(Howard, 1960) e Programação Dinâmica em Tempo Real (Real time Dynamic Programming - RTDP) (Barto et al., 1995). O algoritmo de Iteração de Valor atribui um valor para cada estado do sistema e, em cada iteração, atualiza o valor de todos os estados. Por esta razão ele é chamado de solução síncrona. Já o algoritmo RTDP só atualiza os estados que estão no caminho de alguma meta, durante sucessivos processos de simulação. Por este motivo ele é chamado de solução assíncrona. O algoritmo RTDP (e suas extensões) é considerado uma das principais abordagens para revolver MDPs de maneira eficiente, sendo que o algoritmo reconhecido como o mais eficiente é o LRTDP (Labeled Real Time Dynamic Programming) (Bonet e Geffner, 2003), que verifica a convergência de um estado $s$ através da construção do grafo guloso com raiz em $s$ e estados alcançáveis a partir de $s$. Se todos os estados desse grafo guloso já convergiram (a menos de um valor $\epsilon$ ), o estado $s$ pode ser considerado convergido.

Uma outra abordagem importante para lidar com MDPs com espaço de estados grande é utilizar uma representação fatorada do estado usando múltiplas variáveis de estado (MDPs fatorados). Por exemplo, um estado $s$ pode ser representado pelas variáveis de estado $\mathcal{X}_{1}=0$, $\mathcal{X}_{2}=0$ e $\mathcal{X}_{3}=0$. Soluções recentes exatas e aproximadas para MDPs fatorados exploram a estrutura de cada domínio, representada de forma fatorada, e resolvem problemas com ordem de magnitude maior do que as soluções usando abordagens clássicas enumerativas de programação dinâmica. As principais soluções para MDPs fatorados são baseadas em programação dinâmica. SPUDD (Hoey et al., 1999) estende o algoritmo de Iteração de Valor e faz uso de Redes Bayesianas Dinâmicas (Dynamic Bayesian Networks - DBNs) (modelo gráfico para representar independências probabilísticas) e Diagramas de Decisão Algébrica (Algebraic Decision Diagram - ADDs)-uma estrutura de dados para representar funções $\{0,1\}^{n} \rightarrow \mathbb{R}$, facilitando a representação e computação em domínios fatorados.

Existem ainda formas de combinar as vantagens do SPUDD com as vantagens do RTDP (chamada de RTDP fatorado). São dois os trabalhos nessa linha de pesquisa: sRTDP (Feng et al., 2003) e sBRTDP (Delgado et al., 2010). O sRTDP é uma versão do RTDP que usa uma representação fatorada de MDPs e atualiza um subconjunto do espaço de estados em cada passo. $\mathrm{O}$ sBRTDP é uma outra versão do RTDP que também usa uma representação fatorada de MDPs. Diferentemente do sRTDP, sBRTDP atualiza um estado em cada passo e considera dois limites dos valores dos estados para calcular a política do problema. Levar em consideração dois limites da função valor também é custoso. Análise da literatura mostra que os algoritmos sRTDP e sBRTDP não conseguem resultados satisfatórios porque ambos fazem operações custosas (atualização de conjuntos de estados e considerar dois limites) e impedem a resolução de problemas em domínios complexos.

\subsection{Motivação}

O algoritmo clássico para resolver MDPs, LRTDP enumerativo, considerado o estado-dearte do planejamento probabilístico, apresenta melhor desempenho em problemas com matrizes esparsas de transição de estados porque pode alcançar eficientemente a convergência para a política ótima, sem ter que visitar todos os estados. Porém essa vantagem pode ser perdida em problemas com matrizes densas de transição, nos quais muitos estados podem ser alcançados em 
um passo. Uma abordagem para superar essa limitação é explorar regularidades existentes na dinâmica do domínio através de uma representação fatorada, isto é, uma representação baseada em variáveis de estado.

\subsection{Objetivos}

Neste trabalho de mestrado propomos 4 novos algoritmos fatorados de planejamento probabilístico baseados no RTDP: duas exatas chamdas de FactRTDP e FactLRTDP; e duas aproximadas, chamadas de aFactRTDP e aFactLRTDP. Também realizamos uma análise comparativa entre esses novos algoritmos fatorados, com objetivo de mostrar que eles apresentam melhor desempenho em domínios em que a transição de estados é densa e com pouca dependência entre as variáveis de estado.

\subsection{Contribuições}

As principais contribuições desse trabalho de mestrado são:

- Soluções eficientes assíncronas fatoradas para MDPs. Foram propostos 4 algoritmos programação assíncrona e fatorada: dois algoritmos exatos FactRTDP e FactLRTDP; e dois algoritmos aproximados aFactRTDP e aFactLRTDP. Esses dois algoritmos se mostraram eficientes para domínios densos.

- Versão fatorada do algoritmo considerado o estado-de-arte do planejamento probabilístico, LRTDP, em que o procedimento de teste de convergência CHECKSolved foi modificado para usar operações entre ADDs, representando de forma compacta o grafo guloso.

- Implementação dos algoritmos propostos na plataforma rddlsim usada na competição de planejamento IPPC-2011.

- Análise detalhada de complexidade dos domínios da competição em termos da densidade da função de transição de estados e da dependência entre variáveis de estado na determinação do próximo estado para cada ação.

- Análise comparativa entre os algoritmos assíncronos fatorados propostos, o LRTDP enumerativo e os dois vencedores da competição IPPC-2011. Os resultados experimentais confirmam a conjectura de que os algoritmos fatorados assíncronos apresentam um melhor desempenho de convergência em domínios densos e melhor desempenho online em domínios com pouca dependência entre as variáveis nas transições de estados, comparado com LRTDP enumerativo.

\subsection{Organização do Trabalho}

Nos Capítulos 2, 3 e 4 apresentamos os principais conceitos de planejamento probabilístico, entre eles, o Processo de Decisão Markoviano (enumerativo e fatorado), bem como suas principais soluções. No Capítulo 5 é mostrada a contribuição do trabalho de mestrado, isto é, os algoritmos propostos neste trabalho (FactRTDP, FactLRTDP, aFactRTDP e aFactLRTDP). No 
Capítulo 6 são explicadas as linguagens de descrição de domínios para problemas de planejamento probabilístico, entre elas, o PPDDL (Younes e Littman, 2003) e o RDDL (Sanner, 2010). No Capítulo 7 é apresenta uma descrição dos domínio de planejamento probabilístico usados na competição IPPC 2011 e uma análise de complexidade deles. Finalmente, no Capítulo 8 é mostrada uma análise dos resultados experimentais. Esta análise inclui a avaliação dos algoritmos na convergência (planejamento offline) e a avaliação no ambiente da competição (planejamento online). 


\section{Capítulo 2}

\section{Processo de Decisão Markoviano: modelo enumerativo}

A forma mais simples de planejamento probabilístico, que assume probabilidades precisas e estados totalmente observáveis, pode ser modelada como um Processo de Decisão Markoviano (Markov Decision Process - MDP) (Puterman, 1994). Com esse modelo, problemas de planejamento probabilístico são vistos como problemas de otimização e possuem as seguintes características:

- Um problema de planejamento é modelado como um sistema estocástico, ou seja, um sistema de transição de estados que associa probabilidades às transições de estados.

- O agente tem conhecimento completo do estado atual, ou seja, o ambiente é completamente observável.

- As metas são definidas como funções numéricas de recompensas que indicam preferências sobre os estados a serem visitados; ou podem ser definidas, através de um conjunto de estados metas.

- As soluções de problemas de planejamento probabilístico são políticas que especificam uma ação para cada um dos estados do modelo.

\subsection{Processo de Decisão Markoviano}

O Processo de Decisão Markoviano (Puterman, 1994) é um modelo matemático estocástico usado para resolver problemas de tomada de decisão sequencial. Dado um conjunto de estados, um conjunto de ações, uma função de transição de estado e uma função recompensa que indica o valor que o agente ganha ao atingir um estado executando uma dada ação, o problema do MDP é encontrar uma política ótima. A aplicação de uma ação em um estado faz com que haja uma transição de estado, mas como essa transição de estado tem efeito probabilístico, o estado resultante da transição depende de uma distribuição de probabilidades.

Um Processo de Decisão Markoviano é um modelo formal para a interação síncrona entre um agente e seu ambiente: a cada instante, o agente observa o estado atual $s_{t}$ de seu ambiente e decide executar uma a ação $a_{t}$; essa ação afeta o estado atual produzindo um estado futuro $s_{t+1}$ e uma recompensa $r_{t+1}$. O objetivo do agente é maximizar sua recompensa (esperada) num histórico de transições de estados, ou seja, em $t$ estágios de tomada de decisão (ou execução de ações). 


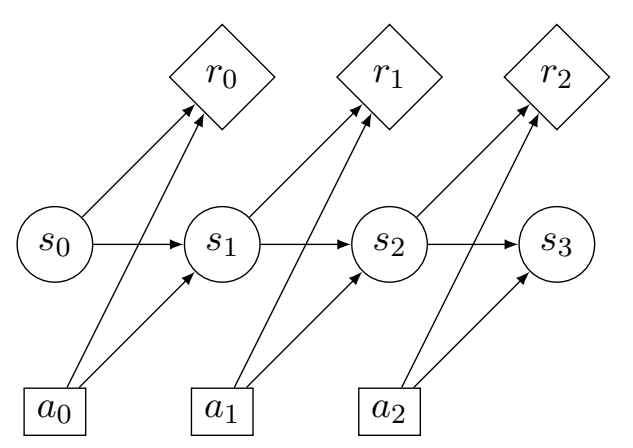

Figura 2.1: Dinâmica de transição de estados de um MDP (Boutilier, 2002).

A Figura 2.3 mostra a dinâmica de transição de estados de um MDP, em que $s_{0}, s_{1}, \ldots$ são estados; $a_{0}, a_{1}, \cdots$ são ações e $r_{0}, r_{1}, \cdots$ são as recompensas. Por exemplo, no estado $s_{0}$ é executada a ação $a_{0}$ que leva o agente para o estado $s_{1}$ e recebe a recompensa $r_{0}$ (que depende da ação $a_{0}$ e do estado $s_{0}$ ).

Definição 2.1.1. MDP Formalmente, um $M D P$ é definido pela tupla $\mathcal{M}=\langle S, A, R, P, \gamma\rangle$, em que:

- S é um conjunto finito de estados do sistema, completamente observáveis;

- A é um conjunto de ações que podem ser aplicadas sobre os estados do sistema provocando assim as mudanças estocásticas;

- $R: S \times A \rightarrow \mathbb{R}$ é uma função que atribui um valor real de recompensa para cada par estado e ação. Quando o agente atinge um estado $s \in S$ através da ação a $\in A$ ganha uma recompensa $R(s, a)$;

- $P: S \times A \times S \rightarrow[0,1] \subset \mathbb{R}$ é uma função de transição probabilística condicional. $P\left(s^{\prime} \mid s, a\right)$ para $s^{\prime}, s \in S$ e $a \in A$ é a probabilidade de ir para o estado $s^{\prime}$ dado que o agente estava em $s$ e executou a ação a, sendo $\sum_{s^{\prime} \in S} P\left(s^{\prime} \mid s, a\right)=1 \mathrm{e}$

- $0<\gamma<1$ é um fator de desconto: depois de $t$ estágios a recompensa é descontada por $\gamma^{t}$ (utilizado para MDPs de horizonte infinito, como descrito a seguir).

Como a transição entre estados é probabilística, o estado resultante da aplicação de uma ação $a$ em um estado $s$ não é totalmente previsível, mas apenas observável. Assim, diferente do planejamento clássico em que a solução é uma seqüência de ações, que pode ser executada sem sensoriamento dos estados, no planejamento probabilístico a solução é uma função $\pi: S \rightarrow A$, chamada de política, que define qual ação executar em cada estado observado. Se a ação $a$ aplicada em um estado $s$ é sempre a mesma, independente do estágio $t$, então a política $\pi$ é chamada de política estacionária, caso contrário, é não-estacionária.

Um MDP em que é especificado um estado inicial $s_{0} \in S$ e um conjunto de estados meta $G \subseteq$ $S$ é chamado de Caminho Estocástico minimo (Stochastic Shortest Path - SSP) (Bertsekas e Tsitsiklis, 1991). Note que as soluções para este tipo de problemas resultam em políticas parciais e não totais (isto é, políticas definidas somente para os estados alcançáveis a partir de $s_{0}$ ). 
Para avaliar uma política, deve-se especificar o número de estágios em que a política será seguida pelo agente. Há dois tipos de política:

- Se o agente segue a política por um número finito de passos, o MDP é de horizonte finito. Nesse caso, a maneira como o agente se comporta costuma mudar à medida em que ele se aproxima de seus últimos passos. Assim, quando o tempo de vida do agente é finito, geralmente, a política é não-estacionária.

- Por outro lado, quando a política aplicada a um estado sempre resulta na mesma ação, independentemente do momento em que é aplicada, ou seja, não depende do número de passos de decisão (também chamados de estágios), o horizonte é infinito e a política é estacionária.

As transições de estados para os MDPs podem ser representadas por Matrizes de Transição Probabilística que representa as probabilidades de transição entre estados para cada ação. Considere o domínio SysAdmin da introdução com três computadores, em que o primeiro computador está conectado com o segundo, o segundo com o terceiro e o terceiro com o primeiro. A quantidade de estados depende da combinação de funcionando ou não dos 3 computadores, portanto, para este exemplo o número de estados é 8.

\begin{tabular}{c|c|c|c}
$c_{1}$ & $c_{2}$ & $c_{3}$ & Estado \\
\hline 0 & 0 & 0 & $s_{0}$ \\
0 & 0 & 1 & $s_{1}$ \\
0 & 1 & 0 & $s_{2}$ \\
0 & 1 & 1 & $s_{3}$ \\
1 & 0 & 0 & $s_{4}$ \\
1 & 0 & 1 & $s_{5}$ \\
1 & 1 & 0 & $s_{6}$ \\
1 & 1 & 1 & $s_{7}$
\end{tabular}

(a)

\begin{tabular}{c|c|c|c|c|c|c|c|c} 
Estado & $s_{0}^{\prime}$ & $s_{1}^{\prime}$ & $s_{2}^{\prime}$ & $s_{3}^{\prime}$ & $s_{4}^{\prime}$ & $s_{5}^{\prime}$ & $s_{6}^{\prime}$ & $s_{7}^{\prime}$ \\
\hline$s_{0}$ & 0 & 0 & 0.8100 & 0.0900 & 0 & 0 & 0.0900 & 0.01000 \\
$s_{1}$ & 0 & 0 & 0.2700 & 0.6300 & 0 & 0 & 0.0300 & 0.07000 \\
$s_{2}$ & 0 & 0 & 0.8200 & 0.0900 & 0 & 0 & 0.0900 & 0.01000 \\
$s_{3}$ & 0 & 0 & 0.0450 & 0.8550 & 0 & 0 & 0.0050 & 0.09500 \\
$s_{4}$ & 0 & 0 & 0.2700 & 0.0300 & 0 & 0 & 0.6300 & 0.07000 \\
$s_{5}$ & 0 & 0 & 0.0150 & 0.0350 & 0 & 0 & 0.2850 & 0.66500 \\
$s_{6}$ & 0 & 0 & 0.2700 & 0.0300 & 0 & 0 & 0.6300 & 0.07000 \\
$s_{7}$ & 0 & 0 & 0.0025 & 0.0475 & 0 & 0 & 0.0475 & 0.99025
\end{tabular}

(b)

Figura 2.2: a) Tabela com a enumeração dos possiveis estados do problema do SysAdmin com 3 computadores. b) Matriz de transição de estados para o problema do SysAdmin com 3 computadores, para a ação Reiniciar o computador 2. Note que o estado $s_{i}$ é o mesmo estado $s_{i}^{\prime}$, após a execução da ação.

A Matriz de transição de estados para ação Reiniciar o computador 2 é mostrada na Figura 2.2b. A Figura 2.2a mostra a enumeração completa dos estados para o problema do SysAdmin com 3 computadores, através das possíveis combinações dos computadores, onde 1 representa que o computador está funcionando e 0 representa que o computador não está funcionando. $\mathrm{Na}$ Figura 2.2b são apresentadas as probabilidades de transição entre os 8 possíveis estados para a ação reiniciar computador 2. As colunas com $s_{i}^{\prime}$ representam os estados no próximo passo. Como ao aplicar essa ação o computador 2 tem 100\% de probabilidade de funcionar no próximo estado, então todos os estados em que o computador 2 não está funcionando tem probabilidade 0 de serem atingidos no próximo estado. Esta Matriz de transição para o SysAdmin com 3 computadores tem tamanho $8 \times 8$ ou $2^{n} \times 2^{n}=2^{2 n}$, em que $n$ é o número de computadores. 


\subsubsection{Avaliação de políticas: horizonte infinito}

Em um MDP com horizonte infinito o agente não altera a forma de agir com o passar do tempo, neste caso a política é estacionária $\pi: S \rightarrow A$ e especifica a ação $a=\pi(s)$ a ser escolhida em cada estado $s$ (independentemente do estágio em que ele se encontra). O objetivo do agente é encontrar a política ótima, ou seja, uma política que maximiza a soma esperada da recompensa descontada num horizonte infinito, isto é:

$$
E_{\pi}\left[\sum_{t=0}^{\infty} \gamma^{t} r_{t} \mid s_{0}\right]
$$

sendo $r_{t}$ a recompensa obtida no estágio t e $s_{0}$ o estado inicial. O valor da política $\pi$ começando no estado $s$ e executando $\pi$, denotado por $V_{\pi}(s)$, é definido como a soma esperada das recompensas e descontadas sob um horizonte infinito, em que $s_{0}=s$, isto é:

$$
V_{\pi}(s)=E_{\pi}\left[\sum_{t=0}^{\infty} \gamma^{t} r_{t} \mid s_{0}=s\right] .
$$

Definimos uma política gulosa $\pi_{V}$ com respeito a alguma função valor $V: S \rightarrow R$, como a política que escolhe uma ação em cada estado, que maximiza o valor esperado de um estado $s$ com relação à $V$, conforme definida a seguir:

$$
\begin{gathered}
\pi_{V}(s)=G_{R E E D Y} A_{C T I O N}(V, s) \\
=\arg \max _{a \in A}(Q(s, a)), \\
Q(s, a)=R(s, a)+\gamma \sum_{s^{\prime} \in S} P\left(s^{\prime} \mid s, a\right) V\left(s^{\prime}\right) .
\end{gathered}
$$

Sendo que $Q(s, a)$ denota o valor do estado $s$ aplicando a ação $a$, ou seja, conhecendo uma estimativa qualquer da função valor $V$ para os próximos estados $s^{\prime} \in S$, as probabilidades de transição $P\left(s^{\prime} \mid s, a\right)$ e a recompensa imediata $R(s, a)$, podemos determinar a melhor ação com relação à $V$ escolhendo a ação que maximiza $Q(s, a)$. Os pares $(s, a)$ obtidos dessa forma constituem uma política gulosa $\pi_{V}$.

Política Ótima. O objetivo do agente em um MDP é encontrar uma política ótima $\pi^{*}$ que produz o máximo valor de recompensa total descontada, ou seja, $\forall s, \pi^{\prime} V_{\pi^{\prime}}(s) \leq V_{\pi^{*}}(s)$.

A função valor ótima, representada por $V^{*}$, é a função valor associada com qualquer política ótima. Assim, para um agente que deseja maximizar sua recompensa esperada, $V^{*}$ satisfaz a seguinte Equação:

$$
V^{*}(s)=\max _{a \in A}\left\{R(s, a)+\gamma \sum_{s^{\prime} \in S} P\left(s^{\prime} \mid s, a\right) V^{*}\left(s^{\prime}\right)\right\} .
$$

A Equação 2.6 é chamada de Equação de Bellman (Bellman, 1957). Os principais algoritmos 
exatos que encontram uma política ótima para MDPs são baseados em programação matemática (Guestrin et al., 2003) e em programação dinâmica, dentre eles: Iteração de Valor (Bellman, 1957), Iteração de Política (Howard, 1960) e programação dinâmica em tempo real (Barto et al., 1995).

\subsubsection{Avaliação de políticas: horizonte finito}

No caso de MDPs com horizonte finito $H$, o agente pode alterar a forma de agir com o passar do tempo. É por isso que as políticas neste caso são não-estacionárias, e dependem do estágio em que é executada a ação $\pi: S \times\{0,1,2, \cdots, H\} \rightarrow A$, em que $H$ é o horizonte do MDP. Esta política especifica a ação $a=\pi(s, h)$, em que $h \in\{0,1,2, \cdots, H\}$, a ser escolhida no estado $s$ e no estágio $h$. O objetivo do agente, como no caso do horizonte infinito, é encontrar a política ótima, mas neste caso, maximiza a soma esperada da recompensa num horizonte finito, isto é:

$$
E_{\pi}\left[\sum_{h=0}^{H} r_{h} \mid s_{0}\right]=E_{\pi}\left[\sum_{h=0}^{H-1} R\left(s_{h}, a_{h}\right)+R\left(s_{H}\right) \mid s_{0}\right],
$$

sendo $r_{h}$ a recompensa obtida no estágio $h$ e $s_{0}$ o estado inicial. Podemos definir a função valor como o valor da política $\pi$ começando no estado $s$ e no estágio $h$, denotado por $V^{\pi}(s, h)$, que é definido como a soma esperada das recompensas até o estágio $H$, em que $s_{0}=s$, isto é:

$$
V^{\pi}(s, h)=E_{\pi}\left[\sum_{h^{\prime}=0}^{h} r_{h^{\prime}} \mid s_{0}=s\right] .
$$

Seja a política $\pi: S \times\{0,1,2, \cdots, H\} \rightarrow A$, uma política gulosa, com relação à alguma função valor $V: S \times\{0,1,2, \cdots, H\} \rightarrow R$. Como a política escolhe uma ação em cada estado num estágio $h$, a ação maximiza o valor esperado de um estado $s$ num estágio $h$ com relação à $V$, conforme definida a seguir:

$$
\pi(s, h)=\arg \max _{a \in A}\left(R(s, a)+\sum_{s^{\prime} \in S} P\left(s^{\prime} \mid s, a\right) V^{\pi}\left(s^{\prime}, h-1\right)\right) .
$$

Política Ótima O objetivo do agente em um MDP de horizonte finito é encontrar uma política ótima $\pi^{*}$ que produz o máximo valor de recompensa total em $H$ estágios, ou seja, $\forall s, \pi^{\prime}, h$ $V_{h}^{\pi^{\prime}}(s) \leq V_{h}^{\pi^{*}}(s)$.

A função valor ótima, representada por $V^{*}$, é a função valor associada com qualquer política ótima. Assim, para um agente que deseja maximizar sua recompensa esperada, $V^{*}$ satisfaz a Equação de Bellman (Bellman, 1957):

$$
V^{*}(s, h)=\max _{a \in A}\left\{R(s, a)+\sum_{s^{\prime} \in S} P\left(s^{\prime} \mid s, a\right) V^{*}\left(s^{\prime}, h-1\right)\right\} .
$$

\subsection{Soluções para MDPs}

As soluções nesta seção estão baseadas no cálculo da função Valor, $V(s)$ (definida na Seção 2.1.1), para a obtenção da política ótima num horizonte infinito. Estas soluções usam a repre- 
sentação enumerativa do MDP, ou seja, considerando que os estados são caixas pretas onde não se sabe que informação contém cada estado.

Nas soluções síncronas, a função valor completa (ou seja, os valores de todo o espaço de estados) é atualizada em cada passo do algoritmo. Dois exemplos de soluções síncronas são: Iteração de Valor (Seção 2.2.1) e Iteração de Política (Seção 2.2.2).

Existe outro tipo de soluções para MDPs que não precisam atualizar todos os estados em cada iteração, este tipo de soluções são chamadas de soluções assíncronas. Estas soluções, em cada iteração, só atualizam aqueles estados alcançáveis a partir de um estado inicial. A sequência de estados atualizados termina quando é alcançado um estado meta, quando é alcançada uma profundidade máxima, ou num tempo limite de busca. Soluções mais eficientes, além de atualizar os estados alcançáveis, também atualizam estados relevantes, que são aqueles estados alcançáveis a partir do estado inicial através do uso política gulosa ótima. Nas Seção 2.2.3, 2.2.4 e 2.2.5 descrevemos três algoritmos assíncronos para MDPs: RTDP, LRTDP e BRTDP, respectivamente.

\subsubsection{Iteração de Valor}

O algoritmo de Iteração de Valor (Bellman, 1957) (Algoritmo 1) é um algoritmo de programação dinâmica que é usado para MDPs enumerativos. Esse algoritmo calcula de forma iterativa a função valor $V^{t}(s) \forall s \in S$, isto é, o valor da recompensa acumulada descontada obtida no estado $s$ em t-estágios-para-frente. A função valor $V^{0}(s)$ deve ser inicializada, por exemplo, com valores aleatórios. O algoritmo faz uso da função $Q(s, a)$ (Equação 2.5), que representa o valor do estado $s$ quando a ação $a$ é selecionada, dada por:

$$
\left.Q^{t}(s, a)=R(s, a)+\gamma \sum_{s^{\prime} \in S} P\left(s^{\prime} \mid s, a\right) V^{t-1}\left(s^{\prime}\right)\right\}
$$

sendo o melhor valor possível, no estágio de decisão $t$ e estado $s$, o valor dado pela escolha da ação $a$ que maximiza $Q^{t}$, isto é:

$$
V^{t}(s)=\max _{a \in A} Q^{t}(s, a) .
$$

A partir da ação que maximiza o valor da função valor para todo estado $s$, é construída a política ótima $\pi^{*}$ (Equação 2.3). No caso de horizonte finito $(\gamma=1)$, a política ótima construída é não-estacionária. No caso de horizonte infinito $(0<\gamma<1)$, as ações escolhidas na última iteração desse processo definem uma política ótima estacionária.

A Figura 2.3 ilustra a execução do algoritmo de Iteração de Valor. Na primeira camada da esquerda estão os valores de todos os estados para a função valor $V^{0}(s)$. Na primeira iteração, se calcula o valor da função valor $V^{1}(s) \forall s \in S$ que maximiza o valor $Q^{1}(s, a)$. O cálculo de cada $Q^{1}(s, a)$ depende do somatório $\sum_{s^{\prime} \in S} P\left(s^{\prime} \mid s, a\right) V^{0}\left(s^{\prime}\right)$ que usa os valores da função valor $V^{0}(s)$. Este mesmo cálculo é feito para $V^{2}(s)$ que usa os valores da função valor $V^{1}(s)$ e assim por diante.

Quando o número de estágios $t$ tende ao infinito, a função valor converge para o ótimo, ou seja, $t \rightarrow \infty \Rightarrow V^{t}(s) \rightarrow V^{*}(s), \forall s \in S$ (Puterman, 1994). Como na prática não é possível fazer infinitas iterações, consideramos um erro $\epsilon>0$, que representa o erro de convergência máximo 
permitido. Assim, consideramos que $V^{t}(s)=V^{*}(s) \forall \in S$ quando $\max _{s \in S}\left|V^{t}(s)-V^{t-1}(s)\right|<\epsilon$ e $V^{t}$ tem $\epsilon$-convergência.
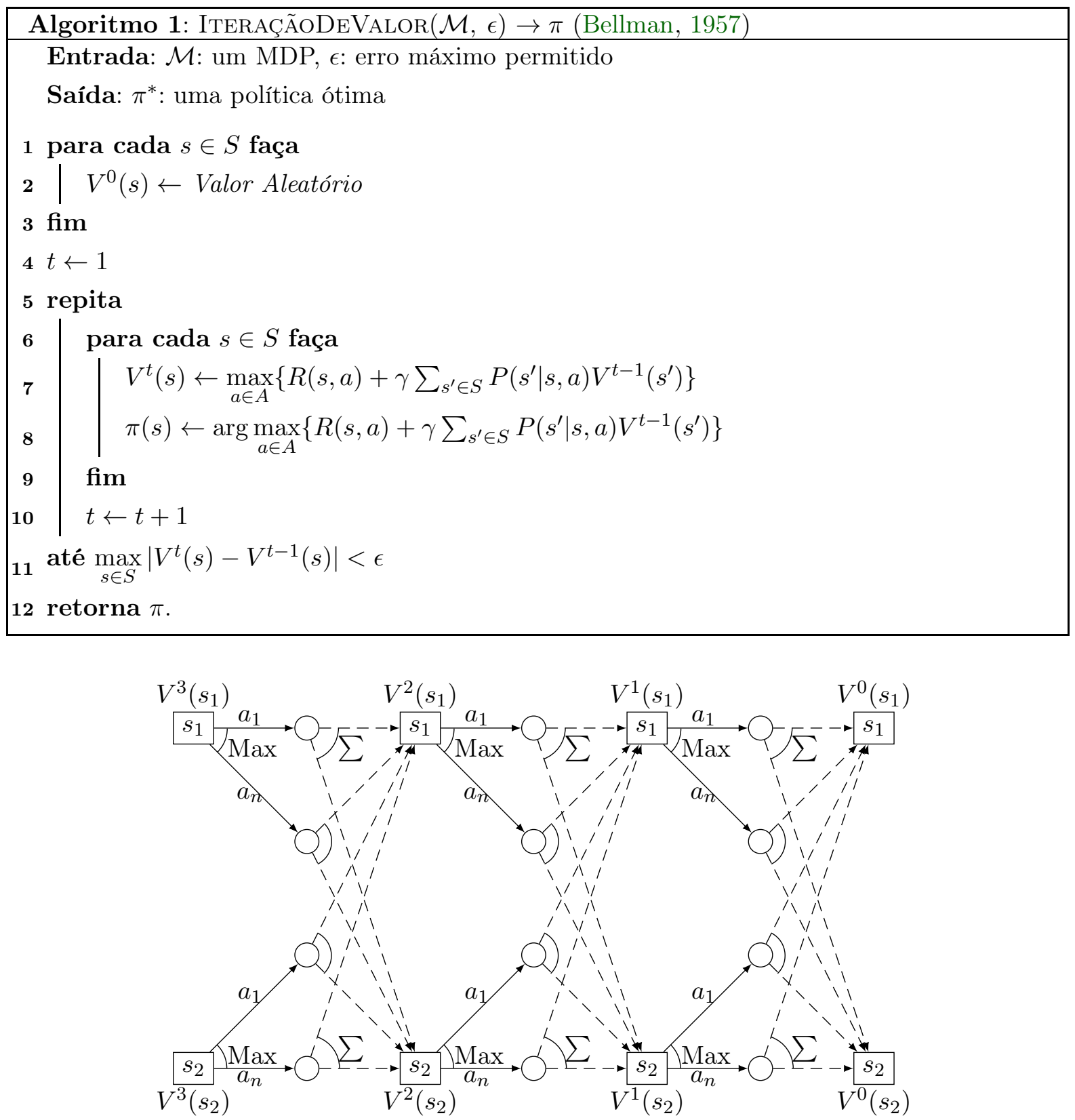

Figura 2.3: Dinâmica de transição de estados.

\subsubsection{Iteração de Política}

O algoritmo de Iteração de Política (Algoritmo 2) (Howard, 1960) seleciona uma política arbitrária inicial $\pi_{0}$ e em cada iteração modifica a política de forma que o valor esperado seja aumentado. Neste algoritmo, cada iteração $i$ é dividida em duas fases:

- Determinação do Valor, em que a política atual é avaliada, isto é, para cada estado $s \in S$, $V_{\pi_{i}}(s)$ é calculado baseado na política $\pi_{i}$. Para fazer isso podemos resolver um sistema de equações lineares. 
- Aperfeiçoamento da Política, em que a política atual é melhorada: obtemos $\pi_{i+1}$ que é a política gulosa com respeito a $V_{\pi_{i}}$, isto é, para cada estado $s \in S$ escolhemos uma ação $a \in A$ que maximiza $Q(s, a)$, isto é:

$$
\pi_{i+1}(s)=\max _{a \in A}\left(P\left(s^{\prime} \mid s, a\right) V_{\pi_{i}}(s)\right)
$$

O algoritmo termina quando $\pi_{i+1}(s)=\pi_{i}(s)$ para todo $s \in S$. A resposta fornecida pelo algoritmo de Iteração de Política é uma política ótima $\pi^{*}$. O algoritmo de Iteração de Política se torna uma solução inviável em problemas grandes por ter que atualizar $V^{\pi}(s)$ para todo $s \in S$ em cada iteração (Nau et al., 2004).

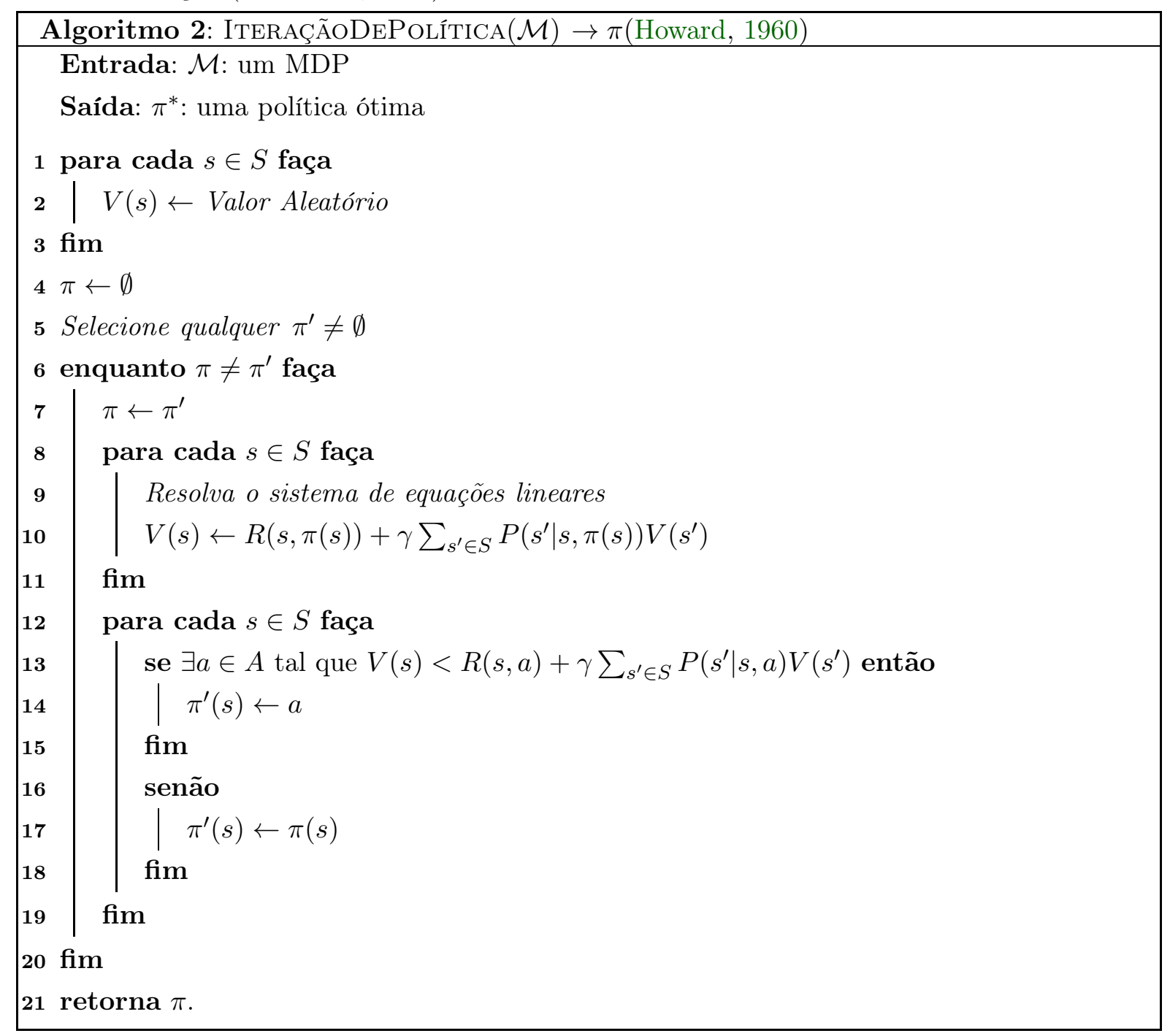

\subsubsection{RTDP: Programação Dinâmica em Tempo Real}

O RTDP (Barto et al., 1995) é baseado no algoritmo de Iteração de Valor, uma vez que usa a equação de Bellman (Equação 2.6) para realizar as atualizações da função valor. Porém, RTDP executa programação dinâmica assíncrona porque não atualiza todos os estados em cada iteração. 
RTDP apresenta duas vantagens quando comparado com os algoritmos de programação dinâmica síncrona: (1) obtém uma política ótima sem visitar todos os estados porque usa a informação do estado inicial e (2) tem um bom desempenho em problemas de planejamento com restrição de tempo, isto é, em que a execução de ações deve ser realizada num tempo menor que o da convergência da função valor ótima.

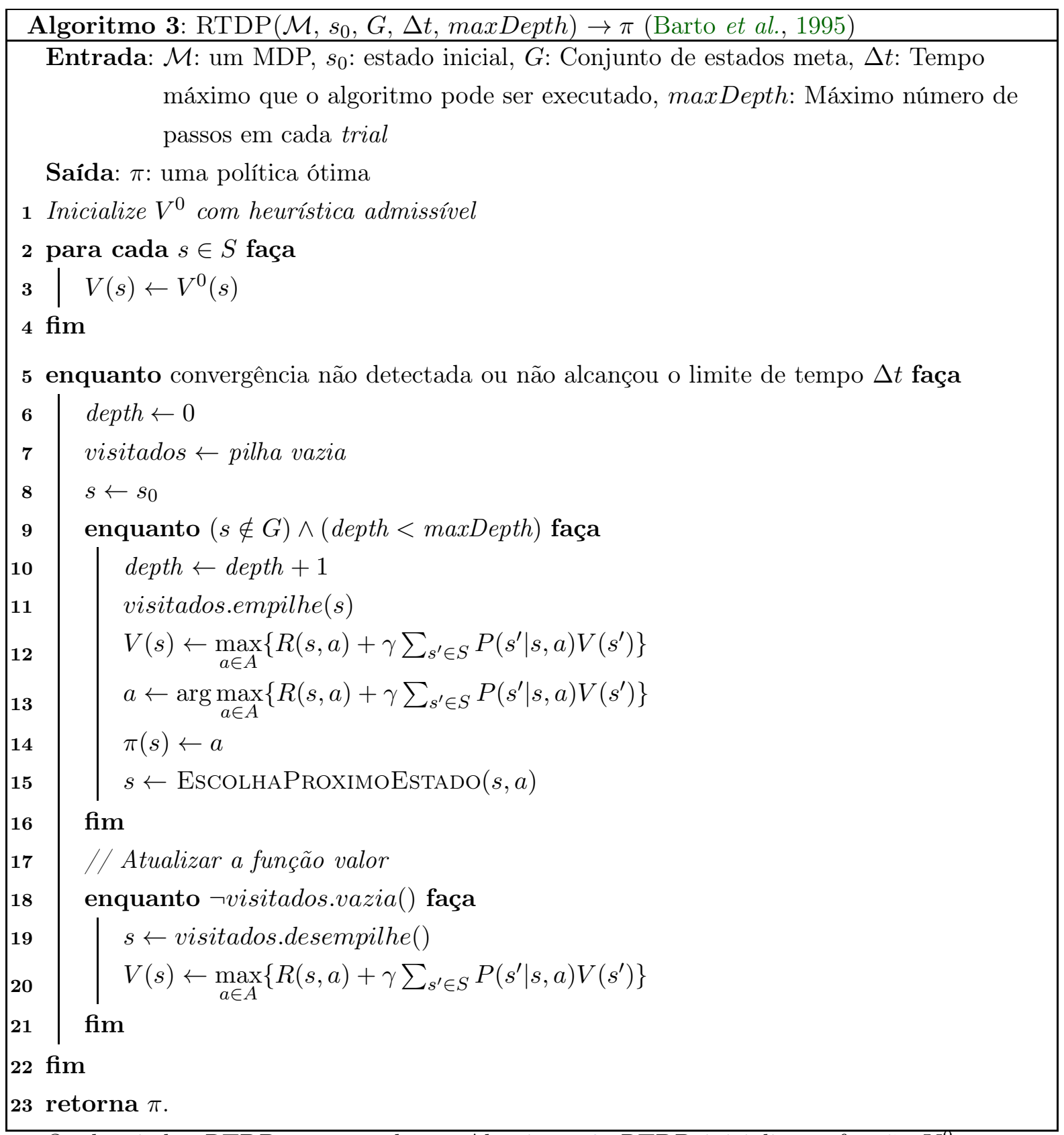

O planejador RTDP é mostrado no Algoritmo 3. RTDP inicializa a função $V^{0}$ com um limite superior admissível, ou seja $V^{0} \geq V^{*}, \forall s \in S$. Uma heurística admissível é aquela que não subestima os valores de $V^{*}$ (quando usamos custo, no caso de recompensas, a heurística admissível é aquela que não superestima os valoes de $V^{*}$ ). A idéia do RTDP é realizar uma busca progressiva a partir de um estado inicial $s_{0}$ para algum estado meta $s_{g} \in G$ ou até alcançar uma profundidade máxima, ou ainda, até alcançar um tempo limite (Figura 2.6). O algoritmo 
faz simulações do comportamento do agente, chamadas de trials. Um trial começa no estado $s_{0}$, calcula a ação gulosa $a$ que maximiza o valor $Q(s, a)$ (Figura 2.4, a ação $a_{2}$ maximiza esse valor), atualiza a função valor com esse valor e sorteia o próximo estado $s^{\prime}$ com uma distribuição dada pela função de transição probabilística $P$, ou seja, $s^{\prime} \sim P(\cdot \mid s, a)$ (Figura 2.5). O sorteio do próximo estado é feito com a função EscolhaProximoEstado, na Linha 12.

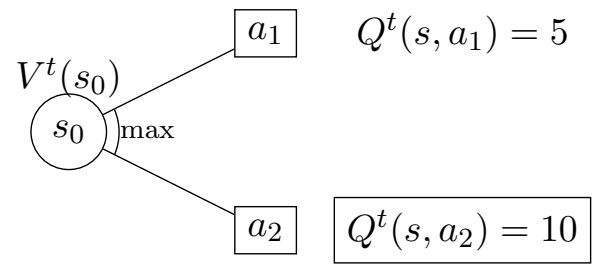

Figura 2.4: RTDP atualiza $V^{t}$ e escolhe uma ação gulosa $a_{2}$, isto é, aquela com o maior valor $Q^{t}$.

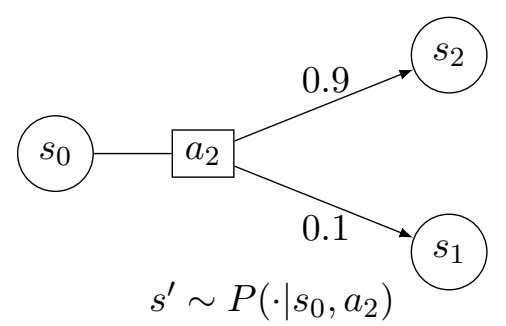

Figura 2.5: RTDP escolhe o próximo estado a ser visitado (o estado mais provável é $s_{2}$ ), baseado na distribuição de probabilidade e um sorteio.

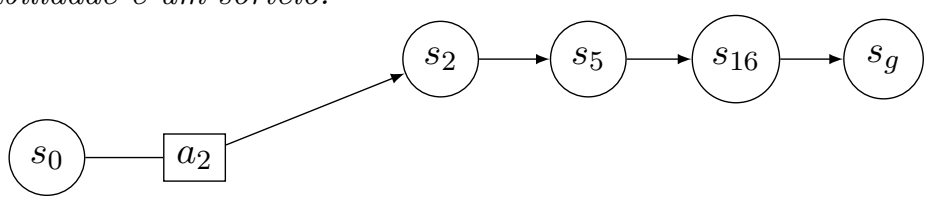

Figura 2.6: Exemplo de um trial de RTDP que terminou ao encontrar um estado meta.

O RTDP mantém uma lista dos estados visitados no trial atual. No final de cada trial, ele faz uma atualização da função valor em ordem inversa à trajetória do trial. Esta atualização inversa permite obter atualizações bem informadas para os estados visitados no trial. Isto porque, uma atualização depende dos estados sucessores, e ao fazer de forma inversa todos os estados visitados durante o trial são atualizados com a informação atualizada de pelo menos um de seus sucessores.

Experimentalmente, foi mostrado que RTDP pode resolver problemas maiores que o algoritmo de Iteração de Valor (Bonet e Geffner, 2001). Uma das desvantagens do RTDP é que os caminhos pouco prováveis tendem a ser ignorados e em consequência disso, a convergência pode ser lenta.

\subsubsection{LRTDP: Programação Dinâmica em Tempo Real Rotulado}

Dado que uma das limitações do RTDP é que sua convergência é lenta e não tem condição de parada, o algoritmo LRTDP (Labeled Real Time Dynamic Programming) (Bonet e Geffner, 2003) tenta melhorar o tempo de convergência verificando se algum dos estados visitados já está resolvido e colocando um rótulo solved nestes estados. O algoritmo para quando todos os estados alcançáveis, a partir de $s_{0}$, estiverem rotulados como solved, sendo que o estado $s_{0}$ é o último em convergir. O algoritmo usa a mesma atualização, baseada em trials, do RTDP. A principal 
diferença é que LRTDP (Algoritmo 4) usa o algoritmo CHEckSolved (Bonet e Geffner, 2003) (Algoritmo 5) para fazer o processo de verificação de convergência e rotulação (aproveitando também para fazer atualizações em mais estados durante essa verificação).

Como é feito no RTDP, LRTDP armazena em uma pilha os estados visitados no trial. Depois de cada trial, LRTDP verifica quais desses estados foram resolvidos através do algoritmo CheckSolved. Para isto, ele percorre os estados visitados no trial em ordem inversa (como no RTDP), usando a pilha de estados visitados (Linhas 21-26, do Algoritmo 4). Porém, LRTDP interrompe as atualizações quando encontra um estado não resolvido.

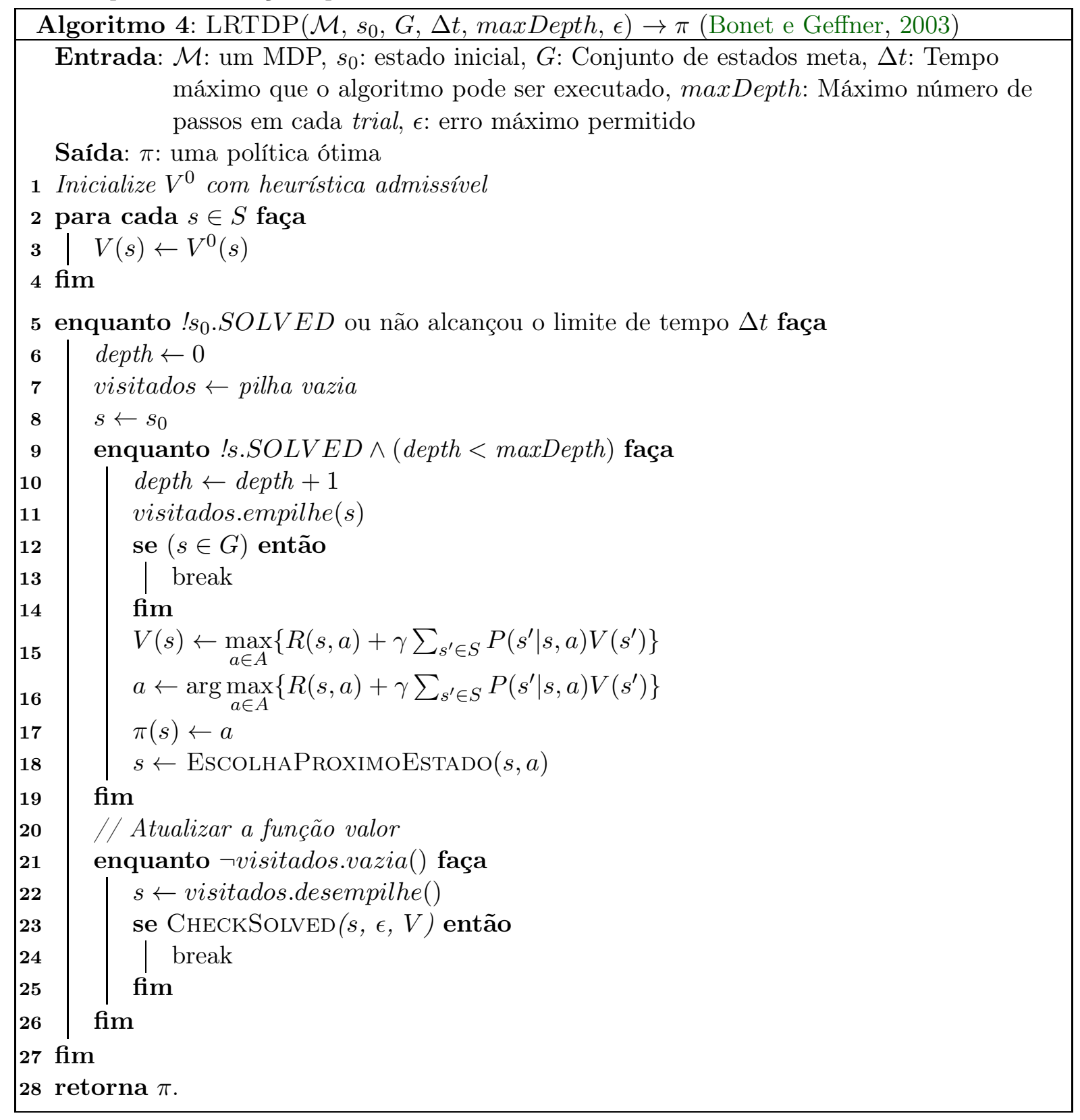

Dado um estado $s$ e um $\epsilon$, que representa o erro máximo de convergência, o algoritmo CheckSolved (Algoritmo 5) verifica se o estado $s$ está resolvido, verificando se todos os estados alcançáveis a partir de $s$ também estão resolvidos. Para isso, o algoritmo percorre um grafo de estados alcançáveis, chamado de greedy graph (grafo guloso, Figura 2.7). A ordem de percurso 
do grafo é feita usando-se o algoritmo de busca em profundidade.

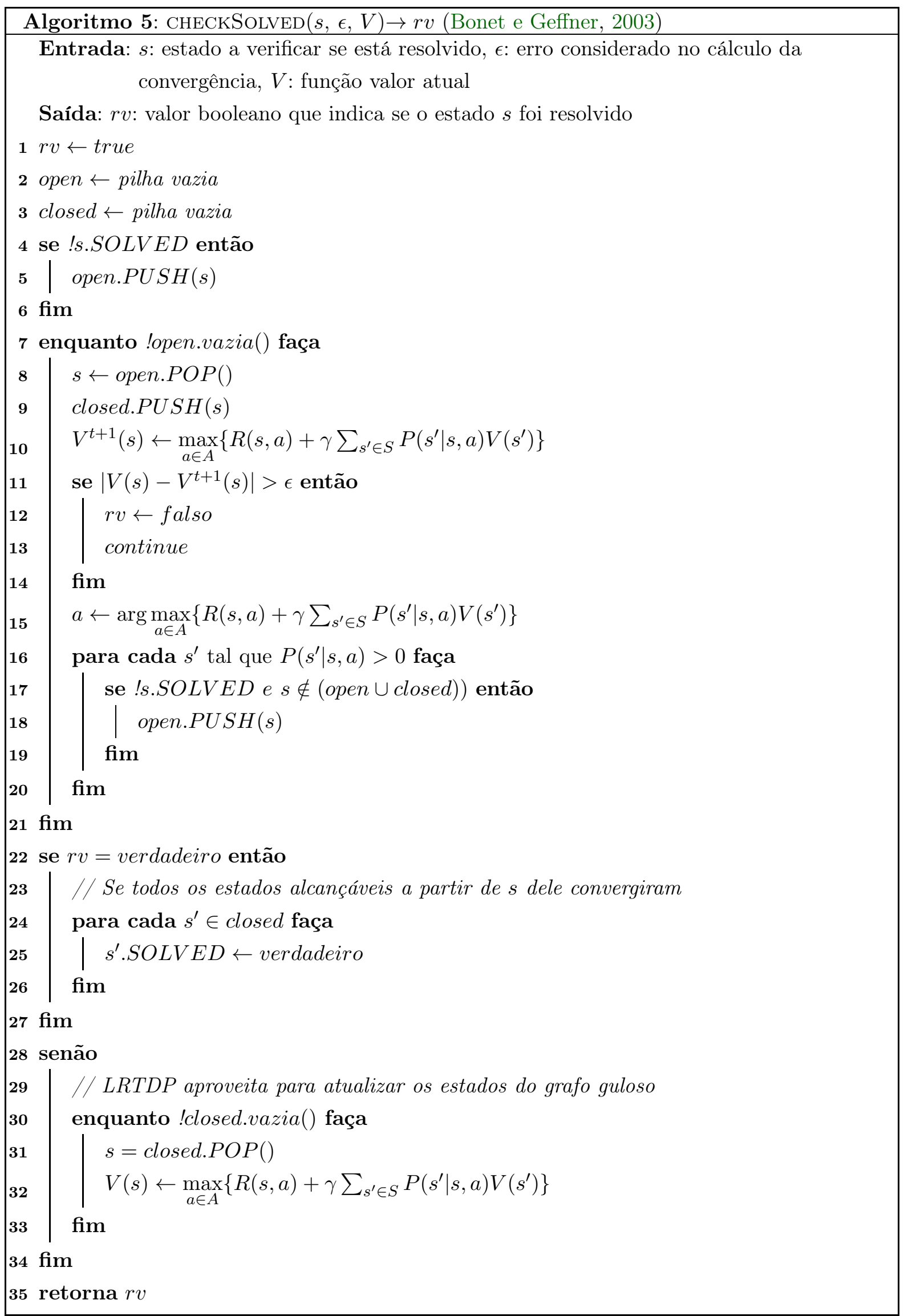




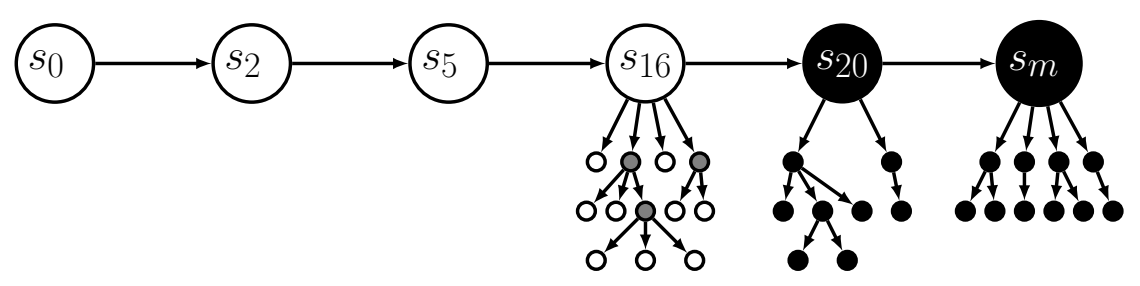

Figura 2.7: Exemplo de um trial de LRTDP e a construção dos grafos gulosos para cada estado visitado. Nos últimos três estados do trial foi construído um grafo guloso. Os dois últimos estados convergiram e foram rotulados, junto com seu grafo guloso, como resolvidos. No grafo guloso do quarto estado só os estados com residual menor que $\epsilon$ (estados de cor cinza) foram expandidos. Como tem pelo menos um estado com residual maior que $\epsilon$ então todos os estados desse grafo guloso, incluido estado raíz, são atualizados.

CheckSolved usa duas pilhas: open e closed. A pilha closed armazena todos os estados que já foram visitados no percurso do grafo e open armazena os estados a visitar. Em cada estado visitado $s^{\prime}$ do grafo o algoritmo decide se vai adicionar os sucessores de $s^{\prime}$ à pilha open. O algoritmo adiciona os sucessores se a diferença entre o valor atual e o valor novo do estado na função valor for menor ou igual a $\epsilon$, isto é, $\left|V^{t}(s)-V^{t+1}(s)\right| \leq \epsilon$. O conjunto de sucessores é calculado segundo a política gulosa, isto é, usando a ação $a$ que maximiza o valor da função valor para o estado $s^{\prime}$. Assim, os sucessores que serão adicionados à pilha open são os sucessores alcançados com a ação $a$ a partir do estado $s^{\prime}$ que ainda não estão resolvidos e que ainda não foram visitados no percurso.

No percurso do grafo, busca-se um estado $s^{\prime}$ em que $\left|V^{t}\left(s^{\prime}\right)-V^{t+1}\left(s^{\prime}\right)\right|>\epsilon$ (Linha 11, Algoritmo 5). Se o estado $s^{\prime}$ é encontrado, significa que o estado $s$ não está resolvido. Neste caso, o algoritmo não adiciona os sucessores de $s^{\prime}$ à pilha open e seus sucessores não são mais visitados (Linha 12), mas continua com o percurso do grafo (isso é feito para aproveitar a busca).

Depois de acabar com o percurso do grafo, o algoritmo verifica se o estado $s^{\prime}$, tal que $\mid V^{t}\left(s^{\prime}\right)-$ $V^{t+1}\left(s^{\prime}\right) \mid>\epsilon$, foi encontrado. Caso $s^{\prime}$ tenha sido encontrado, o algoritmo atualiza todos os estados visitados (os estados armazenados na pilha closed). Estes estados são atualizados segundo a ordem da pilha closed, ou seja, em ordem inversa da ordem em que foram visitados (Linhas 28-31). Isto porque, nesta ordem, o algoritmo assegura que a atualização dos estados será bem informada, ou seja, a atualização de um estado será feita com os valores atualizados de seus sucessores. Portanto, o estado $s$ será atualizado no final.

Caso o estado $s^{\prime}$ não tenha sido encontrado, significa que o estado $s$ e todos os estados alcançáveis do grafo guloso estão resolvidos. Neste caso, o algoritmo rotula todos os estados do grafo guloso como solved (Linha 24). O algoritmo CHECKSOLved devolve um valor booleano, que indica se o estado $s$ foi resolvido.

Note que um dos motivos que faz com que o LRTDP convirja mais rapidamente é o fato do CheckSolved atualizar todos os estados do grafo guloso de cada estado visitado num trial (linhas 30-33 do Algoritmo 5). Com isso, mesmo os estados menos prováveis de serem sorteados num trial, serão atualizados. Em domínios que requerem a análise de um grupo de estados para a escolha da política ótima, essa atualização acelera a aquisição de informação dos estados 
relevantes (por exemplo, um estado meta ou de maior recompensa).

\subsubsection{BRTDP: Programação Dinâmica em Tempo Real Limitado}

O RTDP trabalha com a função valor atualizando-a para os estados visitados. Porém, não é possível estimar quão perto estamos da convergência do valor da função para cada estado. $\mathrm{O}$ algoritmo LRTDP usa o processo de rotulação para evitar a atualização de estados já convergidos. Este algoritmo permite ao RTDP acelerar o processo de convergência.

Um outro algoritmo que informa quais estados estão mais perto da convergência, é Programação Dinâmica em Tempo Real Limitada (Bounded RTDP - BRTDP) (McMahan et al., 2005). O BRTDP usa uma melhoria no cálculo da função valor, que leva em consideração um limite superior e um limite inferior da função valor. A diferença entre o valor do limite superior e o limite inferior para um determinado estado informa quão perto ele está da sua convergência. Na escolha do próximo estado, além de considerar a distribuição de probabilidades, é dada maior preferência aos estados que estão mais longe da convergência (ou seja, com maior diferença entre os valores dos limites).

No Algoritmo 6 se tem os dois limites: $V_{u}$ o limite superior e $V_{l}$ o limite inferior. Note que, quando é preciso obter alguma política, antes ou depois da convergência, são devolvidas as ações gulosas segundo o $V_{u}$. O BRTDP também faz uma atualização da função valor depois de cada trial.

A forma de escolha do próximo estado é feita com uma distribuição baseada nos valores da diferença dos limites, portanto, no BRTP se calcula uma distribuição ponderada pela diferença de limites denominada $\frac{b(\cdot)}{B}$ (Algoritmo 6), onde:

- $b\left(s^{\prime}\right)$ é dado por: $b\left(s^{\prime}\right) \leftarrow P\left(s^{\prime} \mid s, a\right)\left(V_{u}\left(s^{\prime}\right)-V_{l}\left(s^{\prime}\right)\right)$;

- $B$ é dado por: $\sum_{s^{\prime} \in S} b\left(s^{\prime}\right)$;

Um trial não termina quando um estado meta é alcançado. Ao invés disso, termina apenas quando se alcança um estado do qual seus sucessores tem valores bem conhecidos. Para isto, verifica-se a diferença esperada entre $V_{u}$ e $V_{l}$ do estado alcançado executando a ação gulosa. A constante $B$ da linha 20 do Algoritmo 6 tem exatamente esta interpretação, então um trial é terminado quando $B$ é pequeno, ou seja, quando $B<\left(V_{u}\left(s_{0}\right)-V_{l}\left(s_{0}\right) / \tau\right)$. Experimentalmente, para a constante $\tau$ é usado o valor $\tau>1$, geralmente entre 10 e 100 .

A convergência final do BRTDP é alcançada quando $\left(V_{u}^{t}\left(s_{0}\right)-V_{l}^{t}\left(s_{0}\right)\right) \leq \epsilon$ para algum valor de erro $\epsilon$. BRTDP pode convergir sem visitar todo o espaço de estados, mas visitando todos os estados relevantes a partir do estado inicial $s_{0}$.

O BRTDP converge porque ele ainda atualiza todos os estados relevantes que RTDP atualizaria com probabilidade não-zero, mas sorteia com base numa distribuição diferente, isto é, uma distribuição que predispõe as atualizações de estados mais incertos, a fim de reduzir essa incerteza mais rapidamente e assim convergir mais rapidamente (McMahan et al., 2005).

Na prática, o uso de dois limites para o cálculo da função valor é muito custoso, principalmente, em termos de memória. 


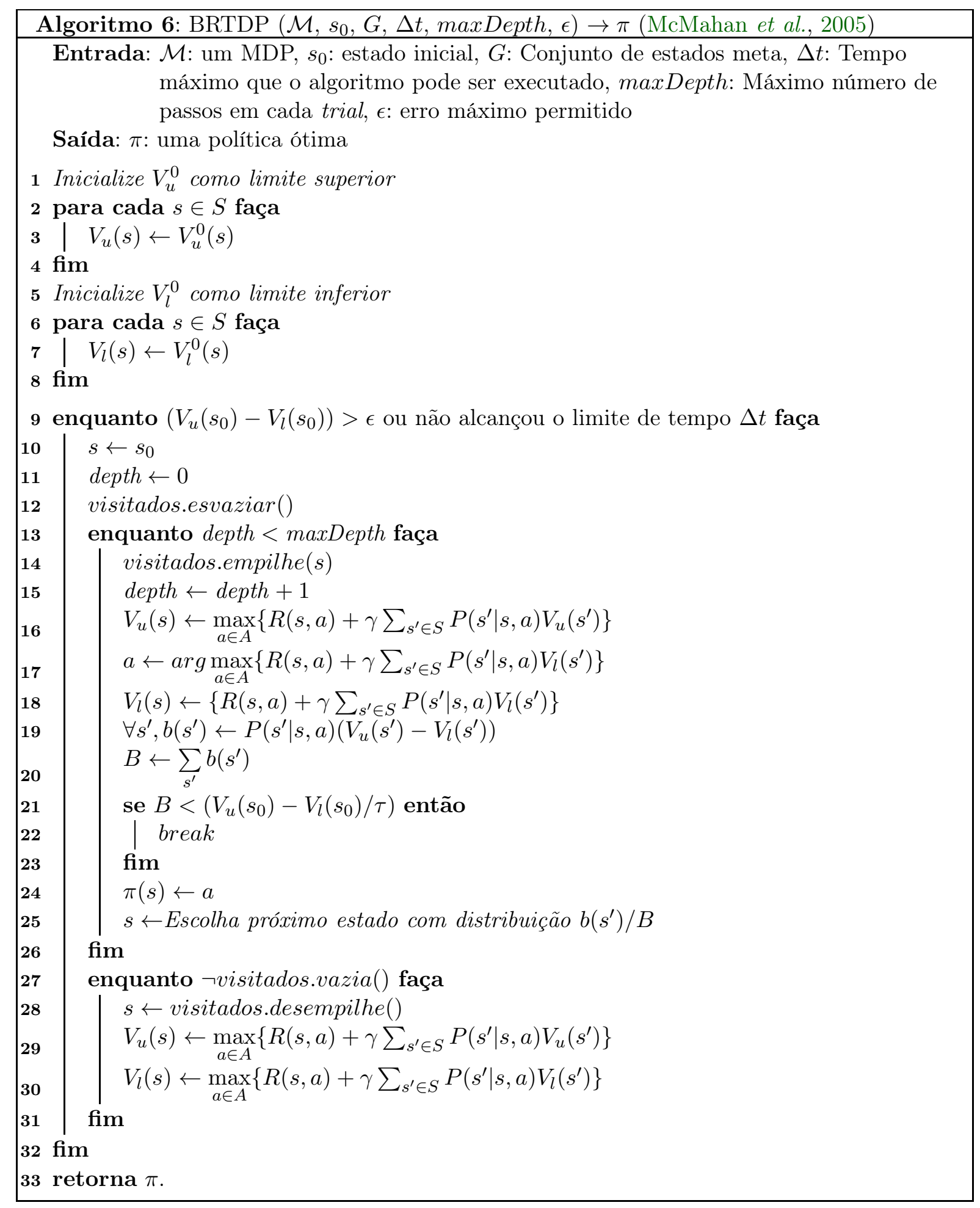




\section{Capítulo 3}

\section{Processo de Decisão Markoviano Fatorado}

No capítulo anterior, definimos os MDPs de forma que os estados podem ser considerados como caixas pretas, sendo que a representação de todos os demais elementos do MDP está baseada nessa representação de estados. Como os estados podem ser enumerados, a representação do MDP descrita é denominada de MDP Enumerativo.

\subsection{Modelo fatorado}

Naturalmente, estados são representados por um conjunto de propriedades do sistema, chamadas de variáveis de estado. Assim, podemos representar um estado como uma configuração dos valores das propriedades do sistema. Um MDP em que os estados, a função de transição e a função recompensa são modelados por variáveis de estado, é chamado de MDP fatorado (Boutilier et al., 1999). Com uma representação baseada em variáveis de estado é possível resolver problemas de planejamento grandes, ou seja, com um número grande de estados, uma vez que, em muitos domínios reais a execução de ações depende de poucas variáveis de estado.

\subsubsection{Representação fatorada de estados}

Dadas $n$ variáveis de estado $\left\{\mathcal{X}_{1}, \mathcal{X}_{2}, \cdots, \mathcal{X}_{n}\right\}$ sendo que cada variável $\mathcal{X}_{i}$ pode assumir um conjunto dos possíveis valores $x_{i}$, um estado é um vetor $\vec{x}=\left(x_{1}, x_{2}, \cdots, x_{n}\right)$ com $x_{i} \in \mathcal{X}_{i}$, sendo que todo $s \in S$ pode ser expresso como $\vec{x}$.

Supondo que temos um problema de planejamento com $n$ variáveis de estado binárias, então o tamanho do espaço de estados é no máximo $2^{n}$ (tipicamente, em um dado domínio, algumas combinações de valores das variáveis de estado nunca ocorrem). Ou seja, o modelo fatorado dos MDPs implica num crescimento exponencial do espaço de estados com relação ao número de variáveis de estado.

\subsubsection{Transições e Recompensas Fatoradas}

Considere o exemplo do domínio SysAdmin descrito no Capítulo 1 da introdução, com três computadores conectados numa topologia de anel (Figura 3.1). As variáveis de estado binárias $\mathcal{X}_{1}, \mathcal{X}_{2}$ e $\mathcal{X}_{3}$, indicam se um computador está funcionando ou não. A probabilidade condicional de transição de estados é dada por $P\left(x_{1}^{\prime}, x_{2}^{\prime}, x_{3}^{\prime} \mid x_{1}, x_{2}, x_{3}, a\right)$, em que $a \in A$ representa a ação de reiniciar um computador e as variáveis linha $x_{i}^{\prime}$ representam os valores das variáveis no estado resultante após a aplicação de $a$. Para cada estado $\vec{x}$ e ação $a$, é definida uma distribuição de probabilidades para todos os valores possíveis para $\overrightarrow{x^{\prime}}$ no próximo estado. 


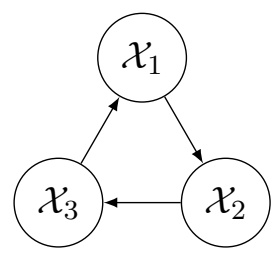

Figura 3.1: Topologia do exemplo de três computadores do SysAdmin.

Para representar as probabilidades de transição de estados consideramos as probabilidades de transição de cada uma das variáveis. Isto porque, como explicado na definição do domínio SysAdmin, a probabilidade de que um computador funcione no próximo estado depende dele mesmo e dos computadores aos quais ele está conectado. Uma forma compacta de representar as probabilidades de transição de cada uma das variáveis de estado para cada ação é através de Redes Bayesianas Dinâmicas (Dynamic Bayesian Network - DBN) (Dean e Kanazawa, 1989).

Uma DBN é um grafo dirigido acíclico de duas camadas, em que os vértices da primeira camada são as variáveis do estado atual; os vértices da segunda camada são as variáveis do próximo estado; e as arestas indicam as dependências que as variáveis do próximo estado têm com relação às variáveis do estado atual (Figura 3.2). O conjunto de variáveis das quais depende uma variável de estado $\mathcal{X}_{i}^{\prime}$ é chamado de pais e são denotados por $p a_{a}\left(\mathcal{X}_{i}^{\prime}\right)$, definida para cada ação do MDP. Assim, a probabilidade do agente ir do estado atual $\left(x_{1}, x_{2}, \cdots, x_{n}\right)$ para o estado $\left(x_{1}^{\prime}, x_{2}^{\prime}, \cdots, x_{n}^{\prime}\right)$ após a execução da ação $a$, é dada por:

$$
P\left(\overrightarrow{x^{\prime}} \mid \vec{x}, a\right)=P\left(x_{1}^{\prime} \mid p a_{a}\left(\mathcal{X}_{1}^{\prime}\right), a\right) \cdot P\left(x_{2}^{\prime} \mid p a_{a}\left(\mathcal{X}_{2}^{\prime}\right), a\right) \cdots P\left(x_{n}^{\prime} \mid p a_{a}\left(\mathcal{X}_{n}^{\prime}\right), a\right),
$$

que pode ser escrita como:

$$
P\left(\vec{x}^{\prime} \mid \vec{x}, a\right)=\prod_{i=1}^{n} P\left(x_{i}^{\prime} \mid p a_{a}\left(\mathcal{X}_{i}^{\prime}\right), a\right),
$$

que representa a probabilidade conjunta para o estado $\vec{x}^{\prime}$.

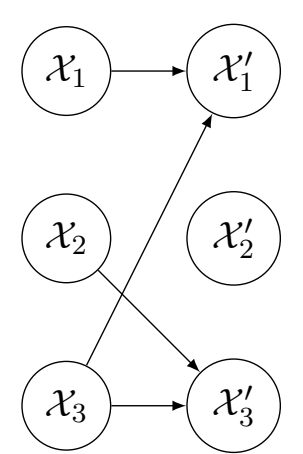

\begin{tabular}{|c|c|c|c|c|c|c|c|}
\hline \multirow{2}{*}{$\mathcal{X}_{1}$} & \multirow{2}{*}{$\mathcal{X}_{3}$} & \multicolumn{2}{|c|}{$P\left(\mathcal{X}_{1}^{\prime} \mid \mathcal{X}_{1}, \mathcal{X}_{3}, a\right)$} & \multirow{2}{*}{$\mathcal{X}_{2}$} & \multirow{2}{*}{$\mathcal{X}_{3}$} & \multicolumn{2}{|c|}{$P\left(\mathcal{X}_{3}^{\prime} \mid \mathcal{X}_{2}, \mathcal{X}_{3}, a\right)$} \\
\hline & & $\mathcal{X}_{1}^{\prime}=1$ & $\mathcal{X}_{1}^{\prime}=0$ & & & $\mathcal{X}_{3}^{\prime}=1$ & $\mathcal{X}_{3}^{\prime}=0$ \\
\hline$\overline{0}$ & 0 & 0.10 & 0.90 & $\overline{0}$ & 0 & 0.10 & 0.90 \\
\hline 0 & 1 & 0.10 & 0.90 & 0 & 1 & 0.70 & 0.30 \\
\hline 1 & 0 & 0.95 & 0.05 & 1 & 0 & 0.10 & 0.90 \\
\hline 1 & 1 & 0.30 & 0.70 & 1 & 1 & 0.95 & 0.05 \\
\hline & & & $P(\jmath$ & $\mid a)$ & & & \\
\hline & & & $\mathcal{X}_{1}^{\prime}=1$ & $\mathcal{X}_{1}^{\prime}=0$ & & & \\
\hline & & & 1 & 0 & & & \\
\hline
\end{tabular}

(a) DBN para a ação Reboot $\left(\mathcal{X}_{2}\right)$.

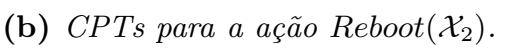

Figura 3.2: Representação fatorada de um problema do domínio SysAdmin.

Na Figura 3.2a é dada a DBN para a ação $a=\operatorname{Reboot}\left(\mathcal{X}_{2}\right)$ do problema da Figura 3.1 e na 
Figura 3.2b são dadas as CPTs das variáveis de estado, isto é, $P\left(x_{1}^{\prime} \mid p a_{a}\left(\mathcal{X}_{1}^{\prime}\right), a\right), P\left(x_{2}^{\prime} \mid p a_{a}\left(\mathcal{X}_{2}^{\prime}\right), a\right)$ e $P\left(x_{3}^{\prime} \mid p a_{a}\left(\mathcal{X}_{3}^{\prime}\right), a\right)$. Note que, a Tabela de Probabilidade Condicional (Conditional Probability Table - CPT) de uma ação $a$ para MDPs enumerativos é decomposta em $n$ tabelas para MDPs fatorados com $n$ variáveis. O cálculo da probabilidade de transição para este exemplo é dado por:

$$
\begin{aligned}
P\left(x_{1}^{\prime}, x_{2}^{\prime}, x_{3}^{\prime} \mid x_{1}, x_{2}, x_{3}, a\right) & =P\left(x_{1}^{\prime} \mid p a_{a}\left(\mathcal{X}_{1}^{\prime}\right), a\right) \cdot P\left(x_{2}^{\prime} \mid p a_{a}\left(\mathcal{X}_{2}^{\prime}\right), a\right) \cdot P\left(x_{3}^{\prime} \mid p a_{a}\left(\mathcal{X}_{3}^{\prime}\right), a\right) \\
& =P\left(x_{1}^{\prime} \mid x_{1}, x_{3}, a\right) \cdot P\left(x_{2}^{\prime} \mid a\right) \cdot P\left(x_{3}^{\prime} \mid x_{2}, x_{3}, a\right) .
\end{aligned}
$$

Note que, assim como nos MDPs enumerativos, as funções de transição na DBN são dadas através de CPTs, porém, elas são definidas para as variáveis de estado, $n$ para cada ação do domínio.

O tamanho da CPT depende das dependências entre as variáveis de estado. No pior caso, o tamanho do conjunto de CPTs de um MDP fatorado é $2^{n} \times n$, isto é, o número de linhas é a quantidade de estados $\left(2^{n}\right)$ e o número de colunas é o número de variáveis de estado $(n)$. As colunas representam as probabilidades de que uma variável de estado se torne verdadeira no próximo estado. Note que, na Figura 3.2b, são apresentadas as probabilidades para cada possível valor das variáveis de estado (0 ou 1), mas a probabilidade de uma variável $\mathcal{X}_{i}^{\prime}$ ter valor 0 no próximo estado é o complemento da probabilidade dela ter valor 1. Portanto, na representação das CPTs só é preciso representar a coluna $\mathcal{X}_{i}^{\prime}=1$, uma vez que a coluna para $\mathcal{X}_{i}^{\prime}=0$ pode ser calculada $\left(1-P\left(\mathcal{X}_{i}^{\prime}=1 \mid p a_{a}\left(\mathcal{X}_{i}^{\prime}\right), a\right)\right)$. Assim, fazendo uma comparação entre as CPTs usadas nos MDPs enumerativos e os fatorados, pode-se ver que o tamanho da CPT para MDPs fatorados é sempre menor. Além disso, depende da função $p a_{a}\left(\mathcal{X}^{\prime}\right)$, uma CPT fatorada pode ser ainda menor. Um cálculo exato do tamanho da CPT fatorada considerando a quantidade de pais de cada variável de estado, é dado por: $\sum_{\mathcal{X}_{i}}\left(2^{\left|p a_{a}\left(\mathcal{X}_{i}\right)\right|}\right) \leq 2^{n} \times n$. Por exemplo, o tamanho da CPT da Figura 3.2b, considerando apenas a coluna $\mathcal{X}^{\prime}=1$, é: $2^{2}+2^{0}+2^{2}=9$ (a variável $\mathcal{X}_{1}^{\prime}$ tem 2 pais, a variável $\mathcal{X}_{2}$ não tem pais e a variável $\mathcal{X}_{3}$ tem 2 pais).

Podemos reescrever a Equação 2.6 em termos de variáveis de estado como (Boutilier et al., 1995):

$$
V^{t}(\vec{x})=\max _{a \in A}\left\{R(\vec{x}, a)+\gamma \sum_{\overrightarrow{x^{\prime}}} \prod_{i=1}^{n}\left\{P\left(x_{i}^{\prime} \mid p a_{a}\left(\mathcal{X}_{i}^{\prime}\right), a\right)\right\} V^{t-1}\left(\overrightarrow{x^{\prime}}\right)\right\} .
$$

A Equação 3.4 difere da Equação de Bellman para MDPs enumerativos basicamente no cálculo da probabilidade condicional $P\left(\vec{x}^{\prime} \mid \vec{x}, a\right)$ (Equação 3.2). A eficiência do cálculo da Equação de Bellman para MDPs fatorados depende do tamanho das CPTs. No caso de todas as variáveis do próximo estado dependerem de todas do estado atual, esse cálculo tão ineficiente quanto num MDP enumerativo.

Note ainda que, as CPTs mostradas na Figura 3.2b tem valores iguais em diferentes linhas (o valor $P\left(\mathcal{X}_{1}^{\prime}=1 \mid \mathcal{X}_{1}, \mathcal{X}_{3}, a\right)=0.1$ independe do valor de $\mathcal{X}_{3}$ ), que poderiam ser representados de uma forma ainda mais compacta (chamada de independência de contexto). Isso faria possível aumentar a eficiência do cálculo da Equação 3.4. Uma forma de compactação das CPTs pode 
ser feita com diagramas de decisão, que exploram essas independências das variáveis de estado nos valores das probabilidades, como veremos a seguir.

\subsection{Diagramas de Decisão}

Formalmente, a sintaxe de uma expressão booleana $\varepsilon$ é definida pela gramática:

$$
\varepsilon::=0|1| x_{i}|\sim \varepsilon| \varepsilon \wedge \varepsilon|\varepsilon \vee \varepsilon| \varepsilon \rightarrow \varepsilon \mid \varepsilon \leftrightarrow \varepsilon,
$$

onde 0 e 1 denotam, respectivamente, as constantes falso e verdade; $x_{i}$ denota uma variável proposicional; e os operadores $\sim, \wedge, \vee, \rightarrow \mathrm{e} \leftrightarrow$ denotam, respectivamente, negação, conjunção, disjunção, implicação e bi-implicação.

Sejam $\varepsilon$ uma expressão booleana e $\varepsilon[c / x]$ a expressão obtida a partir de $\varepsilon$, substituindo-se toda ocorrência da variável $x$ pela constante $c \in 0,1$. A expansão de Shannon da expressão $\varepsilon$, com relação a variável $x$, é dada por

$$
\varepsilon \equiv \varepsilon[1 / x] \vee \varepsilon[0 / x] .
$$

Com base nessa equivalência, definimos o operador condicional ite (if-then-else) como

$$
\operatorname{ite}\left(x, \varepsilon, \varepsilon^{\prime}\right)=(x \wedge \varepsilon) \vee\left(\sim x \wedge \varepsilon^{\prime}\right),
$$

ou seja, ite $\left(x, \varepsilon, \varepsilon^{\prime}\right)$ é verdade se o teste $x$ e a expresso $\varepsilon$ são verdadeiros ou se o teste $x$ é falso e a expressão $\varepsilon$ é verdadeira. A Figura 3.3 mostra o operador ite de forma gráfica, em que a linha contínua representa a parte verdadeira de $x$ e a linha pontilhada mostra a parte falsa de $x$.

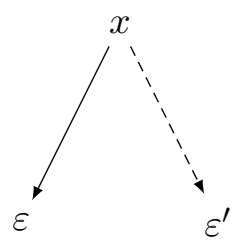

Figura 3.3: A estrutura ite.

Uma árvore de decisão é uma ferramenta de suporte de decisão que usa um grafo para representar uma expressão booleana. Por exemplo, a árvore de decisão correspondente à expressão $\left(\mathcal{X}_{1} \vee \mathcal{X}_{2}\right) \wedge\left(\mathcal{X}_{2} \vee \mathcal{X}_{3}\right)$, pode ser vista na Figura 3.4.

Numa árvore de decisão, folhas são rotuladas por constantes e os demais nós são rotulados com variáveis. Além disso, cada nó interno $\mathcal{X}_{i}$ tem um filho com valor verdadeiro $\left(\mathcal{X}_{i}=1\right)$ e um filho com valor falso $\left(\mathcal{X}_{i}=0\right)$. Na representação gráfica da árvore de decisão, os filhos verdadeiro e falso são indicados através de linhas contínuas e pontilhadas, respectivamente.

Embora as árvores de decisão sejam um dispositivo muito útil para representar funções booleanas, frequentemente, elas podem conter redundância. Veja, por exemplo, a árvore de decisão para a expressão $\left(\mathcal{X}_{1} \leftrightarrow \mathcal{X}_{2}\right) \wedge\left(\mathcal{X}_{3} \leftrightarrow \mathcal{X}_{4}\right)$ (Figura 3.5).

Parte da redundância existente numa árvore de decisão pode ser eliminada através do compartilhamento de subgrafos isomorfos. De fato, quando todo subgrafo isomorfo é compartilhado, 
a árvore de decisão é transformada num grafo dirigido acíclico, denominado diagrama de decisão binária (Binary Decision Diagram - BDD) (Bryant, 1992).

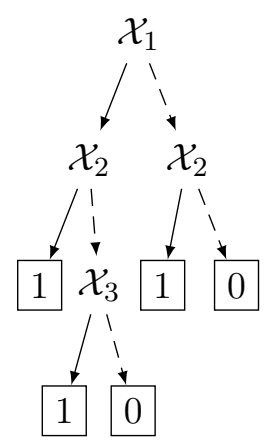

Figura 3.4: Árvore de decisão para a expressão $\left(\mathcal{X}_{1} \vee \mathcal{X}_{2}\right) \wedge\left(\mathcal{X}_{2} \vee \mathcal{X}_{3}\right)$

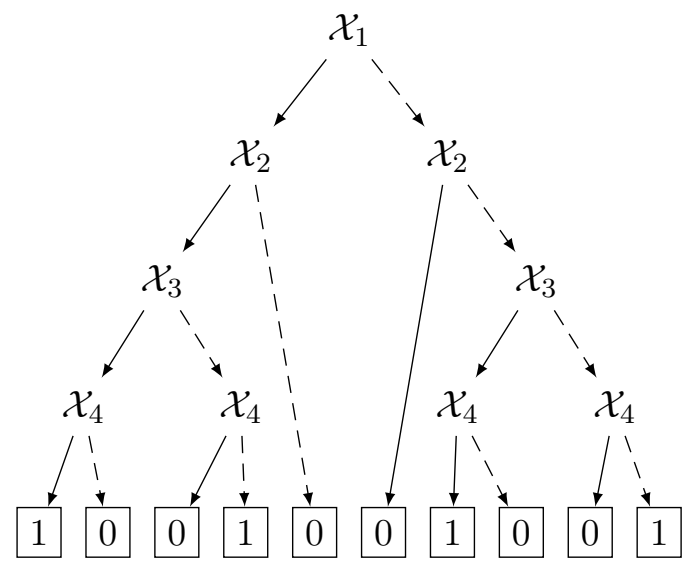

Figura 3.5: Árvore de decisão para a expressão $\left(\mathcal{X}_{1} \leftrightarrow \mathcal{X}_{2}\right) \wedge\left(\mathcal{X}_{3} \leftrightarrow \mathcal{X}_{4}\right)$.

Particularmente, quando a ordem das variáveis de teste nos caminhos que levam da raiz até uma folha é sempre a mesma, o grafo obtido pelo compartilhamento de subgrafos isomorfos é denominado diagrama de decisão binária ordenado (Ordered Binary Decision Diagram OBDD). A Figura 3.6 mostra o resultado do compartilhamento dos subgrafos isomorfos da árvore apresentada na Figura 3.5.

Às vezes, após o compartilhamento de subgrafos, alguns testes podem se tornar redundantes. Para eliminar um teste redundante, basta excluir o nó que representa esse teste e redirecionar todo arco de entrada desse nó para o seu filho (Figura 3.7). Quando todos os testes redundantes num diagrama de decisão binária ordenado são eliminados, o grafo resultante é denominado diagrama de decisão binária ordenado reduzido (Reduced Ordered Binary Decision Diagram ROBDD) (Bryant, 1992).

Formalmente, um BDD é usado para representar uma função booleana $f: \mathbb{B}^{n} \rightarrow \mathbb{B}$, sendo $\mathbb{B}=\{0,1\}$. Portanto, pode-se aplicar operações booleanas sobre os BDDs. Dentre essas operações estão: a disjunção $(\vee)$, conjunção $(\wedge)$ e negação $(\sim)$. 


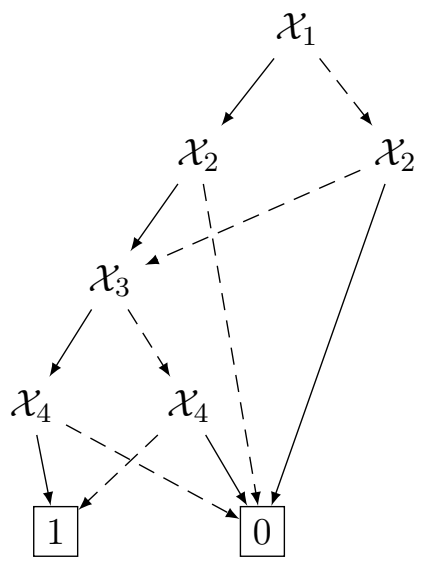

Figura 3.6: Compartilhamento de grafos isomorfos na arvore de decisão da Figura 3.5.

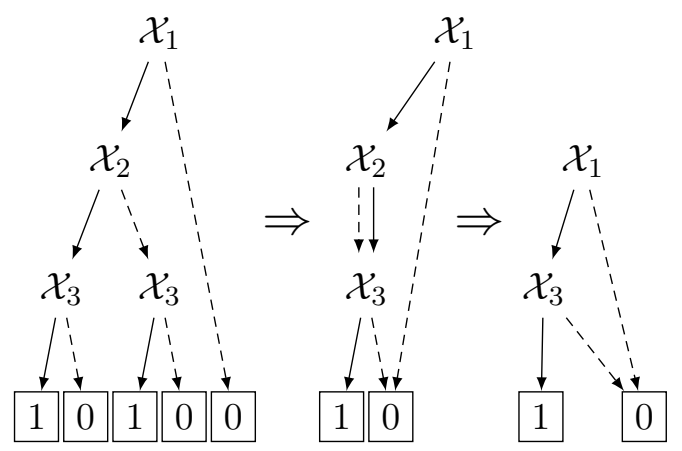

Figura 3.7: Compartilhamento de grafos isomorfos e eliminação de testes redundantes.

\subsubsection{Operações sobre conjuntos com BDDs}

Um BDD pode ser interpretado de múltiplas formas. Uma possível interpretação de um BDD $f_{D D}$ (a notação $D D$ é usada para funções representadas por diagramas de decisão) é como um subconjunto de um conjunto universo $U$. Os elementos do conjunto $U$ são todas as combinações de valores de $n$ variáveis booleanas do domínio $\left(\mathbb{B}^{n}\right)$ de $f_{D D}$. Então, um elemento $\vec{x}$ de $U$ pertence ao conjunto $f_{D D}$ se $f_{D D}(\vec{x})=1$.

Assim, as operações entre dois BDDs, definidos sobre o mesmo domínio $\mathbb{B}^{n}$, vistos como funções booleanas $(\wedge, \vee, \sim)$, podem ser usadas para realizar operações entre esses mesmos BDDs, vistos como conjuntos $\left(\cap, \cup, \overline{f_{D D}}\right)$. A Tabela 3.1 mostra as equivalências entre as operações usadas nos BDDs com operações de conjuntos.

\begin{tabular}{|l|l|}
\hline Operação de BDDs & Operação para conjuntos \\
\hline \hline Disjunção: $\vee$ & União: $\cup$ \\
\hline Conjunção: $\wedge$ & Interseção: $\cap$ \\
\hline Negação: $\sim$ & Complemento: $\overline{f_{D D}}$ \\
\hline
\end{tabular}

Tabela 3.1: Equivalência entre as operações de BDDs e operações de conjuntos.

Na Seção 3.3.2 mostramos em detalhes como essas operações são realizadas. 


\subsubsection{Diagramas de Decisão Algébrico (ADD)}

Um ADD (Bahar et al., 1993) é uma generalização de um Diagrama de Decisão Binária (Binary-Decision Diagram - BDD) e representa uma função $f: \mathbb{B}^{n} \rightarrow \mathbb{R}$, isto é, ADDs mapeiam expressões booleanas para valores reais. Por exemplo, a Tabela 3.8 mostra a definição de uma função $f: \mathbb{B}^{n} \rightarrow \mathbb{R}$ com 4 variáveis binárias.

\begin{tabular}{ccc|c|c}
$x_{1}$ & $x_{2}$ & $x_{3}$ & $x_{4}=1$ & $x_{4}=0$ \\
\hline 0 & 0 & 0 & 0.05 & 0.95 \\
0 & 0 & 1 & 0.05 & 0.95 \\
0 & 1 & 0 & 0.617 & 0.383 \\
0 & 1 & 1 & 0.783 & 0.217 \\
1 & 0 & 0 & 0.05 & 0.95 \\
1 & 0 & 1 & 0.05 & 0.95 \\
1 & 1 & 0 & 0.783 & 0.217 \\
1 & 1 & 1 & 0.95 & 0.05
\end{tabular}

(a) CPT exemplo

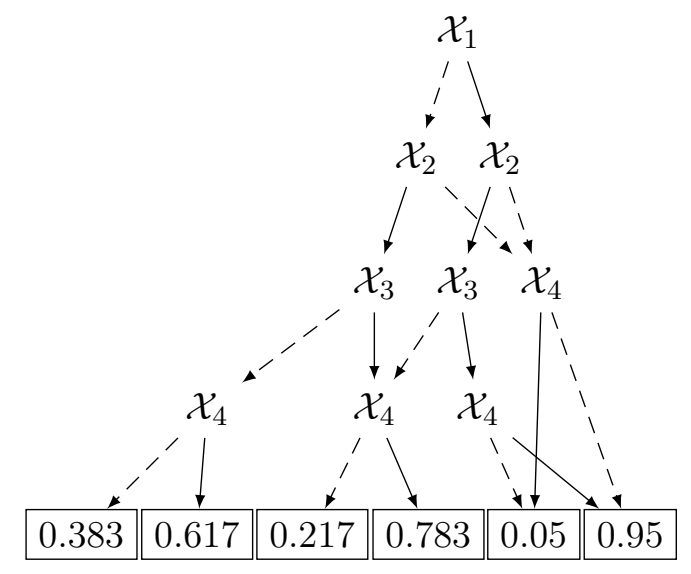

(b) $A D D$ exemplo

Figura 3.8: a) Tabela de uma função $f: \mathbb{B}^{n} \rightarrow \mathbb{R}$ com 4 variáveis; b) Representação da função com um $A D D$.

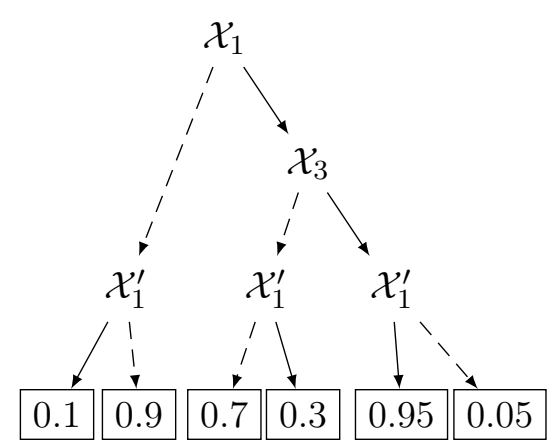

Figura 3.9: $A D D$ que representa a CPT da variável de estado $\mathcal{X}_{1}^{\prime}$ e ação Reboot $\left(\mathcal{X}_{2}\right)$ da Figura 3.2b.

Na função da Tabela da Figura 3.8a pode-se notar que alguns valores reais não dependem dos valores de algumas variáveis binárias, por exemplo, o valor 0.05 quando $x_{4}=1$ independe do valor da variável $x_{3}$. Essa independência de valores binários conhecida como Independência Específica de Contexto (Context-Specific Independence-CSI) (Boutilier et al., 1996), é usada na representação do ADD (Figura 3.8b) correspondente à tabela (Figura 3.8a).

Um ADD é um Grafo Acíclico Dirigido (Directed Acyclic Graph - DAG), em que as variáveis binárias são os nós de decisão e os nós que representam os valores reais da função são nós terminais. A Figura 3.9 mostra o ADD correspondendo à CPT da variável $\mathcal{X}_{1}^{\prime}$ e a ação $\operatorname{Reboot}\left(\mathcal{X}_{2}\right)$, cujas variáveis são $\mathcal{X}_{1}, \mathcal{X}_{3}$ e $\mathcal{X}_{1}^{\prime}$. Ou seja, as ADDs que representam as funções de transição fatoradas envolvem as variáveis do conjunto $p a_{a}\left(\mathcal{X}_{i}\right)$ e a variável $\mathcal{X}_{i}^{\prime}$. 


\subsection{Construção e Manipulação de Diagramas de Decisão}

É possível construir um DD a partir de uma expressão booleana (Andersen, 1997). Para explicar esta seção (e a próxima) é utilizada a notação DD (diagrama de decisão) para se referir tanto a ADDs quanto a BDDs. Nessa seção, especificamos 2 algoritmos fundamentais para o uso de DDs: (1) o algoritmo $\operatorname{Reduzir}(F)$, que constrói uma versão reduzida de um DD $F$ e (2) o algoritmo $\operatorname{Aplica}\left(F_{1}, F_{2}, o p\right)$ que constrói um DD como resultado de uma operação op entre DDs. Para isso definimos a estrutura elementar nó. A estrutura nó pode ser de 2 tipos: (1) nó interno que tem três atributos: uma variável e dois instâncias da mesma estrutura nó; e (2) nó terminal que tem um valor booleno (0 ou 1), caso seja um BDDs; ou um valor real, caso seja um ADD.

Os atributos nós de um nó interno são identificados como: nó low, que representa o ramo do DD quando a variável do nó tem valor 0; e o nó high, que representa o ramo do DD quando a mesma variável tem valor 1 .

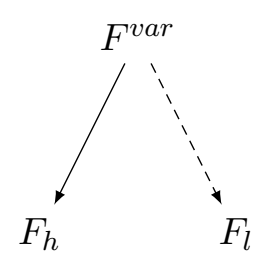

Figura 3.10: A estrutura nó, para um nó interno $F_{h}$ e $F_{l}$ são os ramos do nó (Sanner, 2008).

A Figura 3.10 mostra a estrutura nó, os nós high e low são denotados como $F_{h}$ e $F_{l}$, respectivamente, e $F^{v a r}$ representa a variável desse nó. Nesta seção, vamos usar esta estrutura para descrever os algoritmos de manipulação de DDs.

Esta estrutura nó é uma representação computacional do operador ite da Equação 3.7, que pode ser intepretada segundo o DD representado.

- Para BDDs: ite $\left(F^{v a r}, F_{h}, F_{l}\right)=\left(F^{v a r} \wedge F_{h}\right) \vee\left(\sim F^{v a r} \wedge F_{l}\right)$.

- Para ADDs: eval $\left(F^{v a r}, F_{h}, F_{l}\right)=i f\left(F^{v a r}\right)$ then eval $\left(F_{h}\right)$ else eval $\left(F_{l}\right)$, em que eval $(F)$ devolve um número real se $F$ é um nó terminal.

\subsubsection{Construção de Diagramas de Decisão reduzidos}

Assim como nos BDDs, os ADDs precisam da ordenação de variáveis para que o diagrama de decisão seja ordenado e reduzido. Com esta ordenação e redução se assegura que, dada uma ordenação das variáveis $\mathcal{X}_{1}, \mathcal{X}_{2}, \cdots, \mathcal{X}_{n}$ binárias, para qualquer função (ADD ou BDD) existe uma única representação reduzida.

Dado que existe uma única representação do DD reduzido, a seguir é descrito como a partir de qualquer diagrama de decisão ordenado é possível construir a versão reduzida. Essa operação é feita na ordem bottom-up, isto é, a partir das folhas do DD em direção à raiz. Os algoritmos relacionados com operações sobre DDs fazem uso da função OBTERNo (Algoritmo 7), que dados uma variável e dois nós, devolve um DD em que o nó raiz tem a variável e os dois nós são os 


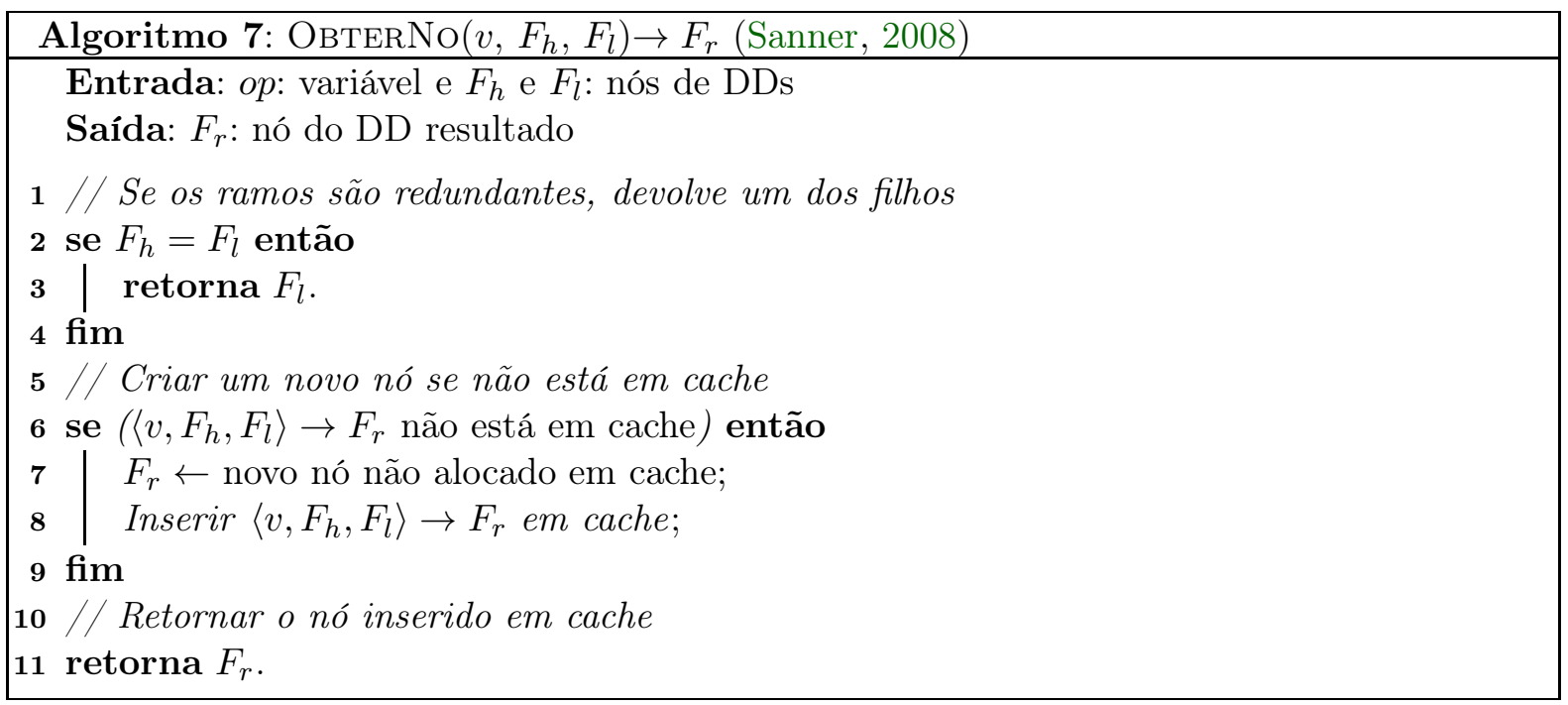

ramos desse nó raiz. Para verificar redundância em um DD, este algoritmo usa um cache que mapeia um nó para a variável e seus ramos.

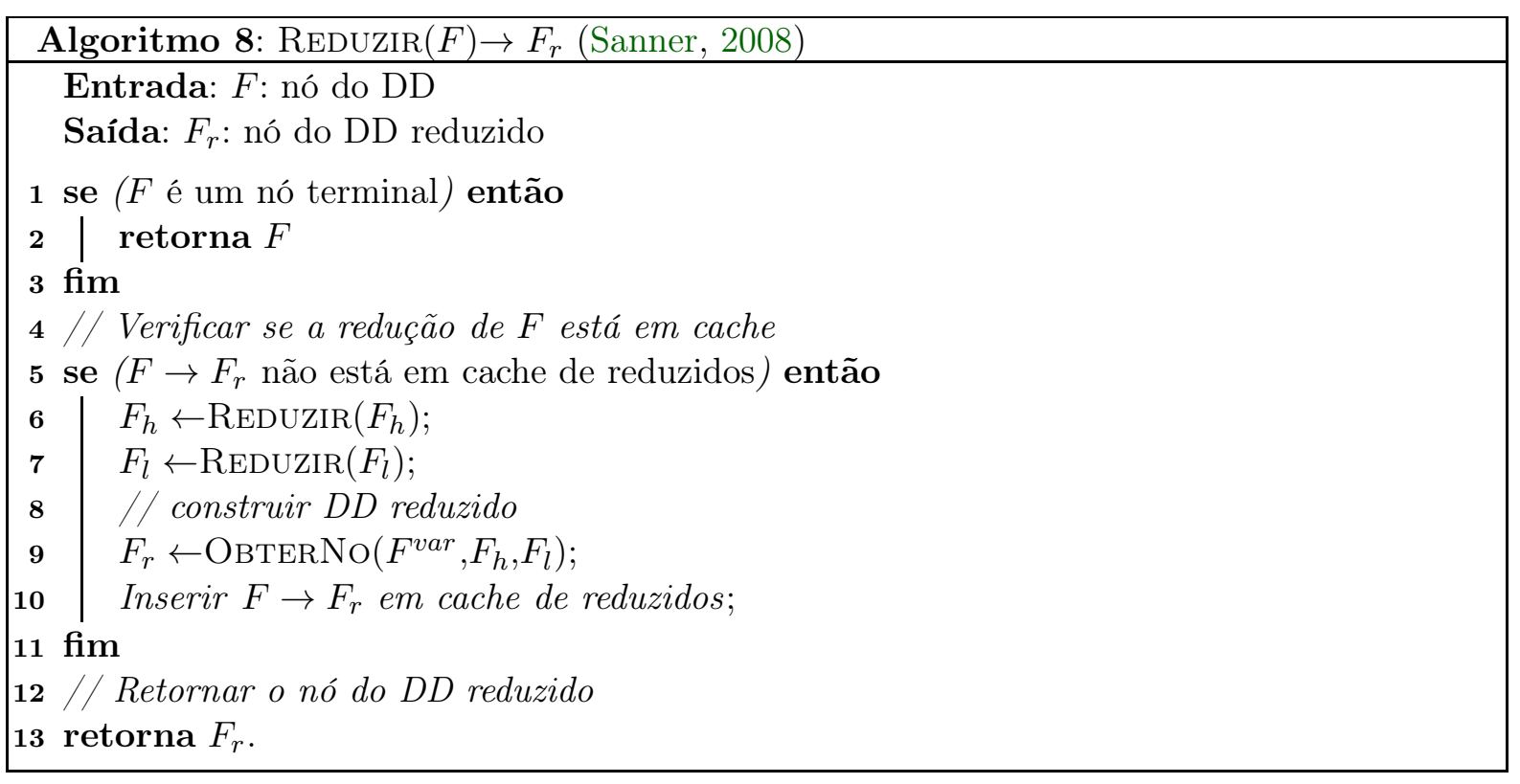

A função OBTERNo primeiro verifica se os nós filhos são iguais. Esta verificação é necessária, porque se uma variável tem seus dois filhos iguais, significa que está apontando ao mesmo nó com o valor verdadeiro e com o valor falso e como pode ser visto na Figura 3.7, este DD deve ser reduzido a um DD em que não está presente o nó dessa variável. É por isso, que na Linha 3, o algoritmo devolve um dos filhos. Caso os filhos sejam distintos, o algoritmo verifica se a combinação de variável e filhos existe no cache (Linha 6), caso exista devolve o nó associado a essa combinação, caso contrário cria um novo nó (Linha 7) e insere no cache a combinação com o novo nó (Linha 8).

A função REDUZIR (Algoritmo 8) pega qualquer diagrama de decisão ordenado e devolve sua 
representação reduzida (isto é, que não possui nenhuma estrutura redundante), para isso, usa a função OBTERNo para construir recursivamente um DD reduzido (desde os nós terminais até o nó raiz). Como no algoritmo ObTerNo, o algoritmo Reduzir também faz uso de um cache. O cache usado neste algoritmo serve para mapear um DD qualquer para a sua representação reduzida, isto principalmente para evitar cálculos repetidos e também para ajudar nos cálculos da redução.

O algoritmo ReDUzir primeiro verifica o caso base (Linha 1), se o nó do ADD é um nó terminal, caso seja um nó terminal devolve esse nó, uma vez que um nó terminal é um DD reduzido. Caso contrário verifica no cache se o DD tem uma representação reduzida já calculada, caso a representação reduzida seja encontrada o algoritmo devolve esse DD reduzido. Caso contrário, faz uma chamada recursiva para reduzir o ramo verdadeiro e outra para reduzir o ramo falso. Em seguida constrói um novo nó com a variável associada ao nó $F$ e os ramos reduzidos. Finalmente insere no cache o nó $F$ com sua representação reduzida.

\subsubsection{Operações sobre Diagramas de Decisão}

Dadas duas funções de tipo $\mathbb{B}^{n} \rightarrow \mathbb{R}$ representadas como ADDs ou duas funções de tipo $\mathbb{B}^{n} \rightarrow \mathbb{B}$ representadas como BDDs, é possível aplicar operações sobre cada par de funções que operam diretamente sobre os DDs. Estas operações evitam, sempre que possível, enumerar todas as possíveis atribuições às variáveis e para realizá-los, usamos a função APLICA (Algoritmo 9), que:

1. aplica uma operação binária a duas funções representadas por ADDs e devolve um ADD com o resultado,

2. aplica uma operação binária a duas funções representadas por BDDs e devolve um BDD com o resultado e

3. aplica uma operação binária a uma função representada como ADD e uma outra função representada como BDD e devolve um ADD como o resultado (isso é possível porque um ADD é uma generalização de um BDD).

Na função Aplica (Algoritmo 9), op denota qualquer operação binária de ADDs, isto é, soma $(\oplus)$, multiplicação $(\otimes)$, diferença $(\ominus)$, divisão $(\oslash)$, mínimo $(\min (\cdot, \cdot))$ e máximo $(\max (\cdot, \cdot))$; ou qualquer operação binária de BDDs: disjunção $(\vee$ ou $\cup)$ e conjunção $(\wedge$ ou $\cap)$. Também podemos usar as funções binárias de comparação: $>,<, \geq$ e $\leq$, que devolvem uma função indicador representada como BDD, que tem valor 1 quando a comparação é satisfeita e 0, caso contrário.

O algoritmo Aplica (Algoritmo 9) primeiro verifica se é possível calcular diretamente o resultado da operação através da função CalcularResultado (Tabela 3.2). Caso isso não seja possível é preciso verificar se o resultado da operação está armazenado em cache. Caso nenhuma das opções anteriores seja possível, APLICA escolhe uma das duas variáveis dos nós raiz dos DDs para fazer a recorrência nos filhos dessa variável chamando o algoritmo APLICA para cada valor desta variável. Um exemplo do funcionamento desse algoritmo é mostrado no Apêndice A. 
A função CalcularResultado, dada na Tabela 3.2, determina se o resultado pode ser calculado diretamente. $F_{i}$ representa o nó raiz de um DD. A primeira linha da tabela mostra que se os nós dos DDs contém constantes (este tipo de nó é chamado de nó terminal), então o resultado é obtido ao aplicar a operação sobre as constantes. O restante das linhas mostra como pode-se obter resultados diretos em casos específicos sem recursão. Por exemplo, sabemos que $F_{1} \oplus 0=F_{1}$ e $F_{1} \otimes 1=F_{1}$. Caso não seja possível calcular um resultado direto, o algoritmo APLICA faz uma recursão nos ADDs até que o resultado seja calculado (Linhas 24-39, Algoritmo 9). Para a recursão se tem três casos, o terceiro caso em que ambos nós são terminais, é tratado na função CalcularResultado. O algoritmo Aplica faz uso da notação da Figura 3.11.

\begin{tabular}{|l|l|}
\hline \multicolumn{2}{|c|}{ CALCULARRESULTADO $\left(F_{1}, F_{2}, o p\right) \rightarrow F_{r}$} \\
\hline Operações e condições & Resultado devolvido \\
\hline \hline$F_{1} o p F_{2} ; F_{1}=C_{1} ; F_{2}=C_{2}$ & $C_{1}$ op $C_{2}$ \\
\hline$F_{1} \oplus F_{2} ; F_{2}=0$ & $F_{1}$ \\
\hline$F_{1} \oplus F_{2} ; F_{1}=0$ & $F_{2}$ \\
\hline$F_{1} \ominus F_{2} ; F_{2}=0$ & $F_{1}$ \\
\hline$F_{1} \otimes F_{2} ; F_{2}=0$ & 0 \\
\hline$F_{1} \otimes F_{2} ; F_{1}=0$ & 0 \\
\hline$F_{1} \otimes F_{2} ; F_{2}=1$ & $F_{1}$ \\
\hline$F_{1} \otimes F_{2} ; F_{1}=1$ & $F_{2}$ \\
\hline$F_{1} \oslash F_{2} ; F_{2}=1$ & $F_{1}$ \\
\hline $\min \left(F_{1}, F_{2}\right) ; \max \left(F_{1}\right) \leq \min \left(F_{2}\right)$ & $F_{1}$ \\
\hline $\min \left(F_{1}, F_{2}\right) ; \max \left(F_{2}\right) \leq \min \left(F_{1}\right)$ & $F_{2}$ \\
\hline \multicolumn{2}{|c|}{$\operatorname{similarmente~para~max~}$} \\
\hline$F_{1} \leq F_{2} ; \max \left(F_{1}\right) \leq \min \left(F_{2}\right)$ & 1 \\
\hline$F_{1} \leq F_{2} ; \max \left(F_{2}\right) \leq \min \left(F_{1}\right)$ & 0 \\
\hline Outros & null \\
\hline
\end{tabular}

Tabela 3.2: Entradas e saídas para CalcularResultado. Se CalcularResultado recebe dois nós constantes como DDs, devolve o resultado da operação sobre essas duas constantes para qualquer operação binária. Em outros casos específicos devolve resultados triviais sem fazer recursão (Sanner, 2008).

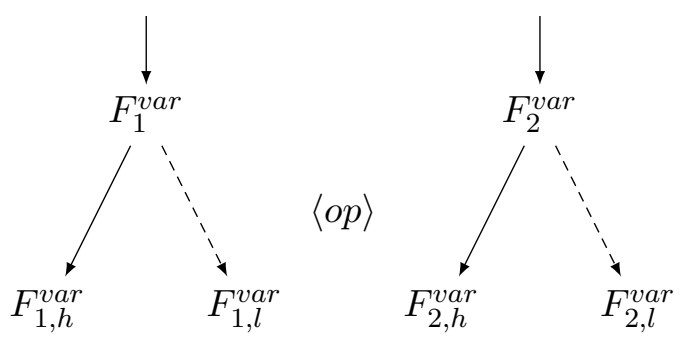

Figura 3.11: Dois nós de DDs, $F_{1}$ e $F_{2}$, e uma operação binária op com a notação correspondente usada no algoritmo Aplica (Sanner, 2008).

Além das operações binárias para ADDs, também pode-se aplicar operações unárias sobre os ADDs. No algoritmo APLICA são usadas duas operações unárias: min e max de um ADD. Mas também pode-se aplicar a operação de marginalização de um ADD, necessária para a solução de MDPs fatorados. A seguir, é apresentada a explicação de algumas operações unárias que podem 


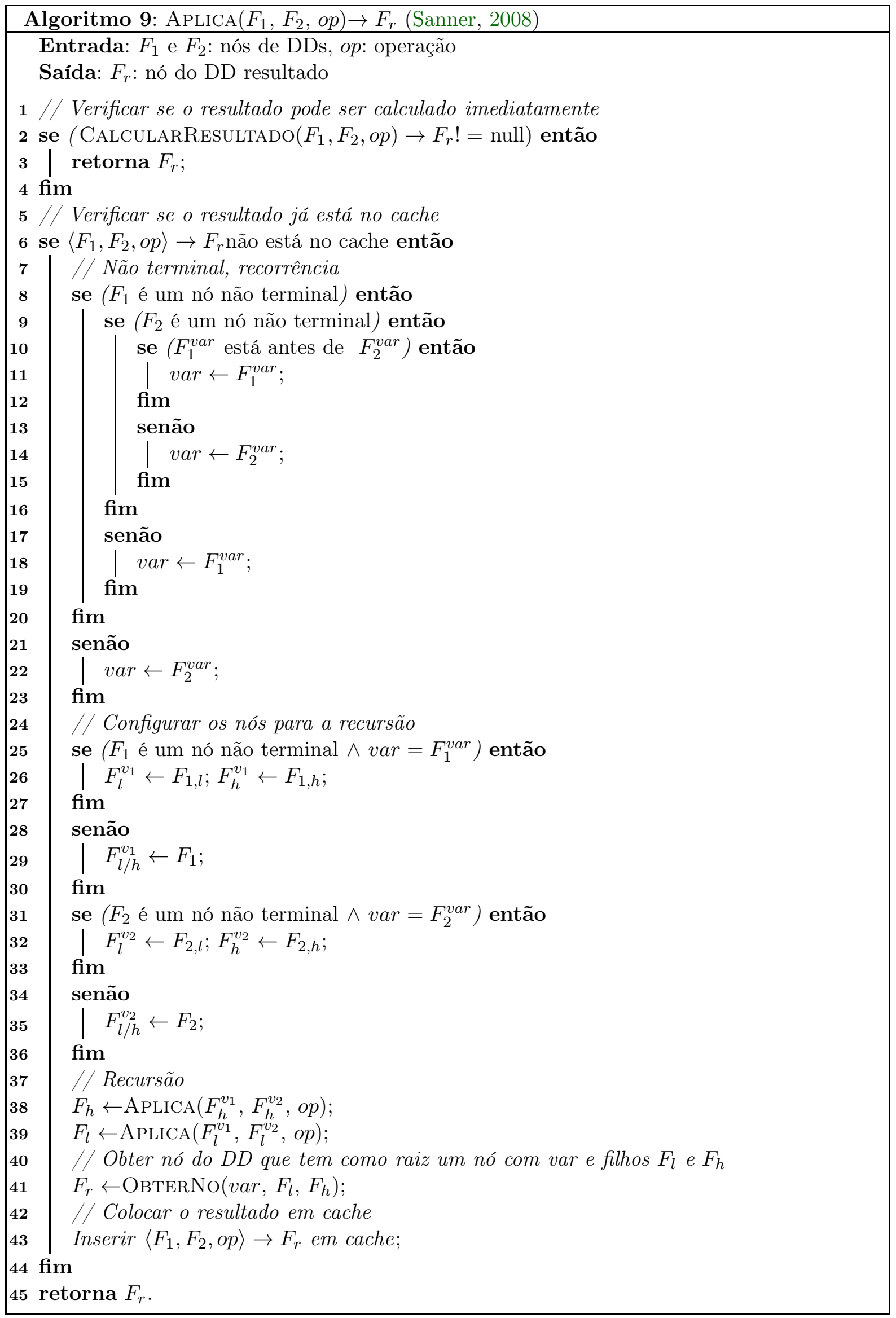


ser feitas eficientemente.

min e max: durante a operação de REDUZIR o ADD pode-se manter os valores de mínimo e máximo para cada nó não terminal. Como um ADD é um DAG, então $\min F=\min \left(F_{l}, F_{h}\right)$. O cálculo de max é realizado de forma similar.

Restrição: calcular o valor de um ADD F fazendo a restrição da variável $\mathcal{X}_{i}$ para o valor verdadeiro ou falso. Ou seja, $\left.F\right|_{\mathcal{X}_{i}=\text { verdadeiro/falso }}$ ), pode ser calculada substituindo os nós da variável $\mathcal{X}_{i}$ com o nó do ramo que corresponde ao valor restringido. A função REDUZIR pode ser aplicada no resultado desta operação.

Marginalização: marginalizar a variável $\mathcal{X}_{i}$ de um ADD $F$, significa calcular a soma dos ADDs resultantes da restrição da variável $\mathcal{X}_{i}$ para os valores verdadeiro e falso. Ou seja, $\sum_{\mathcal{X}_{i}} F=$ $\left.\left.\left.F\right|_{\mathcal{X}_{i}=\text { verdadeiro }} \oplus F\right|_{\mathcal{X}_{i}=\text { falso }}\right)$.

Na Figura 3.12 é ilustrado um exemplo da operação de restrição e marginalização.

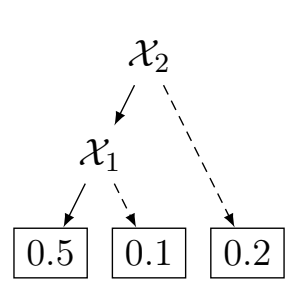

(a) $A D D$ original

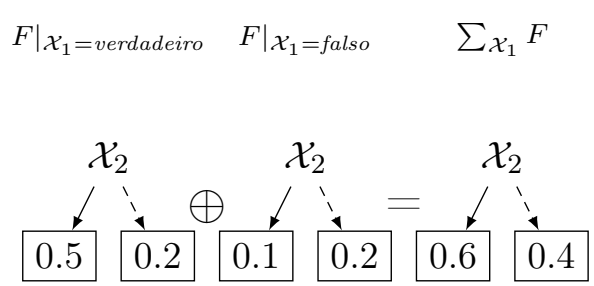

(b) Marginalização do ADD original

Figura 3.12: a) ADD antes da marginalização, b) A marginalização é feita somando-se o ADD resultante da restrição da variável $\mathcal{X}_{1}$ como verdadeiro $\left(\left.F\right|_{\mathcal{X}_{1}=\text { verdadeiro }}\right)$ e o ADD com a restrição da variável $\mathcal{X}_{1}$ como falso $\left(F \mid \mathcal{X}_{1}=\right.$ falso $)$.

Também para os BDDs existe uma operação unária que é a negação $(\sim$ ou $\bar{A})$. Esta operação basicamente inverte os valores das duas folhas do BDD (Algoritmo 10). 


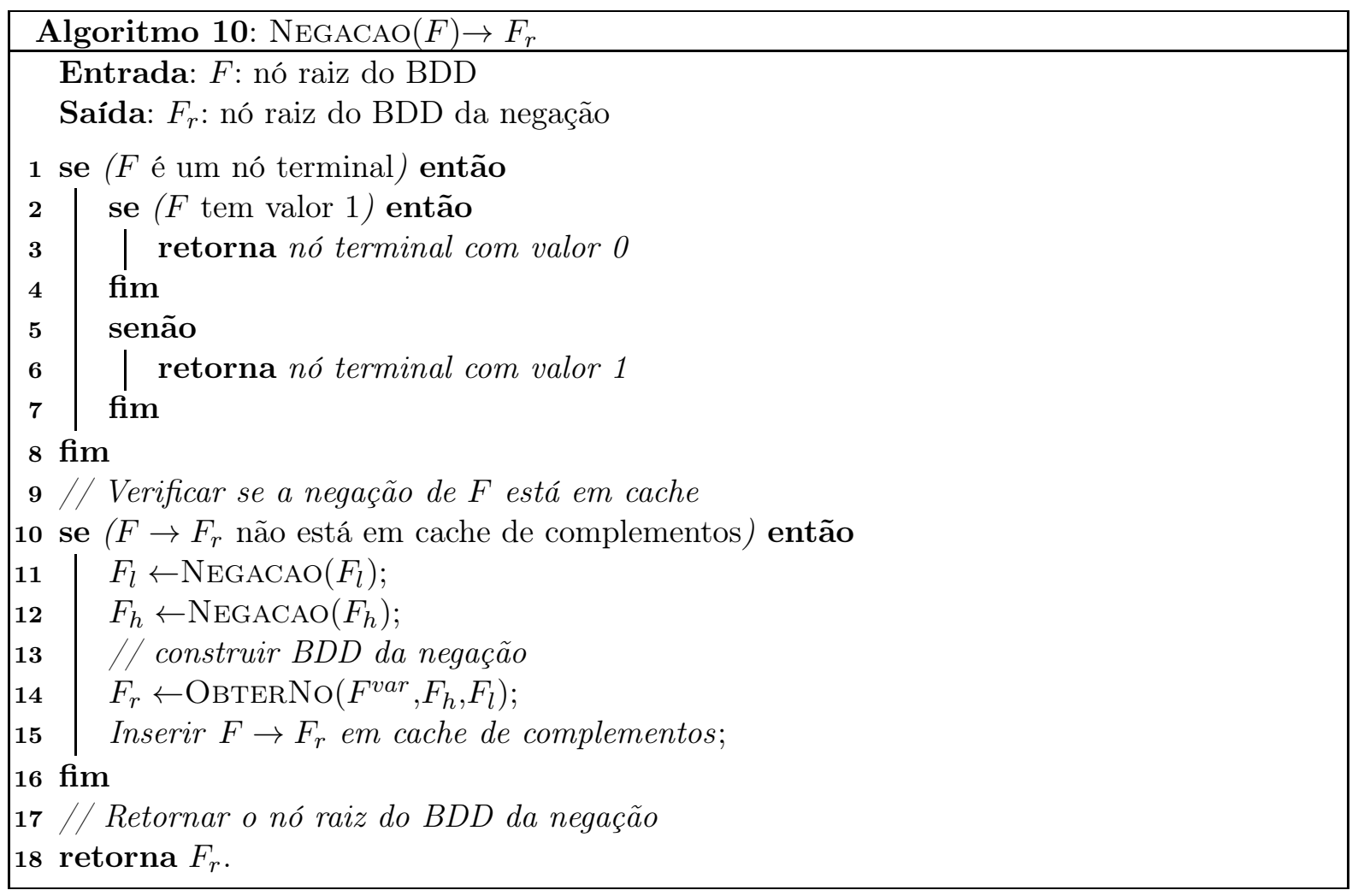




\section{Capítulo 4}

\section{Soluções Fatoradas para MDPs}

Neste capítulo são apresentadas as principais soluções encontradas nas literatura para MDPs fatorados. Serão descritos os algoritmos com ênfase no cálculo da função valor, $V(s)$, que nas soluções fatoradas, é feito usando operações entre ADDs. Existem duas maneiras de se explorar a representação compacta da função valor para realizar as atualizações de Bellman (Equação 4.1):

- no cálculo eficiente da recompensa esperada dos estados sucessores, realizando a operação de marginalização de ADDs; e

- na atualização eficiente de conjuntos de estados, realizando operações entre ADDs que representam esses conjuntos.

\subsection{Soluções Síncronas para MDP Fatorado}

\subsubsection{SPUDD: Iteração de Valor usando Diagramas de Decisão}

O algoritmo de Iteração de Valor foi originalmente projetado para lidar com MDPs enumerativos, porém este algoritmo não é eficiente para problemas com espaço de estados grande $\left(|S|>2^{10}\right)$. Isso porque, como é um algoritmo síncrono, precisa calcular a função valor para todos os estados em cada iteração. Uma solução para MDPs mais eficaz faz uso de MDPs fatorados, denominada Planejamento Estocástico usando Diagramas de Decisão (Stochastic Planning using Decision Diagrams - SPUDD) (Hoey et al., 1999).

O SPUDD é uma extensão do algoritmo de Iteração de Valor que usa ADDs para representar CPTs e a função recompensa. Além disso, SPUDD representa a função valor como um ADD e realiza os cálculos para encontrar a função valor ótima com operações entre ADDs. Na Seção 3.2.2 foram dados exemplos de ADDs para representar de forma compacta tanto as CPTs da função de transição (Figura 3.9) quanto a função recompensa de um MDP fatorado (Figura 3.8b). Esta representação das partes do MDP com DBNs e ADDs, define uma linguagem de definição de domínios e problemas de planejamento, especial para resolver MDPs com o SPUDD. Esta linguagem também é chamada de SPUDD. Uma descrição de linguagens de definição de domínios de planejamento é mostrada no Capítulo 6.

ADDs podem ser usados para representar a função valor de forma extremamente compacta, reagrupando estados de mesmo valor em cada iteração do algoritmo. Para isso, é necessário 
definir a Equação de Bellman do MDP fatorado (Equação 3.4) em termos de operações de ADDs, ou seja:

$$
V_{D D}^{t}(\vec{x})=\max _{a \in A}\left\{R_{D D}(\vec{x}, a) \oplus \gamma \sum_{\mathcal{X}_{i}^{\prime}} \bigotimes_{i=1}^{n} P_{D D}\left(x_{i}^{\prime} \mid p a_{a}\left(\mathcal{X}_{i}^{\prime}\right), a\right) \otimes V_{D D}^{t-1}\left(\overrightarrow{x^{\prime}}\right)\right\},
$$

em que as variáveis com índice DD indicam funções representadas por ADDs. Note que na Equação 4.1, no lugar da somatória $\sum_{s \in S}$, é usada a operação unária de marginalização $\left(\sum_{\mathcal{X}_{i}^{\prime}}\right)$ sobre as operações binárias: $\oplus, \otimes$. Além disso, a maximização é realizada entre ADDs usando o operador $\max (\cdot, \cdot)$, como definido na Seção 3.3.2. A operação $\bigotimes_{i=1}^{n}$ representa um produtório de ADDs. Neste caso, é usado para multiplicar as expressões $P_{D D}\left(x_{i}^{\prime} \mid p a_{a}\left(\mathcal{X}_{i}^{\prime}\right), a\right) \times V_{D D}^{t-1}\left(\overrightarrow{x^{\prime}}\right)$ de todas as variáveis de estado. Note que, $V_{D D}^{t}(\vec{x})$ calculado com a Equação 4.1 é um ADD, uma vez que essas operações são fechadas para ADDs.

A vantagem principal do SPUDD, está na representação das funções como ADDs. Porém, esta representação depende da estrutura do problema, isto é, se o problema tem muitos estados com valores diferentes, o ADD da função valor não será compacto. No melhor caso, onde tem muitos estados com valores iguais, o ADD da função valor cresce linearmente no número de variáveis de estado. Especificamente, o problema linear envolve $n$ variáveis e tem $n+1$ valores distintos. O MDP pode ser representado em espaço $O\left(n^{2}\right)$ usando ADDs e a função ótima pode ser representada em $O(n)$ com um ADD. Portanto, a estrutura do problema pode ser eficientemente explorada.

Considerando a estrutura do problema, no melhor caso, no SPUDD, o tempo de solução é incrementado linearmente com o número de variáveis de estado, enquanto que Iteração de Valor incrementa o tempo exponencialmente com o número de variáveis. Para o pior caso de estrutura de problema, o SPUDD também incrementa exponencialmente o tempo de solução, com relação ao número de variáveis de estado (Hoey et al., 1999).

\subsubsection{APRICODD: Iteração de Valor Aproximada}

Nem sempre o uso de ADDs permite resolver de maneira exata problemas grandes de planejamento dadas as limitações de tempo e espaço. Isso porque as atualizações da função valor (Equação 4.1) fazem com que o ADD cresça, aumentado assim o número de folhas e se aproximando do pior caso, em que o número de folhas é igual a $|S|$. Tais limitações, mesmo com a capacidade de compactação dos ADDs, não podem ser evitadas. Para estes casos, a única solução viável é usar aproximações com garantias de erro limitado.

O algoritmo APRICODD (St-Aubin et al., 2001) propõe uma forma eficiente de aproximar um ADD, baseado nos valores reais das folhas, que reduz o tamanho dos ADDs. Esta abordagem busca compactar ainda mais os ADDs, principalmente para ocupar o menor espaço possível na representação de muitos estados e também para diminuir o tempo de cálculo das operações dos ADDs.

O método de poda do APRICODD recebe dois parâmetros: um ADD que representa uma função e um erro de aproximação. O algoritmo devolve um novo ADD que representa a redução 
do ADD original, em que duas ou mais folhas com valores similares são agregadas numa única folha que representa um valor aproximado de acordo com: (1) a média, (2) a mediana, (3) o mínimo ou (4) o máximo. A escolha do tipo de aproximação no ADD reduzido depende do domínio em questão. O APRICODD primeiro coleta todas as folhas do ADD e em seguida determina quais dessas folhas devem ser agrupadas em uma nova folha. Finalmente, substitui cada folha por um novo valor aproximado.

É importante notar que o APRICODD mantém garantias sobre o erro de aproximação (St-Aubin et al., 2001). Essa técnica será explicada em mais detalhes na Seção 5.3.

\subsection{Soluções Assíncronas para MDPs fatorados}

\subsubsection{SRTDP: RTDP usando Diagramas de Decisão}

O sRTDP (Feng et al., 2003) (symbolic RTDP) é a primeira solução assíncrona proposta para MDPs fatorados (Algoritmo 11). O sRTDP, não implementa exatamente o algoritmo RTDP (Seção 2.2.3) de forma fatorada, mas sim uma modificação do RTDP para atualizar grupos de estados similares em uma mesma iteração do algoritmo. Para isso, sRTDP usa a idéia de masking, que é uma representação de um conjunto de estados em um ADD, onde os estados que pertencem ao conjunto tem valor 1 e o restante, valor 0. Este tipo de ADD é chamado de máscara, e é usado para construir (e atualizar) um estado abstrato $E$ que contêm o estado atual $s$. O sRTDP constrói um estado abstrato $E$, de acordo com algum critério de generalização, e atualiza todos os estados pertencente a $E$, ao invés de atualizar um único estado por vez. Para isso, a Equação (4.1) é modificada da seguinte maneira:

$$
V_{D D}^{t+1, E}(\vec{x}) \leftarrow \max _{a \in A}\left\{R_{D D}^{E, a}(\vec{x}) \oplus \gamma \sum_{\mathcal{X}_{i}^{\prime}} \bigotimes_{i=1}^{n} P_{D D}^{E \cup E^{\prime}}\left(x_{i}^{\prime} \mid p a_{a}\left(\mathcal{X}_{i}^{\prime}\right), a\right) \otimes V_{D D}^{t, E^{\prime}}\left(\vec{x}^{\prime}\right)\right\},
$$

sendo $E$ o conjunto de estados abstratos que contém o estado visitado $\vec{x}$ em um trial do sRTDP; $E^{\prime}$ conjunto de estados sucessores de $E$ e $E \cup E^{\prime}$ representa a partição de estados para os quais a função $P_{D D}$ é definida para a atualização de $\vec{x}$.

Em (Feng et al., 2003) foram propostas duas formas para agrupar estados em um estado abstrato E: (1) baseada na função valor, que agrupa estados com valor similar (AGRUPA_V); (2) baseada na alcançabilidade, que agrupa estados com estados sucessores (AGRUPA_A).

O primeiro método de agrupar, AGRupA_V, constrói o estado abstrato E que contém o estado visitado, usando a função valor atual. Esta primeira forma de generalização, seleciona os estados que tem um valor similar ao valor do estado atual $s_{t}$ de um trial. Para um estado $s$ ser considerado similar ao estado atual $s_{t}$, AGRUPA_V, considera um erro de similaridade $\epsilon$, ou seja, $s \in E$ se $\left|V\left(s_{t}\right)-V(s)\right| \leq \epsilon$.

O segundo método de generalização, AGRUPA_A, constrói o estado abstrato, para o estado atual $s_{t}$, considerando a fórmula: $\operatorname{Preimg}\left(\operatorname{Img}\left(s_{t}\right)\right)-\operatorname{Preimg}\left(S-\operatorname{Im} g\left(s_{t}\right)\right)$, em que $\operatorname{Img}(s)$ calcula o conjunto de todos os estados que podem ser alcançados a partir do estado $s$ em um passo, para qualquer ação. Preimg $(C)$ recebe um conjunto de estados e calcula um novo conjunto de estados que podem alcançar algum estado do conjunto recebido num passo e para qualquer 


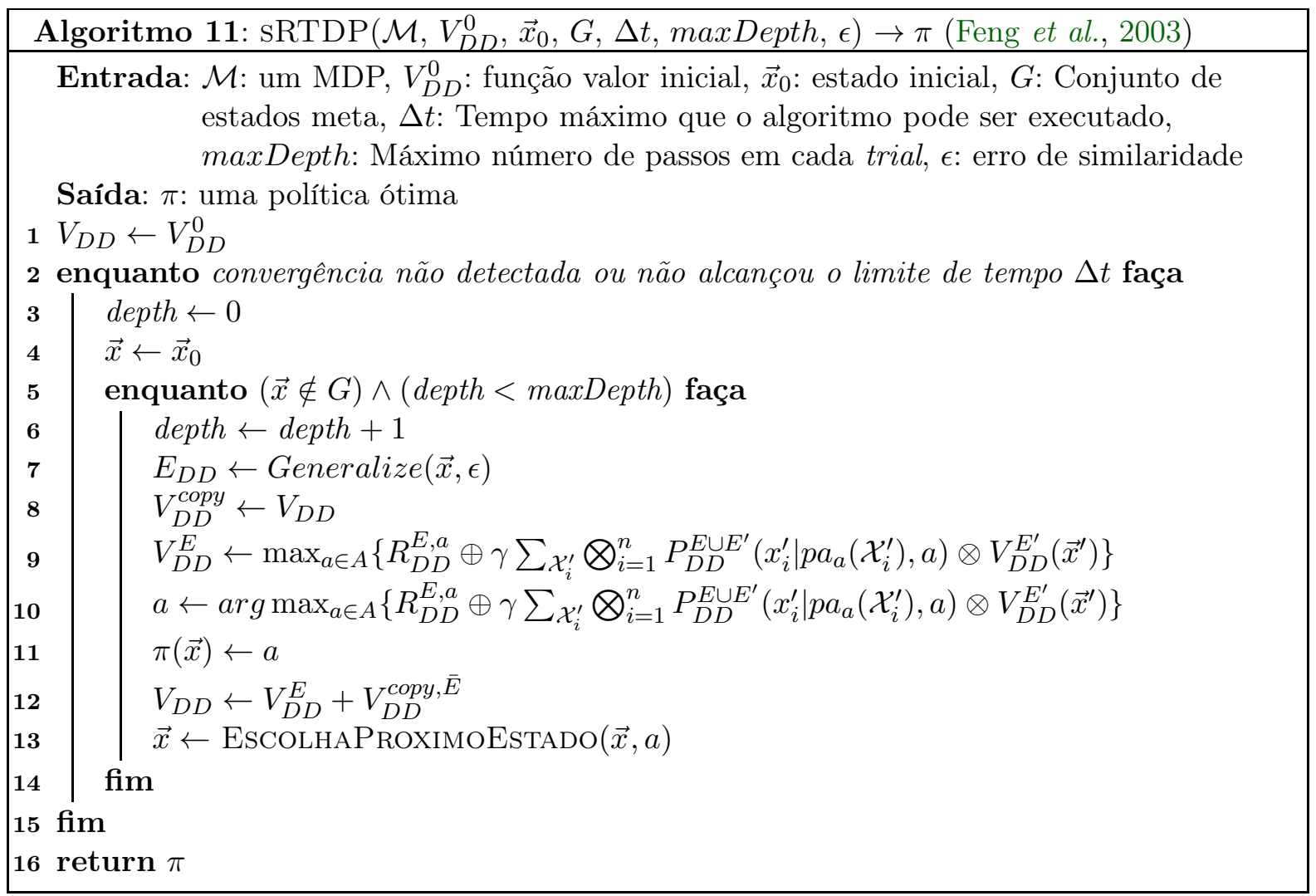

ação. Em geral, a fórmula para a generalização de alcançabilidade calcula o conjunto de todos os estados que podem alcançar, num passo, só os estados alcançáveis do estado $s$.

Empiricamente, (Feng et al., 2003) mostra que a generalização AGRUPA_V obtém melhores resultados do que AGRUPA_A. Por isso, para a análise experimental realizada nesse trabalho implementamos o algoritmo sRTDP com a generalização AGRUPA_V, que é explicada em mais detalhes a seguir.

A função Generalize $(\vec{x})$ (Linha 7, Algoritmo 11) calcula a máscara do conjunto E considerando a generalização AGRUPA_V, A Figura 4.1 mostra um exemplo de uma atualização de Bellman, passo a passo, com operações de ADDs para o estado abstrato $E$ (envolvendo 4 variáveis de estado) para o estado atual $s=\vec{x}=($ true, true, false, false) (estado realçado com linhas grossas na Figura 4.1a), sendo $V(\vec{x})=8.8$. Considerando $\epsilon=0.01$, os estados que pertencem ao estado abstrato $E$ são todos aqueles com valores no intervalo [8.79,8.81]. Na Figura 4.1a é apresentado o ADD da função valor atual, $V_{D D}$, em que aparecem 7 estados e seus respectivos valores $V(s) \in[8.79,8.81]$, e portanto que pertencem ao conjunto $E$. A Figura $4.1 \mathrm{~b}$ mostra o $\operatorname{BDD} E_{D D}$ que representa o conjunto $E$, devolvido por Generalize $(\vec{x}, \epsilon)$.

Na Linha 9 do Algoritmo 11, é calculada a atualização de Bellman do conjunto E. Este cálculo precisa do conjunto $E^{\prime}$ de estados alcançáveis num passo para os estados do conjunto $E$, que é calculado com a ação gulosa, também representado como um BDD. A Figura 4.1c apresenta o resultado da atualização de Bellman para o conjunto E. Este ADD mostra a atualização dos 7 estados do conjunto $E$. 


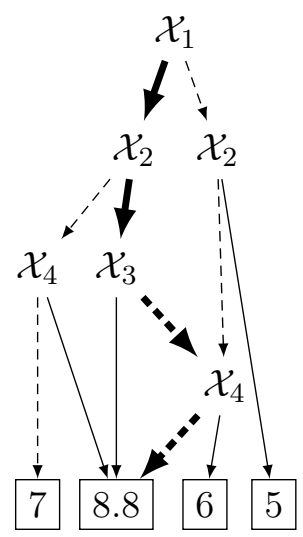

(a) $V_{D D}$

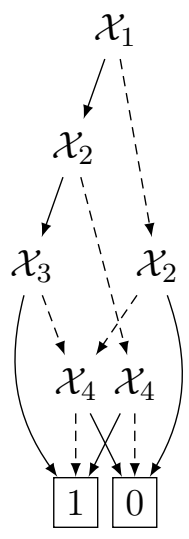

(b) $E_{D D}$

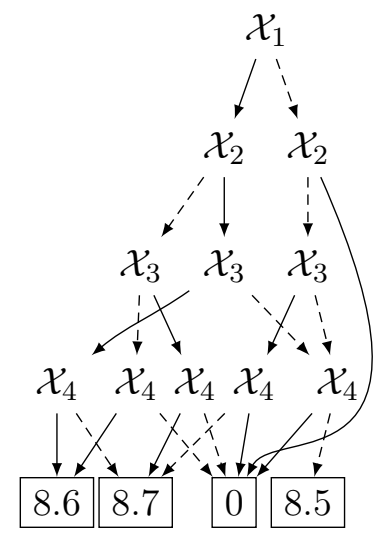

(c) $V_{D D}^{E}$ parcial

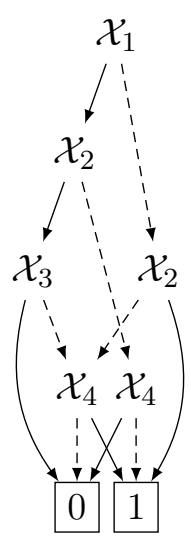

(d) $\bar{E}_{D D}$

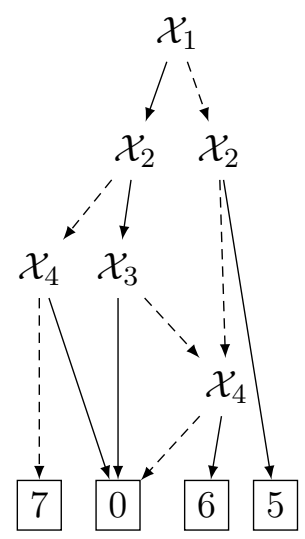

(e) $V_{D D}^{\text {copy, }}$

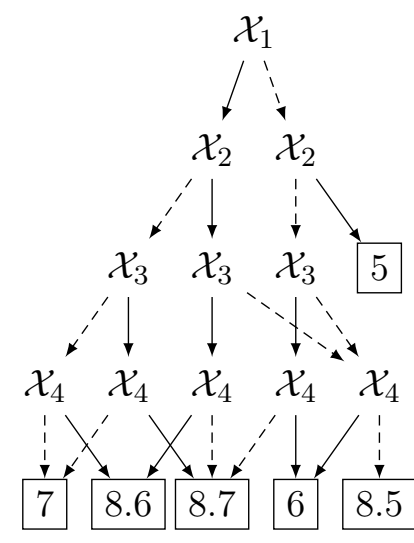

(f) $V_{D D}^{E} \oplus V_{D D}^{c o p y, \bar{E}}$

Figura 4.1: Processo de generalização por valor para o estado abstrato E no sRTDP.

$V_{D D}^{E}$ representa uma parte da função valor atualizada (isto é, contém a atualização somente dos estados pertencentes a $E$ ), portanto deve ser incluída na função valor atualizada. Para isso, o algoritmo armazena a função valor anterior na variável $V_{D D}^{c o p y}$ (Linha 8), e utiliza uma máscara $\bar{E}$ (Figura 4.1d), que representa o complemento do conjunto $E$, para calcular a função valor restrita aos valores que não foram atualizados. Isto é calculado multiplicando $\bar{E}_{D D} \otimes V_{D D}^{\text {copy }}$. A Figura 4.1e mostra o resultado desse produto, denotado por $V_{D D}^{c o p y}, \bar{E}$, que representa a função valor dos demais estados (atualizados com os valores anteriores). Finalmente, para juntar as duas partes da função valor atualizada é usada a operação soma de $\operatorname{ADD} V_{D D}^{E} \oplus V_{D D}^{c o p y, \bar{E}}$. A Figura 4.1f mostra o resultado de todo o processo de atualização da função valor realizado pelo sRTDP.

Depois de realizar a atualização de Bellman para o estado abstrato $E$, sRTDP escolhe o próximo estado a visitar. Isto é feito pelo algoritmo EscolhaProximoEstado (Linha 12 do Algoritmo 11) que sorteia o valor de cada variável de estado $\mathcal{X}_{i}^{\prime}$ :

$$
x_{i}^{\prime} \sim P_{D D}\left(x_{i}^{\prime} \mid \vec{x}, a\right)
$$

Embora agrupar estados em estados abstratos seja uma forma conveniente, a técnica das 
máscaras pode ser computacionalmente muito custosa (em domínios densos), como mostramos nos resultados experimentais (Seção 8). No entanto, a atualização de um conjunto de estados pode ter o mesmo efeito da atualização do grafo guloso realizada pelo LRTDP no CHECKSOLVED: estados menos prováveis de serem sorteados, também são atualizados aumentando a chance de visitar estados relevantes para a convergência.

\subsection{2 sBRTDP: BRTDP usando Diagramas de Decisão}

Para melhorar a escalabilidade do BRTDP (Seção 2.2.5) foi proposto o sBRTDP (Delgado et al., 2010). Este novo algoritmo considera os MDPs fatorados e os ADDs para fazer os cálculos do algoritmo BRTDP. Para isso, são usados três ADDs: um para o limite superior $V_{D D}^{u}$; um para o limite inferior $V_{D D}^{l}$ e um para a diferença $(g a p)$ dos limites $V_{D D}^{G A P}$. Todas as operações do BRTDP são feitas usando estes ADDs.

No sBRTDP, para fazer o sorteio do próximo estado, é preciso estabelecer uma nova distribuição de probabilidade para os valores de cada variável de estado. Este cálculo é feito para cada ação gulosa escolhida e segundo os valores das folhas da função $V_{D D}^{G A P}$.

\section{Cálculo da distribuição ponderada fatorada}

Pode-se decompor a distribuição ponderada pela diferença de limites $\frac{b(\cdot)}{B}$, da seguinte forma:

$$
P\left(x_{1}^{\prime}, \cdots, x_{n}^{\prime} \mid \vec{x}\right)=P\left(x_{n}^{\prime} \mid x_{1}^{\prime}, \cdots, x_{n-1}^{\prime}, \vec{x}\right) \cdots P\left(x_{2}^{\prime} \mid x_{1}^{\prime}, \vec{x}\right) P\left(x_{1}^{\prime} \mid \vec{x}\right) .
$$

Note que o valor de $x_{1}^{\prime}$ pode ser sorteado independentemente. Uma vez sorteado $x_{1}^{\prime}$, é possível sortear $x_{2}^{\prime}$, e assim por diante. Desta forma, podemos sortear todas as variáveis uma a uma até alcançar $x_{n}^{\prime}$. sBRTDP usa este método sequencial de sorteio do próximo estado (diferentemente do método empregado pelo sRTDP (Equação 4.3) que sorteia o valor das variávesi de estado de modo independente). Para isso, começamos por definir a forma fatorada de $b\left(\vec{x}^{\prime}\right)$, é dada por:

$$
b\left(\vec{x}^{\prime}\right)=\left[\prod_{i=1}^{n} P\left(x_{i}^{\prime} \mid \vec{x}, a\right)\right] V_{G A P}\left(\vec{x}^{\prime}\right),
$$

em que $V_{G A P}(\vec{x})=V_{u}(\vec{x})-V_{l}(\vec{x})$. Depois, começando por $x_{1}^{\prime}$ se faz o seguinte cálculo:

$$
p\left(x_{1}^{\prime}\right) \propto b\left(x_{1}^{\prime}\right)=\sum_{x_{i}^{\prime}, i \neq 1}\left[\prod_{i=1}^{n} P\left(x_{i}^{\prime} \mid x, a\right)\right] V_{G A P}\left(\vec{x}^{\prime}\right),
$$

que representa a somatória dos produtos das probabilidades dos possíveis valores de cada variável de estado. Este cálculo pode ser decomposto em:

$$
b\left(x_{1}^{\prime}\right)=P\left(x_{1}^{\prime} \mid \vec{x}, a\right) \sum_{x_{2}^{\prime}} P\left(x_{2}^{\prime} \mid \vec{x}, a\right) \sum_{x_{3}^{\prime}} P\left(x_{3}^{\prime} \mid \vec{x}, a\right) \cdots \sum_{x_{n}^{\prime}} P\left(x_{n}^{\prime} \mid \vec{x}, a\right) V_{G A P}\left(\vec{x}^{\prime}\right) .
$$

Analogamente, isso é feito para todas as demais variáveis $x_{i}^{\prime}, 1<i \leq n$. Dado o cálculo fatorado de $b(\vec{x})$, sBRTDP faz o sorteio das variáveis de estado usando um ADD com arestas etiquetadas. Para isso sBRTDP primeiro constrói o ADD da função $V_{G A P}$, em que as arestas contêm as probabilidades de transição dos estados atuais. Em seguida, o algoritmo percorre este 
ADD de baixo para cima, fazendo os produtos das probabilidades e dos valores da função $V_{G A P}$ (4.8). Os resultados destes cálculos também são armazenados nas arestas do ADD.

$$
b\left(x_{1}^{\prime}\right)=P\left(x_{1}^{\prime} \mid x, a\right) \sum_{x_{2}^{\prime}} P\left(x_{2}^{\prime} \mid x, a\right) \sum_{x_{3}^{\prime}} P\left(x_{3}^{\prime} \mid x, a\right) \cdots \sum_{x_{n}^{\prime}} P\left(x_{n}^{\prime} \mid x, a\right) V_{G A P}\left(x^{\prime}\right)
$$

Finalmente, com o ADD do $V_{G A P}$ resultante, BRTDP fatorado sorteia cada variável de estado no ADD da raiz para as folhas. Isto pode ser feito porque cada caixa na Equação 4.8 é exatamente um dos $P\left(x_{j}^{\prime} \mid x_{1}^{\prime}, \cdots, x_{j-1}^{\prime}, x, a\right)$ na Equação 4.4. Se a fatoração na Equação 4.4 é feita na mesma ordem que a ordem das variáveis do ADD, o cálculo de $P\left(x_{j}^{\prime} \mid x_{1}^{\prime}, \cdots, x_{j-1}^{\prime}, x, a\right)$ sempre se refere ao sub-diagrama com raiz $x_{j}^{\prime}$ no ADD e, de fato, o cálculo recursivo requerido para calcular as probabilidades de $x_{j}$ ser verdadeiro e de $x_{j}$ ser falso, esta armazenado localmente nos ramos de $x_{j}$ no sub-diagrama.
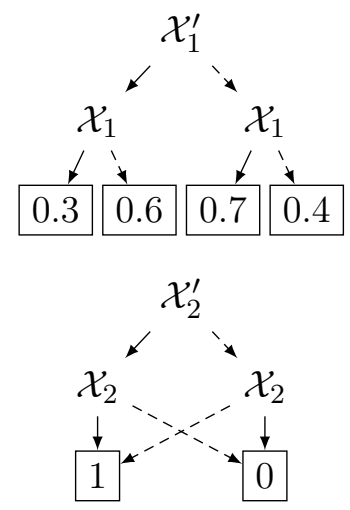

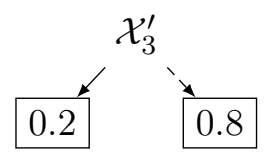

(a) $A D D$ para $\mathcal{X}_{i}^{\prime}$

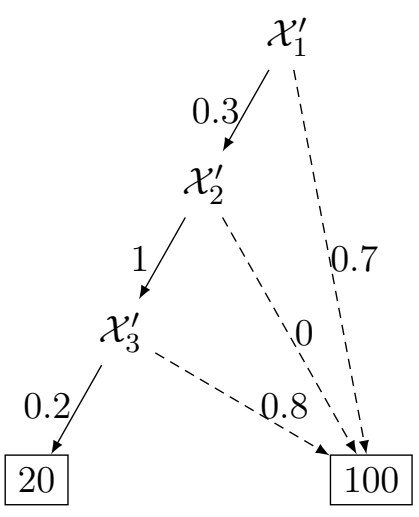

(b) $V_{G A P}$

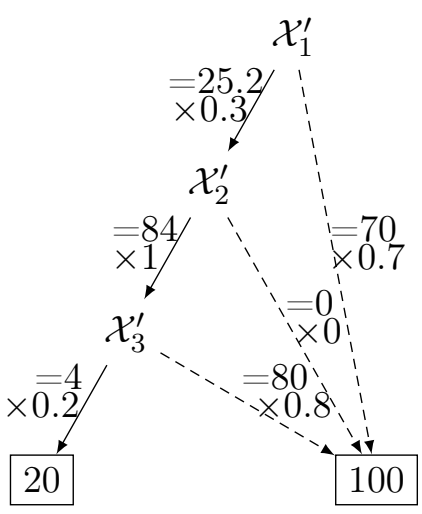

(c) $V_{G A P}$ com pesos

Figura 4.2: Calculando $b\left(x^{\prime}\right)=\prod_{i=1}^{n} P\left(x_{i}^{\prime} \mid \vec{x}, a\right) V_{G A P}\left(\vec{x}^{\prime}\right)$ e armazenando o valor no $V_{G A P}$ (Delgado et al., 2010).

A Figura 4.2 mostra um exemplo do cálculo da distribuição de probabilidades ponderada pela diferença de limites. Suponha que o agente está no estado $x_{1}=V, x_{2}=V$ e $x_{3}=V$; a ação gulosa é $a_{1}$ e queremos escolher o próximo estado. Primeiro deve-se armazenar as probabilidades das CPTs (Figura 4.2a) no $V_{G A P}$ (Figura 4.2b), e logo calcular e armazenar todas as caixas da Equação (4.8) no $V_{G A P}$ das folhas para a raiz (Figura 4.2c). Com base nestes valores pode-se sortear cada variável de estado (da raiz para as folhas), de acordo com os valores atuais das variáveis que já foram sorteadas.

Para obter as novas probabilidades se calcula uma distribuição normalizada dos valores obtidos em cada ramo do nó. Por exemplo, no nó $\mathcal{X}_{1}^{\prime}$, da Figura 4.2c, os valores obtidos em cada ramo são: 25.2 para verdadeiro e 70 para falso, então as novas probabilidades são: $P\left(\mathcal{X}_{1}=\right.$ Verdadeiro $\mid a)=\frac{25.2}{25.2+70}=0.264705882$ e $P\left(\mathcal{X}_{1}=\right.$ Falso $\left.\mid a\right)=\frac{70}{25.2+70}=0.735294118$. Suponha 
que no sorteio se escolhe que $\mathcal{X}_{1}^{\prime}=$ Verdadeiro e $\mathcal{X}_{2}^{\prime}=$ Falso. O percurso do ADD com estes valores leva para a folha de valor 100. Neste caso, como não temos valores para sortear o valor da variável $\mathcal{X}_{3}^{\prime}$, utiliza-se a probabilidade 0.5 para o sorteio.

sBRTDP herda a principal vantagem do BRTDP enumerativo: faz uma escolha melhor do próximo estado a ser visitado em um trial, isto é, escolhe estados mais prováveis e mais longe da convergência. Porém, a manutenção de dois ADDs para representar $V^{l}$ e $V^{u}$, torna esse método computacionalmente custoso. 


\section{Capítulo 5}

\section{Programação Dinâmica Assíncrona e Fatorada: novos algoritmos}

Os algoritmos de programação dinâmica assíncronos, RTDP (Seção 2.2.3), LRTDP (Seção 2.2.4), BRTDP (Seção 2.2.5) e os descritos na Seção 4.2, atualizam somente uma parte do espaço de estados em cada passo, mais especificamente, atualizam somente os estados alcançáveis a partir de um dado estado inicial e por isso podem lidar melhor com grandes espaços de estados. Dizemos que eles usam a informação sobre o estado inicial para melhorar sua eficiência no cálculo de uma política ótima.

Já os algoritmos da Seção 4.2, sRTDP e sBRTDP, são algoritmos fatorados assíncronos, e a princípio, eles podem lidar com MDPs com espaços de estados grandes, porque tem a vantagem de representar o MDP de forma mais compacta e também fazer operações eficientes com ADDs. Porém, esses 2 algoritmos tem suas desvantagens. O algoritmo sRTDP precisa construir um estado abstrato de sucessores de $s\left(E^{\prime}\right)$ que possivelmente tem tamanho $|S|$, caso o MDP tenha matrizes de transição densa. Já o algoritmo sBRTDP precisa levar em consideração dois limites da função valor que, na prática, é muito custoso.

A motivação desse trabalho é propor novas soluções fatoradas assíncronas eficientes que podem representar de maneira compacta o espaço de estados, que não fazem atualização de estados abstratos e não levam em conta dois limites da função valor. Assim, neste capítulo propomos 4 novos algoritmos fatorados:

1. FactRTDP, versão fatorada do algoritmo RTDP,

2. FactLRTDP, versão fatorada do algoritmo LRTDP,

3. aFactRTDP, versão aproximada e fatorada do algoritmo RTDP, com dois tipo de aproximação: max (máxima) e ave (média), e

4. aFactLRTDP, versão aproximada e fatorada do algoritmo LRTDP, com um tipo de aproximação: ave.

\subsection{FactRTDP: RTDP Fatorado}

FactRTDP é a versão fatorada exata do RTDP enumerativo descrito na Seção 2.2.3. Este novo algoritmo aproveita as representações fatoradas de estados, função de transição, função 
recompensa e função valor, e atualiza estados individuais, ao invés de estados abstratos, como no sRTDP.

No algoritmo FactRTDP, a atualização do SPUDD (Equação 4.1) é modificada para calcular a atualização de um estado individual $\vec{x}$ no passo $t+1$, da seguinte forma:

$$
v^{t+1}(\vec{x}):=\max _{a \in A}\left\{r(\vec{x}, a)+\gamma \sum_{\mathcal{X}_{i}^{\prime}} \bigotimes_{i=1}^{n} P_{D D}\left(x_{i}^{\prime} \mid \vec{x}, a\right) \otimes V_{D D}^{t}\left(\vec{x}^{\prime}\right)\right\},
$$

sendo $v^{t+1}(\vec{x})$ um valor real, uma vez que a expressão dentro do $\sum_{\mathcal{X}_{i}^{\prime}}$ só contém variáveis $\mathcal{X}_{i}^{\prime}$, que são eliminadas, uma a uma, na operação de marginalização $\left(\sum_{\mathcal{X}_{i}^{\prime}}\right)$, resultando num ADD com apenas um nó terminal (com valor real).

Para obter a função valor $V_{D D}^{t+1}$, o algoritmo FactRTDP insere o novo valor real $v^{t+1}(\vec{x})$ na função valor atual $V_{D D}^{t}$. Esta atualização pode ser feita de maneira eficientemente usando ADDs.

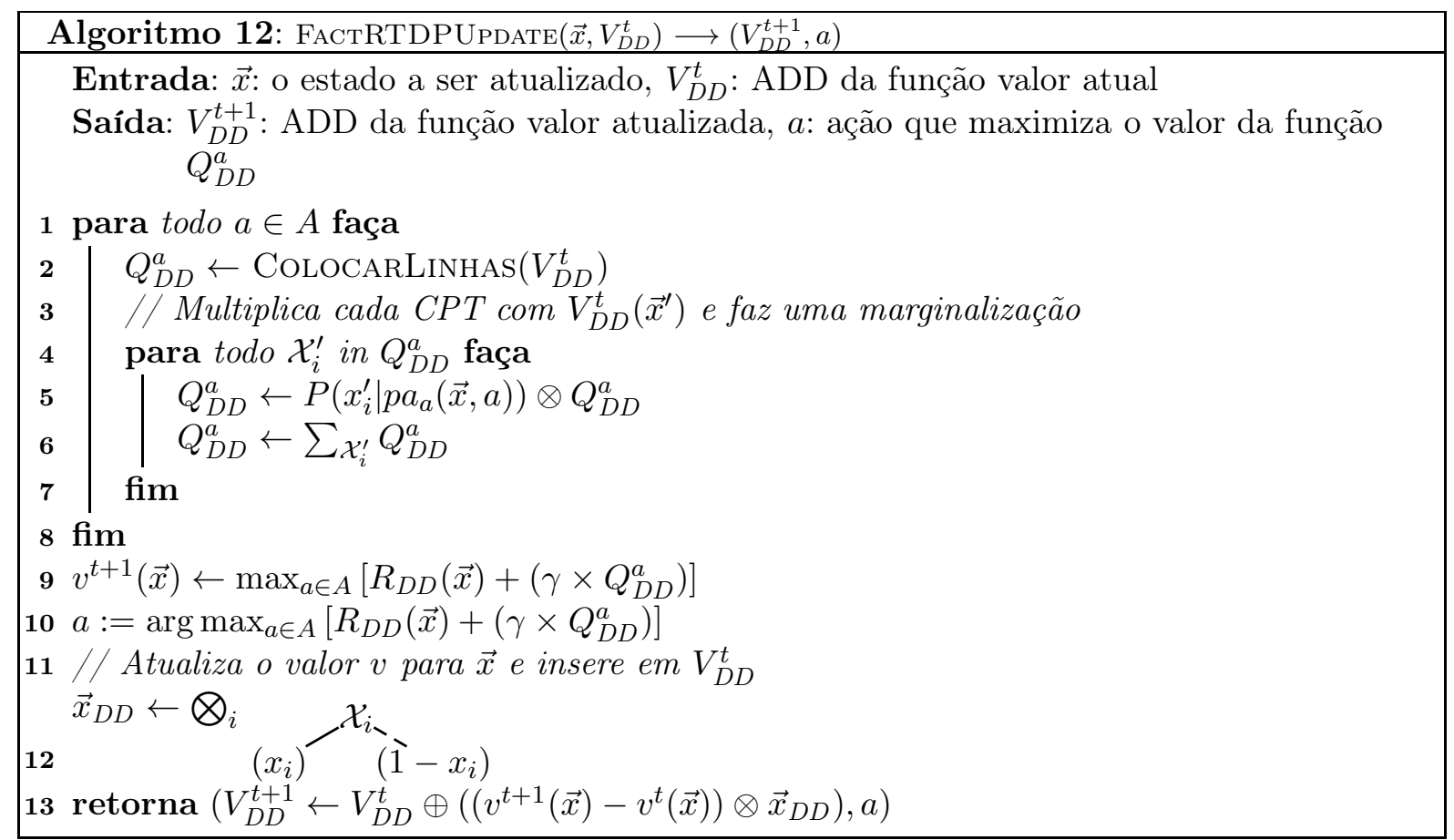

FactRTDP usa o mesmo procedimento básico do RTDP (Algoritmo 3), inicializando a função valor com um ADD (por exemplo, uma constante, cujo valor é o limite superior da função valor para todos os estados). O algoritmo FACTRTDPUpdate (Algoritmo 12) implementa a atualização de Bellman de cada estado visitado durante um trial de acordo com a Equação 5.1. FACTRTDPUPDATE primeiro coloca linhas em todas as variáveis de $V_{D D}^{t}$, isto é, converte cada $\mathcal{X}_{i}$ em $\mathcal{X}_{i}^{\prime}$ com a função COlOCARLinhas. Esta operação é feita porque parte da próxima função valor $V_{D D}^{t+1}$ permanece a mesma de $V_{D D}^{t}$. Em seguida, é calculada a função $Q(s, a)$ (Linhas 4-7) (Equação 2.5), chamada de $Q_{D D}^{a}$ no algoritmo FACTRTDPUPDATE. A função $Q_{D D}^{a}$ é calculada usando as operações multiplicação $(\otimes)$ e marginalização $\left(\sum_{\mathcal{X}_{i}}\right)$ de ADDs.

O valor atualizado $v^{t+1}(\vec{x})$ do estado $\vec{x}$ (Linha 9 do Algoritmo 12) é obtido computando a Equação (5.1). Esse novo valor $v^{t+1}(\vec{x})$ é inserido na função valor anterior $V_{D D}^{t}$ para obter a 
função atualizada $V_{D D}^{t+1}$ (Linha 13 do Algoritmo 12). Para isso, construímos uma máscara $\vec{x}_{D D}$ para o conjunto unitário $\{\vec{x}\}$. A construção da máscara é feita na Linha 12 do Algoritmo 12, multiplicando-se os BDDs que representam o valor de cada variável de estado $\mathcal{X}_{i}$ no estado $\vec{x}$, sendo que o resultado da produtória é um BDD em que o estado $\vec{x}$ tem valor 1 e o restante de estados de $S$ tem valor 0 .

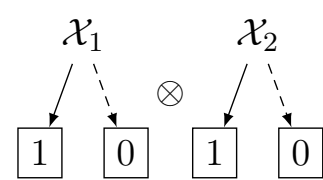

(a) $\vec{x}_{D D}$

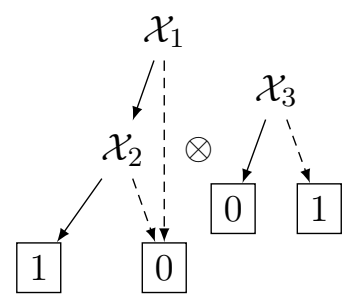

(b) $\vec{x}_{D D}$

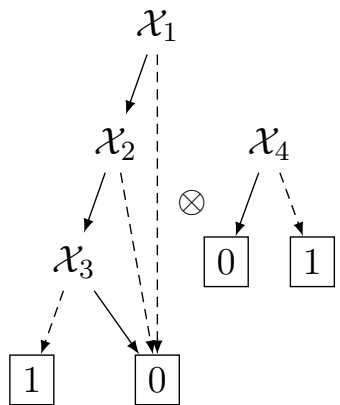

(c) $\vec{x}_{D D}$

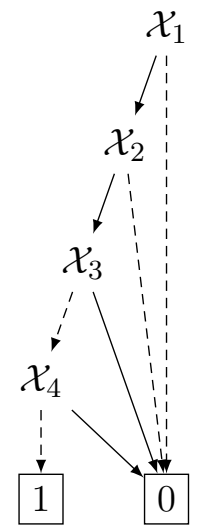

(d) $\vec{x}_{D D}$

Figura 5.1: Exemplo, passo a passo, do cálculo da máscara $\vec{x}_{D D}$.

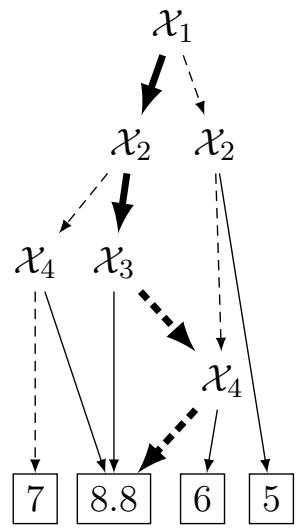

(a) $V_{D D}^{t}$

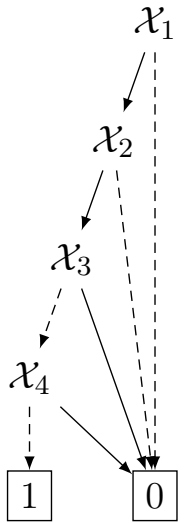

(b) $\vec{x}_{D D}$

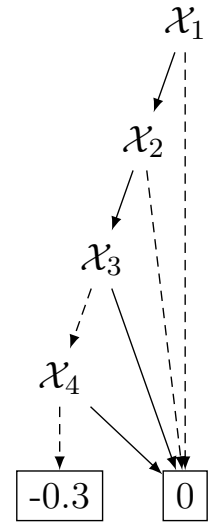

(c) $\left(v^{t+1}(\vec{x})-v^{t}(\vec{x})\right) \otimes \vec{x}_{D D}$

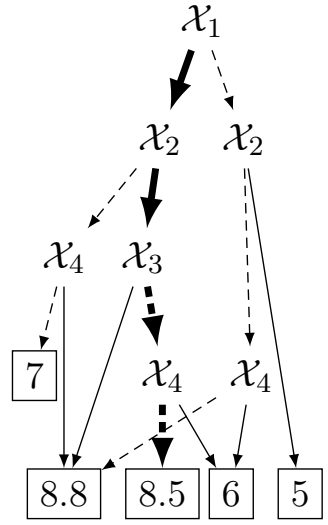

(d) $V_{D D}^{t+1}$

Figura 5.2: Função valor atualizada no FactRTDP para $\vec{x}=($ true, true, false, false $)$. Note que $v^{t+1}(\vec{x})$ e $v^{t}(\vec{x})$ são valores reais.

A Figura 5.1 mostra esse cálculo: a Figura 5.1a mostra o produto de um BDD com o valor da variável $\mathcal{X}_{1}$ para o estado $\vec{x}$ e um BDD que representa o valor da variável $\mathcal{X}_{2}$ no estado $\vec{x}$; a Figura $5.1 \mathrm{~b}$ e $5.1 \mathrm{c}$ mostram os resultados das multiplicações das Figuras 5.1a e 5.1b multiplicados por BDDs que representam os valores da variáveis $\mathcal{X}_{3}$ e $\mathcal{X}_{4}$ no estado $\vec{x}$; e a Figura $5.1 \mathrm{~d}$ mostram o BDD resultante da multiplicação dos BDDs dos valores do estado $\vec{x}$, que representam como é feita a operação produtório $\bigotimes_{i}$.

Finalmente, na Linha 13, a máscara $\vec{x}_{D D} 5.2 \mathrm{~b}$ é multiplicada com o resultado da diferença entre o valor novo $v^{t+1}(\vec{x})$ e o valor anterior $v^{t}(\vec{x})$ do estado $\vec{x}$. A idéia desta forma de atualização é adicionar a variação $\Delta V_{D D}(\vec{x})$ do valor do estado $\vec{x}$ ao valor anterior de $\vec{x}$ para obter o valor atualizado. É por isso que o ADD com essa variação é somado com o $V_{D D}^{t}$, para finalmente obter 
a função valor atualizada $V_{D D}^{t+1}$.

A Figura 5.2 mostra um exemplo de uma atualização feita pelo Algoritmo 12. A função valor $V_{D D}^{t}$ é mostrada na Figura 5.2a. A Figura 5.2b mostra a máscara $\vec{x}_{D D}$ para o estado $\vec{x}=$ (verdadeiro, verdadeiro, falso, falso), calculada na Figura 5.1. O resultado de $\left(v^{t+1}(\vec{x})-\right.$ $\left.v^{t}(\vec{x})\right) \cdot \vec{x}_{D D}$ é mostrado na Figura 5.2c. A Figura 5.2d mostra a atualização do valor de $\vec{x}=$ (verdadeiro, verdadeiro, falso, falso), que era 8.8 no estágio $t$ e torna-se 8.5 no estágio $t+1$.

Note que FactRTDP não pode ser considerado como uma instância de sRTDP com $|E|=1$, sendo $E=\{\vec{x}\}$. Neste caso, sRTDP ainda deve construir o estado abstrato $E^{\prime}$ para $\{\vec{x}\}$, que pode ser muito grande para domínios com matrizes de transição densa.

\subsection{FactLRTDP: RTDP Fatorado e Rotulado}

O segundo algoritmo proposto é oFactLRTDP, uma versão fatorada do LRTDP. Este algoritmo também faz a atualização de Bellman para apenas um estado em cada passo, usando ADDs, tal como é feito no FactRTDP. Além disso, FactLRTDP calcula o algoritmo ChECKSolved (Algoritmo 5, Seção 2.2.4), porém numa versão fatorada que chamamos de FACTCHECKSolved (Algoritmo 13). A seguir destacamos as principais operações fatoradas realizadas no algoritmo FactLRTDP.

No algoritmo FactLRTDP o conjunto de estados rotulados como resolvidos são representados por um BDD que é chamado solved $D D$. Assim, cada vez que o algoritmo CHECKSolved verifica que um estado foi resolvido, o valor deste será mudado para 1 em solved $_{D D}$.

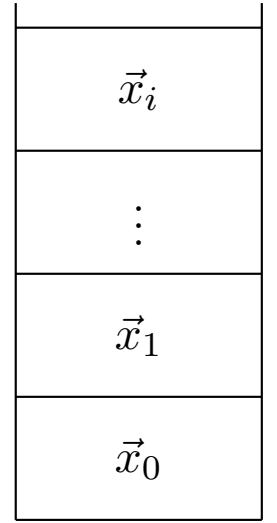

(a) Pilha closed

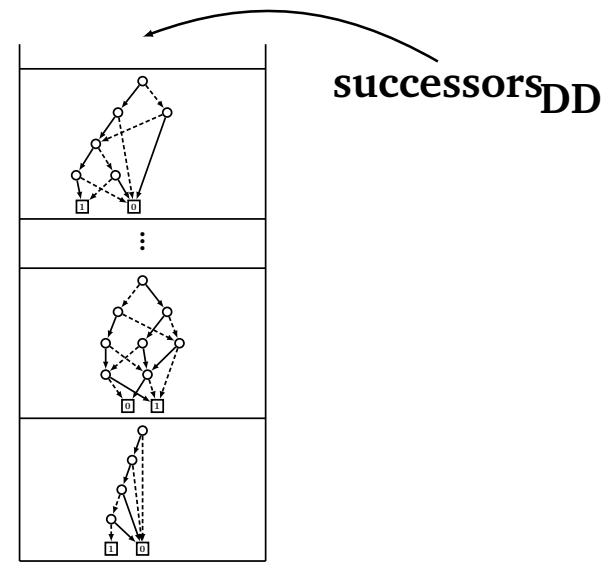

(b) Pilha open

Figura 5.3: Ilustração das pilhas closed $e$ open usadas no algoritmo FACTCHECKSOLVED. closed é uma pilha de estados, como no LRTDP; open é a pilha de BDDs que representa conjuntos de estados sucessores.

Como foi descrito na Seção 2.2.4, o algoritmo CheckSolved percorre o grafo guloso usando duas pilhas open e closed. FACTCHECKSOLVED representa a pilha open através de uma pilha de BDDs, em que cada BDD representa um conjunto de estados sucessores em um passo, chamada de successors $_{D D}$. Assim, cada vez que o FACTCHeCKSOlved armazena os estados sucessores de um estado visitado num trial, ele insere um BDD na pilha open que representa o conjunto de sucessores. Já a pilha closed contém apenas os nomes dos estados já visitados. A Figura 5.3 
ilustra as pilhas open e closed usadas no FACTCHECKSOLVED.

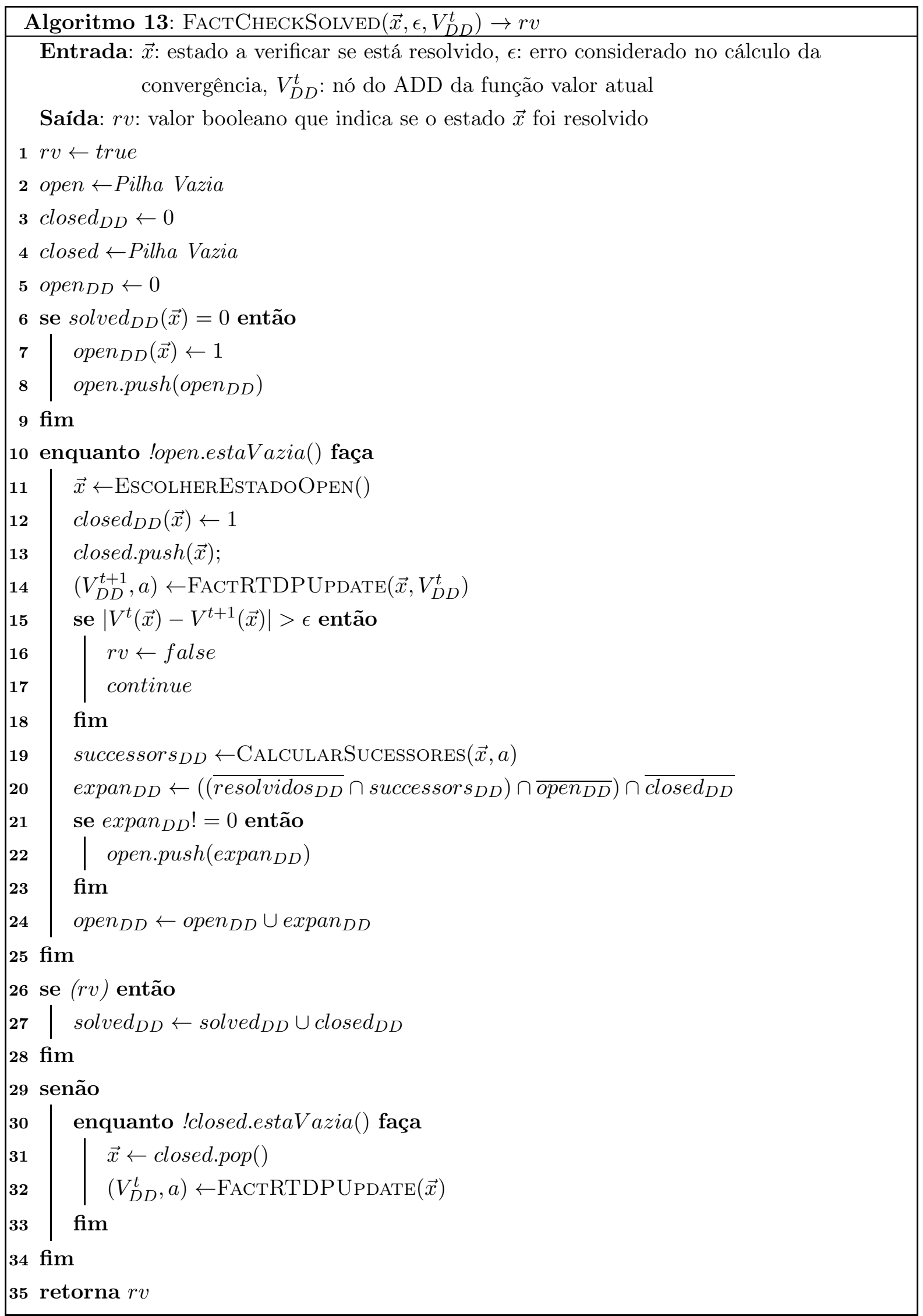


O algoritmo FACTCheCKSOLved faz operações com os conjuntos de estados armazenados nas pilhas open e closed bem como com o BDD solved $D D$. Por exemplo, quando adicionamos o conjunto de estados sucessores na pilha open, adicionamos apenas aqueles estados que não foram resolvidos, que não estão em open e nem em closed. Para fazer essas verificações definimos ainda dois BDDs para representar os estados pertencentes às pilhas open e closed, chamados de open $_{D D}$ e closed $_{D D}$ e usamos operações entre BDDs descritas na Seção 3.2.1.

Para calcular o grafo guloso, um estado $\vec{x}$ é expandido se $\left|V^{t}(\vec{x})-V^{t+1}(\vec{x})\right| \leq \epsilon$ e seu conjunto de sucessores é calculado a partir das funções de transição, que possuem a informação das probabilidades de transição: estados com probabilidade maior que 0 são estados sucessores. As probabilidades de transição nos MDPs fatorados são definidas para cada par variável de estado e ação. Assim, é preciso calcular a probabilidade conjunta (Equação 3.2) para obter as probabilidades para os pares estado e ação.

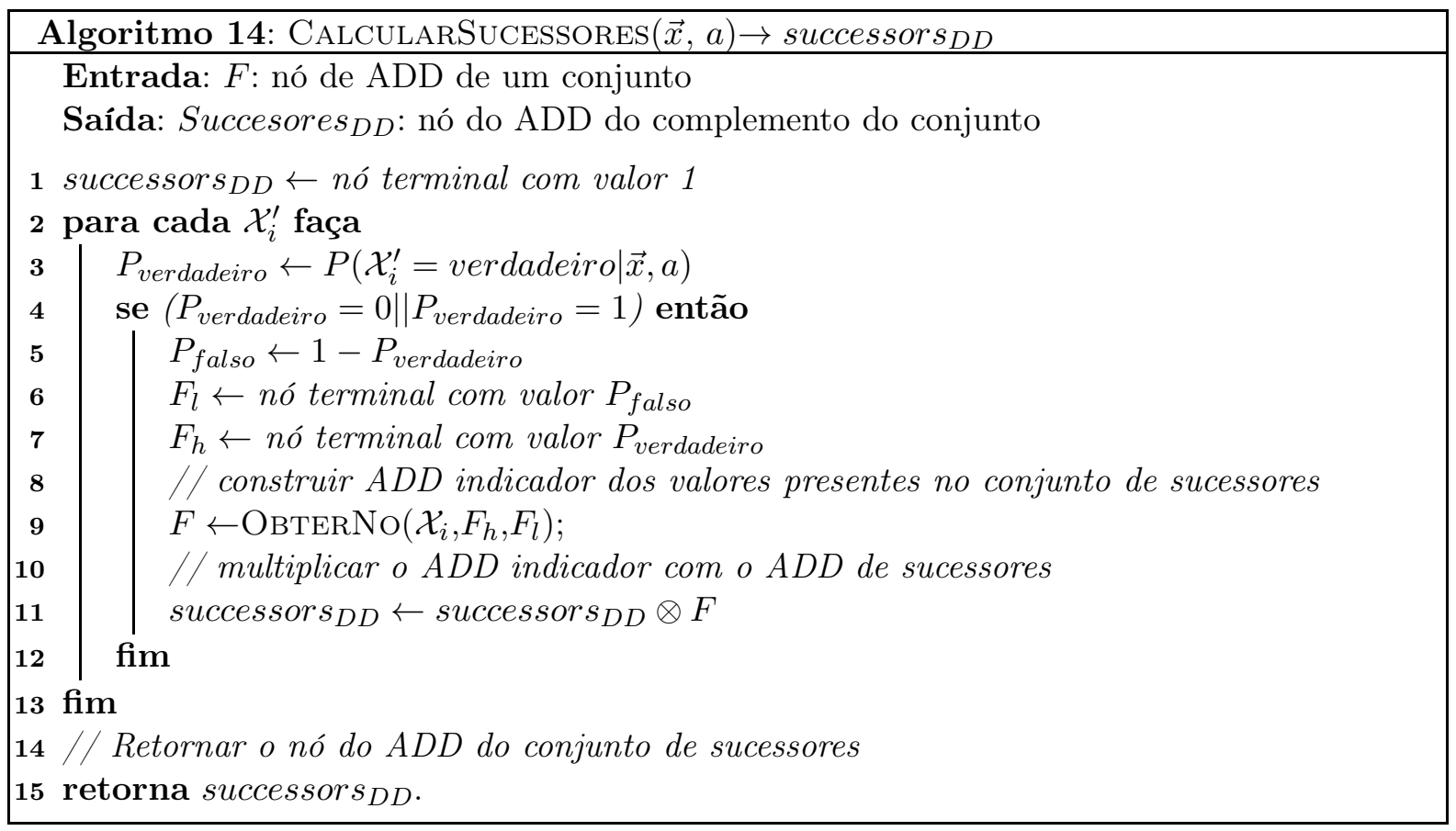

As probabilidades conjuntas dos estados sucessores de um estado $s$, para uma ação $a$, podem ser representadas por um ADD para cada ação $a$. Para uma ação $a$, este ADD é calculado através da multiplicação das probabilidades de transição de cada variável no estado $\vec{x}, P_{D D}\left(x_{i}^{\prime} \mid \vec{x}, a\right)$, representado por um ADD de três nós: a raiz, com a variável representada $\mathcal{X}_{i}$; e os dois filhos de $\mathcal{X}_{i}$, que tem os valores das probabilidades de que $\mathcal{X}_{i}$ seja verdadeiro ou falso. O ADD resultante dessa multiplicação representa a probabilidade conjunta dos estados sucessores de $s$ para a ação $a$. A partir deste ADD é possível obter o conjunto de sucessores de $\vec{x}$. Como só estamos interessados no conjunto de sucessores, e não nas probabilidades conjuntas de transição, podemos simplificar esse cálculo para obter um BDD que represente somente o conjunto de estados sucessores. Para isto, mudamos o cálculo das probabilidades conjuntas: ao invés de multiplicar ADDs com probabilidades, multiplicamos BDDs que indicam quais dos valores de cada variável de estado está presente no conjunto de sucessores. Isto pode ser feito substituindo no ADD de cada variável 
as probabilidades que tem valor maior que 0 por um valor 1 . Esta substituição resulta em dois possíveis BDDs: (1) se ambas probabilidades são maiores que 0, o BDD resultante é um nó terminal com valor $1 ;(2)$ se uma probabilidade é 0 e a outra 1 , o BDD resultante é o ADD original. Como sabemos que $F \otimes 1=F$, então só precisamos multiplicar aqueles BDDs que tenham uma probabilidade 0 e a outra 1. O Algoritmo 14 mostra como é calculado o conjunto de sucessores de um estado $s$ para a ação $a$, sem a necessidade de calcular as probabilidades conjuntas.

Sendo a pilha open uma pilha de BDDs, precisamos definir a função ESCOLHERESTADOOPEN (Algoritmo 15) que escolhe um estado desta pilha. Esta função desempilha o BDD successors $s_{D D}$ do topo de open, escolhe qualquer estado $\vec{x}$ pertencete a successor $s_{D D}$ e atualiza o valor deste estado nos ADDs successors $s_{D D}$ e open $_{D D}$ para 0 (representando que o estado foi eliminado desse conjunto). Finalmente, se o BDD successor $s_{D D}$ não ficou vazio, ou seja, se o BDD não é um nó terminal com valor 0, este BDD é empilhado na pilha open.

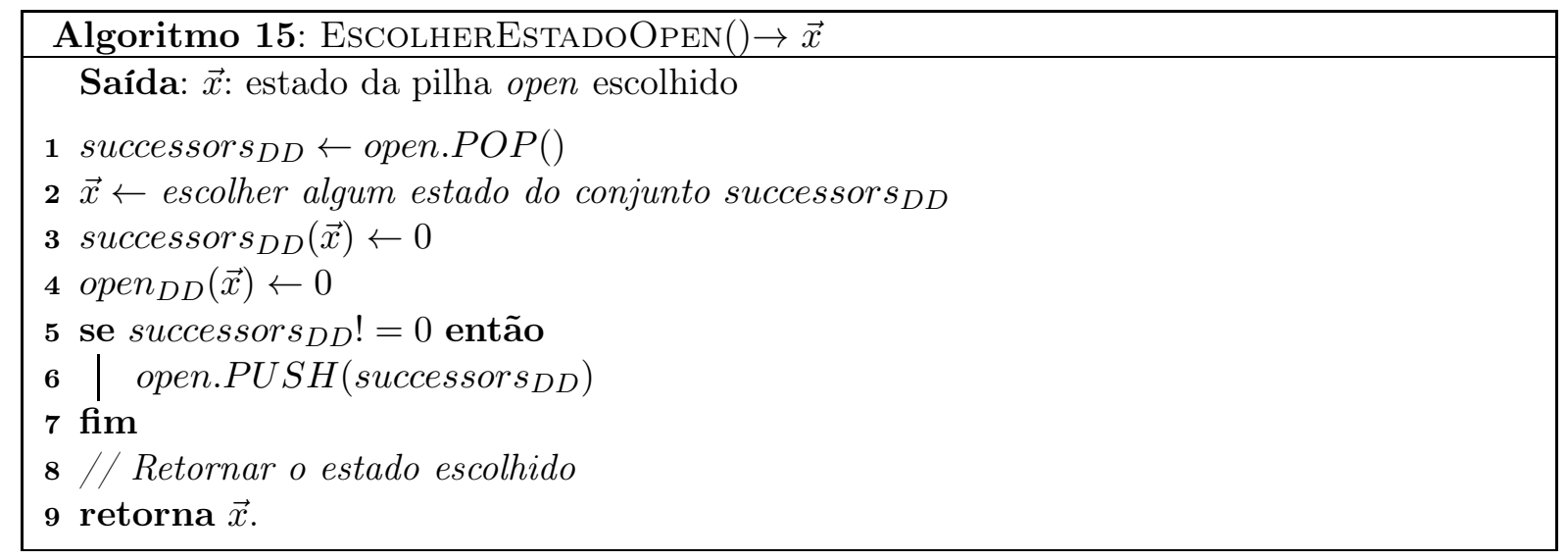

O Algoritmo 13 mostra o algoritmo FACTCheckSolved. No início (Linha 10) do laço principal, a função EscolherEstadoOpen seleciona um estado da pilha open, isto é, um estado $\vec{x}$ pertencente a successor $s_{D D}$ do topo da pilha open. Depois de verificar $\left|V^{t}(\vec{x})-V^{t+1}(\vec{x})\right|>\epsilon$, o algoritmo calcula o conjunto de sucessores de $\vec{x}$ com o método CAlCularSucessores. Em seguida, calcula o conjunto de estados a ser inseridos em open (linha 20) que é o conjunto de sucessores que não está em nenhum dos três conjuntos: $\operatorname{solved}_{D D}$, open ${ }_{D D}$ e $\operatorname{closed}_{D D}$. Para fazer este cálculo, o algoritmo aplica as operações de conjuntos explicadas na Seção 3.2.1. Este novo conjunto é inserido na pilha open e também é feita uma união com o conjunto open ${ }_{D D}$. Esse processo é repetido até que a pilha open fique vazia. Finalmente, o algoritmo verifica se o grupo de estados visitados está resolvido. Em caso afirmativo, é feita uma união do conjunto closed $_{D D}$ com o conjunto solved ${ }_{D D}$. Caso contrário, cada estado na pilha closed é atualizado em ordem reversa.

\section{3 aFactRTDP: RTDP Fatorado e Aproximado}

Para lidar com o crescimento do tamanho do ADD da função valor, implementamos um algoritmo que permite reduzir o tamanho da função valor calculada pelo algoritmo FactRTDP, produzindo uma aproximação dentro de um erro limitado. Este algoritmo aproximado, chamado 
de aFactRTDP, é baseado no algoritmo APRICODD (St-Aubin et al., 2001), que une folhas do $V_{D D}$ com valores dentro de uma margem de erro. Assim, dado um $V_{D D}$ e um erro de aproximação percentual, o algoritmo devolve um novo $V_{D D}$. Para unir folhas, o algoritmo estabelece os grupos que devem ser unidos, e depois determina um valor que represente esse grupo, que pode ser o valor máximo do grupo ou o valor médio do grupo. Assim, o método de aproximação é decomposto em: (1) seleção das folhas que devem ser unidas; e (2) cálculo do valor aproximado final.

$\mathrm{Na}$ prática, essas duas terefas podem ser realizadas de maneira integrada, como explicadas a seguir, para isso definimos duas variantes do algoritmo aFactRTDP: o algoritmo aFactRTDP_max, que coloca o valor máximo do grupo de folhas e; o algoritmo aFactRTDP_ave, que coloca o valor da média do conjunto das folhas.

O cálculo do erro permitido entre as folhas é feito da seguinte forma: dada uma porcentagem $\epsilon_{\%}$, calcula-se um erro de aproximação para os valores das folhas, chamada de mergeError, a partir da máxima recompensa descontada com a seguinte equação:

$$
\text { mergeError }=\frac{\max R e w a r d}{1-\gamma} \times \epsilon_{\%},
$$

que calcula o produto do limite superior da recompensa acumulada descontada num horizonte infinito com a porcentagem de erro dado.

O Algoritmo 16, é usado pelo aFactRTDP para obter ADDs aproximados. Este algoritmo inicia coletando todos os nós terminais do $V_{D D}$ (Linha 2 do Algoritmo 16) com a função ColeTANosTerminais (Algoritmo 17). Esta função percorre todo o ADD buscando nós. Primeiro, verificando se um nó $F$ é terminal ou não terminal. No caso de $F$ ser um nó não terminal, o algoritmo faz chamadas recorrentes para cada ramo do ADD (Linhas 2-3). Caso $F$ seja terminal, ele é inserido na lista de nós terminais (Linha 6).

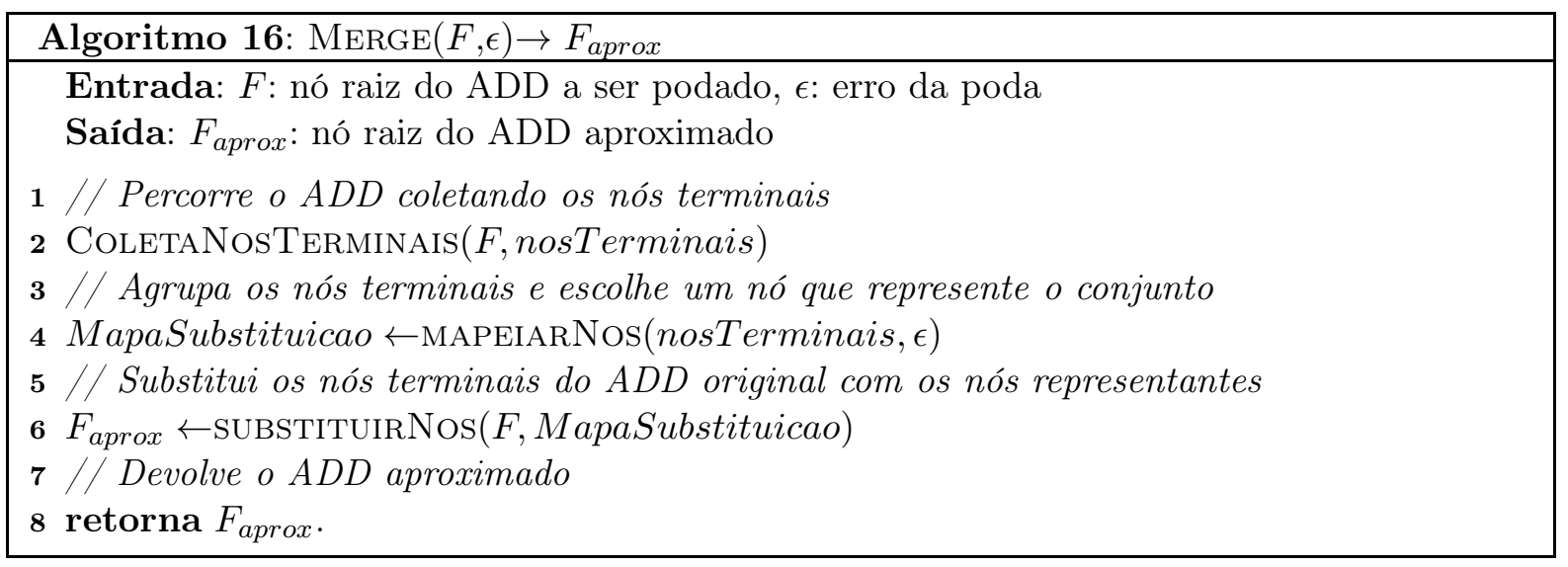

Depois de coletar os nós terminais do ADD, o algoritmo Merge agrupa os nós terminais e escolhe um nó representante para cada grupo (Linha 4 do Algoritmo 16). Os Algoritmos 18 e 19 mostram as duas variações da função MAPEARNos para o algoritmo aFactRTDP. A função MapearNosmedia (Algoritmo 18) implementa a aproximação considerando a média dos nós agrupados e a função MAPEARNosMAx (Algoritmo 19) implementa a aproximação considerando o valor máximo dos nós agrupados. 


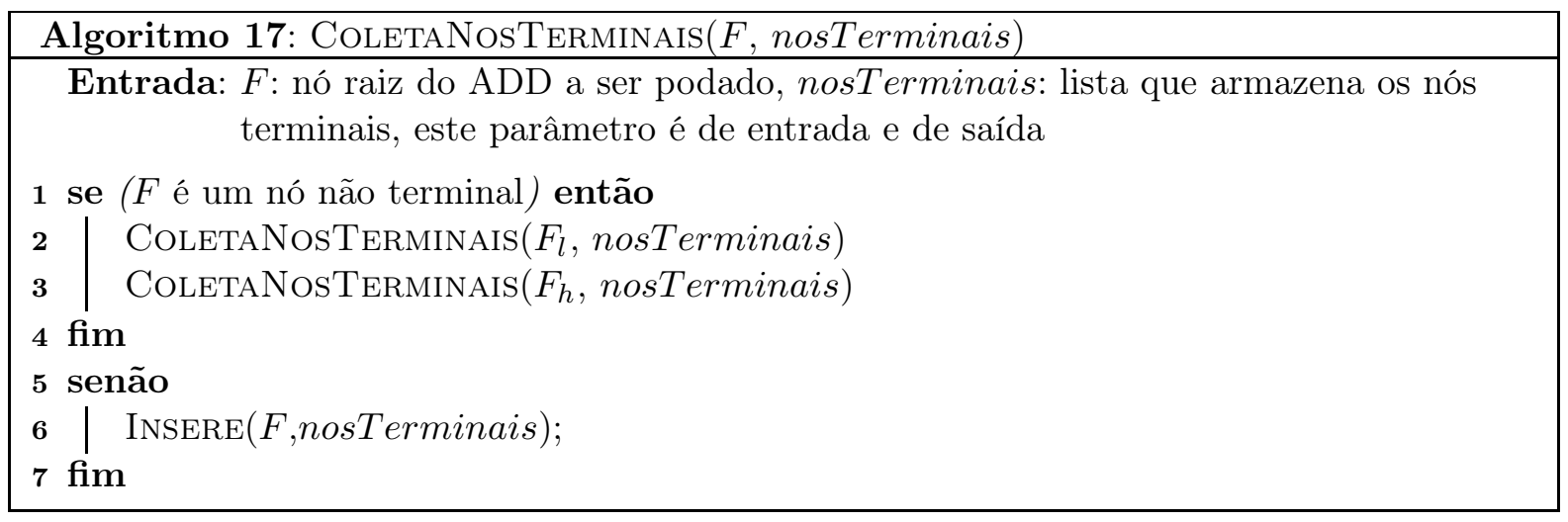

A função MapearNosmedia (Algoritmo 18) pega a lista de nós terminais coletados e ordena-a de forma crescente, segundo os valores dos nós terminais (Linha 2), percorre os nós terminais na ordem crescente e calcula, numa iteração, a média de todos os grupos de nós terminais. Para isto, inicializa as variáveis: no, nó terminal que indica o representante de cada grupo de nós terminais; soma, que acumula a soma dos valores dos nós terminais de cada grupo; max, que contém o valor máximo de cada grupo; e numElementos, que indica quantos elementos pertencem a cada grupo. Em cada iteração, o algoritmo MAPEARNosMEDiA verifica se o nó visitado ainda tem menor valor que o máximo permitido no grupo atual. Caso seja menor (Linhas 9-10), o valor deste nó é acumulado na variável soma e a quantidade de elementos do grupo atual é incrementada (variável numElementos). Caso o valor do nó visitado seja maior que o máximo (Linhas 13-19), então inicia-se um novo grupo. Para isto, verifica-se que a variável no seja diferente de null. Caso seja null, significa que o nó visitado é o primeiro da lista de nós terminais, isto é, o nó com menor valor. Como é o primeiro e também o nó com menor valor do grupo, inicializa-se os valores do nó representante e as variáveis soma, max e numElementos. A variável no recebe um novo nó terminal com um valor aleatório (Linha 16), max recebe o valor do limite máximo desse grupo que é $F_{i}+$ mergeError (Linha 17), a variável soma recebe o valor do primeiro nó (Linha 18) e a variável numElementos recebe o valor 1 que representa a quantidade de nós atuais do grupo. Depois de várias iterações, o algoritmo alcança um nó terminal que é maior que o máximo do grupo atual e então precisa iniciar um novo grupo. Para isto, verifica se a variável no é diferente de null, e calcula a média do grupo que vai ser fechado mudando o valor aleatório da variável no para o valor da média do grupo fechado, e em seguida, inicia um novo grupo. A Linha 20 armazena os mapeamentos dos nós terminais para os nós representantes. A Figura 5.4 ilustra como é feito agrupamento das folhas.

A função Mapearnosmax (Algoritmo 19) também calcula um mapeamento de nós terminais para os nós representantes de cada grupo, ordenando a lista de nós terminais de forma decrescente. Esta função também percorre todos os nós terminais e inicia um novo grupo cada vez que o valor do nó terminal é menor que o valor mínimo (variável min) do grupo anterior. Ao iniciar um novo grupo, elege como representante do grupo o primeiro elemento que visita (este elemento é o maior elemento do grupo, uma vez que a ordem do percurso é decrescente).

Depois de calcular o mapeamento dos nós terminais para os nós representantes de cada grupo, 

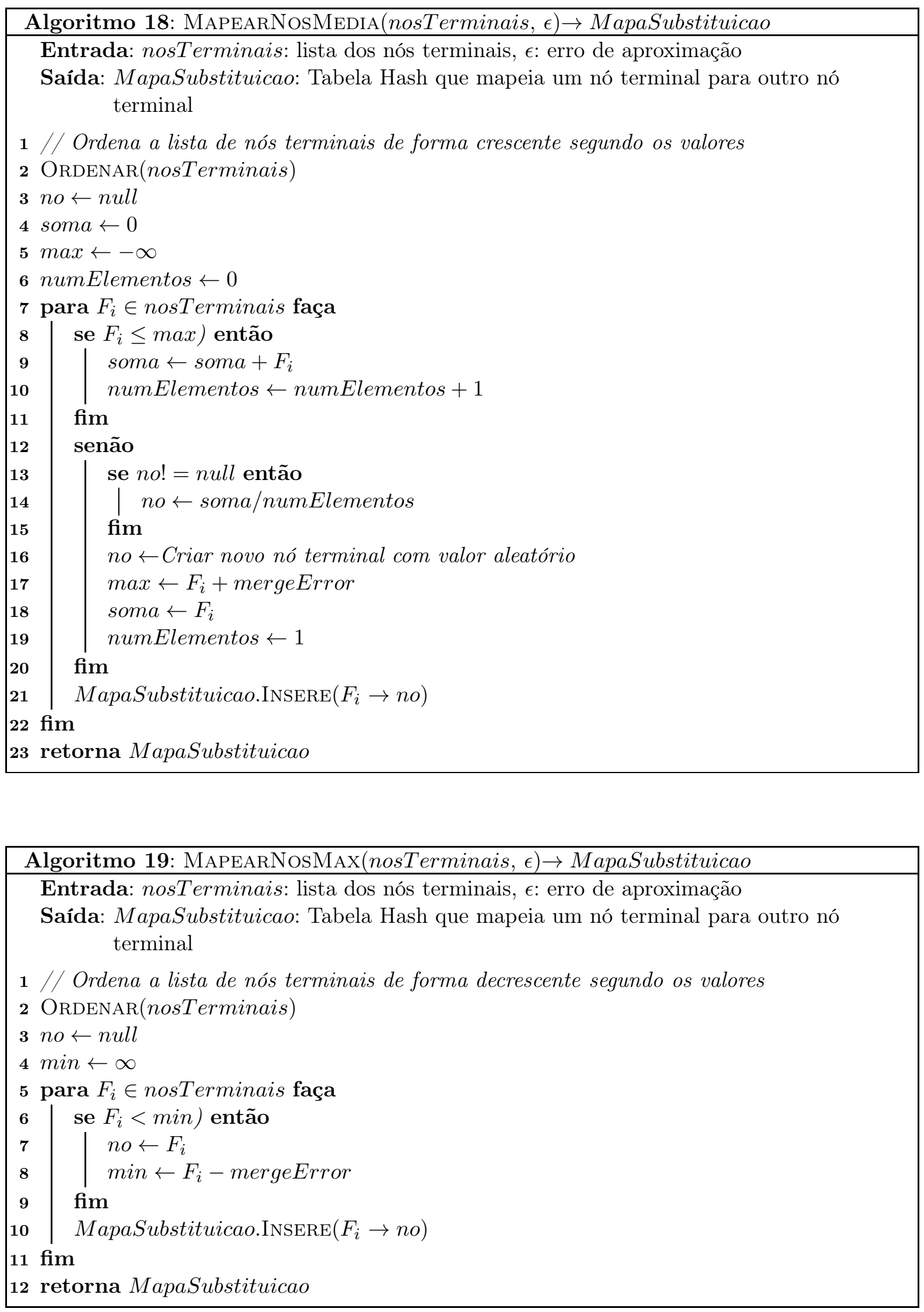


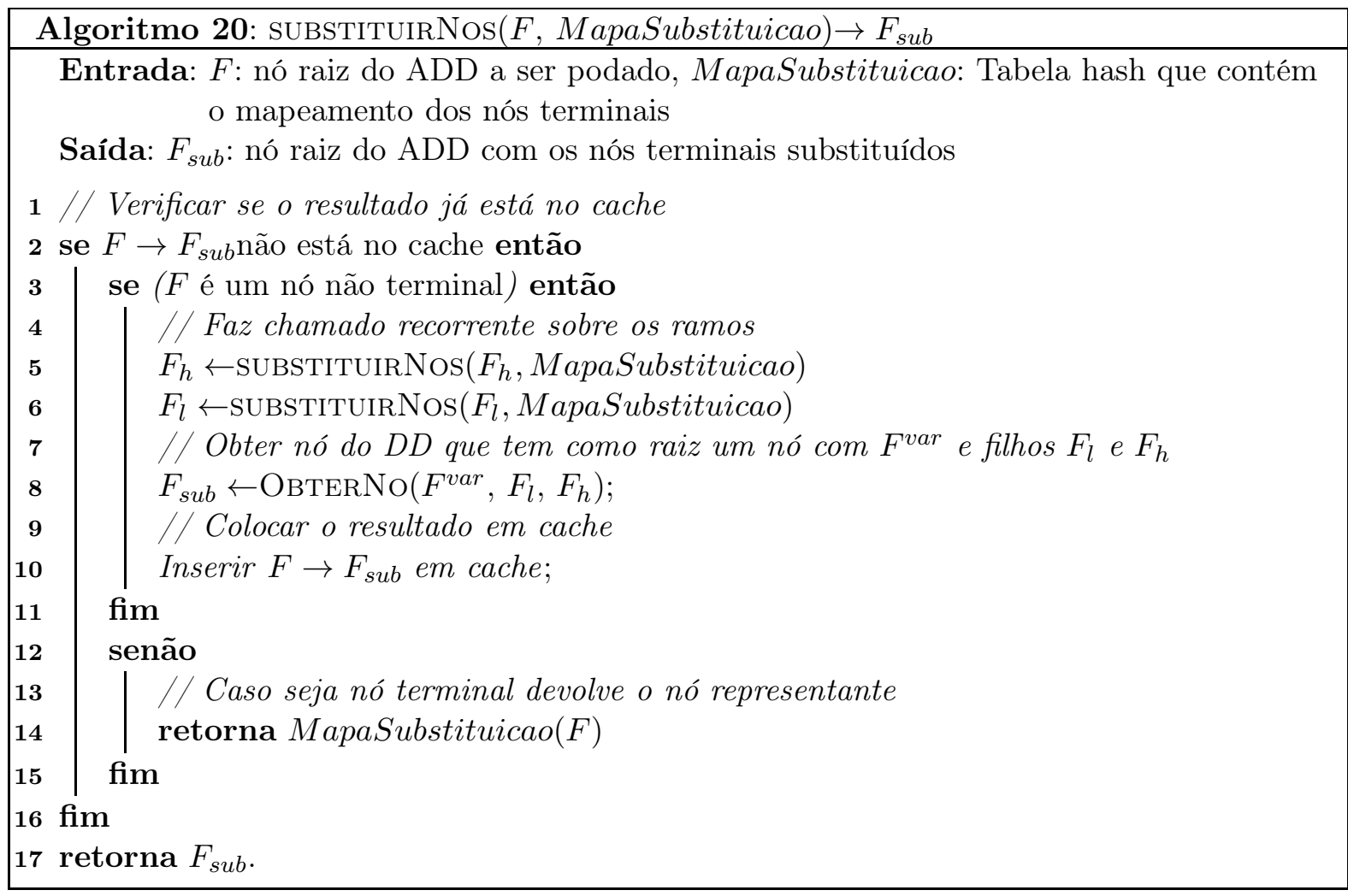

\begin{tabular}{|c|c|c|c|c|c|c|c|c|c|c|c|c|c|}
\hline$n_{0}$ & $n_{1}$ & $\ldots$ & $n_{i}$ & $n_{i+1}$ & $\ldots$ & $n_{j}$ & $n_{j+1}$ & $\ldots$ & $n_{k}$ & $\ldots$ & $n_{l}$ & $\ldots$ & $n_{m}$ \\
\hline \multicolumn{14}{|c|}{$n_{i+1}>n_{0}+$ Error } \\
\hline
\end{tabular}

Figura 5.4: Forma de agrupar os nós terminais. O algoritmo MAPEARNosMedia começa no nó no, que é o nó com menor valor dos nós terminais, adiciona o mergeError a seu valor (representado com Error), os próximos nós com valor $\leq n_{0}+\epsilon$ são considerados do mesmo grupo. O nó $n_{i+1}$ tem valor $>n_{0}+\epsilon$, portanto um novo grupo é iniciado neste nó. O algoritmo MAPEARNosMedia faz o mesmo processo, porém começando no nó $n_{l}$, o maior dos nós terminais, e subtrai o mergeError do valor de $n_{m}$.

a função Merge substitui os nós terminais com seus respectivos nós representantes (Linha 6 do Algoritmo 16). O Algoritmo 20 mostra a função SUBSTITUIRNos. Esta função percorre o ADD e substitui os nós terminais com o nó terminal mapeado na tabela hash MapaSubstituicao. Se o nó é não terminal, o algoritmo faz chamadas recursivas para os filhos do nó. Se o nó é terminal (caso base) o algoritmo devolve o nó terminal mapeado na tabela hash MapaSubstituicao. Este algoritmo usa um cache para armazenar os resultados da substituição, evitando cálculos repetidos. Se o ADD tem dois ou mais caminhos distintos desde o nó raiz até um mesmo nó $F_{i}$, então o cálculo da substituição para o nó $F_{i}$ será feito quando este seja alcançado através do primeiro caminho e quando seja alcançado através do restante dos caminhos. Com o valor armazenado no cache, não é necessário calcular novamente. 


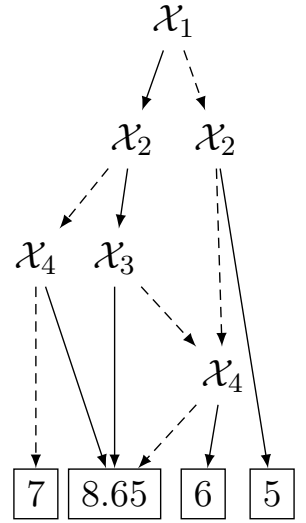

(a) Approx $V_{D D}^{t+1}$ para a média

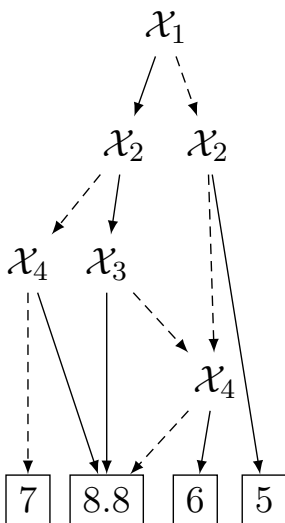

(b) Approx $V_{D D}^{t+1}$ para o máximo

Figura 5.5: $A D D$ com 4\% de aproximação feito sobre o ADD da Figura 5.2d.

A Figura 5.2d mostra um exemplo da função $V_{D D}$ com 4 variáveis de estado e é necessário reduzi-la. Suponha que a recompensa máxima descontada é 10 e a aproximação percentual considerada é de 4\%. Então, o erro de aproximação mergeError é 0.4 (Equação 5.2). Afim de calcular a redução, coletamos os nós terminais em uma lista: $\{7,8.8,8.5,6,5\}$. No caso do aFactRTDP_ave, a lista ordenada de forma crescente é usada para calcular a tabela do mapeamento, isto é:

$\{5 \rightarrow 5,6 \rightarrow 6,7 \rightarrow 7,8.5 \rightarrow 8.65,8.8 \rightarrow 8.65\}$.

Caso o algoritmo usado seja o aFactRTDP_max, a lista é ordenada de forma decrescente e a tabela do mapeamento é:

$$
\{8.8 \rightarrow 8.8,8.5 \rightarrow 8.8,7 \rightarrow 7,6 \rightarrow 6,5 \rightarrow 5\}
$$

Finalmente, cria-se um novo ADD com os nós terminais substituídos. A Figura 5.5a mostra o resultado para o algoritmo aFactRTDP_ave e a Figura 5.5b mostra o resultado para o algoritmo aFactRTDP_max.

\section{4 aFactLRTDP: LRTDP Fatorado e Aproximado}

O algoritmo aFactLRTDP é uma versão aproximada do algoritmo FactLRTDP (Seção 5.2), que usa a função Merge explicada na seção anterior e a função FACTCHECKSOLVEd da Seção 5.2. A aproximação feita para esse algoritmo calcula a média do grupo de folhas agrupadas, que chamaremos de aFactLRTDP_ave. A vantagem dessa implementação é deixar de atualizar estados convergidos e ter uma condição de parada para o algoritmo aproximado fatorado assíncrono. 


\section{Capítulo 6}

\section{Linguagens de Definição de Domínios de Planejamento}

Linguagens de definição de domínios de planejamento, em geral, usam formalismos de representação de conhecimento da Inteligência Artificial. Tais formalismos, em geral, são extensões da linguagem de representação de ações STRIPS (Fikes e Nilsson, 1971), que por sua vez é baseada no Cálculo de Situações da Lógica de Predicados.

Em 1970, Nils Nilsson e Richard Fikes, do Instituto de Pesquisa de Standford, propuseram o planejador STRIPS (Fikes e Nilsson, 1971) (STandford Research Institute Problem Solver), cuja linguagem de definição de problemas e domínios (também chamada de linguagem STRIPS), representa um estado como um conjunto de átomos, e as ações como operadores com précondições para definir a aplicabilidade das ações e efeitos que adicionam ou eliminam átomos do estado atual para gerar o próximo estado.

Uma melhoria ao STRIPS foi proposta por Pednault como Linguagem de Descrição de Ações (Action Description Language - ADL) (Pednault, 1989), que torna o STRIPS mais expressivo, incluindo os efeitos condicionais e quantificadores lógica. Diferentemente da linguagem STRIPS, que só permitia ações proposicionais, em ADL ações são representadas por esquemas, ou seja, operadores cujos objetos manipulados são identificados por variáveis.

Porém, linguagens de definição de domínios de planejamento devem ser mais expressivas, e em 1998 foi proposta a Linguagem de Definição de Domínios de Planejamento (Planning Domain Definition Language - PDDL) (Ghallab et al., 1998). Esta linguagem suporta as seguintes características (dentre outros):

- estilo básico de ações STRIPS,

- efeitos condicionais,

- quantificação universal sobre universos dinâmicos (extensão de ADL),

- axiomas de domínio em teorias estratificadas,

- especificação de restrições de segurança e

- especificação de ações hierárquicas.

A Linguagem PPDDL (PDDL Probabilístico) (Younes e Littman, 2003) é uma extensão do PDDL para representar efeitos probabilísticos. A seguir, descrevemos mais detalhadamente as linguagens PDDL, e PPDDL. 


\subsection{Linguagem de Definição de Domínios de Planejamento (PDDL)}

A linguagem padrão para codificar tarefas de planejamento "clássico" é a linguagem PDDL (Planning Domain Definition Language) (Ghallab et al., 1998). Em PDDL, os componentes de uma tarefa de planejamento são:

- Objetos: elementos do ambiente que nos interessam.

- Predicados: propriedades dos objetos em que estamos interessados; podem ser verdadeiras ou falsas.

- Estado: uma descrição do ambiente em determinado instante de tempos dada em termos de conjuntos de predicados considerados verdadeiros.

- Estado inicial: o estado inicial do ambiente em que se deseja planejar.

- Especificação da meta: predicados que devem ser verdadeiros após a execução do plano.

- Ações/Operadores: formas de mudar os estados do ambiente.

As tarefas de planejamento especificadas em PDDL estão separadas em dois arquivos:

1. um arquivo de domínio com a descrição de predicados e ações.

2. um arquivo do problema com a descrição dos objetos, estado inicial e a especificação da meta do problema (ou tarefa).

\section{Arquivo do Domínio}

Um arquivo do domínio tem a seguinte estrutura:

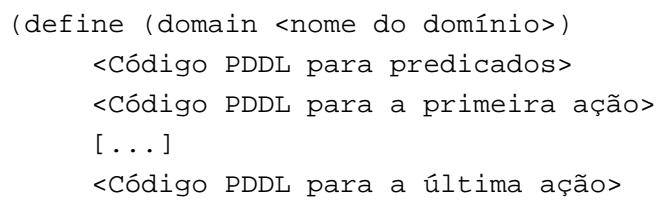

Sendo <nome do domínio> um texto que identifica o domínio de planejamento.

\section{Arquivo de Problema}

Um arquivo de problema tem a seguinte estrutura:

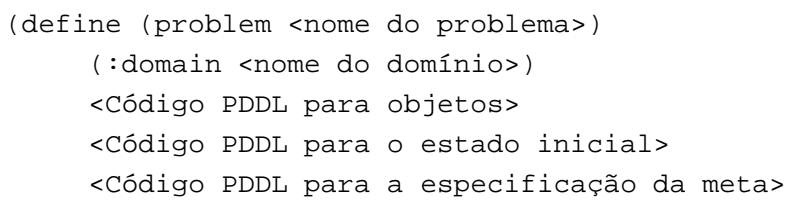


Sendo <nome do problema> um texto que identifica um problema de planejamento e $<$ nome do domínio> nome do arquivo ao qual o problema se refere.

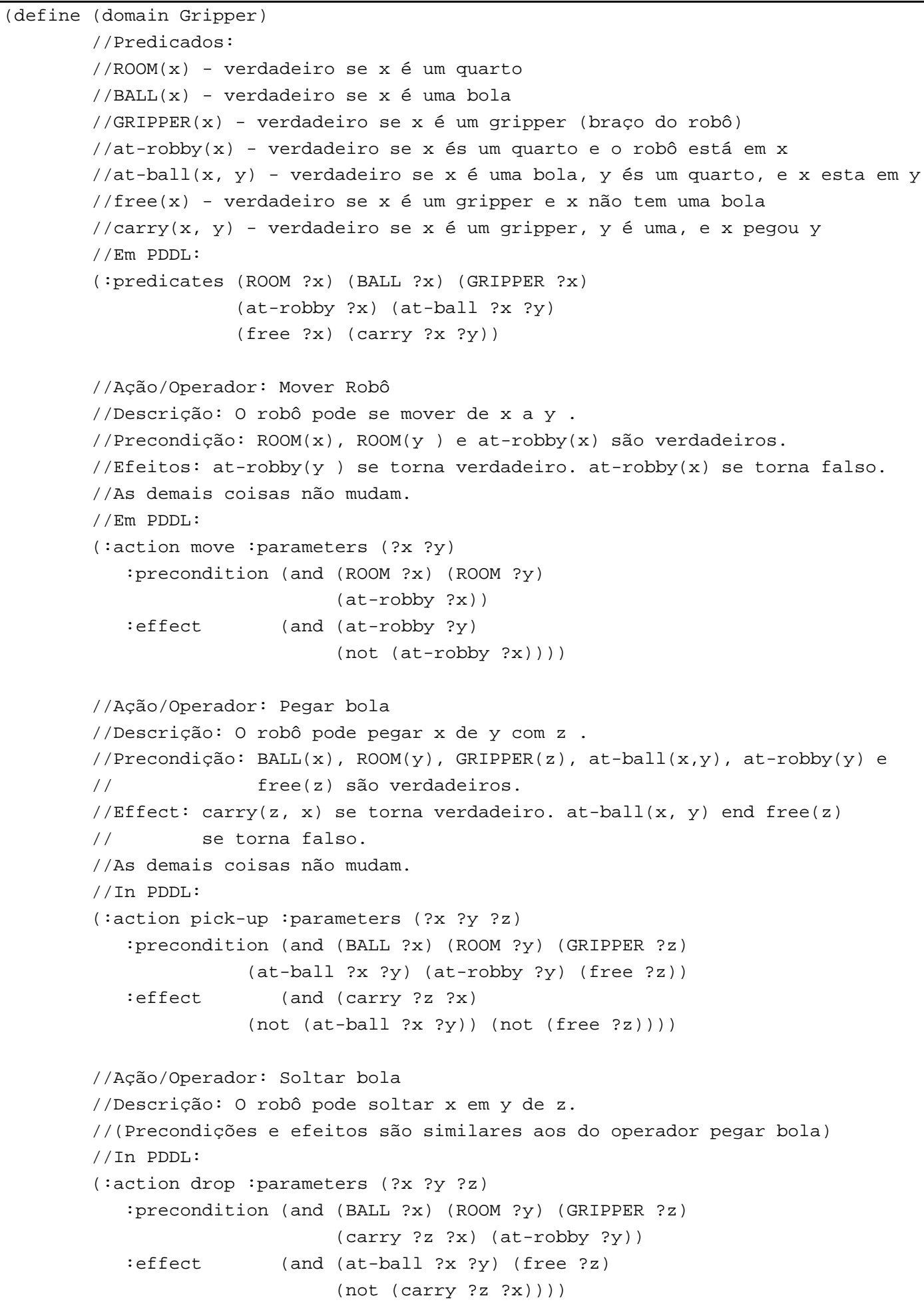

Figura 6.1: Código em PDDL do dominio Gripper. 
Um exemplo de domínio PDDL está na Figura 6.1, que descreve o domínio Gripper, em que um robô se move entre dois quartos e pega ou solta bolas com qualquer um de seus dois braços.

- Predicados: (linhas 11-14)

- (ROOM ?x) : $x$ é um quarto?

- (BALL ?X) : $x$ é uma bola?

- (GRIPPER ?x): $x$ é um braço do robô?

- (at-robby ?x) : o robô está no quarto $x$ ?

- (at-ball ?x ?y) : a bola $x$ está dentro do quarto $y$ ?

- (free ?x): o braço $x$ está vazio?

- (carry ?x ?y): o braço $x$ tem a bola $y$ ?

- Ações/Operadores: O robô pode se mover entre os quartos (linhas 21-25), pode pegar uma bola (linhas 35-39) ou soltar a bola (linhas 45-49).

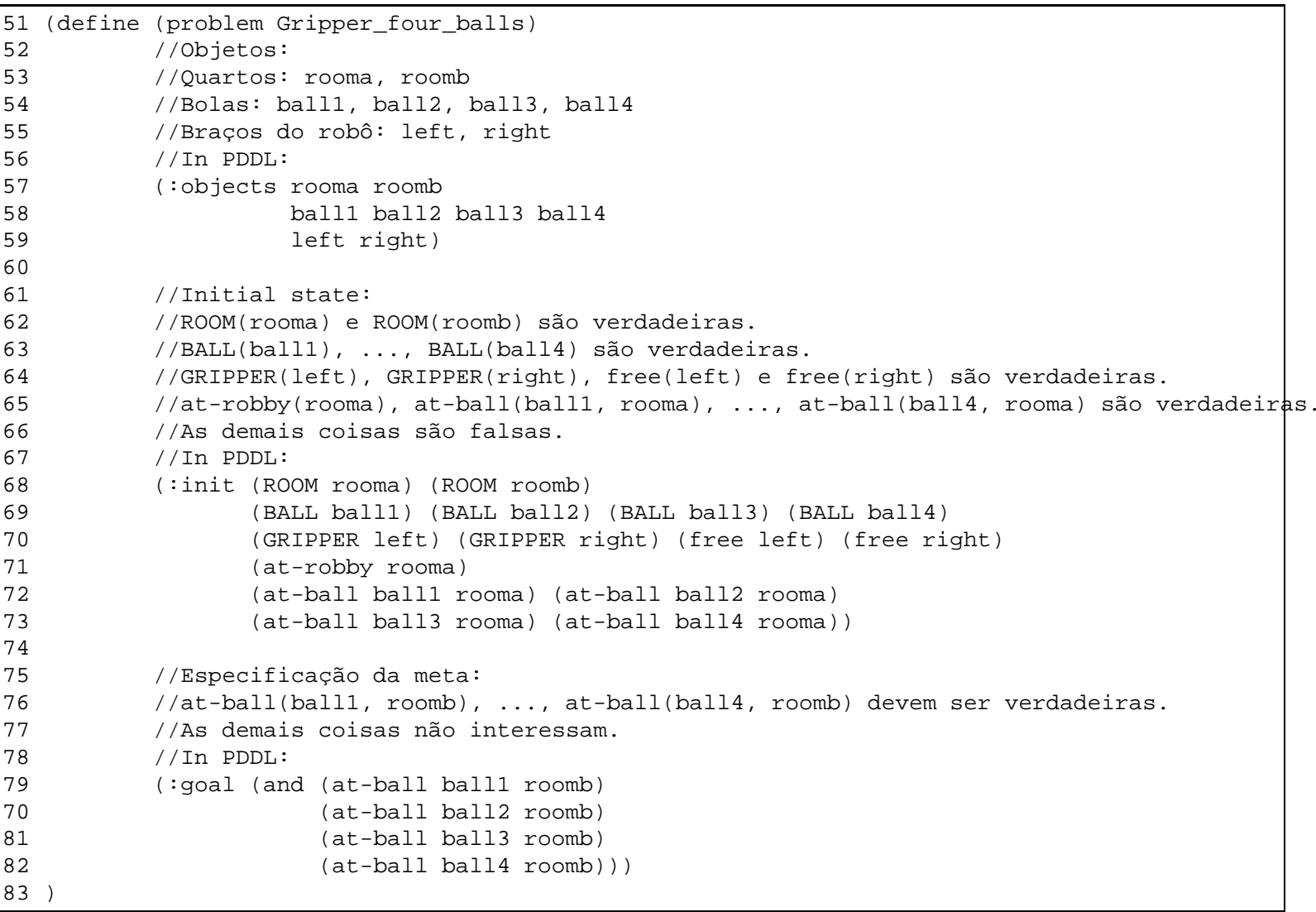

Figura 6.2: Código em PDDL do problema envolvendo 4 bolas e 2 quartos do domínio Gripper.

Um problema para esse domínio envolvendo 4 bolas e 2 quartos é dado na Figura 6.2. Inicialmente, todas as bolas e o robô estão no primeiro quarto. O objetivo é que as bolas estejam no segundo quarto. 
- Objetos: 2 quartos, 4 bolas e dois braços de robô (linhas 57-59).

- Estado inicial: Todas as bolas e o robô estão no primeiro quarto. Todos os braços de robô estão vazios (linhas 68-73).

- Especificação da meta: Todas as bolas devem estar no segundo quarto (linhas 78-82).

Note que os efeitos das ações envolvem quantificadores universais, por exemplo:

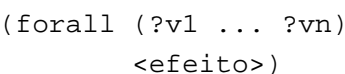

ou podem ser condicionais:

$$
\begin{aligned}
\text { (when } & <\text { condição> } \\
& <\text { efeito>) }
\end{aligned}
$$

\subsubsection{Extensões do PDDL}

A versão original de PDDL foi desenvolvida por Drew McDermott, para a competição de planejamento de 1998 (McDermott, 2000). Fahiem Bacchus selecionou um subconjunto da linguagem original para a competição do ano 2000 (Bacchus, 2000). Maria Fox e Derek Long estenderam a linguagem da competição para permitir variáveis numéricas, e a execução concorrente de ações com tempo de execução (o PDDL original já apresentava uma forma de variáveis numéricas, no entanto, nunca foi colocada em uso) (Fox e Long, 2003). A seguir, mostraremos com mais detalhes as extensões de PDDL.

PDDL2.1: A linguagem da competição do 2002, PDDL2.1 (Fox e Long, 2003), tem as seguintes características:

- Uso de um conjunto finito de fluentes (predicados que mudam com as ações) com valores numéricos.

- Representação explícita do tempo e duração de ações.

- Define especificações métricas como parte de instâncias de problema.

PDDL2.1 está separado em diferentes níveis de expressividade. Nível 1 é o planejamento ADL; nível 2 adiciona construções numéricas; e nível 3 adiciona ações com tempo de execução.

PDDL2.2: PDDL2.1 serviu de base para a linguagem da quarta competição de planejamento, chamada de PDDL2.2 (Edelkamp e Hoffmann, 2004), desenvolvida por Stefan Edelkamp e Joerg Hoffmann. Como PDDL2.1, PDDL2.2 está dividida em três níveis correspondentes ao ADL, construções numéricas, e planejamento com tempo de execução das ações. Sobre as características da linguagem PDDL2.1, duas novas construções foram adicionadas:

- Predicados derivados que permitem a manipulação de axiomas de domínio.

- Literais iniciais cronometrados que permitem representar facilmente eventos exógenos determinísticos. 
PDDL3: Uma nova versão, a linguagem PDDL3.0 (Gerevini et al., 2009), foi desenvolvida por Alfonso E. Gerevinia, Patrik Haslumb, Derek Longc, Alessandro Saettia e Yannis Dimopoulos. As principais novas características da linguagem são os soft goals (metas suaves), que são metas desejadas, que um plano válido não precisa necessariamente satisfazer, e state trajectory constraints (restrições da trajetória de estados), que são restrições na estrutura dos planos. Restrições de trajetória podem ser fortes ou suaves. Restrições de trajetória fortes podem ser usadas para expressar conhecimento de controle ou restrições sobre planos válidos para um domínio de planejamento e/ou para um problema de planejamento específico. Metas suaves e restrições de trajetória suaves podem ser usadas para expressar preferências que afetam a qualidade do plano, sem restringir o conjunto dos planos válidos.

Em PDDL3, uma meta ou restrição suave é uma preferência que tem um peso de penalidade associado com sua violação no plano. A especificação da métrica do plano inclui estas violações com pesos de penalidade que devem ser minimizadas. Em geral, todas as preferências especificadas (possivelmente com diferentes pesos de penalidade) não podem ser satisfeitas (o que caracteriza um problema de planejamento super-descrito over-subscription planning problems). Identificar o melhor subconjunto de preferências que podem ser alcançadas é uma dificuldade extra para lidar no processo de planejamento. Ademais, se existe um tempo limite de CPU para o planejamento, para produzir uma boa qualidade de solução, o planejador também tem que identificar um bom (possivelmente sub-ideal) conjunto de metas ou restrições suaves que podem ser alcançadas dentro da quantidade disponível de recursos computacionais.

\subsubsection{PPDDL: PDDL com probabilidades}

Para os problemas de planejamento probabilístico também foram feitas extensões da linguagem PDDL, chamada de PPDDL (Probabilistic Planning Domain Definition Language) (Younes e Littman, 2003), que inclui distribuições de probabilidades sobre os efeitos das ações (e/ou sobre os estados inciais).

\section{Descrição da Linguagem PPDDL}

PPDDL foi projetada especialmente para representar MDPs, e assim representar problemas em que as ações têm efeitos probabilísticos.

Na linguagem PPDDL a sintaxe dos efeitos probabilísticos é da forma:

$$
\text { (probabilistic } \left.p_{1} e_{1} p_{2} e_{2} p_{3} e_{3} \cdots p_{k} e_{k}\right) \text {, }
$$

em que a probabilidade de que ocorra o efeito $e_{i}$ é $p_{i}, \operatorname{com} p_{i} \geq 0$ e $\sum_{i=1}^{k} p_{i}=1$. Não é preciso definir todos os efeitos da ação. Para os efeitos não declarados assume-se que a probabilidade seja o complemento da soma das probabilidades declaradas. Isso porque existem ações que com certa probabilidade não mudam de estado $\left(\sum_{i=1}^{k} p_{i}<1\right)$. Por exemplo, imagine uma ação que produz um efeito $e_{k}$ com 0.9 de probabilidade, e em sua representação temos somente a representação: (probabilistic $0.9 e_{k}$ ). Assim, podemos inferir que com probabilidade 0.1 a ação não produz nenhum efeito (o agente permanece no mesmo estado). 
Para usar efeitos probabilísticos é preciso especificar isso como um requisito no arquivo de domínio, da seguinte maneira: (:requirements :probabilistic-effects).

Recompensas: No PPDDL são usados fluentes para representar as recompensas. O fluente (reward) (o paréntesis é opcional) é reservado para armazenar a recompensa acumulada a partir do estado inicial. Para poder usar o fluente reward é preciso declarar o requisito : rewards. Se num problema é preciso usar recompensas e efeitos probabilísticos, podemos declarar o requisito : mdp. Uma recompensa é dada da forma ( $\langle$ operação $\rangle\langle$ fluente-de-recompensa $\rangle\langle$ expressão$f\rangle)$, em que operação pode ser increase ou decrease, e expressão-f é uma expressão numérica que envolve a variável reward. As pré-condições e as condições dos efeitos não podem fazer referência ao fluente reward.

Objetivos: Num problema de planejamento que necessita do requisito : reward, a meta padrão é maximizar a recompensa esperada. Porém, quando é especificado um objetivo, então são definidos estados absorventes (estado de alcançabilidade). A sintaxe da declaração das metas é ( : goal $\phi$ ), que representa que a probabilidade de alcançar $\phi$ deve ser maximizada. Também é possível especificar uma recompensa para o estado meta, e isto é feito com (: goal-reward $f$ ) em que $f$ é uma expressão numérica.

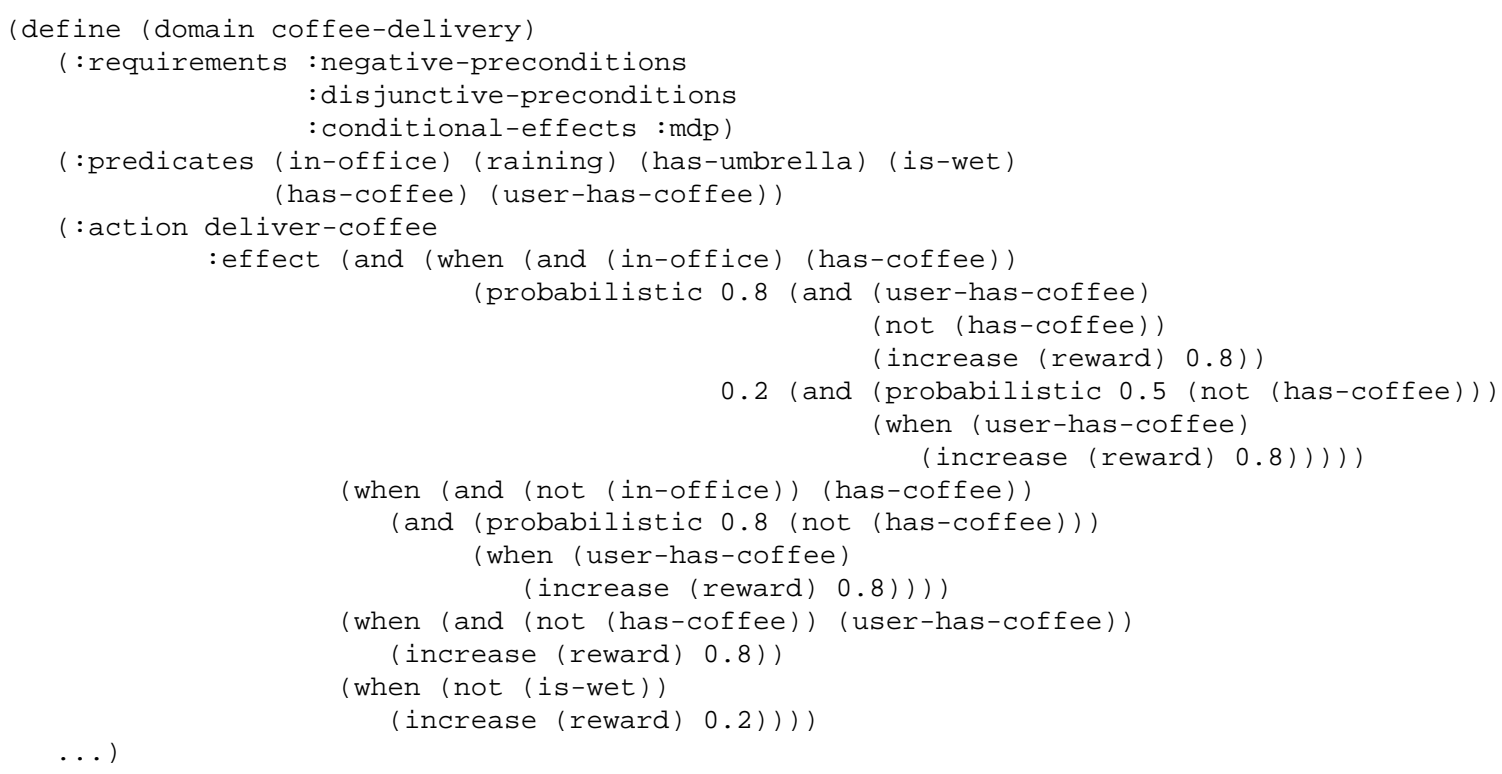

Figura 6.3: Parte do código em Linguagem PPDDL do domínio Delivery Coffee.

Na Figura 6.3 é dado o código em PPDDL do domínio da entrega de café (Delivery Coffee) (Dearden e Boutilier, 1997). Dado um robô, seu principal objetivo é entregar café a um usuário. O robô pode se mover entre o escritório do usuário e a loja de café no outro lado da rua, comprar café na loja, e entregar o café ao usuário. Se está chovendo, o robô fica molhado se ele se move, a menos que tenha um guarda-chuva (que pode ser obtido no escritório do usuário). O robô tem recompensa por não se molhar, mas tem mais recompensa se o usuário recebe o café. 


\subsection{Linguagem Relacional de Diagramas Dinâmicos de Influência}

Problemas complexos de planejamento nem sempre podem ser descritos na linguagem PPDDL, uma vez que ela não permite representar: ações concorrentes; múltiplos eventos exógenos que afetam o sistema; diferentes distribuições de probabilidades nas transições; observação parcial (estados de crença); a diferença entre fluentes e não-fluentes; a função recompensa e a probabilidade de transição através de funções não-lineares, etc.

Para melhorar o nível de representação da linguagem é preciso permitir a representação de:

1. MDPs e POMDPs (Kaelbling et al., 1998; Sanner e Kersting, 2010) fatorados;

2. diagramas de influência (Howard e Matheson, 1984);

3. ADDs como é usado pelo sistema SPUDD (Hoey et al., 1999);

4. PPDDL (Younes e Littman, 2003);

Para obter uma descrição de problemas de planejamento com todas as características descritas acima, foi proposta a Linguagem Relacional de Diagramas Dinâmicos de Influência (Relational Dynamic Influence Diagram Language - RDDL) (Sanner, 2010), usada na IPPC 2011 (Sanner, 2011).

A linguagem RDDL parte do princípio de que tudo pode ser visto como variáveis parametrizadas (pvariable), incluindo fluentes de ações, fluentes de estados, fluentes de observações, fluentes intermediários e não-fluentes (fluentes de valor constante). RDDL suporta diferentes tipos flexíveis de fluentes, como fluentes binários, fluentes multi-valorados, fluentes inteiros e contínuos. A semântica é a mesma de uma Rede Bayesiana Dinâmica estendida a um diagrama de influência, com estados fatorados, observações fatoradas, ações fatoradas e concorrentes, fluentes de estados intermediários (predicados derivados, efeitos correlacionados, estratificação por níveis que define um DBN relacional com múltiplas camadas) e os eventos exógenos independentes.

Em RDDL pode-se usar expressões gerais em funções de transição e recompensa, como expressões lógicas $(\wedge, \mid, \sim,=>,<=,<=>$, quantificadores $\exists / \forall$ sobre variáveis), expressões aritméticas $\left(+,-, *, /\right.$, agregação $\sum / \prod$ sobre variáveis $)$, expressões de comparação $(==, \sim=,<,>$, $<=,>=$ ), expressões condicionais (if-then-else, switch) e distribuições clássicas de probabilidade (Bernoulli, Discrete, Normal, Poisson, ...). Além disso, RDDL mantém as características clássicas como recompensa aleatória, metas, horizonte finito e fator de desconto, bem como permite a representação de restrições para ações e estados.

\section{ESTRUTURA DE UM ARQUIVO RDDL}

Como no PDDL, o domínio e as instâncias de problemas são definidos separadamente. Um arquivo RDDL pode ter três tipos de declarações de alto nível: dominios, não-fluentes e instâncias. 


\section{Bloco de Domínio}

O bloco do domínio contém uma descrição do domínio que consiste das declarações dos requisitos do dominio, a definição dos tipos de parâmetros, a definição das variáveis, as funções de transição probabilística e a função recompensa. Os possíveis requisitos do domínio são:

- continuous: o domínio pode usar pvariables com valores reais;

- multivalued: as pvariables tem valores enumerados;

- reward-deterministic: a recompensa não é estocástica;

- intermediate-nodes: as pvariables podem estar em nós intermediários;

- constranined-state: o domínio usa restrições de estados;

- partially-observed: o domínio usa observações como pvariables. As observações são usadas para modelar POMDP;

- integer-valued: o domínio usa variáveis inteiras e

- cpf-deterministic: o domínio usa funções condicionais determinísticas para as transições.

Tipos de parâmetros: Os tipos de parâmetros das variáveis permitidos são object e tipos enumerativos. Os valores dos tipos enumerativos devem ser especificados em um conjunto e devem ter o prefixo e.

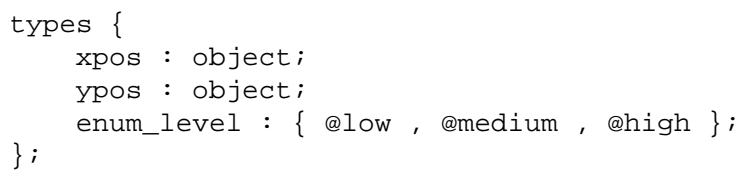

Figura 6.4: Exemplo de declaração de tipos.

pvariables: Na Figura 6.5 se descreve um exemplo de declaração de pvariables para um domínio que descreve uma grade, em que uma célula está definida por uma combinação de (xpos, ypos), nesta grade um robô se move de célula em célula, e em cada célula pode aparecer um obstáculo. As pvariables descrevem o ambiente do domínio modelado e podem ser de tipo: (1) non-fluent (não-fluentes), isto é fluentes que não mudam seu valor com as ações, por exemplo, o non-fluent NORTH (ypos, ypos) determina que uma posição ypos está ao norte de outro posição ypos, o valor desse non-fluent não muda com nenhuma ação; (2) action-fluent (fluentes de ação), estes fluentes podem ser ativadas em qualquer momento, se um fluente de ação é ativada então produz uma mudança de valor nos fluentes de estado, o exemplo da grade tem 4 fluentes de ação: move-north, move-south, move-west, move-east; (3) state-fluent (fluentes de estado), estes fluentes mudam seu valor segundo uma ação ou por eventos exógenos, por exemplo, o state-fluent robot-at (xpos, ypos) indica em 
que célula está o robô e seu valor muda com o efeito de uma das 4 ações e o state-fluent obstacle-at (xpos, ypos) indica se existe um obstáculo em uma célula, este fluente muda seu valor por um evento exógeno que indica uma probabilidade de o obstáculo aparecer numa célula; (4) interm-fluent (fluentes intermediários) e (5) observ-fluent fluentes de observação, estes dois últimos tipo de pvariables são definidos para MDPs parcialmente observáveis e modelam as observações parciais de cada estado.

Os possíveis tipos de valores das pvariables são bool, int, real, object ou enumerativos. Os dois últimos precisam que seus nomes sejam definidos pelo usuário.

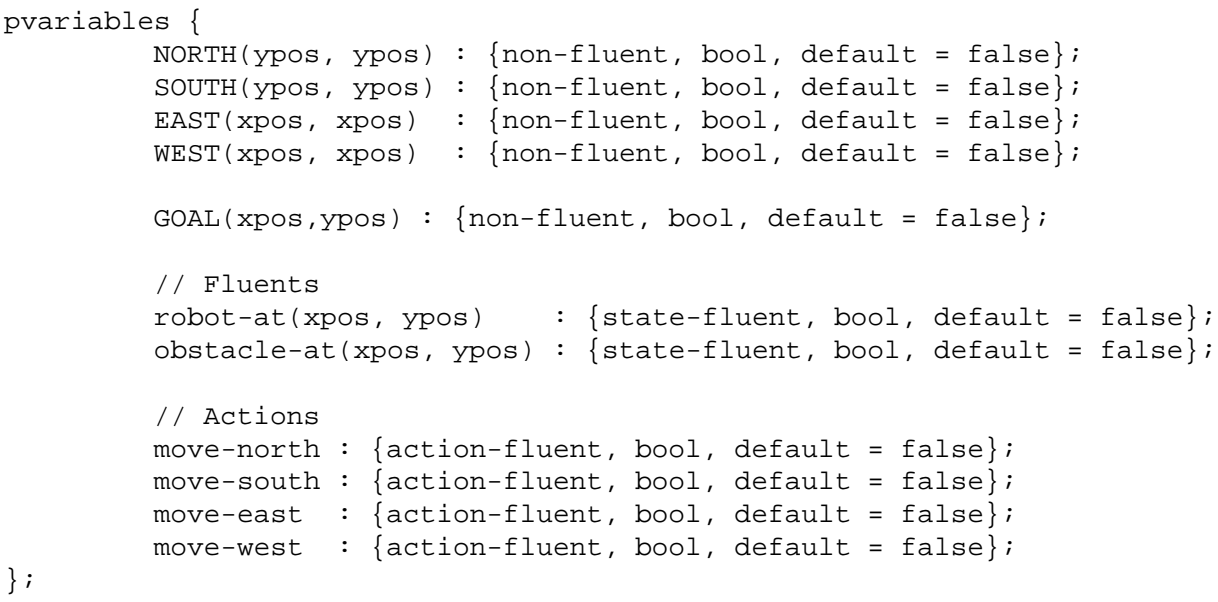

Figura 6.5: Exemplo de declaração de pvariables.

A Figura 6.5 presenta um exemplo de definição de pvariables para fluentes de estados (robot-at e obstacle-at), de ações (move-north, move-south, move-east e movewest) e adicionalmente para não-fluentes (NORTH, SOUTH, EAST, WEST, MIN-XPOS, MAX-XPOS, MIN-YPOS, MAX-YPOS, INPUT-RATE, GOAL). Os fluentes intermediários devem especificar o nível de estratificação. Variáveis intermediárias estão estratificadas porque uma variável intermediária pode estar condicionada a pvariables intermediárias de nível menor.

Funções condicionais probabilísticas (CPFs): Esta seção explica a definição das funções condicionais probabilísticas (Conditional Probabilistic Functions - CPFs) e das funções condicionais determinísticas (Conditional Deterministic Functions - CDFs). Se o requisito cpfdeterministic é definido então o domínio usa CDFs caso contrário usa CPFs.

CPFs e CDFs devem ser especificadas para todos as pvariables, exceto para as ações e os não-fluentes. As CPFs começam com o nome da pvariable e uma lista de parâmetros, precedidos por "?", que correspondem à declaração da pvariable. O nome de uma pvariable para um fluente de próximo estado deve ter uma variável linha, para se diferenciar das pvariables do estado atual.

As expressões CPFs são compostas por:

- constantes que podem ser true, false, inteiros, reais, valores enumerados;

- agrupamentos, através de parenteses $(\cdots)$ ou colchetes $[\cdots]$; 
- expressões lógicas;

- expressões aritméticas;

- expressões de comparações com igualdade ou desigualdade;

- expressões condicionais if-then-else e switch;

- distribuições de probabilidade básicas, entre elas:

- KronDelta $(v)$ : associa a probabilidade 1 à variável discreta $v$;

- DiracDelta $(v)$ : associa a probabilidade 1 à variável contínua $v$;

- Bernoulli $(p)$ : sorteia a probabilidade de que um valor booleano seja verdadeiro, dado o parâmetro $p \in[0,1]$;

- Discrete(nome-de-var, $\vec{p})$ : sorteia um valor para nome-de-var dado o vetor $\vec{p}$ $\left(\sum_{i} \vec{p}_{i}=1\right)$

- Normal $\left(\mu, \sigma^{2}\right)$ : sorteia um valor contínuo de uma distribuição normal com a média $\mu$ e a variança $\sigma^{2}, \sigma^{2}>0$;

- Poisson $(\lambda)$ : sorteia um valor inteiro de uma distribuição de Poisson com uma taxa $\lambda$.

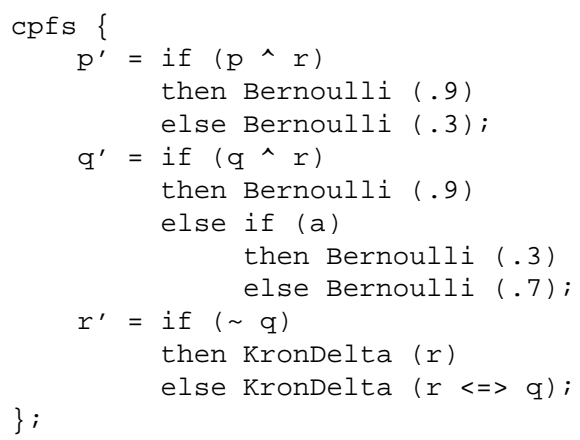

Figura 6.6: Exemplo de declaração de CPFs, p, q e r são as fluentes de estado, e a é uma fluente de ação.

\begin{tabular}{c|c|c|c} 
& & \multicolumn{2}{|c}{$P\left(p^{\prime} \mid p, r, a\right)$} \\
& $r$ & $p^{\prime}=0$ & $p^{\prime}=1$ \\
\hline 0 & 0 & 0.9 & 0.1 \\
0 & 1 & 0.3 & 0.7 \\
1 & 0 & 0.3 & 0.7 \\
1 & 1 & 0.3 & 0.7
\end{tabular}

Figura 6.7: Tabela de probabilidade condicional para $P\left(p^{\prime} \mid p, r, a\right)$. 
Na Figura 6.6 é dado um exemplo de definição das funções de transição probabilística de um domínio RDDL. As variáveis do próximo estado são descritas com linhas ( $p^{\prime}$, $q^{\prime}$ e $r^{\prime}$ ) para diferenciar das variáveis do estado atual ( $\mathrm{p}$, q e r). A definição para $\mathrm{p}^{\prime}$ corresponde à tabela de probabilidade condicional $P\left(p^{\prime} \mid p, r, a\right)$ da Figura 6.7.

Do mesmo modo, uma tabela de probabilidade condicional é definida para $P\left(q^{\prime} \mid q, r, a\right)$ (Figura 6.8). Note que aqui a transição de probabilidade depende da ação $a . P\left(r^{\prime} \mid r, q, a\right)$ (Figura 6.9) é uma expressão condicional sobre uma função Kronecker delta. A função Kroneckor delta estabelece a probabilidade 1.0 em seu argumento e 0 para todos os demais possíveis valores. Ela é usada quando a transição é determinística. Se q é falso, então a $r$ se atribui o mesmo valor de $r$, caso contrário a $r$ se atribui o valor booleano da expressão lógica $r \Leftrightarrow q$ (se o argumento da função delta é contínuo, devemos usar a função Dirac delta).

\begin{tabular}{c|c|c|c} 
& & \multicolumn{2}{|c}{$P\left(q^{\prime} \mid q, r, a\right)$} \\
$q$ & $r$ & $q^{\prime}=0$ & $q^{\prime}=1$ \\
\hline 0 & 0 & 0.9 & 0.1 \\
0 & 1 & 0.3 & 0.7 \\
1 & 0 & 0.3 & 0.7 \\
1 & 1 & 0.3 & 0.7
\end{tabular}

Figura 6.8: Tabela de probabilidade condicional para $P\left(q^{\prime} \mid q, r, a\right)$.

\begin{tabular}{c|c|c|c} 
& & \multicolumn{2}{|c}{$P\left(r^{\prime} \mid r, q, a\right)$} \\
$r$ & $q$ & $r^{\prime}=0$ & $r^{\prime}=1$ \\
\hline 0 & 0 & 0 & 1 \\
0 & 1 & 0 & 1 \\
1 & 0 & 1 & 0 \\
1 & 1 & 0 & 1
\end{tabular}

Figura 6.9: Tabela de probabilidade condicional para $P\left(r^{\prime} \mid r, q, a\right)$.

Função recompensa: Na função recompensa é especificada uma expressão aritmética que pode ser avaliada ou sorteada para obter um valor numérico sobre o estado atual para qualquer pvariable non-fluent, state-fluent, action-fluent, interm-fluent. Se o requisito reward-deterministic for definido, a recompensa é calculada simplesmente pela avaliação da expressão aritmética.

Restrições de ações sobre estado: Restrições são definidas como expressões lógicas sobre as variáveis non-fluent, state-fluent e action- fluent. A solução de um problema termina em erro se alguma restrição é violada, ou seja, todas as restrições lógicas devem ser satisfeitas durante o planejamento. Um exemplo é mostrado nas linhas 26-29 da Figura 6.10. 


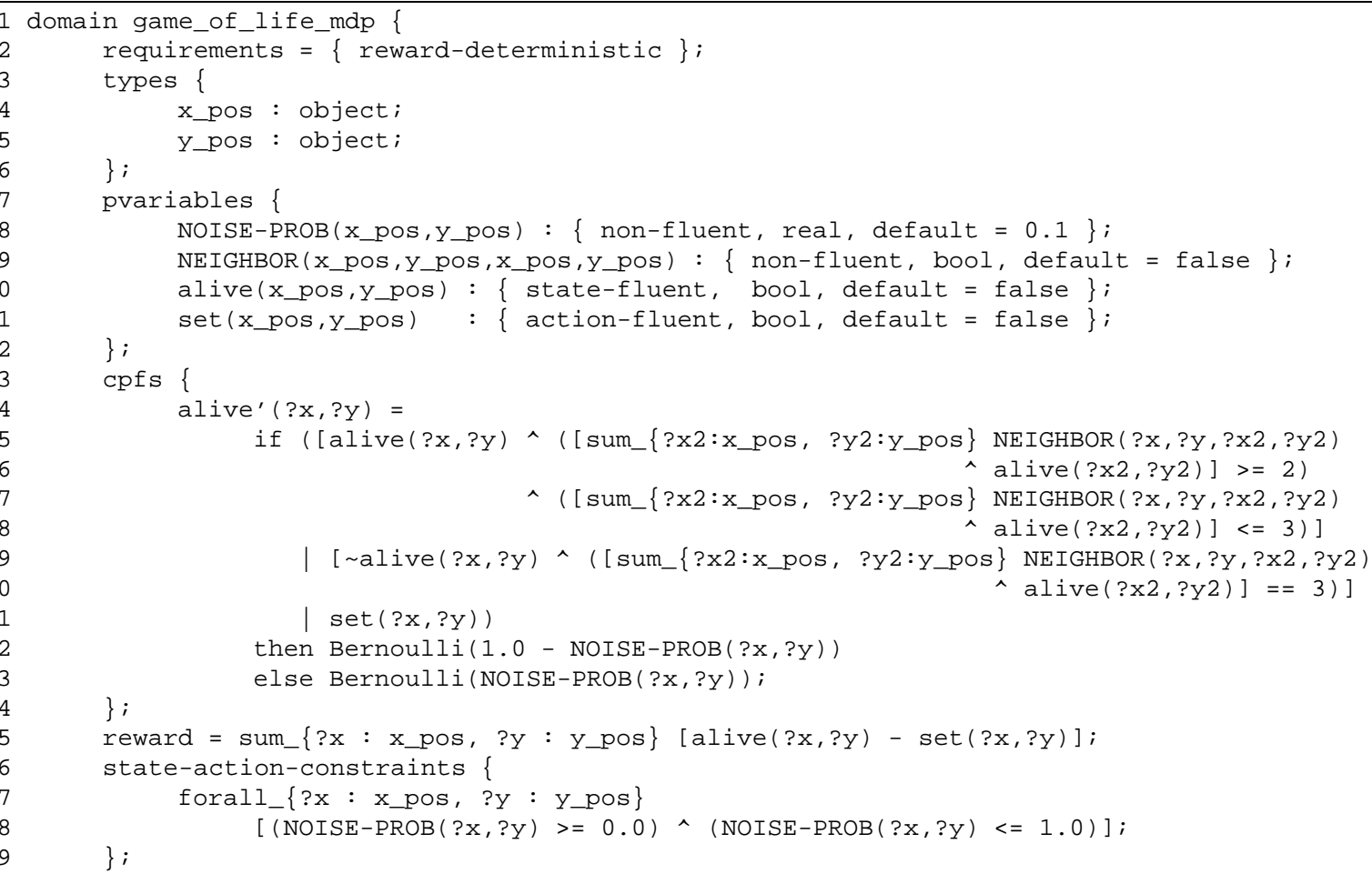

Figura 6.10: Código em RDDL do domínio Game of Life.

\section{Bloco de não-fluentes}

Este bloco é opcional e descreve a instanciação dos non-fluents. Este bloco pode conter as seções domain para colocar o nome do domínio ao que pertence, objects para definir os objetos usados nos parâmetros dos non-fluents, e non-fluents para definir valores das variáveis non-fluents para a instância de problema do domínio. A Figura 6.11 mostra um exemplo de bloco de não-fluentes para o domínio Game of Life

\section{Bloco da instância}

Este bloco define um problema de planejamento (isto é, uma instância de um domínio de planejamento). Ele define o conjunto de objetos usados, um estado inicial e um critério da meta. Este bloco pode conter as seguintes seções:

- domain, define o nome do bloco do domínio;

- non-fluents, define o nome do bloco de non-fluents;

- objects, define o conjunto de objetos da instância;

- init-state, define a configuração do estado inicial;

- max-nondef-actions, define o número máximo de ações concorrentes que a solução deve usar; 
- horizon, define o horizonte da instância; e

- discount, que define o fator de desconto $\gamma$.

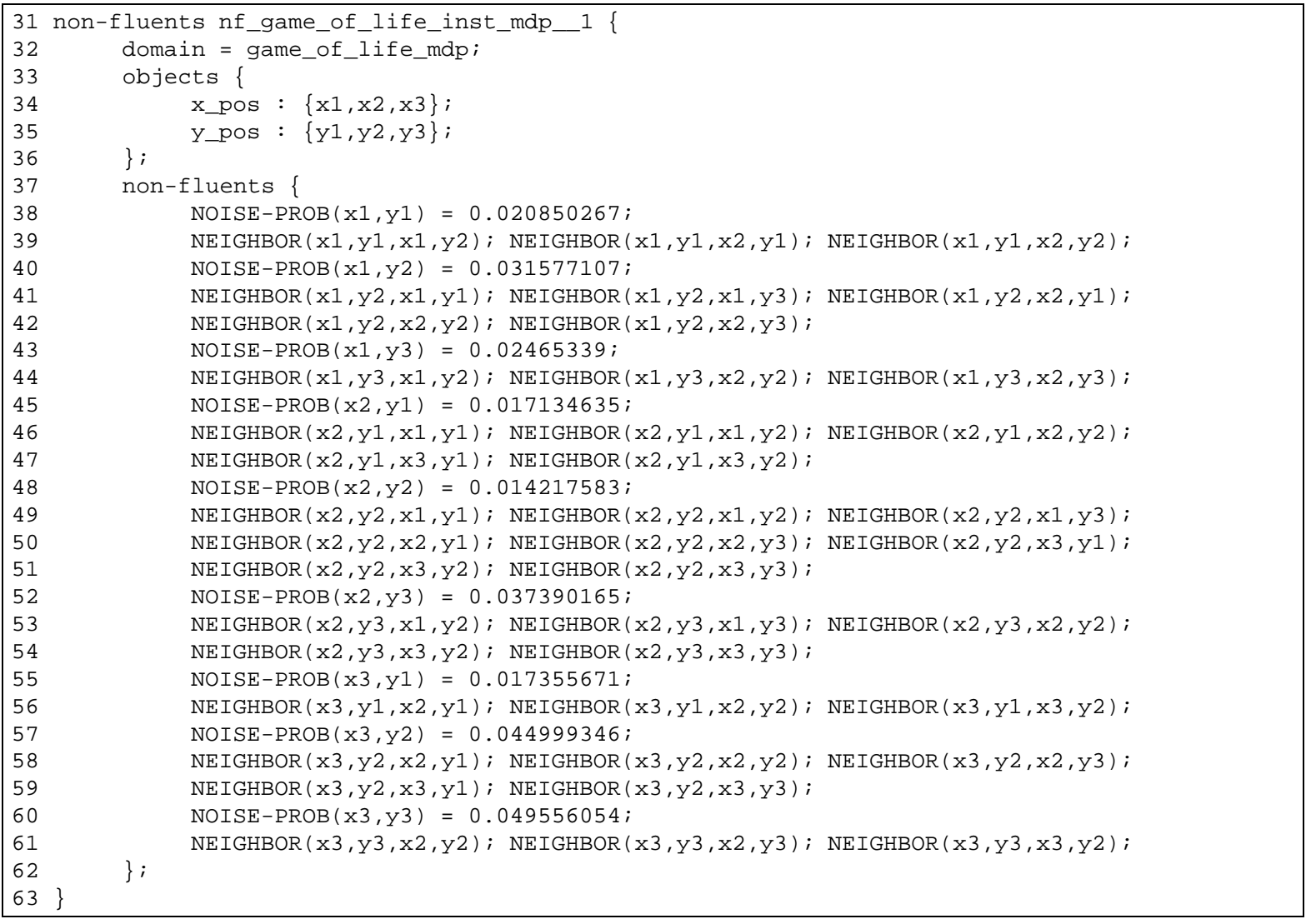

Figura 6.11: Código em RDDL dos não-fluentes da instância 1 do domínio Game of Life.

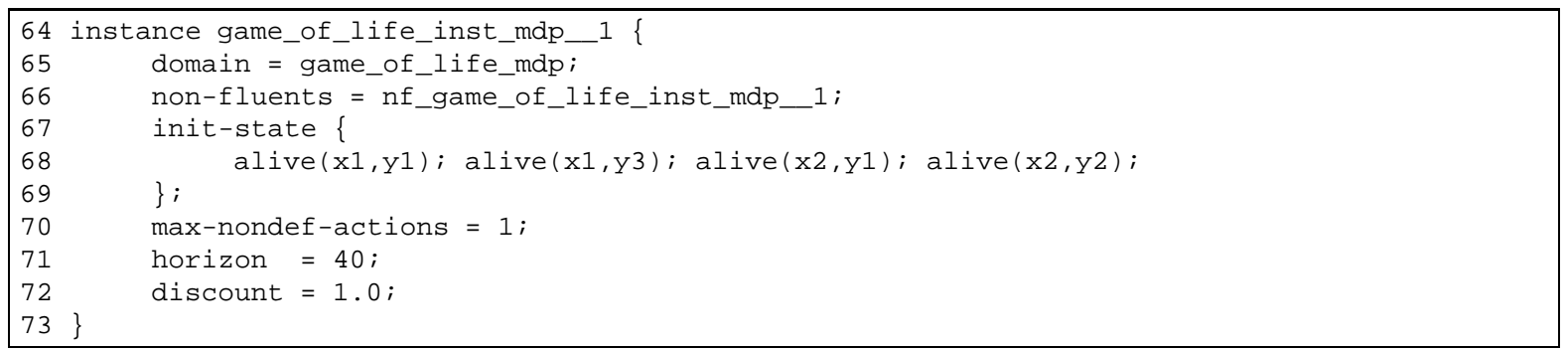

Figura 6.12: Código em RDDL da instância 1 do dominio Game of Life.

No exemplo da Figura 6.10 é dado o código em RDDL da versão interativa e estocástica do domínio Jogo da Vida (Game of Life) de John H.Conway (Gardner, 1970) (descrito em mais detalhes na Seção 7.1.3). Uma instância deste domínio é mostrada nas Figuras 6.11 e 6.12. A Figura 6.11 descreve os objetos e as variáveis de tipo não-fluente. A Figura 6.12 define uma instância desse domínio. 
O domínio de planejamento Jogo da Vida, especifica regras simples para um autômato celular em que as propriedades do próximo estado de uma célula depende das células vizinhas. Na codificação do RDDL uma célula é representada por suas coordenadas $(x, y)$ e as células vizinhas são especificadas através de variáveis booleanas non-fluents. 


\section{Capítulo 7}

\section{Domínios de Planejamento Probabilístico}

O objetivo das competições de planejamento probabilístico é promover o desenvolvimento de sistemas de planejamento que sejam capazes de resolver problemas complexos envolvendo um grande número de estados.

A quarta competição internacional de planejamento probabilístico (IPPC-2011) (Sanner, 2011), organizada por Scott Sanner em 2011, introduziu uma nova linguagem de representação de domínios e problemas de planejamento, a linguagem RDDL (Sanner, 2010), para que fosse possível modelar novos domínios e problemas de planejamento com características semelhantes às existentes em problemas do mundo real.

Na IPPC-2011 foram definidos 8 domínios de planejamento probabilístico, para avaliar os planejadores da competição, cada domínio com 10 problemas.

Os 8 domínios propostos na IPPC 2011 foram: Crossing Traffic, Elevators, Game of Life, Navigation, Recon, Skill Teaching, SysAdmin e Traffic. Neste capítulo descrevemos esses domínios e também fazemos uma análise sobre a complexidade dos domínios, para cada uma das 80 instâncias. Nesta análise, calcula-se a porcentagem de densidade das matrizes de transição (ou densidade de transição) e a porcentagem de dependências das variáveis de estado (nas DBNs).

Para a porcentagem da densidade de transição, fazemos o cálculo da densidade para cada ação, da seguinte maneira:

$$
\begin{gathered}
\text { Densidade\% }(a)=\frac{\text { DensidadeMedia }(a)}{|S|} * 100 . \\
\text { DensidadeMedia }(a)=\frac{\sum_{\vec{x} \in S} \mid\left\{\vec{x}^{\prime} \text { tal que } P\left(\vec{x}^{\prime} \mid \vec{x}, a\right)>0\right\} \mid}{|S|},
\end{gathered}
$$

sendo DensidadeMedia(a) a média da densidade de transição de todos os estados, para a ação $a$. Primeiro fazemos uma contagem de quantos estados sucessores tem cada estado, quando aplicamos a ação $a$, isto é, $\mid\left\{\vec{x}^{\prime}\right.$ tal que $\left.P\left(\vec{x}^{\prime} \mid \vec{x}, a\right)>0\right\} \mid$. Em seguida, calculamos a somatória dessas quantidades para todos os estados. Esta somatória é dividida pelo número de estados $|S|$ para obter a média de estados alcançáveis através da ação $a$. Para obter a porcentagem do espaço de estados que representa essa média de estados alcançáveis, dividimos essa média por $|S|$ e multiplicamos por 100 (Equação 7.1).

Consideramos duas medidas para a porcentagem de densidade de transição: (1) a média da 
porcentagem das densidades das ações (Equação 7.3):

$$
\text { DensidadeMedia } \%=\frac{\sum_{a \in A} \text { Densidade\% }(a)}{|A|}
$$

e (2) a máxima porcentagem de densidade das ações (Equação 7.4):

$$
\text { DensidadeMaxima } \%=\max _{a \in A}\{\text { Densidade } \%(a)\} \text {. }
$$

O cálculo da porcentagem de dependência das variáveis de estado também é feito para cada ação de todas as instâncias. Para este cálculo, contamos quantas variáveis estão presentes na CPT de cada variável de estado:

$$
\text { Dependencia } \%(a)=\frac{\sum_{i=1}^{n}\left|p a_{a}\left(\mathcal{X}_{i}\right)\right|}{n^{2}} * 100
$$

A Equação 7.5 calcula a porcentagem de dependências de variáveis de estado para uma ação. Primeiro, fazemos uma contagem da quantidade de pais de cada variável, isto é, de quantas variáveis depende cada variável. Em seguida, calculamos a somatória dessas quantidades. Dividimos esta somatória pela quantidade de variáveis $n$ para obter a média de dependências e, finalmente, dividimos a média por $n$ e multiplica por 100 para obter a porcentagem.

Para obter a média das porcentagens de todas as ações calculamos a Equação 7.6.

$$
\text { Dependencia } \%=\frac{\sum_{a \in A} \operatorname{Dependencia\% }(a)}{|A|} .
$$

Como existem instâncias muito grande (até 100 variáveis de estado), estes cálculos não podem ser feitos de maneira exata, uma maneira aproximada de fazer estes cálculo é mostrada no Apêndice B.

A seguir, a descrição dos domínios e sua análise da complexidade. As descrições dos domínios na linguagem RDDL é dada no Apêndice D.

\subsection{Descrição dos domínios de teste}

\subsubsection{Crossing Traffic}

Numa grade (Figura 7.1), um robô $(\mathrm{R})$ deve chegar à meta $(\mathrm{G})$ evitando os obstáculos $(\mathrm{O})$ que aparecem aleatoriamente e se movimentam para a esquerda. Se um obstáculo está na mesma célula que o robô, o robô desaparece. Quando um carro está na direita do robô, ele pode-se abaixar enquanto o obstáculo passa sobre ele, isto permite que o robô avance para a célula da direita. Assim, pode-se construir uma solução interessante em que o robô inicie no lado direito da grade. O estado meta é absorvente com 0 de recompensa. Enquanto o robô não alcançar a meta, ele recebe uma penalidade de -1 por cada passo. Neste domínio as ações são probabilísticas: o robô tem uma probabilidade de desaparecer se estiver na mesma célula que um obstáculo.

A Figura 7.1 mostra uma instância do domínio Crossing Traffic. As células verdes representam os obstáculos, a célula azul da segunda linha indica a localização do robô e a célula com a letra $\mathrm{G}$ da última linha indica a meta do robô. 


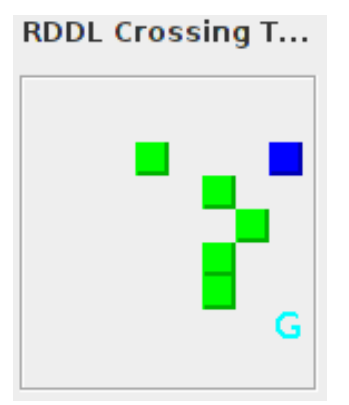

Figura 7.1: Simulador do sistema rddlsim para o dominio Crossing Traffic.

\begin{tabular}{|r|l|l|l|l|l|}
\hline \multicolumn{7}{|c|}{ Crossing Traffic } \\
\hline Instância & Variáveis & Ações & \% Densidade Méd. & \% Densidade Máx. & \% Dependências \\
\hline 1 & 18 & 5 & $7.6293945312 \mathrm{E}-4$ & $7.6293945312 \mathrm{E}-4$ & 7.5925925925 \\
\hline 2 & 18 & 5 & $7.6293945312 \mathrm{E}-4$ & $7.6293945312 \mathrm{E}-4$ & 7.5925925925 \\
\hline 3 & 32 & 5 & $2.98754094 \mathrm{E}-8$ & $3.092281986 \mathrm{E}-8$ & 4.765625 \\
\hline 4 & 32 & 5 & $3.0870343 \mathrm{E}-8$ & $3.30047649 \mathrm{E}-8$ & 4.765625 \\
\hline 5 & 50 & 5 & $1.0062013 \mathrm{E}-13$ & $1.015030073 \mathrm{E}-13$ & 3.24 \\
\hline 6 & 50 & 5 & $1.0028726 \mathrm{E}-13$ & $1.015030073 \mathrm{E}-13$ & 3.24 \\
\hline 7 & 72 & 5 & $3.3881318 \mathrm{E}-19$ & $3.3881318 \mathrm{E}-19$ & 2.3379629629 \\
\hline 8 & 72 & 5 & $3.3881318 \mathrm{E}-19$ & $3.3881318 \mathrm{E}-19$ & 2.3379629629 \\
\hline 9 & 98 & 5 & $1.009742 \mathrm{E}-26$ & $1.009742 \mathrm{E}-26$ & 1.7638483965 \\
\hline 10 & 98 & 5 & $1.009742 \mathrm{E}-26$ & $1.009742 \mathrm{E}-26$ & 1.7638483965 \\
\hline
\end{tabular}

Tabela 7.1: Características do domínio Crossing Traffic.

A Tabela 7.1 mostra a evolução da complexidade deste domínio. A primeira coluna mostra o número da instância, a segunda coluna mostra a quantidade de variáveis da instância, a terceira coluna mostra a quantidade de ações, a quarta coluna mostra a média de densidade de transição de todas as ações e a quinta coluna mostra a média da porcentagem de dependência das variáveis de estado.

Como todas as instâncias têm densidade de transição menor do que 1\% em todas as instâncias e menos de $10 \%$ de dependência (cada variável depende de uma ou duas variáveis), este domínio pode ser considerado esparso e com poucas dependências nas variáveis de estado. Além disso, a porcentagem de densidade de transição e a porcentagem de dependências diminuem quando as instâncias crescem. Para todas as instâncias, o número de ações é a mesma (5 ações). Portanto, a complexidade só aumenta com o número de variáveis, variando de 18 para a instância 1 a 98 para a instância 10 .

\subsubsection{Elevators}

O domínio elevators descreve um problema de planejamento para um grupo de elevadores, que transportam passageiros entre apenas dois andares (primeiro e segundo andar). Os passageiros chegam a qualquer andar com uma probabilidade de chegada que é completamente diferente para cada andar.

O sentido em que um elevador se move é determinado automaticamente no momento de abrir as portas e é sempre contrário ao sentido que estava antes. Por exemplo, se o elevador estava 
descendo, quando chegou ao primeiro andar, abre as portas e o sentido muda para subida. Um elevador pode movimentar-se só com as portas fechadas e no sentido atual. O elevador pode permanecer num andar ou pode fechar as portas e mover-se.

Um plano aceitável neste domínio é pegar um passageiro e levá-lo a seu destino. Um plano melhorado inclui ter o elevador próximo ao andar que tem maior probabilidade de um passageiro chegar e, além disso, coordenando com os outros elevadores para levar passageiros a seus destinos.

\begin{tabular}{|r|l|l|l|l|l|}
\hline \multicolumn{7}{|c|}{ Elevators } \\
\hline Instância & Variáveis & Ações & \% Densidade Méd. & \% Densidade Máx. & \% Dependências \\
\hline 1 & 13 & 5 & 0.029754638672 & 0.029754638672 & 28.4023668639 \\
\hline 2 & 20 & 25 & $1.0299682617 \mathrm{E}-4$ & $1.4305114746 \mathrm{E}-4$ & 22.5 \\
\hline 3 & 20 & 25 & $1.0299682617 \mathrm{E}-4$ & $1.4305114746 \mathrm{E}-4$ & 22.5 \\
\hline 4 & 16 & 5 & 0.001678466797 & 0.001907348633 & 24.140625 \\
\hline 5 & 24 & 25 & $6.1988830566 \mathrm{E}-6$ & $7.4505805969 \mathrm{E}-6$ & 20.0694444444 \\
\hline 6 & 24 & 25 & $6.1988830566 \mathrm{E}-6$ & $7.4505805969 \mathrm{E}-6$ & 20.0694444444 \\
\hline 7 & 19 & 5 & $1.9788742065 \mathrm{E}-4$ & $2.0861625671 \mathrm{E}-4$ & 20.9418282548 \\
\hline 8 & 28 & 25 & $3.7811696529 \mathrm{E}-7$ & $4.0745362639 \mathrm{E}-7$ & 18.0102040816 \\
\hline 9 & 28 & 25 & $3.7811696529 \mathrm{E}-7$ & $4.0745362639 \mathrm{E}-7$ & 18.0102040816 \\
\hline 10 & 22 & 5 & $2.4139881134 \mathrm{E}-5$ & $2.4586915969 \mathrm{E}-5$ & 18.4710743802 \\
\hline
\end{tabular}

Tabela 7.2: Características do domínio Elevators.

A Tabela 7.2 mostra as características deste domínio. Uma vez que todas as instâncias tem menos que $1 \%$ de densidade de transição e tem mais que $10 \%$ de dependência (a maioria das instâncias tem mais que $20 \%$ de dependência), este domínio pode ser considerado esparso e com muita dependência entre as variáveis. Este domínio diminui a porcentagem de densidade de transição e a porcentagem de dependência conforme a instância cresce. Assim, a complexidade com relação às variáveis e às ações muda de uma instância a outra. Por exemplo, as instâncias 8 e 9 tem maior quantidade de variáveis (28 variáveis cada). No caso das ações, as instâncias 1 , 4, 7 e 10 têm 5 ações e o restante de instâncias têm 25 ações.

\subsubsection{Game of Life}

No domínio Game of Life (Gardner, 1970) há uma grade em que cada célula pode estar viva ou morta. As células podem morrer ou nascer a qualquer momento. A evolução da grade é determinada pelo estado inicial e as regras que determinam a transição de estados:

- qualquer célula viva com menos de dois vizinhos vivos morre por solidão,

- qualquer célula viva com mais de três vizinhos vivos morre por superpopulação,

- qualquer célula viva com dois ou três vizinhos vivos continua viva e

- qualquer célula morta com dois ou três vizinhos vivos se torna uma célula viva por reprodução.

Como nos domínios de planejamento é necessário que o agente interaja com o ambiente, então neste domínio o agente pode determinar qualquer célula como morta ou viva. Além disso, 
define-se uma margem de falha $\epsilon$, que define probabilidades nas transições determinísticas do jogo original. Assim, a probabilidade de uma célula com menos de dois vizinhos vivos, morrer no próximo passo é $1-\epsilon$. No jogo original, a transição é determinística e a célula morre no próximo passo. Desta forma, definem-se probabilidades de transição para todas as regras do jogo original. Fazendo com que o domínio seja denso. O objetivo do agente neste domínio é manter a maior quantidade de células vivas.

\begin{tabular}{|r|l|l|l|l|l|}
\hline \multicolumn{6}{|c|}{ Game of Life } \\
\hline Instância & Variáveis & Ações & \% Densidade Méd. & \% Densidade Máx. & \% Dependências \\
\hline 1 & 9 & 10 & 100.0 & 100.0 & 54.4444444444 \\
\hline 2 & 9 & 10 & 100.0 & 100.0 & 54.4444444444 \\
\hline 3 & 9 & 10 & 100.0 & 100.0 & 54.4444444444 \\
\hline 4 & 16 & 17 & 100.0 & 100.0 & 36.7647058823 \\
\hline 5 & 16 & 17 & 100.0 & 100.0 & 36.7647058823 \\
\hline 6 & 16 & 17 & 100.0 & 100.0 & 36.7647058823 \\
\hline 7 & 25 & 26 & 100.0 & 100.0 & 26 \\
\hline 8 & 25 & 26 & 100.0 & 100.0 & 26 \\
\hline 9 & 25 & 26 & 100.0 & 100.0 & 26 \\
\hline 10 & 30 & 31 & 100.0 & 100.0 & 21.0752688172 \\
\hline
\end{tabular}

Tabela 7.3: Características do dominio Game of Life.

A Tabela 7.3 mostra a evolução da complexidade deste domínio. Este domínio é muito denso, (um estado pode levar para todos os estados do espaço de estados, isto é, tem 100\% de densidade de transição em todas as instância) e tem muita dependência entre as variáveis de estado. Todas as instâncias tem mais de $10 \%$ de dependência, e a complexidade com relação à dependência diminui conforme a instância cresce.

\subsubsection{Navigation}

Em uma grade, um robô $(R)$ deve atingir uma meta $(M)$. Em cada célula o robô tem diferentes oportunidades de desaparecer e a transição de uma célula para outra é determinística. O robô precisa escolher um caminho que o leve a meta da forma mais segura dentro de um horizonte finito.

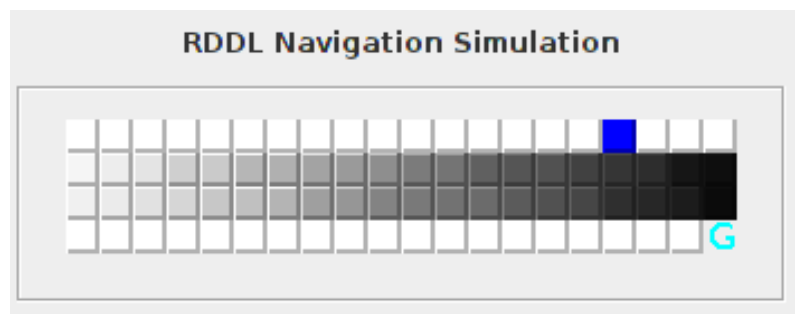

Figura 7.2: Simulador do sistema rddlsim para o dominio Navigation.

A Figura 7.2 mostra uma instância do domínio Navigation. Neste domínio se tem uma grade em que as células mais escuras tem maior probabilidade do robô desaparecer, a célula azul da primeira linha indica a localização do robô e a célula com a letra G da última linha indica a 
meta do robô.

\begin{tabular}{|r|l|l|l|l|l|}
\hline \multicolumn{9}{|c|}{ Navigation } \\
\hline Instância & Variáveis & Ações & \% Densidade Méd. & \% Densidade Máx. & \% Dependências \\
\hline 1 & 12 & 5 & 0.035753250 & 0.0420093536 & 16.5277777777 \\
\hline 2 & 15 & 5 & 0.005071461 & 0.0061824917 & 13.7777777777 \\
\hline 3 & 20 & 5 & $9.536743164 \mathrm{E}-5$ & $9.536743164 \mathrm{E}-5$ & 10.95 \\
\hline 4 & 30 & 5 & $9.8454100745 \mathrm{E}-8$ & $1.1974147387 \mathrm{E}-7$ & 7.7111111111 \\
\hline 5 & 30 & 5 & $9.7788870334 \mathrm{E}-8$ & $1.1641532182 \mathrm{E}-7$ & 7.4444444444 \\
\hline 6 & 40 & 5 & $9.0949470177 \mathrm{E}-11$ & $9.0949470177 \mathrm{E}-11$ & 5.8625000000 \\
\hline 7 & 50 & 5 & $9.1778436702 \mathrm{E}-14$ & $1.0362081563 \mathrm{E}-13$ & 4.8240000000 \\
\hline 8 & 60 & 5 & $9.1072982488 \mathrm{E}-17$ & $1.0842021724 \mathrm{E}-16$ & 3.8611111111 \\
\hline 9 & 80 & 5 & $8.2718061255 \mathrm{E}-23$ & $8.2718061255 \mathrm{E}-23$ & 3.028125 \\
\hline 10 & 100 & 5 & $8.151562687 \mathrm{E}-29$ & $9.2033772275 \mathrm{E}-29$ & 2.486 \\
\hline
\end{tabular}

Tabela 7.4: Características do dominio Navigation.

A Tabela 7.4 mostra a evolução da complexidade deste domínio. Como todas as instâncias tem menos que $1 \%$ de densidade de transição, este domínio pode ser considerado esparso. $\mathrm{O}$ Navigation varia a porcentagem de dependência entre as variáveis de estado, as 4 primeiras instâncias tem mais do que $10 \%$ de dependência entre as variáveis de estado, e o restante das instâncias têm porcentagem menor do que 10\%. Igual que o domínio Crossing Traffic, o domínio Navigation tem 5 ações para todas as instâncias. Neste domínio a complexidade só aumenta ao passo que aumenta a quantidade de variáveis que (a menor instância tem 12 variáveis enquanto que a maior instância tem 100 variáveis).

\subsubsection{Recon}

Este domínio, possui uma grade com um agente, uma célula base, algumas células perigosas, e objetos em diferentes células. O agente tem 2 sensores (um para detectar água e outro para detectar de vida) e uma câmera para tirar fotos. A transição de uma célula para outra é determinística. Cada sensor tem uma probabilidade de detectar vida ou água em qualquer objeto. Se o agente cai numa célula perigosa ou passa por uma célula adjacente à célula perigosa, há uma probabilidade de danificar os sensores. Se um sensor é danificado, a probabilidade de deteç̧ão diminui drasticamente. Se a câmera é danificada, o agente não pode tirar fotos. A única forma de reparar um sensor ou a câmera é ir para a célula base e reparar cada sensor ou a câmera individualmente.

O objetivo do agente é tirar fotos de objetos onde se detectou vida. O agente pode tentar detectar vida num objeto se ele está na mesma célula desse objeto. Para isso, utiliza o sensor de vida nesse objeto. A probabilidade de detectar vida nesse objeto é a probabilidade de detecção do sensor de vida, se o sensor está danificado, a probabilidade de detecção é menor. Caso a vida não seja detectada nesse objeto, o agente pode tentar novamente e se na segunda tentativa o agente não conseguir detectar vida nesse mesmo objeto, a vida não poderá mais ser detectada nesse objeto. No caso da detecção de água, o agente só tem uma tentativa. Depois dessa tentativa, a água não poderá mais ser detectada nesse objeto. Estas restrições fazem com que o agente evite 
usar sensores danificados.

As principais decisões de planejamento neste domínio são:

- Escolher em quais objetos usar os sensores ou a câmera.

- Reparar ou não os sensores ou a câmera.

- Arriscar ou não o uso de sensores danificados.

- Arriscar ou não passar pelas células perigosas ou perto delas.

\begin{tabular}{|r|l|l|l|l|l|}
\hline \multicolumn{9}{|c|}{ Recon } \\
\hline Instância & Variáveis & Ações & \% Densidade Méd. & \% Densidade Máx. & \% Dependências \\
\hline 1 & 31 & 20 & $4.842877388 \mathrm{E}-8$ & $6.5192580223 \mathrm{E}-8$ & 3.7200832466 \\
\hline 2 & 31 & 20 & $4.842877388 \mathrm{E}-8$ & $6.5192580223 \mathrm{E}-8$ & 3.7200832466 \\
\hline 3 & 42 & 23 & $2.3132800023 \mathrm{E}-11$ & $3.1832314562 \mathrm{E}-11$ & 2.4918663117 \\
\hline 4 & 42 & 23 & $2.3725948741 \mathrm{E}-11$ & $3.4106051316 \mathrm{E}-11$ & 2.8320023661 \\
\hline 5 & 55 & 26 & $2.7755575615 \mathrm{E}-15$ & $2.7755575615 \mathrm{E}-15$ & 1.9211697393 \\
\hline 6 & 55 & 26 & $2.7755575615 \mathrm{E}-15$ & $2.7755575615 \mathrm{E}-15$ & 1.9211697393 \\
\hline 7 & 55 & 26 & $2.8111416328 \mathrm{E}-15$ & $3.7007434154 \mathrm{E}-15$ & 1.9872854418 \\
\hline 8 & 70 & 29 & $8.4703294725 \mathrm{E}-20$ & $8.4703294725 \mathrm{E}-20$ & 1.6375791695 \\
\hline 9 & 70 & 29 & $8.4703294725 \mathrm{E}-20$ & $8.4703294725 \mathrm{E}-20$ & 1.4743138634 \\
\hline 10 & 70 & 29 & $8.5537809944 \mathrm{E}-20$ & $1.0890423607 \mathrm{E}-19$ & 1.4743138634 \\
\hline
\end{tabular}

Tabela 7.5: Características do dominio Recon.

A Tabela 7.5 mostra a evolução da complexidade deste domínio. O domínio Recon pode ser considerado esparso, porque todas as instâncias têm densidade de transição menor que 1\%. Este domínio tem pouca dependência entre as variáveis de estado pelo fato de todas as instâncias terem menos que $10 \%$ de dependência entre as variáveis de estado. A complexidade na densidade de transição e na dependência entre as variáveis diminui conforme a instância cresce, mas aumenta em termos de número de variáveis de estado (31 na primeira instância e 70 na última instância) e no número de ações (20 na primeira instância e 29 na última instância).

\subsubsection{Skill Teaching}

Neste domínio, o agente tenta ensinar um conjunto de habilidades a um estudante através de dicas e questões de múltipla escolha. O estudante pode ter dois níveis de proficiência para cada habilidade (média e alta) que indica sua capacidade de responder perguntas sobre essa habilidade. Cada habilidade tem um peso indicando seu valor. Para uma alta proficiência na habilidade é dada uma recompensa positiva que equivale ao peso da habilidade. Para uma proficiência média é dada uma recompensa negativa que equivale ao peso negativo da habilidade.

Muitas habilidades estão conectadas de forma que algumas são precondições de outras. O estudante tem uma probabilidade de contestar de forma correta as perguntas sobre uma habilidade e esta probabilidade aumenta por cada precondição aprendida com nível alto de proficiência. $\mathrm{O}$ conhecimento de todas as precondições de uma habilidade pode levar a uma probabilidade mais 


\begin{tabular}{|r|l|l|l|l|l|}
\hline \multicolumn{7}{|c|}{ Skill Teaching } \\
\hline Instância & Variáveis & Ações & \% Densidade Méd. & \% Densidade Máx. & \% Dependências \\
\hline 1 & 12 & 5 & 0.0329589843 & 0.0366210937 & 20.0 \\
\hline 2 & 12 & 5 & 0.0329589843 & 0.0366210937 & 20.0 \\
\hline 3 & 24 & 9 & $6.8434962519 \mathrm{E}-6$ & $7.94728597 \mathrm{E}-6$ & 11.5354938271 \\
\hline 4 & 24 & 9 & $6.8434962519 \mathrm{E}-6$ & $7.94728597 \mathrm{E}-6$ & 11.5354938271 \\
\hline 5 & 36 & 13 & $1.6790671417 \mathrm{E}-9$ & $1.9402553637 \mathrm{E}-9$ & 8.6063627730 \\
\hline 6 & 36 & 13 & $1.6790671417 \mathrm{E}-9$ & $1.9402553637 \mathrm{E}-9$ & 8.6182336182 \\
\hline 7 & 42 & 15 & $2.6274291384 \mathrm{E}-11$ & $3.0316490059 \mathrm{E}-11$ & 7.7739984882 \\
\hline 8 & 42 & 15 & $2.6274291384 \mathrm{E}-11$ & $3.0316490059 \mathrm{E}-11$ & 7.8080120937 \\
\hline 9 & 48 & 17 & $4.110002099 \mathrm{E}-13$ & $4.7369515717 \mathrm{E}-13$ & 7.1435866013 \\
\hline 10 & 48 & 17 & $4.110002099 \mathrm{E}-13$ & $4.7369515717 \mathrm{E}-13$ & 7.1742238562 \\
\hline
\end{tabular}

Tabela 7.6: Características do domínio Skill Teaching.

alta que a soma das probabilidades adicionadas por cada precondição. As dicas só funcionam se todas as precondições são conhecidas e só podem levar a uma proficiência média.

A proficiência dos estudantes aumenta com perguntas respondidas de forma correta e diminui com perguntas respondidas de forma incorreta e, algumas vezes, diminui por acaso. Para modelar a interação do professor com o estudante, os turnos são alternados: o agente fornece questões de múltipla escolha ou dicas e; o estudante responde perguntas.

Os problemas de planejamento são:

1. Ensinar ou não todas as precondições de uma habilidade antes de ensinar essa habilidade.

2. Em que habilidade concentrar-se no próximo passo

3. Quando dar uma dica e quando usar questões de múltipla escolha.

A Tabela 7.6 mostra a evolução da complexidade deste domínio. Este domínio também pode ser considerado esparso (todas as instâncias têm menos que $1 \%$ de densidade de transição), e tem pouca dependência entre as variáveis de estado nas instâncias 5 até 10 (nessas instâncias a porcentagem de dependência é menor do que 10\%). Nas instâncias de 1 a 4 a porcentagem de dependência é maior que $10 \%$ (20\% nas instâncias 1 e 2). Neste domínio, a complexidade, na densidade de transição e na dependência nas variáveis de estado, diminui enquanto as instâncias crescem, mas aumenta em termos de variáveis de estado (12 na primeira instância e 28 na última instância) e número de ações (5 na primeira instância e 17 na última instância).

\subsubsection{SysAdmin}

Este domínio foi descrito na introdução (Capítulo 1).

A Tabela 7.7 mostra a evolução da complexidade deste domínio. Este domínio é denso, visto que todas as instâncias têm porcentagem de densidade de transição maior que 50\%, além disso, podemos ver que a densidade máxima é $100 \%$, que corresponde à ação que não faz nada. Portanto este domínio pode ser considerado muito denso. SysAdmin tem pouca dependência entre as variáveis de estado nas instâncias 5, 7, 8, 9 e 10 (a porcentagem de dependência é menor do que $10 \%$ nessas instâncias). No restante das instâncias há muita dependência nas variáveis de estado 


\begin{tabular}{|r|l|l|l|l|l|}
\hline \multicolumn{7}{|c|}{ SysAdmin } \\
\hline Instância & Variáveis & Ações & \% Densidade Méd. & \% Densidade Máx. & \% Dependências \\
\hline 1 & 10 & 11 & 54.5454545454 & 100.0 & 21.8181818181 \\
\hline 2 & 10 & 11 & 54.5454545454 & 100.0 & 34.5454545454 \\
\hline 3 & 20 & 21 & 52.3809523809 & 100.0 & 13.8095238095 \\
\hline 4 & 20 & 21 & 52.3809523809 & 100.0 & 18.3333333333 \\
\hline 5 & 30 & 31 & 51.6129032258 & 100.0 & 9.2473118279 \\
\hline 6 & 30 & 31 & 51.6129032258 & 100.0 & 11.9354838709 \\
\hline 7 & 40 & 41 & 51.2195121951 & 100.0 & 7.1951219512 \\
\hline 8 & 40 & 41 & 51.2195121951 & 100.0 & 9.5121951219 \\
\hline 9 & 50 & 51 & 50.9803921568 & 100.0 & 5.8823529411 \\
\hline 10 & 50 & 51 & 50.9803921568 & 100.0 & 7.6862745098 \\
\hline
\end{tabular}

Tabela 7.7: Características do dominio SysAdmin.

(com porcentagem de dependência maior que 10\%). A complexidade em termos de densidade de transição vai diminuindo enquanto a instância cresce. A complexidade em termos da dependência nas variáveis de estado varia enquanto a instância cresce, mas, em geral diminui, considerando pares de instâncias. Por exemplo, as instâncias 1 e 2 têm $21.81 \%$ e $34.54 \%$, respectivamente, e as instâncias 3 e 4 têm $13.08 \%$ e $18.33 \%$, respectivamente. O segundo par de porcentagens é menor que o primeiro par, considerando que a porcentagem maior do segundo par é menor que a menor porcentagem do primeiro par, este mesmo padrão é repetido para todas as instâncias. A complexidade em termos de número de variáveis e número de ações aumenta a medida que a instância cresce (de 10 para 50 nas variáveis de estado e de 11 para 51 nas ações).

\subsubsection{Traffic}

O domínio Traffic (Delgado et al., 2011), descreve uma configuração de células que representam o tráfego em ruas. Para cada célula é indicada a próxima célula à qual vai o sentido do tráfego, nessa rua. Existem células que representam uma interseção entre ruas. Diferente do descrito em (Delgado et al., 2011), neste domínio as ruas só tem um sentido de tráfego e o agente só controla o passo nas interseções, através da ação Avançar $(i)$, em que $i$ é a interseção. Cada interseção tem um semáforo, este semáforo é definido com duas variáveis binárias (sinal_luz_1 e sinal_luz_2), da seguinte forma:

\begin{tabular}{c|c|l}
\multicolumn{2}{c|}{ sinal_luz } & \multirow{2}{*}{ Estado do semáforo } \\
\hline 1 & 2 & Vermelho para as duas ruas \\
\hline \hline 0 & 0 & Verde em direção norte-sul \\
\hline 0 & 1 & Verde \\
\hline 1 & 0 & Verde em direção leste-oeste \\
\hline 1 & 1 & Vermelho para as duas ruas
\end{tabular}

Tabela 7.8: Configuração do semáforo do domínio Traffic.

A Tabela 7.8 mostra a configuração do semáforo com relação às variáveis sinal_luz_1 e sinal_luz_2. Se o agente decide aplicar a ação Avançar $(i)$, numa interseção $i$, o tráfego avança na rua em que o semáforo indica a luz verde. Em cada célula de uma rua pode haver um carro, 
numa célula intermediária da rua está apenas o carro que vem da célula anterior. A primeira célula de uma rua tem uma probabilidade, que indica se aparece ou não um carro nessa célula. O objetivo deste domínio é minimizar a congestão das ruas. A congestão é definida como a somatória dos pares de células consecutivas e ocupadas.

Este domínio considera ações concorrentes (até 4). A pesar de ter ações concorrentes o número máximo de ações é $2^{I}$, em que $I$ é o número de interseções.

\begin{tabular}{|r|l|l|l|l|l|}
\hline \multicolumn{7}{|c|}{ Traffic } \\
\hline Instância & Variáveis & Ações & \% Densidade Méd. & \% Densidade Máx. & \% Dependências \\
\hline 1 & 32 & 16 & $2.7830417209 \mathrm{E}-8$ & $3.4823158287 \mathrm{E}-8$ & 10.15625 \\
\hline 2 & 32 & 16 & $2.4128150717 \mathrm{E}-8$ & $3.7282849048 \mathrm{E}-8$ & 10.15625 \\
\hline 3 & 44 & 16 & $9.0856411 \mathrm{E}-12$ & $9.0856411 \mathrm{E}-12$ & 7.2314049586 \\
\hline 4 & 44 & 16 & $9.8545445 \mathrm{E}-12$ & $9.8545445 \mathrm{E}-12$ & 7.2314049586 \\
\hline 5 & 56 & 16 & $2.4846847 \mathrm{E}-15$ & $2.4846847 \mathrm{E}-15$ & 5.6122448979 \\
\hline 6 & 56 & 16 & $2.5712618 \mathrm{E}-15$ & $2.5712618 \mathrm{E}-15$ & 5.6122448979 \\
\hline 7 & 68 & 16 & $7.6227832 \mathrm{E}-19$ & $7.6227832 \mathrm{E}-19$ & 4.5847750865 \\
\hline 8 & 68 & 16 & $8.0267603 \mathrm{E}-19$ & $8.0267603 \mathrm{E}-19$ & 4.5847750865 \\
\hline 9 & 80 & 16 & $5.72950022 \mathrm{E}-22$ & $5.72950022 \mathrm{E}-22$ & 3.875 \\
\hline 10 & 80 & 16 & $2.0604219 \mathrm{E}-22$ & $2.0604219 \mathrm{E}-22$ & 3.875 \\
\hline
\end{tabular}

Tabela 7.9: Características do dominio Traffic.

A Tabela 7.9 mostra a evolução da complexidade deste domínio. Este domínio pode ser esparso porque para todas as instâncias a porcentagem de densidade de transição é menor que $1 \%$. No caso da dependência entre as variáveis de estado, todas as instâncias têm pouca dependência entre as variáveis de estado porque a porcentagem de dependência é menor do que $10 \%$ ou bem próxima a 10\% como é o caso das duas primeiras instâncias. A complexidade neste domínio, só aumenta com o número de variáveis (32 na primeira instância e 80 na última instância), pois em todas as instâncias tem 16 ações, e no caso de densidade de transição e dependência, a complexidade diminui enquanto a instância cresce.

\subsection{Resumo da complexidade dos domínios}

\begin{tabular}{|r|l|l|l|l|}
\hline \multicolumn{5}{|c|}{ Resumo das características dos domínios } \\
\hline Domínio & Variáveis & Ações & Densidade & Dependência \\
\hline Crossing Traffic & 18 a 98 & 5 & Esparso & Pouca \\
\hline Elevators & 13 a 28 & 5 a 25 & Esparso & Muita \\
\hline Game of Life & 9 a 30 & 10 a 31 & Denso & Muita \\
\hline Navigation & 12 a 100 & 5 & Esparso & Muita(1-3) Pouca(4-10) \\
\hline Recon & 31 a 70 & 20 a 29 & Esparso & Pouca \\
\hline Skill Teaching & 21 a 48 & 5 a 17 & Esparso & Muita(1-4) Pouca(5-10) \\
\hline SysAdmin & 10 a 50 & 11 a 51 & Denso & Muita $(1-4,6)$ Pouca(5,7-10) \\
\hline Traffic & 31 a 80 & 16 & Esparso & Pouca \\
\hline
\end{tabular}

Tabela 7.10: Características dos domínios da IPPC 2011. A coluna independência indica as instâncias com ou sem independência.

Como foi visto nas seções anteriores, a complexidade de um domínio de planejamento depende 
das seguintes características: número de variáveis, número de ações, densidade de transição de estados e dependência entre variáveis de estado. Assim, é possível fazer uma classificação dos domínios em termos de densidade de transição e dependência. A Tabela 7.10 mostra um resumo das características e da complexidade dos domínios.

Com base nas características dos domínios e suas instâncias é possível classificá-los segundo a Figura 1.1. A Figura 7.3 mostra essa classificação. Note que somente os domínios Game of Life e SysAdmin podem ser considerados domínios densos. Sendo que todas as instâncias do Game of Life são consideradas de tipo sem independência, enquanto que no SysAdmin, suas instâncias podem ser consideradas sem ou com independência entre variáveis.

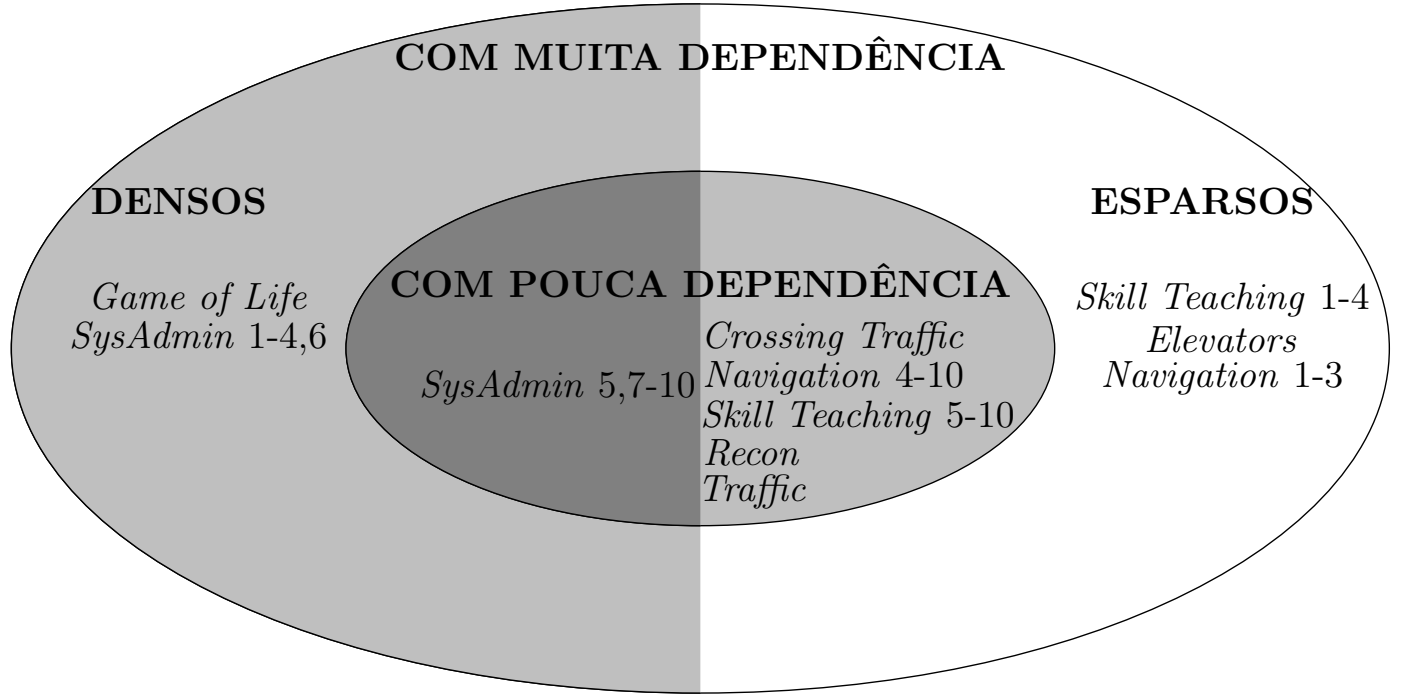

Figura 7.3: Classificação dos domínios de planejamento probabilístico, em termos de: domínios/instâncias DENSOS Vs ESPARSOS e SEM INDEPENDENCIA Vs. COM INDEPENDENCIA.

O principal motivo desta classificação é encontrar os domínios e instâncias nas quais os algoritmos desenvolvidos conseguiram um melhor desempenho. Desta forma podemos identificar de maneira exata a contribuição desse trabalho de mestrado. 


\section{Capítulo 8}

\section{Resultados Experimentais}

O objetivo deste capítulo é mostrar as vantagens dos algoritmos fatorados assíncronos, propostos neste trabalho, quando comparados com uma versão enumerativa eficiente, o LRTDP enumerativo. Assim, é apresentada uma análise de desempenho dos algoritmos fatorados, do LRTDP enumerativo e os planejadores probabilísticos considerados o estado-de-arte, Prost (Keller e Eyerich, 2012) e Glutton (Kolobov et al., 2012), primeiro e segundo vencedores da competição IPPC 2011. Para esta análise usamos o sistema rddlsim (Sanner e Yoon, 2010) e rodamos os planejadores nos domínios da competição IPPC-2011, descritos na linguagem RDDL. Foram analisados os seguintes algoritmos: LRTDP (Seção 2.2.4), sRTDP (Seção 4.2.1), FactRTDP (Seção 5.1), FactLRTDP (Seção 5.2), aFactRTDP_max (Seção 5.3), aFactRTDP_ave (Seção 5.3) e aFactLRTDP_ave (Seção 5.4). Todos os algoritmos foram implementados em Java utilizando a biblioteca de ADDs do rddlsim.

Na Seção 8.1 descrevemos como os planejadores probabilísticos foram executados na competição IPPC-2011 de modo online, usando o simulador rddlsim. Na Seção 8.3 apresentamos a análise de convergência desses algoritmos para dois domínios: Game of Life, um domínio considerado denso (de acordo com a análise feita na Seção 7.1.3) e Navigation, um domínio considerado esparso (Seção 7.1.4). Na Seção 8.4 apresentamos a análise de desempenho online, comparando os diferentes algoritmos propostos com os vencedores da IPPC-2011.

\subsection{Planejamento (online) na IPPC-2011}

Os algoritmos propostos no Capítulo 5, bem como todos os algoritmos assíncronos descritos neste trabalho, foram definidos para serem executados de forma offline. Porém, com algumas modificações simples, mostradas nesta seção, eles podem ser executados de modo online. Note que essa é uma das vantagens atribuidas aos algoritmos assíncronos: eles produzem boas políticas quando interrompidos antes da convergência. Executar os algoritmos de forma online permite executá-los no sistema da competição IPPC 2011, reddlsim, para compará-los com os vencedores da competição IPPC-2011: Prost (Keller e Eyerich, 2012) e Glutton (Kolobov et al., 2012), sendo esse um dos objetivos da análise de desempenho online realizada na Seção 8.4.

\subsubsection{Simulador rddlsim}

O sistema rddlsim (Sanner e Yoon, 2010) foi usado na competição IPPC 2011 para rodar, um planejador desenvolvido em Java ou C++ e computar a melhor política para um problema descrito na linguagem RDDL. 
No rddlsim, um planejador pode calcular uma política ótima de forma offline ou online. Nas soluções offline a política ótima é calculada antes de ser executada. Nas soluções online a política é calculada durante a execução de ações. Geralmente, as políticas calculadas por soluções online são não-estacionárias, por que a política calculada para um estado $s$ no início do algoritmo não será tão boa quanto a política calculada para o mesmo estado em um estágio futuro, em que foi realizado um maior número de atualizações da função valor.

O sistema rddlsim inclui: um simulador que executa ações e devolve estados; uma arquitetura cliente/servidor para a execução de planejadores de modo online; uma biblioteca de ADDs; parsers para traduzir da linguagem RDDL para o PPDDL (Seção 6.1.2) e para o SPUDD (Seção 4.1.1); um simulador visual, que permite ver a execução de uma política; um conjunto de planejadores que servem como baseline; e um avaliador das recompensas dos competidores, que devolve uma nota para cada competidor. Uma descrição em detalhes da estrutura do sistema rddlsim é mostrada no Apêndice C.

A arquitetura cliente/servidor, simula a interação de um planejador com um ambiente. Este sistema passa um arquivo RDDL como entrada ao planejador e faz 30 simulações para cada instância, cada simulação é feita executando 40 ações, isto é, para um horizonte 40. Cada simulação é chamada de round. Cada round começa no estado inicial $s_{0}$ definido para cada instância. Em cada passo do round, o sistema passa ao planejador um estado e o planejador devolve uma ação, em seguida, o sistema aplica essa ação no estado e faz um sorteio do próximo estado, de acordo com as probabilidades de transição de estados para aquela ação. A função implementada em cada planejador que devolve a ação para um estado é chamada de getAction (a chamada à função getAction faz a chamada aos planejadores).

Ao obter a ação devolvida pela função getAction, o simulador calcula a recompensa do par estado/ação; as recompensas dos 40 pares são usados para obter uma recompensa acumulada do round em questão. Depois de executar 30 rounds, o sistema calcula a média das 30 recompensas acumuladas. Desta forma, para cada instância tem-se a média das recompensas acumuladas como indicador da qualidade da política calculada pelo planejador.

Na competição, o objetivo do planejador é resolver 10 problemas de 8 domínios em 24 horas, sendo que a distribuição de tempo para os domínios e problemas, fica a critério de cada competidor. Como mostra a Figura 8.1, a divisão do tempo é feita da seguinte forma: a primeira divisão de tempo é entre os domínios; dentro de cada domínio, é feita a divisão entre as instâncias; dentro de cada instância é feita a divisão entre os rounds e; dentro de cada round é feita a divisão entre os getActions.

Note que um planejador pode usar a informação dos rounds anteriores e, durante uma simulação de 40 passos, usar a informação dos passos anteriores, melhorando assim a sua política a medida que executa as 40 ações de um round e a medida que executa os 30 rounds.

É importante observar que, dada a limitação de tempo, a maioria dos competidores tiveram que optar pelo planejamento online e calcular políticas sub-ótimas. 


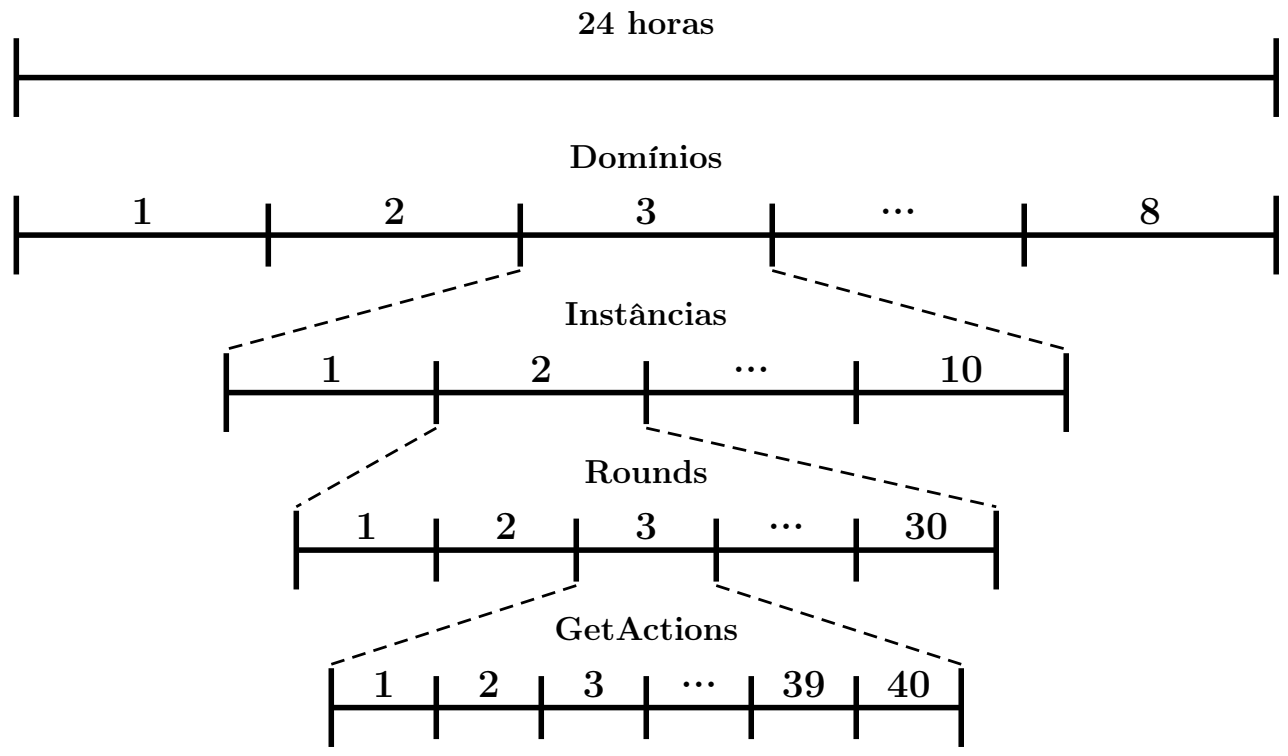

Figura 8.1: Divisão de tempos para a competição.

\subsubsection{Execução dos algoritmos de modo online}

Como dissemos anteriormente, os algoritmos propostos no Capítulo 5, e os descritos nas Seções 2.2.3, 2.2.4 2.2.5 e 4.2, estão definidos para a encontrar a política ótima verificando a convergência da função valor. Para executá-los de modo online definimos a função ExECUTARONLINE (Algoritmo 21). A idéia dessa função é executar um algoritmo de planejamento offline por um tempo limitado para cada um dos getActions. Na execução offline, a profundidade dos trials é fixada para toda a execução ou termina quando no trial é encontrado um estado meta. Devido à limitação de tempo, na execução online, não se deve terminar o trial somente quando um estado meta for encontrado. Por isso, nos experimentos realizados neste trabalho, a profundidade dos trials é incrementada de um trial para outro; isto é, o primeiro trial tem profundidade 2 , o segundo tem profundidade 3 , e assim por diante. Desta forma, os primeiros trials são de menor profundidade, para explorar um maior número de estados e ações (exploração), e os últimos trials são de maior profundidade, para obter mais informação do futuro (explotação).

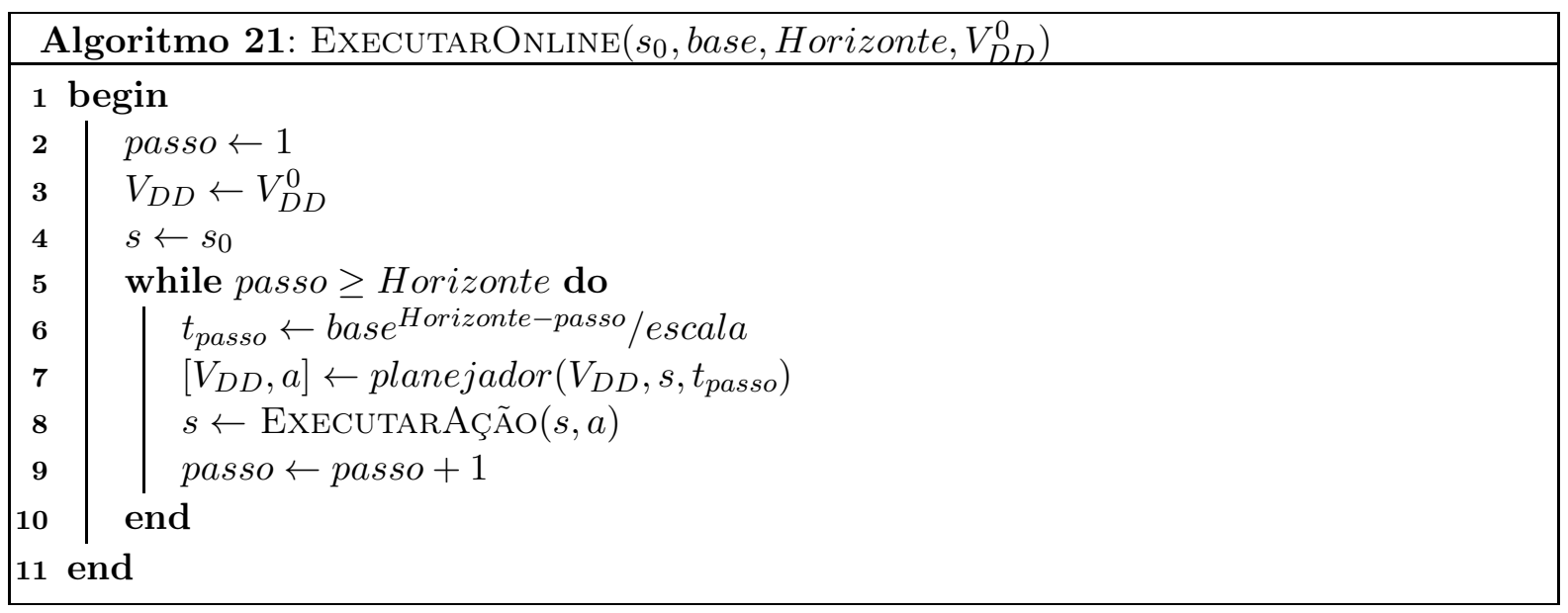


Como é definido um tempo de execução para cada getAction, a quantidade de trials também é limitada por esse tempo. No início, o algoritmo não tem muita informação, por este motivo decidimos atribuir maior tempo para cada getAction nos primeiros passos e menos tempo para os últimos. Assim, definimos uma distribuição de tempo exponencial, para os 40 getActions de um round, fazendo o seguinte cálculo $t_{\text {passo }}=$ base $^{\text {Horizonte-passo }} /$ escala, em que base e escala são parâmetros ajustados ao tempo máximo de execução do algoritmo, e passo indica o número de passos em que o agente está.

Os parâmetros base e escala, além de definirem o tempo máximo de execução do algoritmo, também definem o tipo de distribuição de tempo. Desta forma, através da distribuição de tempo e da modificação no número de trials, foi possível adaptar nossos algoritmos para serem executados de forma online e com horizonte finito.

\subsubsection{Os planejadores vencedores da IPPC-2011: Prost e Glutton}

Glutton é um algoritmo baseado em LRTDP enumerativo, ao qual foi adicionado uma técnica chamada Reverse Iterative Deepening, resultando no algoritmo $\mathrm{LR}^{2} \mathrm{TDP}$ (Kolobov et al., 2012). Glutton foi o segundo melhor algoritmo da competição IPPC-2011.

$\mathrm{O}$ algoritmo $\mathrm{LR}^{2} \mathrm{TDP}$ resolve um MDP de horizonte finito $H$, chamado de $M(H)$, resolvendo $H$ MDPs de horizontes menores, isto é, $M(1), M(2), \cdots, M(H)$, a partir do estado inicial $s_{0}$, de modo offline (isto é, calculando políticas ótimas). Essa estrategia é chamada de reverse iterative deepening e tenta buscar as melhores ações segundo o passo do horizonte em que se encontra. Como o algoritmo é de programação dinâmica, o algoritmo usa os resultados obtidos nos problemas $M(1), M(2), \cdots, M(h-1)$, quando tenta resolver o problema $M(h)$ : primeiro resolve $M(1)$ supondo que tem só uma ação para executar, em seguida resolve $M(2)$ usando os resultados de $M(1)$, e assim por diante.

Para que o algoritmo offline $\mathrm{LR}^{2} \mathrm{TDP}$ pudesse competir na IPPC 2011, de modo online e resolver problemas grandes, foram feitas algumas otimizações de engenharia. O LR ${ }^{2} \mathrm{TDP}$ com estas melhorias é chamado de Glutton, sendo elas:

- Sub-amostragem da função de transição, isto é, realiza uma amostragem do conjunto de estados sucessores para reduzir o custo computacional da atualização de Bellman. Esta técnica é chamada de subsampling.

- Separação dos efeitos de uma ação $a \in A$ em efeitos produzidos por: (I) eventos exógenos, pela ação $a$ e pela combinação da ação $a$ e os eventos exógenos. Esta separação de efeitos leva a uma separação das variáveis em 4 grupos de variáveis, para cada ação $a \in A$, segundo o tipo de evento que as modifique: (1) eventos exógenos, (2) a ação $a$ a, (3) combinação da ação $a$ e eventos exógenos e (4) nenhuma das anteriores (variáveis que não são afetadas pela ação $a$ e nem pelos eventos exógenos). Esta análise serve para priorizar estados no sorteio do estado sucessor, especialmente para escolher estados com variáveis que são diretamente afetadas pelas ações.

- Armazenar as funções valor para cada horizonte e reusá-las nos próximos horizontes. 
- Uso de políticas pré-determinadas. Glutton testa três tipos de políticas (e escolhe a melhor delas): (1) política cíclica que aplica um conjunto de ações de forma cíclica; (2) política que usa uma combinação entre ações aleatórias e ações cíclicas; e (3) política completamente aleatória. Este tipo de política é usada para aqueles domínios em que o política devolvida pelo LR ${ }^{2} \mathrm{TDP}$ não consegue bons resultados.

Prost (Keller e Eyerich, 2012) é um algoritmo baseado em planejamento UCT (Upper Confidence Bounds applied to trees) (Kocsis e Szepesvári, 2006). UCT trata o problema da exploração versus explotação como um problema do multi-armed bandit (Auer et al., 2002). Neste caso, a exploração testa diferentes ações, e a explotação efetua simulações de Monte-Carlo para uma dada ação. UCT constrói uma árvore do jogo, sendo que em cada nó UCT armazena um estado e um contador de visitas para esse estado. UCT é um algoritmo de planejamento baseado em técnicas de amostragem de Monte-Carlo projetado para resolver MDPs. Ao contrário de outras técnicas, UCT precisa fazer amostragem da função de transição e da função recompensa de um simulador, não precisando conhecer as probabilidades de transição ou valores da recompensa das ações. De modo similar ao RTDP, UCT realiza um número de trials, chamados de rollouts, através do espaço de estados e atualizações da função valor nos estados que visita nessas trajetórias.

A escolha dos estados sucessores é estocástica, porém a escolha das ações é gulosa como no RTDP mas adicionando um termo que garante que as ações aplicáveis são testadas em todos os estados. Para cada estado, UCT mantém um contador do número de vezes que um estado foi visitado e um outro contador que mantém quantas vezes uma ação foi selecionada num estado dado. $\mathrm{O}$ algoritmo mantém também um grafo parcial explícito que é expandido incrementalmente. Os rollouts começam da raiz e acabam num estado terminal ou em um estado que não pertence ao grafo. Quando um novo estado for gerado, este é adicionado no grafo explícito e a recompensa é amostrada simulando uma política base para $d$ passos a partir do estado inicial. Os valores são propagados usando atualizações de Monte-Carlo (Sutton e Barto, 1998).

O planejador Prost (Keller e Eyerich, 2012), primeiro lugar da competição, usa o algoritmo UCT e introduz algumas otimizações para melhorar seu desempenho, entre elas, técnicas para reduzir o fator de ramificação e para limitar a profundidade da busca.

Apesar dessa dissertação ter como objetivo propor extensões do algoritmo RTDP, mostramos que para alguns domínios e problemas, os algoritmos propostos são comparáveis ao desempenho dos competidores Glutton e Prost.

\subsection{Algoritmos usados nas Análises}

A Tabela 8.1 mostra um resumo dos 6 algoritmos analisados: FactRTDP, FactLRTDP, aFactRTDP, aFactLRTDP, LRTDP enumerativo e sRTDP. A análise de desempenho de convergência é feita usando os algoritmos FactRTDP, FactLRTDP, aFactRTDP e aFactLRTDP, LRTDP enumerativo e sRTDP. O objetivo da análise de convergência é comparar o desempenho dos algoritmos propostos com os algoritmos conhecidos, sRTDP e LRTDP enumerativo.

O desempenho online é feito usando os algoritmos FactLRTDP, aFactRTDP e LRTDP enumerativo. Para o algoritmo usamos as versões da média (aFactRTDP_ave) e do máximo 


\begin{tabular}{|r|l|l|l|l|}
\hline \multicolumn{5}{|c|}{ Algoritmos analisados e suas características } \\
\hline Algoritmo & tipo & Atualiza & Cálculo & característica \\
\hline LRTDP & enumerativo & um estado & Exato & $\begin{array}{l}\text { constrói e atualiza } \\
\text { o grafo guloso }\end{array}$ \\
\hline FactRTDP & fatorado & um estado & Exato & $\begin{array}{l}\text { constrói estados } \\
\text { abstratos }\end{array}$ \\
\hline FactLRTDP & fatorado & um estado & Exato & $\begin{array}{l}\text { contrução fatorada atualização } \\
\text { fatoradas do grafo guloso }\end{array}$ \\
\hline aFactRTDP & fatorado & um estado & Aproximado & $\begin{array}{l}\text { aproxima o ADD da } \\
\text { função valor }\end{array}$ \\
\hline aFactLRTDP & fatorado & um estado & Aproximado & $\begin{array}{l}\text { aproxima o ADD da } \\
\text { função valor }\end{array}$ \\
\hline
\end{tabular}

Tabela 8.1: Características dos dominios da IPPC 2011. A coluna independência indica as instâncias com ou sem independência.

(aFactRTDP_max). No caso do algoritmo aFactLRTDP usamos a versão da média (aFactLRTDP_ave). O principal objetivo da análise online é comparar os algoritmos fatorados propostos com o algoritmo estado-da-arte da literatura, LRTDP enumerativo. sRTDP não foi analisado por não conseguiu resolver a grande maioria dos problemas. Além disso, na análise online os algoritmos propostos foram comparados com os 2 competidores da IPPC 2011 para verificar o alto desempenho dos algoritmos propostos.

\subsection{Análise de Convergência}

É importante recordar que nas abordagens de programação dinâmica assíncrona, o valor do estado inicial converge quando o valor de todos os seus estados sucessores já convergiram. Assim, podemos analisar o desempenho dos algoritmos assíncronos, analisando o comportamento de $V\left(s_{0}\right)$.

Os experimentos feitos para esta análise, foram realizados num computador com 3 GB de memória RAM, com processador core i5 e se considerou uma profundidade 40 para todos os trials dos algoritmos testados.

A Figura 8.2 mostra as curvas de convergência do estado inicial, $V\left(s_{0}\right)$, para os algoritmos: sRTDP, FactRTDP, aFactRTDP_max, aFactRTDP_ave, aFactLRTDP_ave, FactLRTDP e LRTDP, para as instâncias 1, 2 e 3 do domínio Game of Life (domínio denso). As Figuras 8.3 e 8.4 mostram as curvas de convergência do estado inicial, $V\left(s_{0}\right)$, para esses mesmos algoritmos para as instâncias 1, 3, 5, 7, 8 e 10 do domínio Navigation (domínio esparso).

Para os problemas dos dois domínios, o algoritmo FactLRTDP foi rodado até a convergência de $V\left(s_{0}\right)$, isto é até alcançar o valor ótimo $V^{*}\left(s_{0}\right)$. O tempo gasto nessa convergência foi o mesmo usado para rodar os algoritmos LRTDP, sRTDP, FactRTDP, aFactRTDP_max, aFactRTDP_ave e aFactLRTDP_ave. 
Game of Life 1

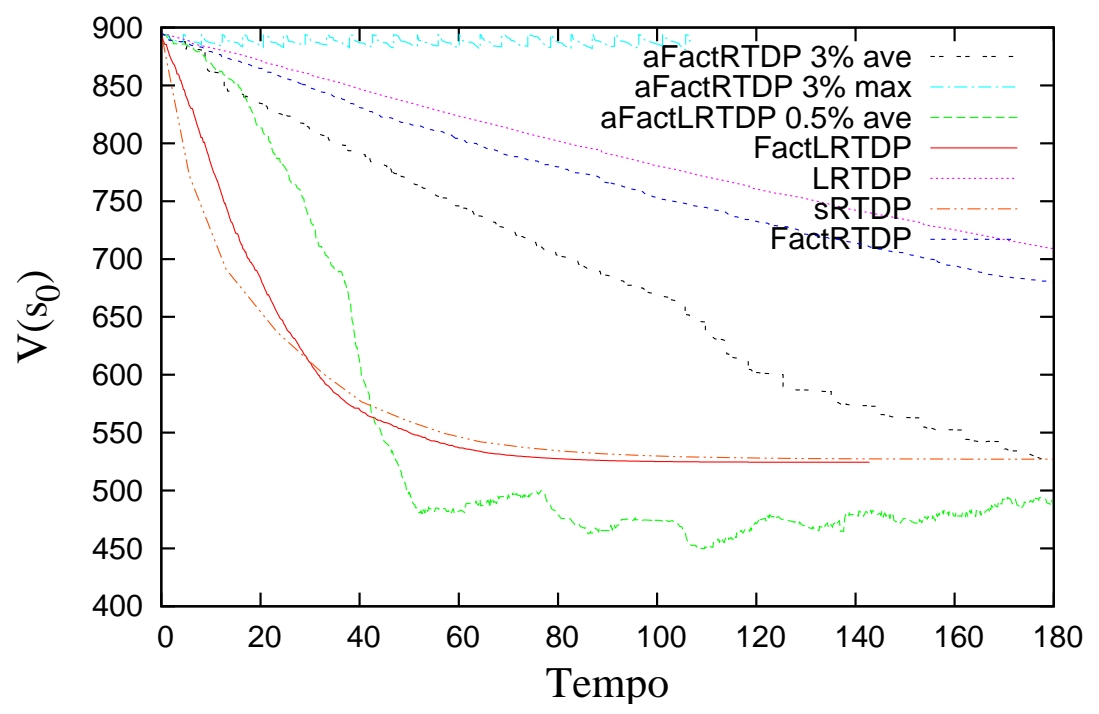

Game of Life 2

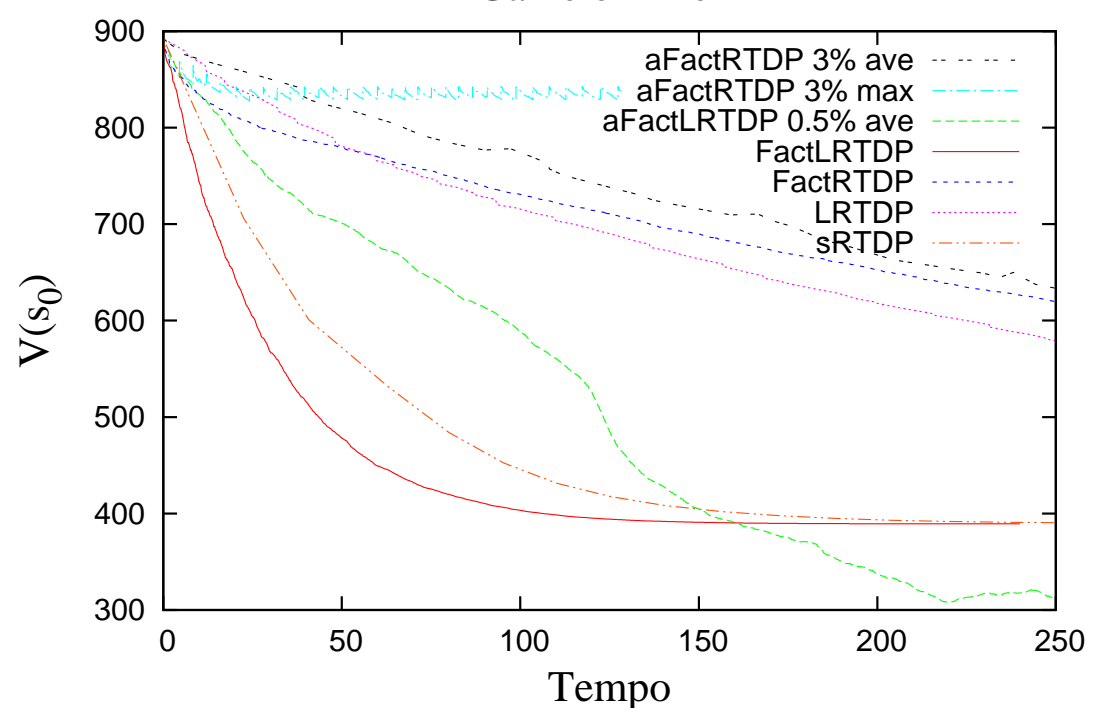

Game of Life 3

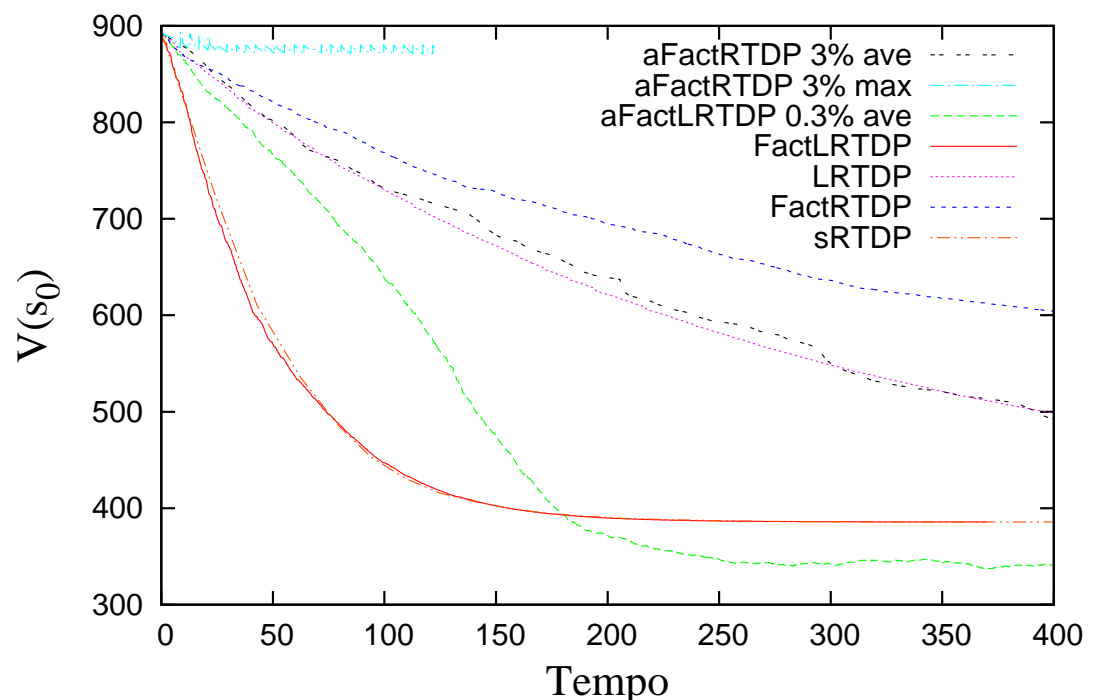

Figura 8.2: Variação do valor do estado inicial, com respeito ao tempo (em segundos), para três instâncias do dominio Game of Life, cada uma com 9 variáveis. 


\subsubsection{Domínio Denso: Game of Life}

Game of Life é um domínio complexo, uma vez que sua função de transição é densa, com muita dependência entre as variáveis de estado, o que indica a necessidade de um grande número de atualizações da função valor para a escolha da melhor política. As primeiras instâncias 1, 2 e 3 envolvem 10 ações e 9 variáveis com $55 \%$ de dependência entre elas. Já as instâncias médias (4, 5 e 6) envolvem 16 variáveis e 17 ações. Os algoritmos analisados só conseguiram encontrar a política ótima para as instâncias 1, 2 e 3, uma vez que, em geral, a convergência é muito difícil de se obter para esse domínio. Apesar disso, as 3 primeiras instâncias do Game of Life possibilitaram fazer uma análise comparativa dos algoritmos propostos.

A Figura 8.2 mostra que o sRTDP, o FactLRTDP e o aFactLRTDP_ave são os algoritmos que convergem mais rapidamente para as três instâncias. Isso pode ser justificado pelas atualizações que esses algoritmos fazem em um trial. Como planejar nesse domínio envolve analisar um número grande de possibilidades para a escolha da melhor política, os três algoritmos que fazem mais atualizações num trial foram os que obtiveram melhor desempenho: FactLRTDP e aFactLRTDP_ave executam a função FACTCHECKSOLved que atualiza vários estados no grafo guloso; sRTDP faz atualizações de todos os estados pertencentes ao estado abstrato $E$. Note que esses estados não são estados sorteados no trial o que faz com que um estado relevante com probabilidade baixa de ser sorteado também seja atualizado.

Como era previsto o LRTDP enumerativo obteve o pior desempenho no domínio denso Game of Life. LRTDP enumerativo também usa o procedimento CHECKSOLVED, porém, ele não é capaz de lidar com o grande número de estados desse domínio. Com isso, podemos concluir que, no domínio Game of Life, além do número de atualizações, a representação e cálculos fatorados tornam os planejadores mais eficientes.

Dentre os algoritmos aproximados, o aFactLRTDP_ave se mostrou o melhor, uma vez que converge para um valor aproximado quase no mesmo tempo que o FactLRTDP e sRTDP. Isso porque ele também usa o CHECKSOLved que atualiza todos os estados do grafo guloso, em cada trial.

Entre os demais algoritmos aproximados, o algoritmo aFactRTDP_ave consegue um melhor desempenho que o aFactRTDP_max. Isto porque, ao escolher a média dos valores agrupados ele não faz com que os valores dos estados oscilem tanto quanto o aFactRTDP_max. Note que esses dois algoritmos oscilam porque são inicializados com um valor maior que o valor ótimo (heurística admissível). Desta forma, $V\left(s_{0}\right)$ diminui com as atualizações de Bellman em direção do valor ótimo, enquanto as aproximações fazem com que $V\left(s_{0}\right)$ aumente para a média ou o $\max$

\subsubsection{Domínio Esparso: Navigation}

Navigation é um domínio menos complexo, uma vez que sua função de transição pode ser considerada esparsa e com pouca dependência entre as variáveis de estado. O domínio Navigation tem mais variáveis que o domínio Game of Life (60, 80 e 100 variáveis nas instâncias maiores) mas somente 5 ações para todas as instâncias. Assim, para encontrar políticas ótimas as atualizações feitas em um trial não precisam ser como no FACTCHeCKSolved. 

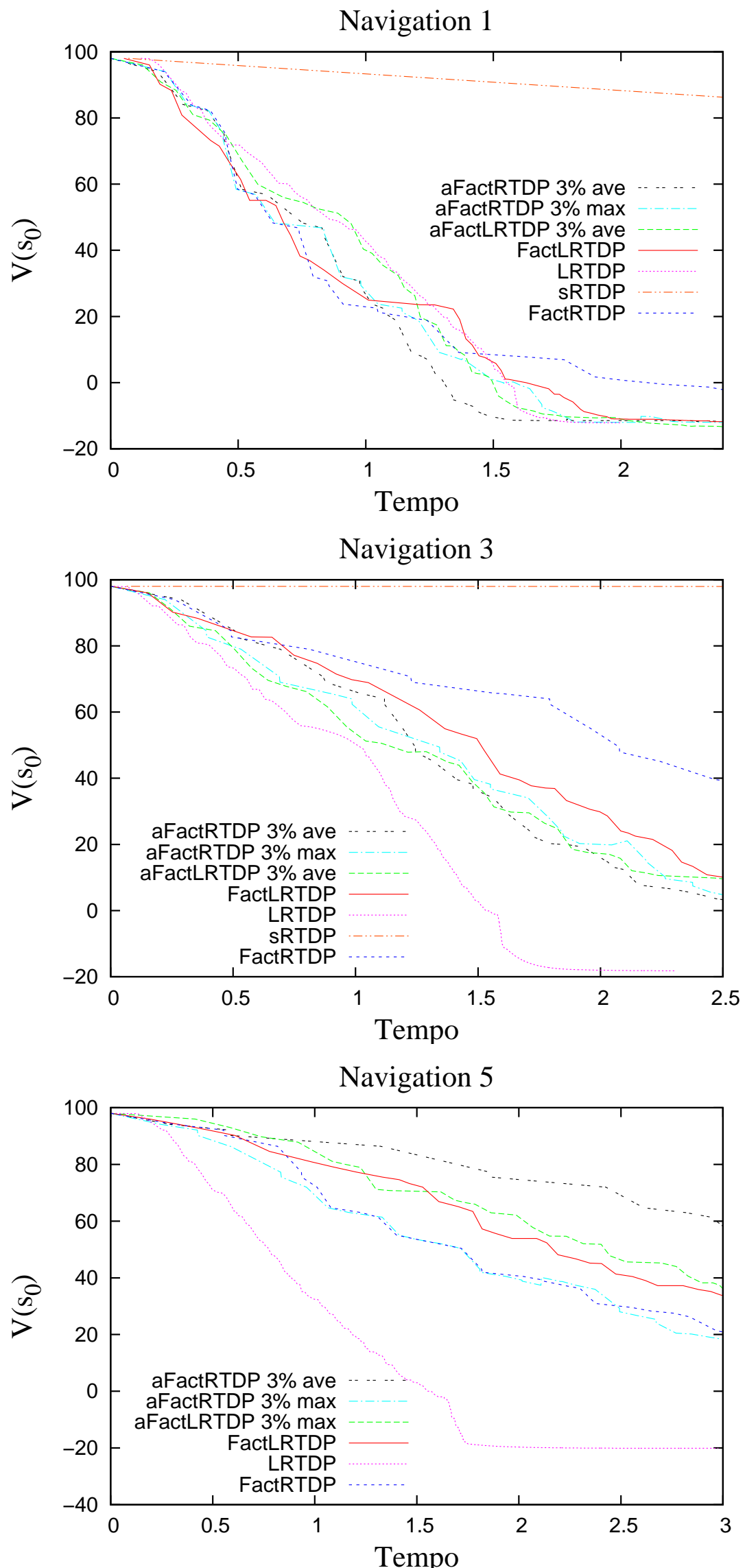

Figura 8.3: Variação do valor do estado inicial, com respeito ao tempo (em segundos), para as instâncias 1, 3 e 5 do domínio Navigation. Note que o sRTDP não conseguiu resolver as instância 5. 

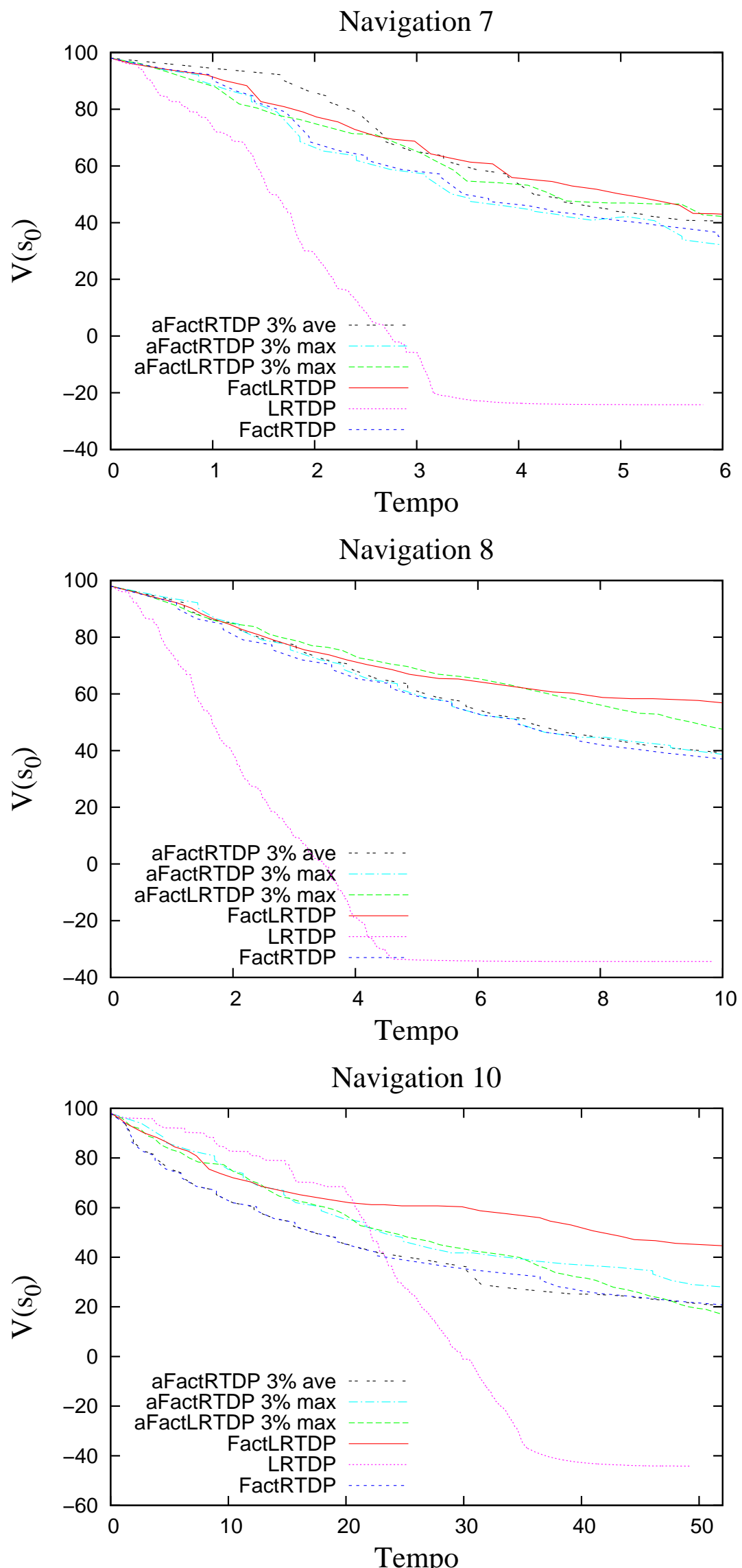

Figura 8.4: Variação do valor do estado inicial, com respeito ao tempo (em segundos), para as instâncias 7, 8 e 10 do domínio Navigation. Note que os tempos máximos dos gráficos são fixado em função do tempo de parada (e de convergência) do LRTDP. 
Com exceção do planejador sRTDP, todos os planejadores analisados conseguiram resolver todas as instâncias desse domínio. As Figuras 8.3 e 8.4 mostram o desempenho dos planejadores para 6 instâncias $(1,3,5,7,8$ e 10) sendo que as demais foram omitidas por motivo de espaço (e por não trazerem informações adicionais).

As Figuras 8.3 e 8.4 mostram que entre todos os algoritmos, o LRTDP foi o melhor no domínio esparso de Navigation e atingiu mais rapidamente a convergência (tempo $<10$ s para as instâncias de 1-8, 27 s para a instância 9 e 49 s para a instância 10). Isto já era esperado, uma vez que o LRTDP apresenta um ótimo desempenho em domínios esparsos.

No domínio Navigation, LRTDP superou o desempenho de todos os algoritmos fatorados (FactRTDP, FactLRTDP, aFactRTDP_ave, aFactRTDP_max e aFactLRTDP_ave), uma vez que ele faz atualizações rápidas quando comparadas às atualizações feitas por esses algoritmos. LRTDP mostra desempenho melhor para instâncias maiores.

O sRTDP apresentou o pior desempenho entre os planejadores analisados. A Figura 8.3 (linhas que mantém valores próximos de 100) mostra que o tempo consumido em cada trial faz com que a convergência do sRTDP seja muito lenta, sendo que para as instâncias de 4-10, o sRTDP não conseguiu terminar o primeiro trial. Isso porque a generalização por valor em estados abstratos, como foi implementada (AGRUPA_V), computa o estado abstrato $E$ inicial como o espaço completo de estados, que é muito grande.

\subsection{Análise de desempenho online dos algoritmos}

Nesta seção fazemos uma análise comparativa dos algoritmos propostos com o LRTDP enumerativo, e com os planejadores da competição de forma online, executados no sistema rddlsim. Para isso, usamos os logs dos competidores disponíveis em (Sanner, 2011) e rodamos os algoritmos tomando os seguintes cuidados:

- Os algoritmos foram testados no mesmo ambiente da competição, ou seja, numa instância do Amazon Cloud EC2 com 7.5 GB de memória RAM.

- O tempo total máximo para resolver todos os domínios foi 24 horas para cada algoritmo com uma distribuição de tempo descrita na Seção 8.1.2.

Os algoritmos analisados nesta seção são: LRTDP, FactLRTDP, aFactRTDP_max, aFactRTDP_ave e os competidores. Para os algoritmos aproximados foram selecionados erros de aproximação que resultaram no melhor desempenho para cada domínio.

\subsubsection{Domínios Densos}

A Figura 8.5 mostra os desempenhos dos algoritmos nos domínios densos, Game of Life e SysAdmin, em termos da Recompensa Média (com desvio padrão) de 30 simulações com horizonte 40, calculada pelo sistema rddlsim.

Como era de esperar, o LRTDP enumerativo se mostrou muito pior nos dois domínios densos, quando comparada às 3 versões fatoradas propostas nesse trabalho. O LRTDP enumerativo conseguiu resolver as instâncias 7-10 do Game of Life e de 3-10 do SysAdmin. Nas instâncias 2-4 do Game of Life obteve piores resultados que o FactLRTDP e aFactRTDP_max. 
Quanto aos competidores, para o domínio do Game of Life, Prost obteve melhores resultados para a maioria dos problemas. O Glutton só consegue bons resultados até a instância 6 e nas últimas 4 instâncias não consegue se aproximar do Prost. Os algoritmos FactLRTDP e aFactRTDP_max conseguem resultados bem próximos do Glutton até a instância 3 e nas instâncias 7, 8 e 9 os algoritmos FactLRTDP, aFactRTDP_max e aFactRTDP_ave conseguem resultados parecidos com o Glutton. Comparando todos os algoritmos propostos, aFactRTDP_max obteve os melhores resultados.
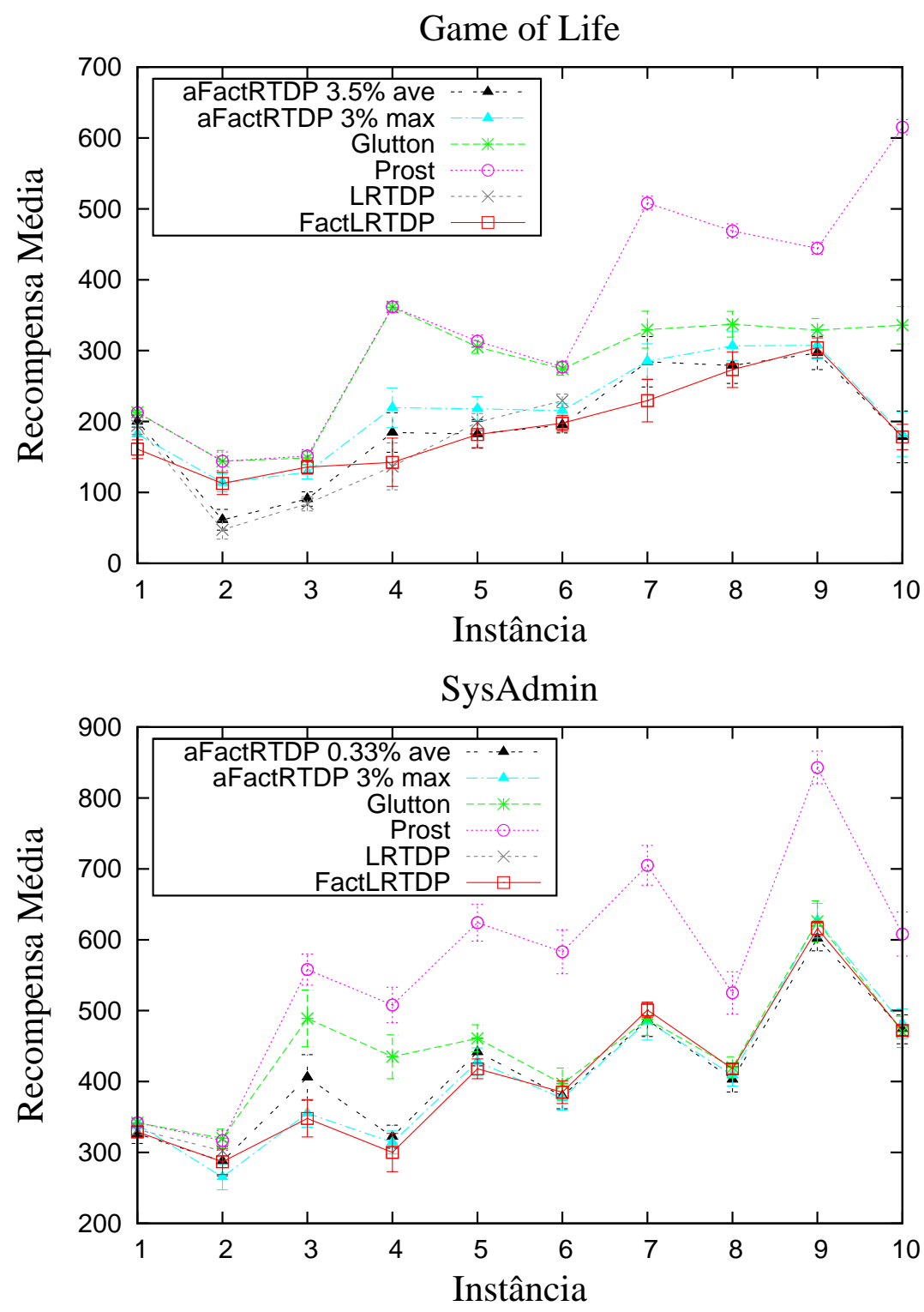

Figura 8.5: Desempenho dos algoritmos nos dominios densos da IPPC 2011.

No domínio SysAdmin o competidor Prost consegue os melhores resultados em todas as instâncias. Os algoritmos FactLRTDP, aFactRTDP_max e aFactRTDP_ave são bem parecidos entre si até a instância 4, e a partir da instância 5 estes algoritmos conseguem um desempenho tão bom quanto o competidor Glutton. Uma vez que as instâncias 5, 7, 8, 9 e 10 deste domínio 
tem transições com pouca dependência entre as variáveis (Seção 7.1.7), já era esperado que os algoritmos fatorados obtivessem um desempenho bastante superior ao LRTDP enumerativo para essas instâncias.

Em resumo, nos domínios densos, os algoritmos fatorados propostos mostraram um desempenho superior ao algoritmo LRTDP enumerativo, como era de se esperar. Além disso, os algoritmos fatorados mostraram um desempenho similar ao Glutton, o que é um resultado muito importante, uma vez que o sistema Glutton implementa uma serie de otimizações que não foram implementadas nos algoritmos propostos. Isso sugere que com essas melhorias, os algoritmos propostos podem superar o desempenho do Glutton.

\subsubsection{Domínios Esparsos}

Nos domínios esparsos (Figura 8.6 e 8.7), o LRTDP enumerativo conseguiu resolver todas as instâncias.

Ainda que esse resultado fosse o esperado, os algoritmos fatorados propostos obtiveram melhores resultados que o LRTDP enumerativo para as seguintes instâncias dos domínios esparsos:

- 5 e 7 do Crossing Traffic,

- 3, 8 e 9 do Elevators,

- 1, 3, 4 e 8 do Navigation,

- 7, 8 e 9 do Recon,

- 1, 2, 3 e 4 do Skill Teaching e

- 9 e 10 do Traffic.

Quanto aos competidores, no domínio Crossing Traffic, o Glutton foi o algoritmo com melhor desempenho. Os algoritmos aFactRTDP_max, aFactRTDP_ave e FactLRTDP conseguem um desempenho melhor ou igual ao Prost até a instância 4. O algoritmo aFactRTDP_ave consegue um desempenho parecido ao Prost na instância 5.

No caso do domínio Elevators os competidores são superiores em praticamente todas as instâncias, sendo que o FactLRTDP obtem um resultado similar somente nas instâncias 1 e 4 .

No domínio Navigation, o algoritmo com melhor desempenho foi o aFactRTDP_ave, e se mostrou melhor que os competidores (e que o LRTDP), nas instâncias 1-8. Os algoritmos LRTDP, FactLRTDP e aFactRTDP_max conseguiram um desempenho praticamente igual que o Glutton até a instância 7. Surprendentemente, para este domínio o algoritmo com pior desempenho foi o planejador Prost.

Para o domínio Recon, todos os algoritmos analisados tiveram desempenhos parecidos, pelo menos até a instância 7. Os competidores tiveram desempenhos inferiores que os algoritmos fatorados propostos nas instâncias 3, 5, 6 e 7 do domínio Recon. Nas três últimas instâncias o algoritmo FactLRTDP teve um desempenho bem parecido com o Prost, que foi o melhor nestas instâncias. Em geral, o algoritmo aFactRTDP_max conseguiu um bom desempenho, comparável aos competidores para o domínio Recon. 
Crossing Traffic

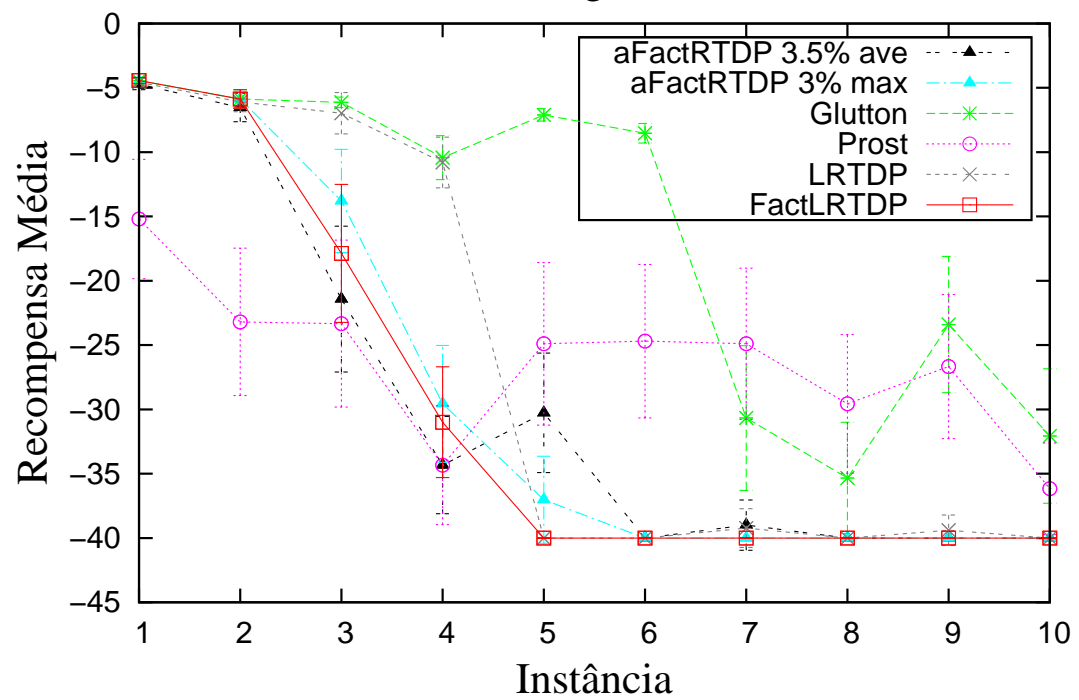

Elevators

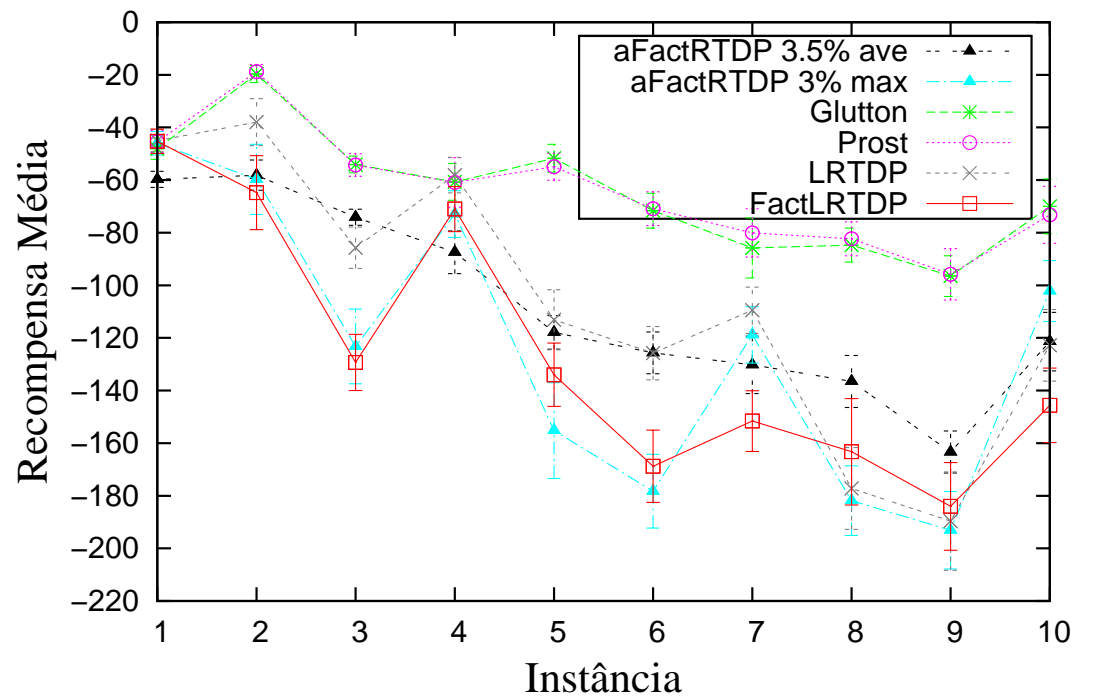

Navigation

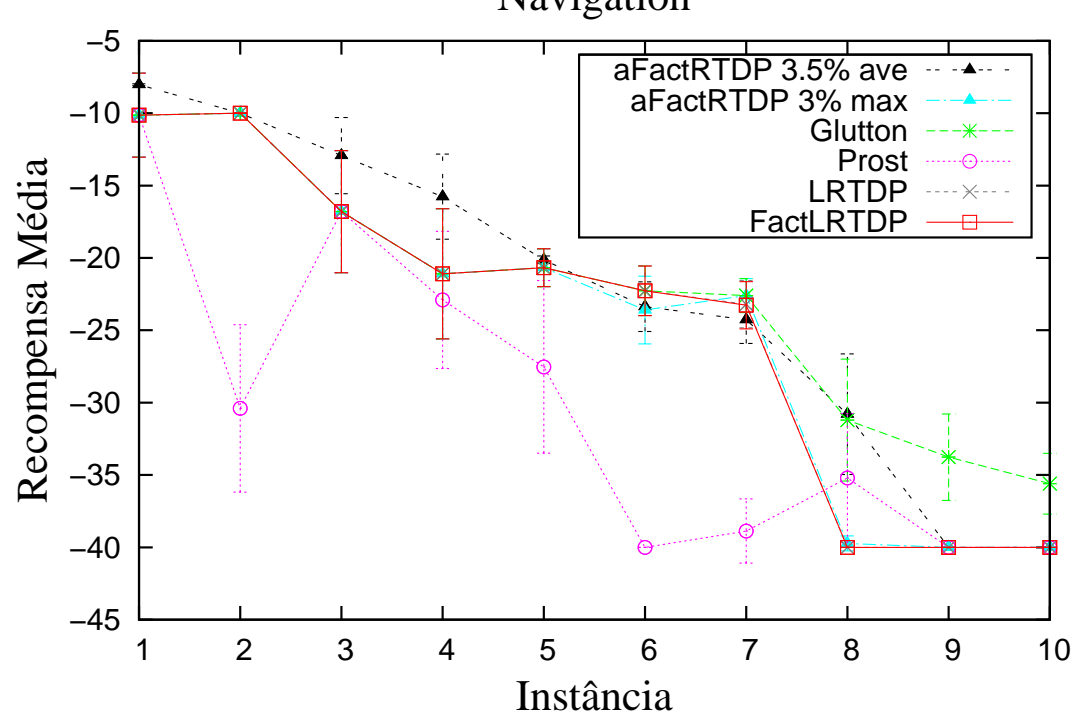

Figura 8.6: Desempenho dos algoritmos nos dominios esparsos (Crossing Traffic, Elevators $e$ Navigation) $d a I P P C 2011$. 
Recon

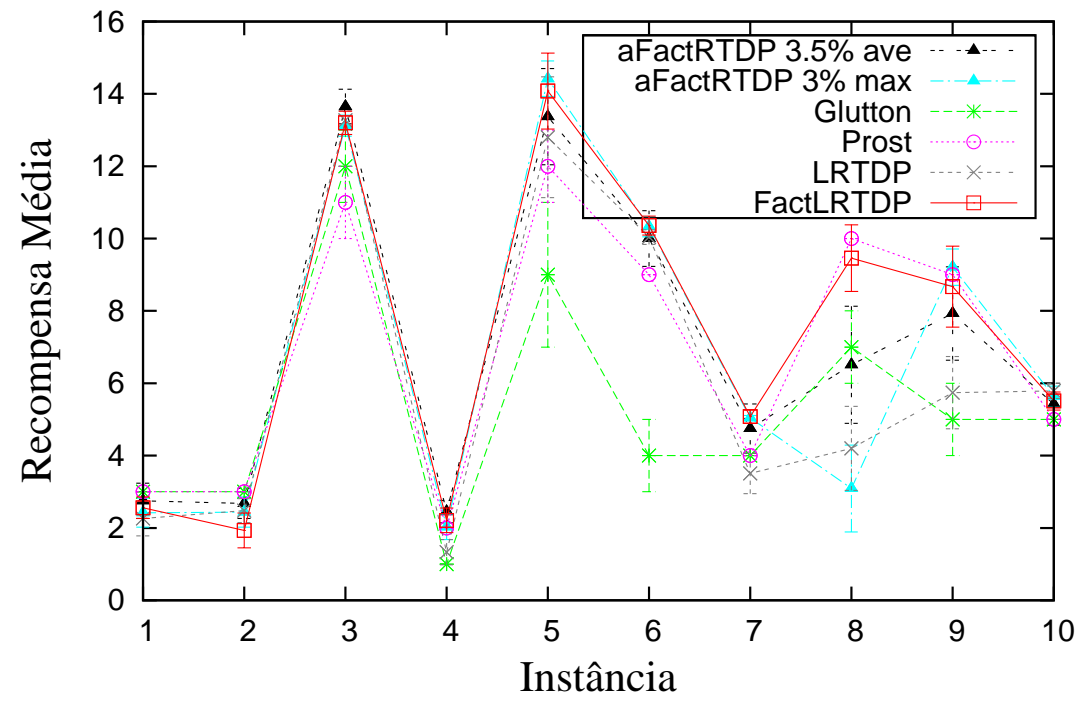

Skill Teaching

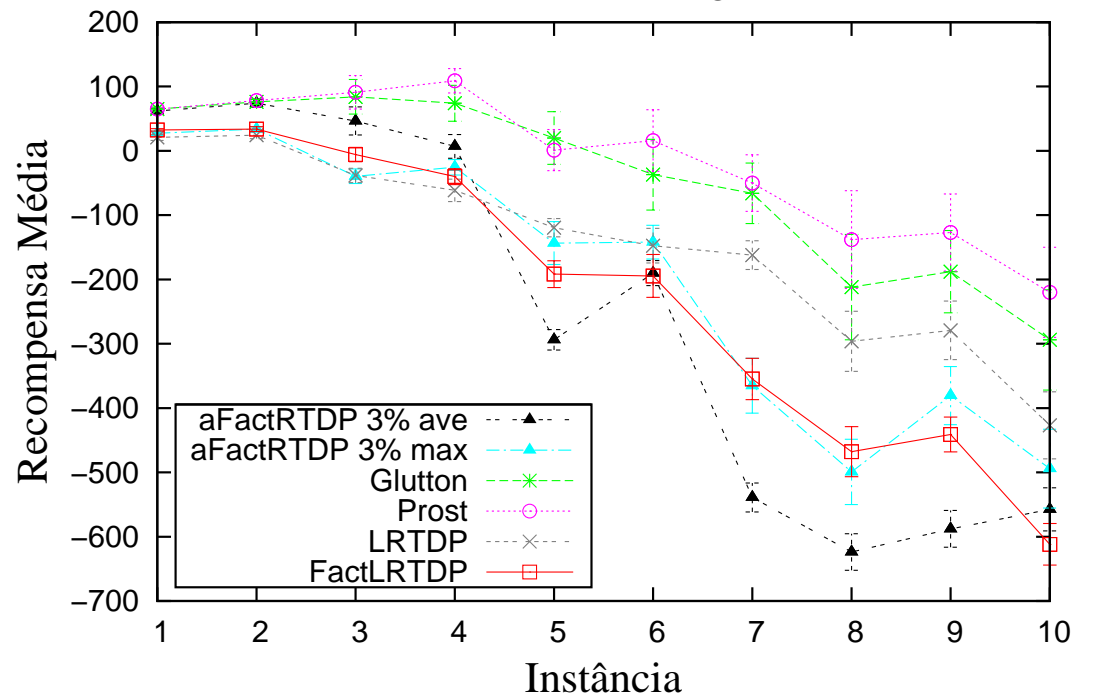

Traffic

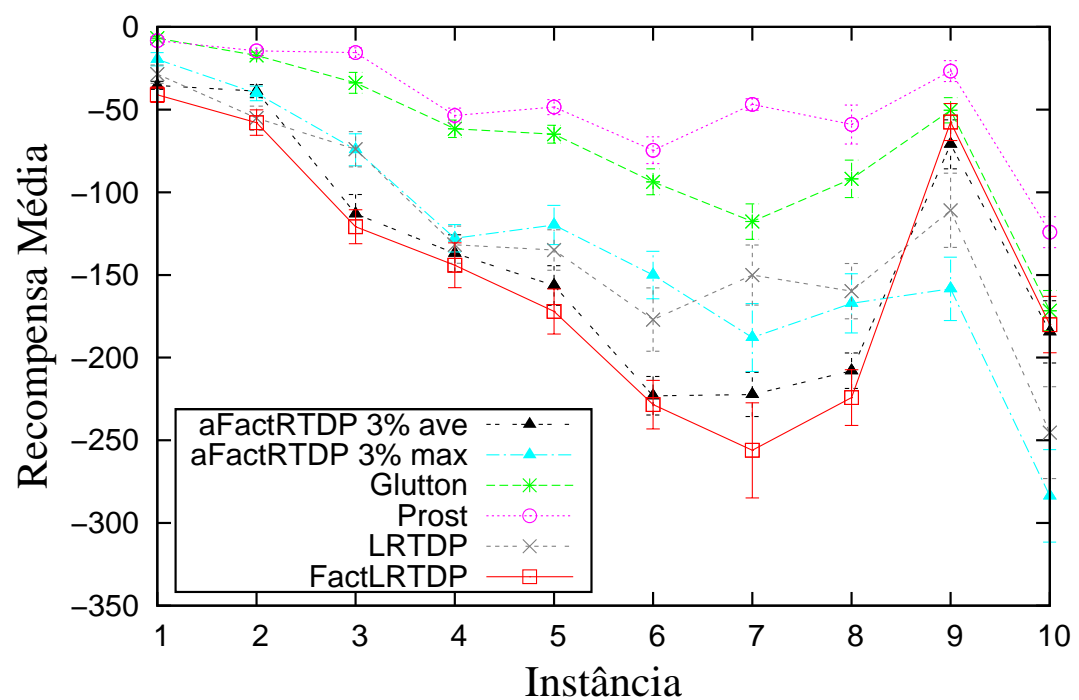

Figura 8.7: Desempenho dos algoritmos nos domínios esparsos (Recon, Skill Teaching $e$ Traffic) da IPPC 2011. 
No domínio Skill Teaching, os competidores foram superiores para todas as instâncias, sendo que nossos algoritmos tiveram um desempenho similar para as instâncias 1, 2 e 3.

No domínio Traffic, os competidores também foram superiores. Nas instâncias 9 e 10 os algoritmos aFactRTDP_ave e FactLRTDP conseguiram bons resultados, comparáveis com os resultados do Glutton.

Em geral, os competidores ganhadores da competição IPPC 2011 (Prost e Glutton), conseguiram os melhores resultados, mas os algoritmos desenvolvidos neste trabalho conseguiram resultados similares (ou superiores) para as seguintes instâncias dos domínios esparsos:

- 5 e 7 do Crossing Traffic,

- 3, 8 e 9 do Elevators,

- 1, 3, 4 e 8 do Navigation,

- 7,8 e 9 do Recon,

- 1, 2, 3 e 4 do Skill Teaching e

- 9 e 10 do Traffic.

Considerando que os competidores implementaram otimizações (Seção 8.1.3) que não foram implementadas nos algoritmos fatorados propostos, esses resultados foram bastante satisfatórios e promissores.

É importante observar que o algoritmo sRTDP não foi mostrado nos gráficos de desempenho online das Figuras 8.6 e 8.7, uma vez que ele só conseguiu resolver as instâncias 1 e 2 do domínio Elevators; 1 do Navigation; 1 e 2 do Skill Teaching. Esse mau desempenho do sRTDP em experimentos online é porque suas atualizações de estados abstratos são muito custosas.

Em suma, a análise de desempenho online para domínios esparsos mostrou que, apesar de ser esperado um melhor desempenho do LRTDP enumerativo em comparação com os algoritmos fatorados propostos, em cerca da metade das instâncias resolvidas, pelo menos uma das versões fatoradas teve desempenho igual o maior que o LRTDP enumerativo. Além disso, em 29 das 60 instâncias, os algoritmos propostos obtiveram desempenho igual o maior que o Glutton, segundo lugar da IPPC-2011. 


\section{Conclusões e Trabalhos Futuros}

O algoritmo clássico para resolver MDPs, LRTDP enumerativo, considerado o estado-dearte do planejamento probabilístico, apresenta melhor desempenho em problemas com matrizes esparsas de transição de estados porque pode alcançar eficientemente a convergência para a política ótima, sem ter que visitar todos os estados. Porém essa vantagem pode ser perdida em problemas com matrizes densas de transição, nos quais muitos estados podem ser alcançados em um passo. Uma abordagem para superar essa limitação é explorar regularidades existentes na dinâmica do domínio através de uma representação fatorada, isto é, uma representação baseada em variáveis de estado.

Nesse trabalho, foram propostos 4 algoritmos originais de planejamento probalilístico assíncrono e fatorado: dois algoritmos exatos, FactRTDP e FactLRTDP; e dois algoritmos aproximados, aFactRTDP e aFactLRTDP. Sendo FactLRTDP a primeira versão fatorada do algoritmo LRTDP enumerativo, (usado pelo planejador Glutton, segundo lugar no IPPC 2011).

Uma das principais contribuições desse trabalho é mostrar como realizar operações entre diagramas de decisão (BDDs e ADDs), para desenvolver algoritmos fatorados eficientes para MDPs. O procedimento de teste de convergência CHECKSolved, do LRTDP, foi modificado para usar operações entre BDDs e ADDs, representando de forma compacta o grafo guloso.

Os resultados experimentais sobre a convergência dos algoritmos propostos, confirmam a conjectura de que os algoritmos fatorados assíncronos apresentam um melhor desempenho em domínios densos quando comparados com uma implementação eficiente do LRTDP enumerativo. As soluções fatoradas assíncronas são mais eficientes que uma solução assíncrona enumerativa eficiente (LRTDP enumerativo).

Na análise de desempenho online dos domínios densos, os algoritmos fatorados propostos também mostraram um desempenho superior ao algoritmo LRTDP enumerativo, como era de se esperar. Além disso, os algoritmos fatorados mostraram um desempenho similar ao Glutton, o que é um resultado muito importante, uma vez que o sistema Glutton implementa uma serie de otimizações que não foram implementadas nos novos algoritmos fatorados. Isso sugere que com essas melhorias, os algoritmos propostos podem superar o desempenho do Glutton.

A análise de desempenho online para domínios esparsos mostrou que, apesar de ser esperado um melhor desempenho do LRTDP enumerativo, para esses domínios, em comparação com os algoritmos fatorados propostos, em cerca da metade das instâncias resolvidas, pelo menos uma das versões fatoradas teve desempenho igual o maior que o LRTDP enumerativo.

A análise experimental online realizada nos 6 domínios esparsos do IPPC 2011 mostrou que, em geral, o algoritmo aFactRTDP_ave o melhor desempenho dentre todos os algoritmos 
fatorados propostos.

Os experimentos mostraram que os algoritmos propostos tiveram um desempenho igual ou melhor aos vencedores da competição IPPC-2011 em 30 de 80 instâncias dos domínios da competição.

Também foi feita uma análise detalhada de complexidade dos domínios da competição em termos da densidade da função de transição de estados e da dependência entre variáveis de estado na determinação do próximos estado para cada ação, análise não encontrada na literatura.

\section{Contribuições}

As principais contribuições desse trabalho de mestrado são:

- Soluções eficientes assíncronas fatoradas para MDPs. Foram propostos 4 algoritmos programação assíncrona e fatorada: dois algoritmos exatos FactRTDP e FactLRTDP; e dois algoritmos aproximados aFactRTDP e aFactLRTDP. Esses dois algoritmos se mostraram eficientes para domínios densos.

- Versão fatorada do algoritmo considerado o estado-de-arte do planejamento probabilístico, LRTDP, em que o procedimento de teste de convergência CHECKSolved foi modificado para usar operações entre ADDs, representando de forma compacta o grafo guloso.

- Implementação dos algoritmos propostos na plataforma rddlsim usada na competição de planejamento IPPC-2011.

- Análise detalhada de complexidade dos domínios da competição em termos da densidade da função de transição de estados e da dependência entre variáveis de estado na determinação do próximo estado para cada ação.

- Análise comparativa entre os algoritmos assíncronos fatorados propostos, o LRTDP enumerativo e os dois vencedores da competição IPPC-2011. Os resultados experimentais confirmam a conjectura de que os algoritmos fatorados assíncronos apresentam um melhor desempenho de convergência em domínios densos e melhor desempenho online em domínios com pouca dependência entre as variáveis nas transições de estados, comparado com LRTDP enumerativo.

\section{Trabalhos Futuros}

Como trabalhos futuros propomos as seguintes melhorias dos algoritmos fatorados:

- Cálculo mais eficiente das atualizações do FactRTDP e suas extensões. Uma das possíveis melhorias que pode ser realizada nos algoritmos assíncronos fatorados propostos, é fazer a atualização de Bellman de modo mais eficiente. Uma idéia para isso é usar a função $V_{D D}\left(\vec{x}^{\prime}\right)$ no cálculo da Equação 5.1 (Capítulo 5) restrita aos estados sucessores de $\vec{x}$. Espera-se com isso que cada atualização de um trial seja realizado em menor tempo. 
- No aFactLRTDP, não aproximar folhas já convergidas. A oscilação durante a convergência da função $V\left(s_{0}\right)$ para o algoritmo aproximado aFactLRTDP nos problemas do Game of Life, sugere que os estados marcados como resolvidos pelo algoritmo FACTCHECKSOLVED não devem ser aproximados.

- Implementar os algoritmos orientados para um horizonte finito. Assim como o Glutton usa o algoritmo LR ${ }^{2} \mathrm{TDP}$ para horizonte finito, armazenando a função valor para cada horizonte, podemos implementar uma versão de horizonte finito para o FactLRTDP.

- Modificar o sRTDP para trabalhar somente com estados válidos. Devido à inicialização da função valor por uma constante (limite superior) para todos os estados, o sRTDP faz atualizações de estados não válidos mas que possuem valores similares ao estado atual. Essa é a explicação para o seu mau desempenho em termos de convergência no domínio Navigation. Se $V^{0}(s)$ for definida somente para os estados válidos, o sRTDP poderá resolver problemas desse domínio.

- Implementar as técnicas de otimização do Glutton e do Prost. Por exemplo, a técnica de (subsampling e de análise das variáveis de estado para o sorteio do próximo estado, como descritas na Seção 8.1.3.

- Análise experimental com novos domínio densos. Através da análise de complexidade dos domínios da competição verificamos que apenas dois dos 8 domínios podem ser considerados densos. Assim, como principal vantagem dos algoritmos propostos é um bom desempenho em domínios densos é preciso descrever novos domínios com essas características para uma análise mais ampla. 


\section{Apêndice A}

\section{Exemplo do funcionamento do algoritmo APLICA}

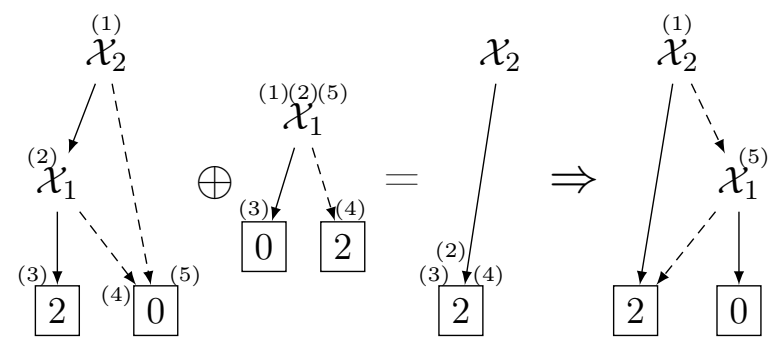

Figura A.1: Um exemplo de funcionamento do algoritmo APLICA para a operação soma $\oplus$. Os índices (i) no diagrama correspondem a chamadas sucessivas (recursivas) ao algoritmo APLICA: para os ADDs somados, os índices denotam qual nó de cada ADD é passado como um parâmetro à chamada de APLICA (op é sempre $\oplus$ ); para o resultado os índices indicam o nó que é devolvido pela chamada de APLICA (Sanner, 2008).

No exemplo da Figura A.1, é apresentado a ordem das chamadas recursivas feitas pelo algoritmo Aplica para a soma de dois ADDs. A chamada inicial tem como parâmetros o nó $\mathcal{X}_{2}$ (marcado com (1) no primeiro ADD) que representa $F_{1}$, o nó $\mathcal{X}_{1}$ (marcado como (1) no segundo ADD) que representa $F_{2}$ e a operação $o p=\oplus$ (a mesma em todas as chamadas recursivas). Como os dois nós são não terminais, então verifica-se qual das duas variáveis está antes na ordem definida das variáveis (Linha 10). Supondo que a ordem é: $\mathcal{X}_{2}, \mathcal{X}_{1}, F_{1}^{v a r}$ está antes de $F_{2}^{v a r}$, então var $\leftarrow F_{1}^{v a r}$ (Linha 11), isso significa que a recursão será feita com os filhos da variável $F_{1}^{v a r}$ e a variável $F_{2}^{v a r}$. Nas linhas 25-36, configura-se os nós para a recursão, na Linha 26 se atribui os filhos de $F_{1}^{v a r}$ para as variáveis $F_{l}^{v_{1}}$ e $F_{h}^{v_{1}}$ e na Linha 35 se atribui a variável $F_{2}^{v a r}$ para as variáveis $F_{l}^{v_{2}}$ e $F_{h}^{v_{2}}$. Na Linha 38 se faz a primeira recursão que tem como parâmetros o nó $\mathcal{X}_{1}$ (marcado com (2) no primeiro ADD) que representa $F_{1}$ e o nó $\mathcal{X}_{1}$ (marcado como (2) no segundo ADD) que representa $F_{2}$.

Na segunda recursão $F_{1}$ e $F_{2}$ são nós não terminais e $F_{1}^{v a r}=F_{2}^{v a r}$, então as variáveis $F_{l}^{v_{1}}$ e $F_{h}^{v_{1}}$ recebem os valores dos filhos de $F_{1}$ e as variáveis $F_{l}^{v_{2}}$ e $F_{h}^{v_{2}}$ recebem os valores dos filhos de $F_{2}$. A próxima recursão tem como parâmetros o nó terminal com valor 2 (marcado com (3) no primeiro ADD) que representa $F_{1}$ e o nó terminal com valor 0 (marcado com (3) no segundo ADD) que representa $F_{2}$. Para esta recursão se pode calcular um resultado imediato para a soma dos valores dos nós terminais, portanto é devolvido um nó com valor $0+2=2$ na Linha 3 , este nó resultante é o nó marcado com (3) do terceiro ADD. O controle retorna para a recursão das 
variáveis marcadas com (2) e faz a próxima recursão (Linha 39) que tem como parâmetros o nó terminal com valor 0 (marcado com (4) no primeiro ADD) que representa $F_{1}$ e o nó terminal com valor 2 (marcado com (4) no segundo ADD) que representa $F_{2}$. Esta recursão também pode ser calculada de forma imediata e devolve um nó terminal com valor 2 que é o mesmo da recursão dos nós marcados com (3), por isso, o nó resultante marcado (4) do terceiro ADD também está marcado com (3).

Depois das duas recursões o controle retorna para a recursão das variáveis marcadas com (2). Neste ponto do algoritmo, as variáveis $F_{l}$ e $F_{h}$ são iguais e as duas tem o valor de um nó terminal com valor 2. Em seguida, na Linha 41, é calculado o novo nó que será devolvido para esta recursão e para isto se faz uma chamada ao algoritmo OBTERNo com parâmetros var $=\mathcal{X}_{1}$, $F_{l}$ e $F_{h}$. Como $F_{l}$ e $F_{h}$ são iguais o resultado é o nó terminal com valor 2 . Este é o mesmo que foi devolvido nas recursões (3) e (4). Depois da recursão (4), o controle do algoritmo retorna para a recursão (1) e a próxima linha ser executada é a Linha 39, em que os parâmetros são: o nó terminal com valor 0 (marcado com (5) no primeiro ADD) que representa $F_{1}$ e o nó $\mathcal{X}_{1}$ (marcado com (5) no segundo ADD) que representa $F_{2}$. Esta recursão também pode ser calculada de forma imediata porque temos a operação $0 \oplus F_{2}$ que resulta em $F_{2}$. O nó resultante é o nó marcado com (5) no último ADD. Note que os caches dos algoritmos não permitem que existam vários nós terminais com o mesmo valor, é por isso que o nó marcado com (5) do último ADD tem como filho o nó terminal com valor 2, que é o mesmo que está marcado com (2), (3) e (4) do terceiro ADD.

O controle novamente retorna para a recursão (1). As variáveis $F_{l}$ e $F_{h}$ são: o nó marcados com (2) do terceiro ADD e o nó marcado com (5) do último ADD. Finalmente, a Linha 41 calcula o nó resultante da operação dos dois ADDs através do algoritmo OBTERNo. Este algoritmo constrói o nó marcado com (1) no último ADD. 


\section{Apêndice B}

\section{Cálculo fatorado das porcentagens de densidade e de- pendência}

É possível calcular esta porcentagem usando operações de ADDs e BDDs. Para isto, devemos obter a probabilidade conjunta de todo o espaço de estados. Como estamos interessados somente na quantidade de estados e não nas probabilidades, devemos converter os ADDs representando as transições em BDDs. Esta mesma operação é feita no cálculo de estados sucessores no Algoritmo FactLRTDP (Seção 5.2). Essa operação de cálculo de sucessores já é feita para um estado. Então, podemos fazer com que essa operação calcule os sucessores para um conjunto de estados restringindo os ADDs para um conjunto e não somente para um estado.

Uma vez calculado o BDD representando a transição de estados para todo o espaço de estados, devemos contar quantos caminhos (ou quantas combinações de valores das variáveis de estado) do BDD tem valor 1. Se convertemos o BDD numa expressão booleana, o problema sería calcular quantas valorações das variáveis da expressão são satisfatíveis, ou seja, é um problema NP-completo.

Está é a razão pela qual o cálculo de forma exata essa porcentagem é muito difícil. Na prática, esse cálculo só pode ser feito de forma exata para domínio densos ou para instâncias de domínios esparsos com menos que 18 variáveis. como nos domínios densos os BDDs que representam as transições de estados são extremamente compactos para qualquer quantidade de variáveis, fazer o cálculo da transição conjunta resulta num BDD bem compacto. No caso dos domínios esparsos, os BDDs de transição são bem complexos e fazer o cálculo da transição conjunta é bem custoso em termos de tempo e espaço.

Uma forma de aproximar a porcentagem é fazer este cálculo para um subconjunto de estados. Para isto, consideramos um conjunto $V$ de estados visitados e escolhemos um estado $s$ qualquer (geralmente o estado inicial, definido na instância). Inserimos $s$ em $V$ e calculamos o conjunto de estados alcançáveis $C$ num passo seguinte a ação da qual estamos calculando a densidade. Em seguida, pegamos o conjunto $C$ e retiramos dele todos os estados visitados $D=C-V$. Depois, fazemos a união $V=V \cup D$ e calculamos o conjunto de estados alcançáveis $E$ de cada um dos estados do conjunto $D$. Fazemos as operações $F=E-V$ e $V=V \cup F$ e calculamos os sucessores dos estados do conjunto $F$. Este algoritmo pode ser repetido até que o conjunto $V$ não varie ou até esgotar a memória. Em cada iteração, podemos calcular a média de estados alcançáveis num passo para os estados já visitados. Este algoritmo não devolve a densidade exata das instâncias, 
mas pode-se obter uma boa aproximação da densidade verdadeira.

As instâncias que podem ser calculadas de forma exacta são: todas do domínio SysAdmin, todas do domínio Game of life, instância 1 do domínio Elevators, instâncias 1 e 2 do domínio Navigation e instâncias 1 e 2 do domínio Skill teaching. Os domínios SysAdmin e Game of life são os únicos domínios densos do IPPC-2011, como descrito nas Seções 7.1.7 e 7.1.3 respectivamente. As outras instâncias resolvidas de forma exacta têm menos de 15 variáveis.

O cálculo da porcentagem das dependências pode ser feito de maneira exata para as 80 instâncias do IPPC-2011. Isto porque, a contagem dos pais de cada variável é feita contando as variáveis envolvidas em cada ADD que representa uma função de transição e não precisa fazer nenhuma operação entre ADDs. 


\section{Apêndice C}

\section{Sistema rddlsim}

O sistema rddlsim implementa, principalmente, o ambiente da competição. Ele também oferece um tradutor da linguagem RDDL para a linguagem PPDDL (Seção 6.1.2) e também para a linguagem do SPUDD (Seção 4.1.1). O tradutor recebe arquivos RDDL de entrada, converte esses arquivos em DBNs e ADDs. A partir dos ADDs pode ser feita a tradução para PPDDL. A representação dos ADDs é feita através de um conjunto de objetos implementados no pacote dd. O sistema também oferece uma representação gráfica dos ADDs e DBNs através de geração de arquivos dot que podem ser transformados em imagens com o GraphViz. A Figura C.1 mostra um exemplo rede bayesiana dinâmica gerada e a Figura C.2 mostra um exemplo de um ADD gerados pelo rddlsim.

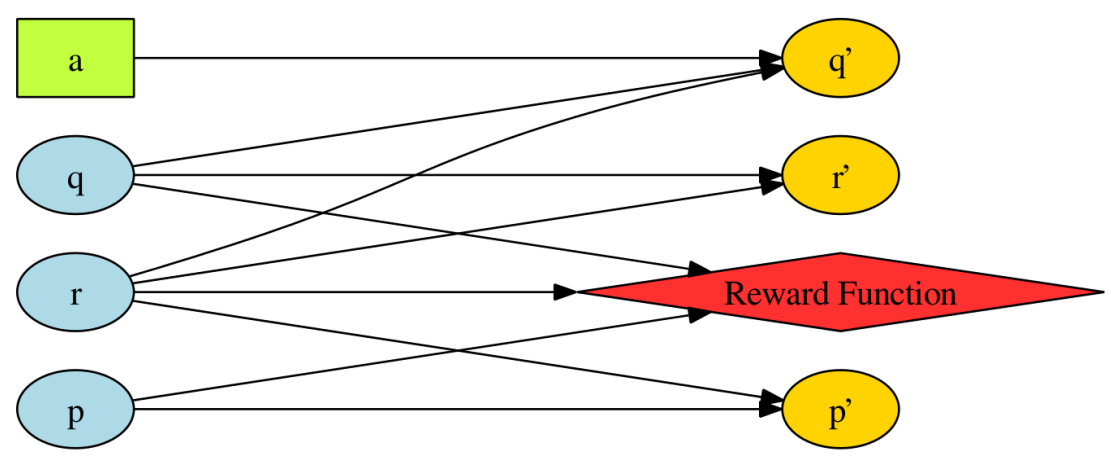

Figura C.1: Diagrama de Influência Gerado pelo simulador.

O ambiente de competição está programado na arquitetura cliente-servidor. Um cliente envia o planejador com o nome de uma instância e o servidor executa 30 simulações (chamadas de rounds), sendo que cada round começa no estado inicial da instância. O servidor passa ao planejador o estado e o planejador devolve uma ação, a partir da qual o servidor sorteia, segundo a função de transição probabilística, o próximo estado para enviar novamente ao planejador. Um round tem profundidade $h$ (horizonte da instância). Em cada próximo estado o servidor também calcula a recompensa ganha pelo planejador.

Ao final de um round é calculada a recompensa acumulada total, bem como o tempo total que o planejador usou para resolver esse round. Estas informações são armazenadas no arquivo . log do competidor. Neste mesmo arquivo é armazenada a informação de todas as sessões feitas pelo competidor. 


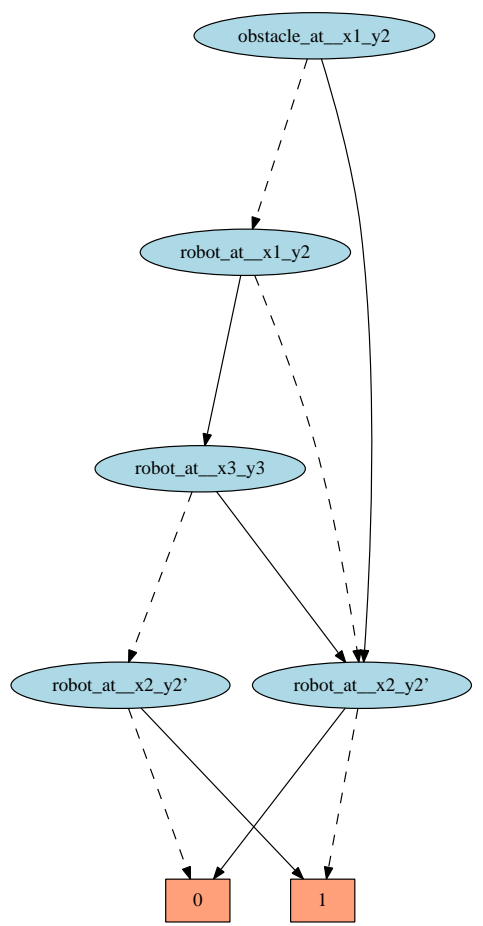

Figura C.2: Diagrama de Decisão Algébrico Gerado pelo simulador.

Para comparar os resultados de todos os competidores é preciso juntar seus arquivos . log e executar o pacote evaluate que gera um arquivo em formato . csv pronto para fazer gráficos estatísticos de comparação do desempenho dos competidores. Outros pacotes úteis na implementação do sistema são:

- dd: Este pacote contém uma biblioteca de diagramas de decisão (ADDs). A classe ADDNode representa a forma básica de um nó do ADD. A classe ADD INode estende a classe ADDNode para representar um nó interno, e adicionar dois filhos. A classe ADDDNode representa um nó folha, e adiciona um valor real. Como um ADD é uma generalização dos BDDs, com estas classes também pode ser representado um BDD, para o qual se implementa a classe ADDBNode que representa um nó folha com valor booleano.

- graph: Neste pacote se implementa um gerador de arquivos dot para a representação visual dos diagramas de decisão (ADDs) e redes bayesianas dinâmicas (DBNs). A classe Graph constrói um texto a partir da representação dos ADDs do pacote dd.

- utils: Neste pacote são implementadas algumas classes úteis usadas pelo sistema. A classe mais importante é CString, que otimiza em até 7 vezes a comparação da igualdade de strings, comparando somente seus valores hashcode.

Implementação do sistema da competição: pacote rddl Este é o pacote mais importante do sistema. Neste pacote se tem: (i) a implementação do sistema da competição em arquitetura cliente/servidor; (ii) o tradutor; (iii) alguns algoritmos de planejamento probabilístico e os critérios de comparação dos resultados dos competidores. O pacote rddl é composto pelos seguintes 
sub-pacotes:

- parser: contém um analisador sintático da linguagem RDDL.

- translate: contém a implementação do tradutor da linguagem RDDL para SPUDD ou PPDDL.

- policy: é a classe que representa de forma geral qualquer algoritmo de planejamento. Esta classe tem três funções importantes:

- roundInit: nesta função o planejador inicializa todas as suas variáveis para executar um round;

- getAction: esta função recebe um estado e devolve a ação calculada pela política; e

- roundEnd: finaliza o round e mostra a recompensa total recebida pela política.

Os competidores devem implementar seus algoritmos estendendo a classe Policy. Por exemplo, foram implementados alguns algoritmos de planejamento com políticas gerais, entre eles:

- Randompolicy: sorteia uma ação aleatória para todos os estados.

- NoopPolicy: devolve a ação noop para todos os estados.

- FixedBoolPolicy: devolve a primeira ação da lista de ações aplicáveis de cada estado.

- sim: Este pacote contém a classe Simulator que implementa a simulação de um round. Para cada domínio é disponibilizado um simulador do ambiente específico. Por exemplo, as Figuras 7.2 e 7.1 mostram os simuladores para os domínios Navigation (Seção 7.1.4) e Crossing Traffic (Seção 7.1.1).

- competition: Neste pacote estão as classes Client e Server. A classe Server implementa o servidor da competição. Esta classe recebe os algoritmos dos competidores e executa 30 simulações, calculando em cada uma a recompensa obtida pelo competidor e o tempo gasto na simulação.

A classe cliente implementa a interface de conexão com o servidor, e permite ao competidor enviar o seu planejador e a instância que vai resolver.

- evaluate: Este pacote implementa os critérios de avaliação dos resultados dos competidores, em que se calcula a média dos tempos e recompensas acumuladas nas 30 simulações de cada problema.

- solver: Algumas soluções de planejamento probabilístico estão implementadas neste pacote. Os algoritmos implementados são sRTDP, BRTDP Fatorado e o SPUDD, sendo que os algoritmos sRTDP e BRTDP foram implementados como produto desse mestrado, e disponibilizados para a comunidade de planejamento. 

APÊNDICE C 


\section{Apêndice D}

\section{Descrição em RDDL dos domínios do IPPC}

\section{D.1 Descrição do domínio Crossing Traffic}

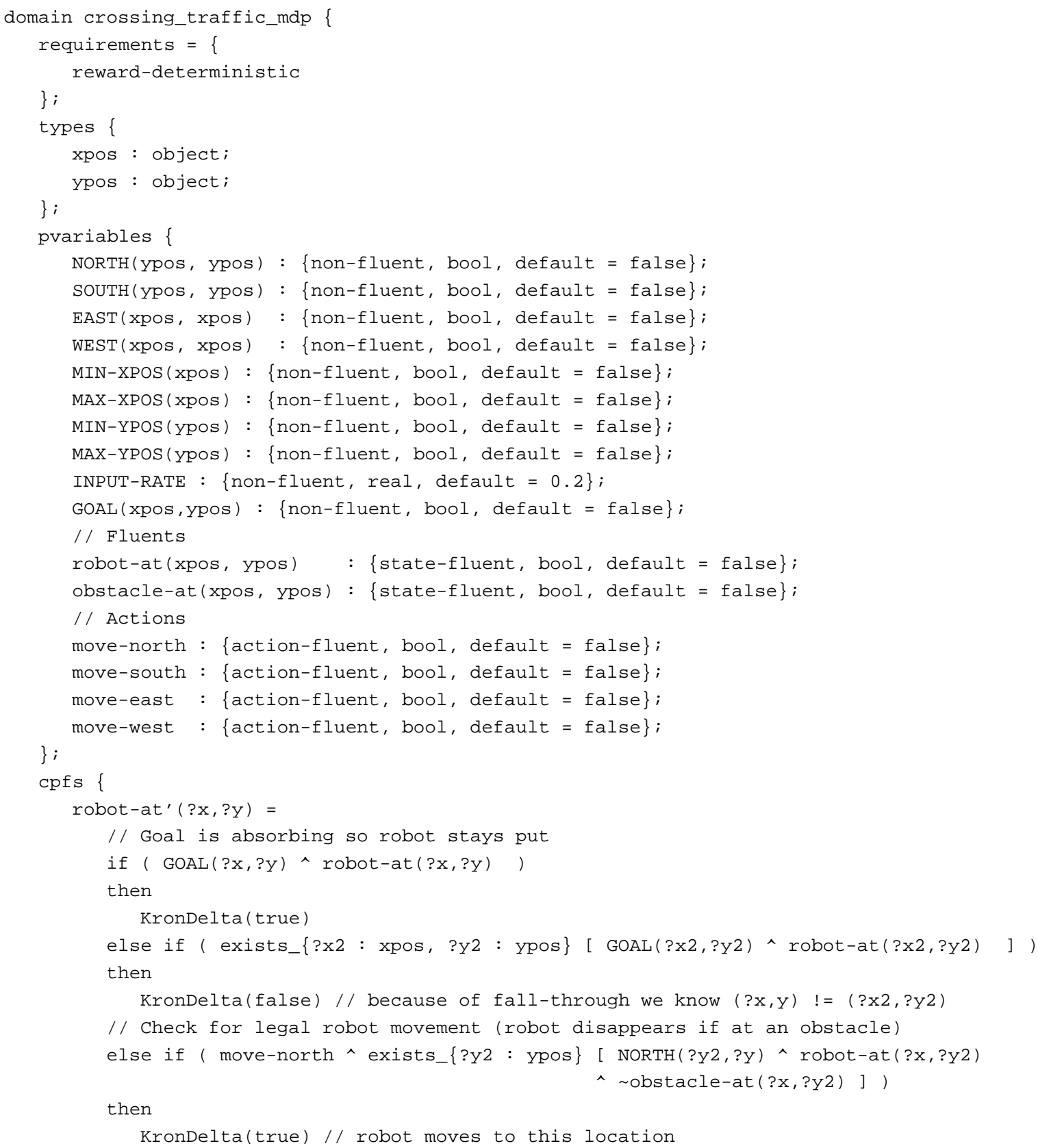




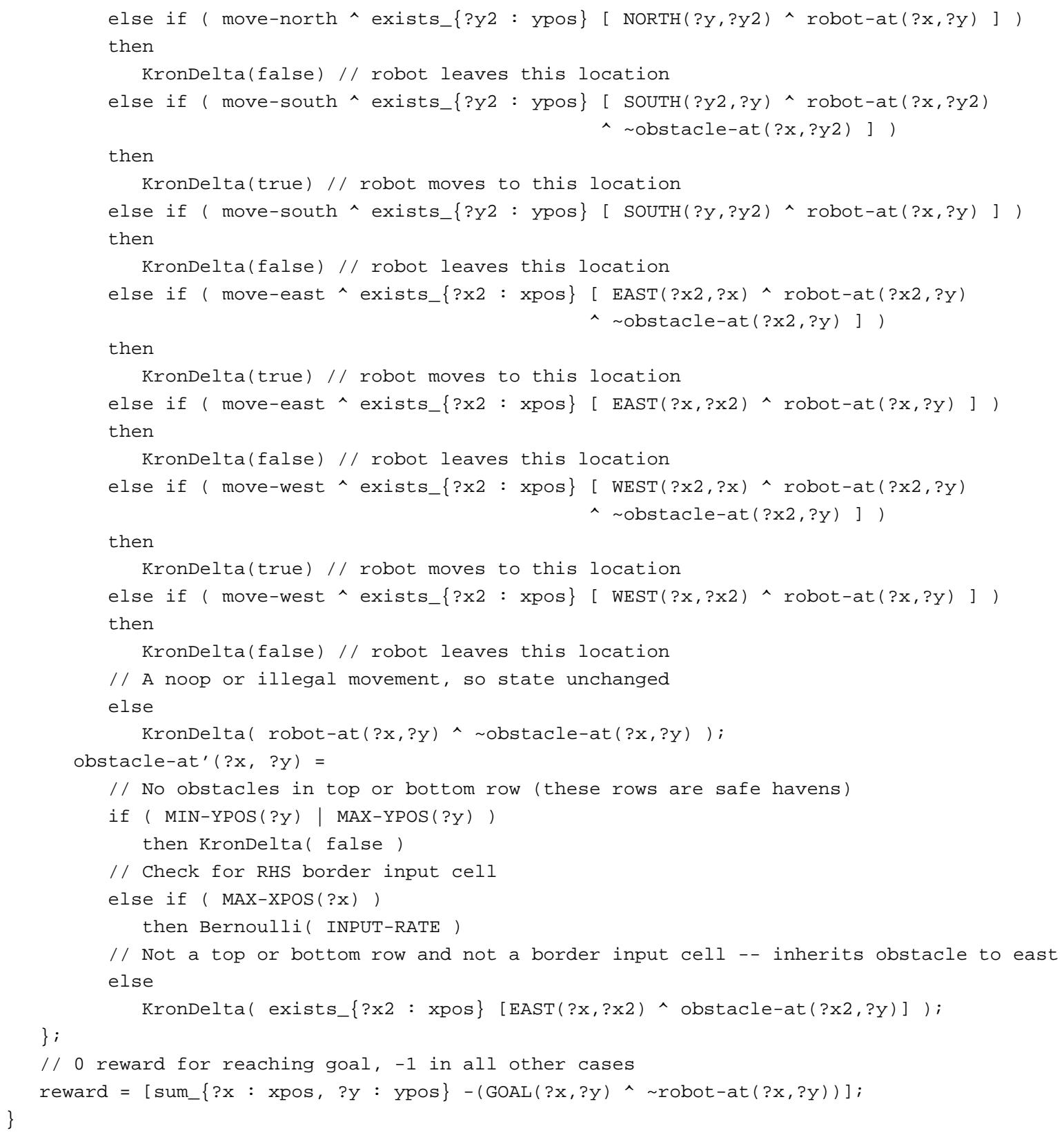

\section{D.2 Descrição do domínio Elevators}

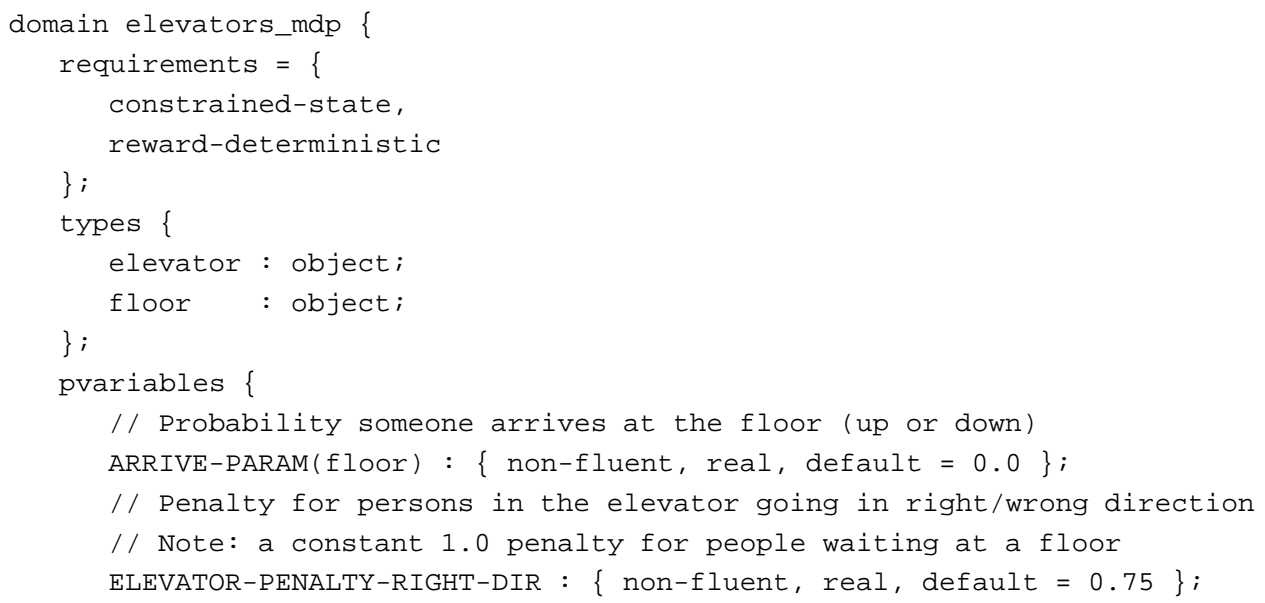




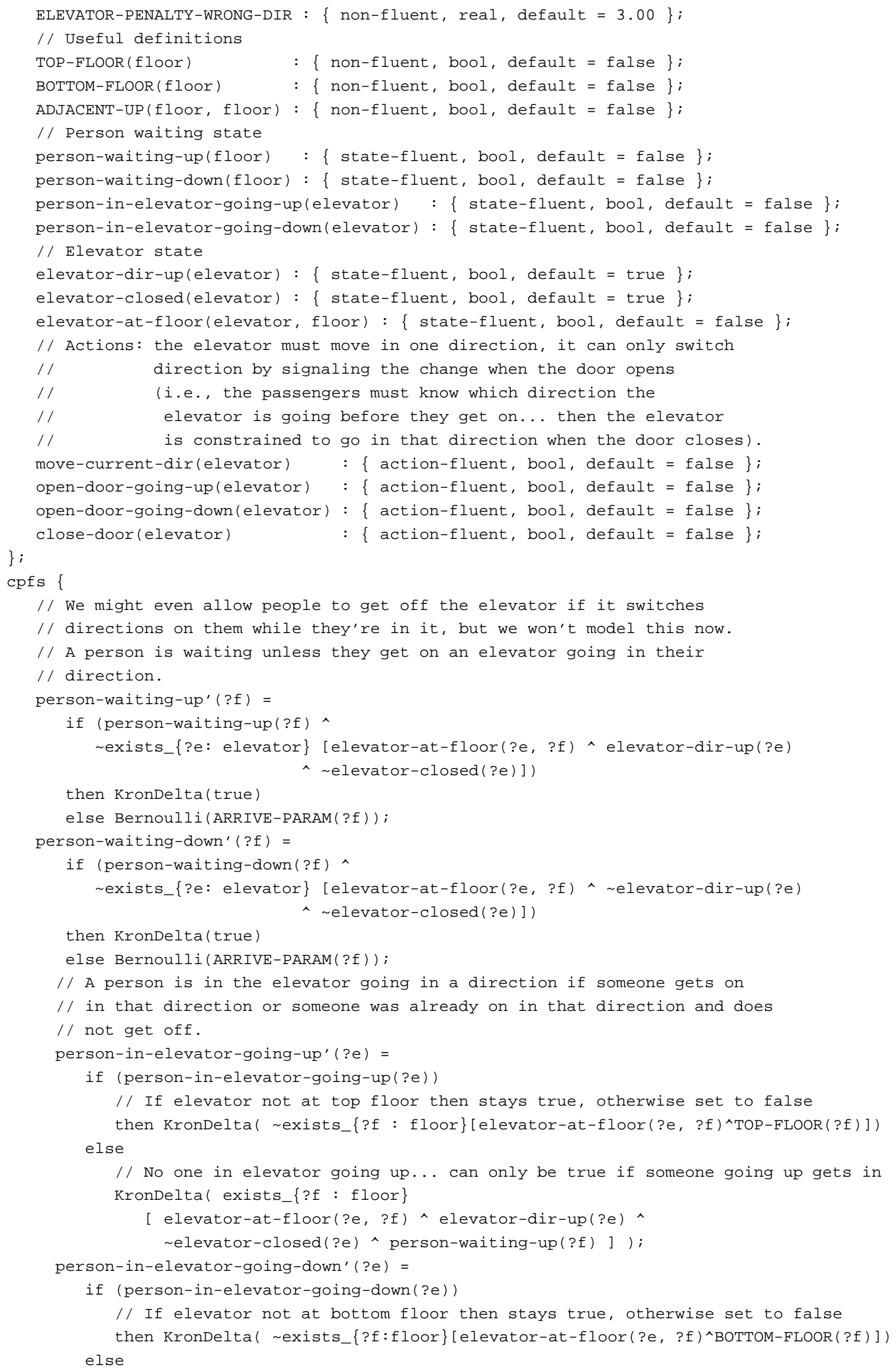


// No one in elevator going up... can only be true if someone going up gets in KronDelta( exists_\{?f : floor\}

[ elevator-at-floor(?e, ?f) ^ elevator-dir-up(?e) relevator-closed(?e) ^ person-waiting-down(?f) ] ) ;

// Elevator needs to be explicitly closed

elevator-closed' (?e) =

KronDelta ( [elevator-closed (?e)^ open-door-going-up (?e)^ open-door-going-down (?e) ]

| close-door(?e));

// Elevator's destination is set when door is opened (to signal

// to people which direction the elevator is going)

elevator-dir-up' (?e) =

if (open-door-going-up (?e))

then KronDelta (true)

else if (open-door-going-down(?e))

then KronDelta (false)

else

// If not explicitly set then previous direction persists

KronDelta( elevator-dir-up(?e) );

// Elevator movement

/ /

// Note: if the elevator should pause at a floor, it can simply open

// do noops (all actions false).

elevator-at-floor' (?e, ?f) =

////////////////////////////////////////////////////////

// Elevator does not move if door is open or elevator does not move

////////////////////////////////////////////////////////

if ( elevator-closed(?e) | move-current-dir(?e))

then KronDelta( elevator-at-floor(?e, ?f) )

/////////////////////////////////////////////////////

// These handle the floor that is moved to

////////////////////////////////////////////////////////

else if (move-current-dir(?e) ^ elevator-dir-up(?e) $\wedge$ exists_\{?cur : floor\}

[elevator-at-floor(?e, ?cur) ^ADJACENT-UP(?cur, ?f)])

then KronDelta (true)

else if (move-current-dir(?e) ^ elevator-dir-up(?e) ^ exists_\{?cur : floor\}

[elevator-at-floor(?e, ?cur) ^ ADJACENT-UP(?f,?cur)])

then KronDelta (true)

////////////////////////////////////////////////////////

// These handle failed actions -- stay at current floor

///////////////////////////////////////////////////////

else if (move-current-dir(?e) ^ elevator-dir-up(?e) ^ exists_\{?next : floor\}

[elevator-at-floor(?e, ?f) ^ ADJACENT-UP (?f, ?next)])

then KronDelta ( elevator-at-floor(?e, ?f) )

else if (move-current-dir(?e) ^ elevator-dir-up(?e) ^ exists_\{?next : floor\} [elevator-at-floor(?e, ?f) ^ ADJACENT-UP (?next, ?f)])

then KronDelta( elevator-at-floor(?e, ?f) )

/////////////////////////////////////////////////////

// Otherwise elevator ?e does not move to floor ?f

///////////////////////////////////////////////////////

else

// If here, state persists

KronDelta( false);

\} ;

// Reward is a sum of waiting penalties for those in elevators and at floor reward =

[sum_\{?e: elevator $\}$ [

-ELEVATOR-PENALTY-RIGHT-DIR* (person-in-elevator-going-up (?e)^elevator-dir-up (?e))

] ] + 


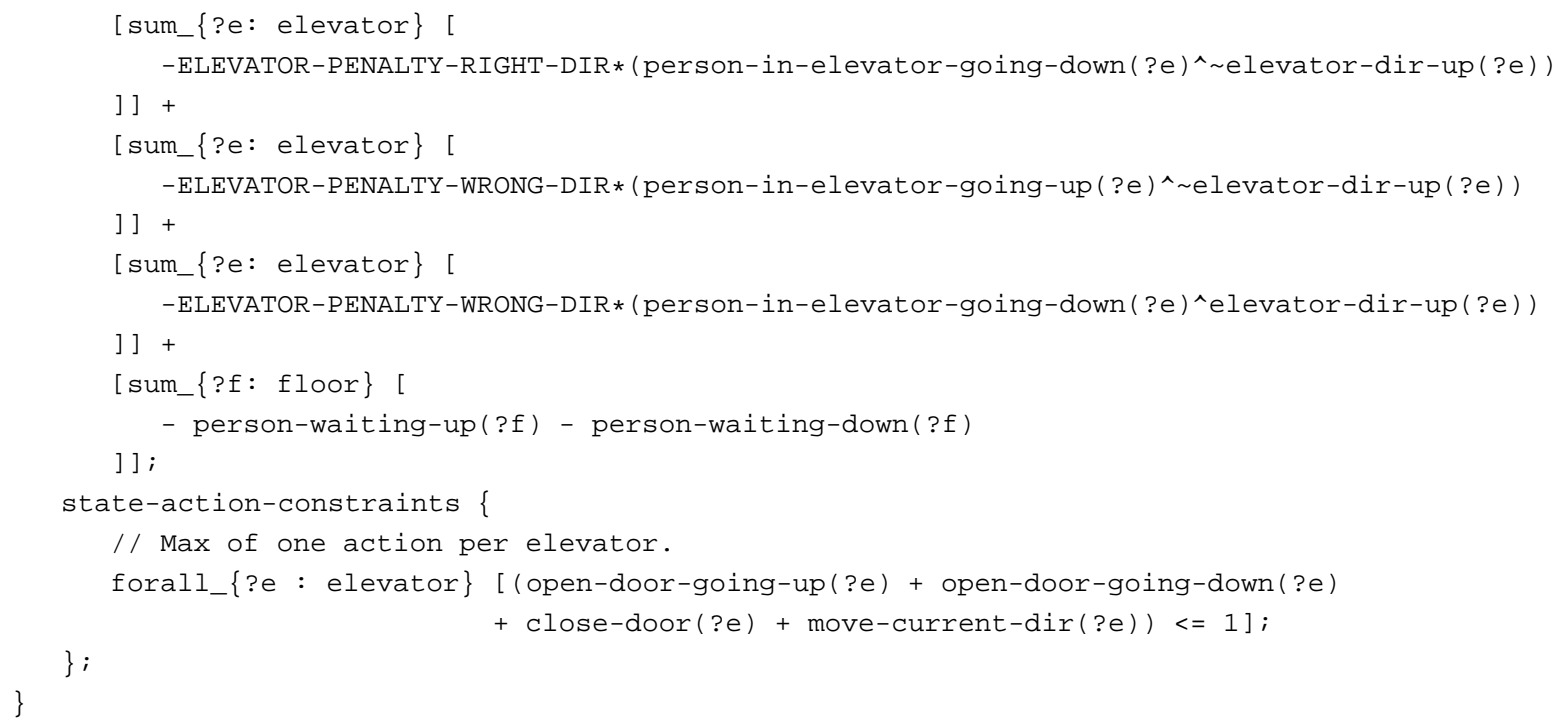

\section{D.3 Descrição do domínio Game of Life}

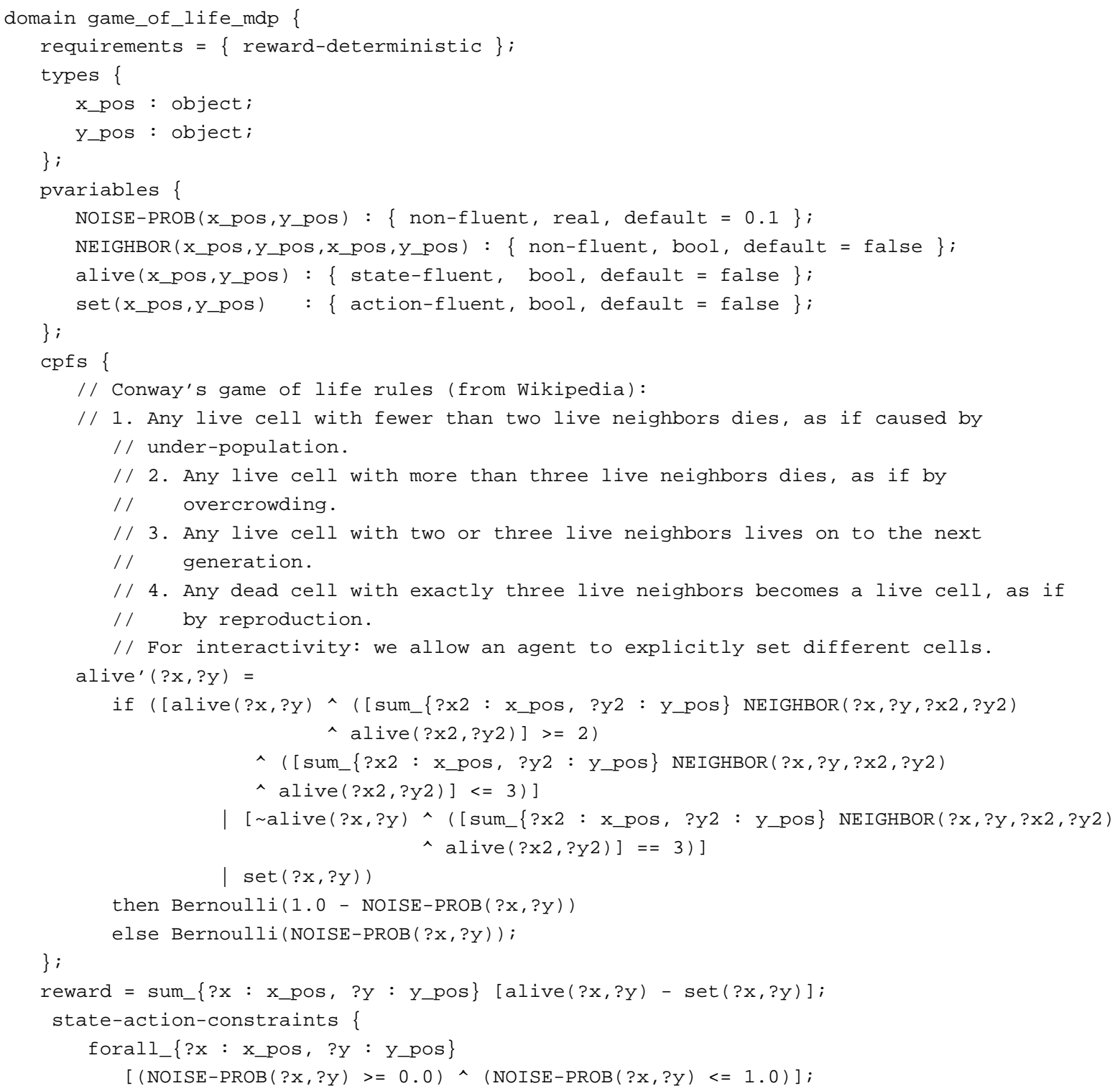




\section{D.4 Descrição do domínio Navigation}

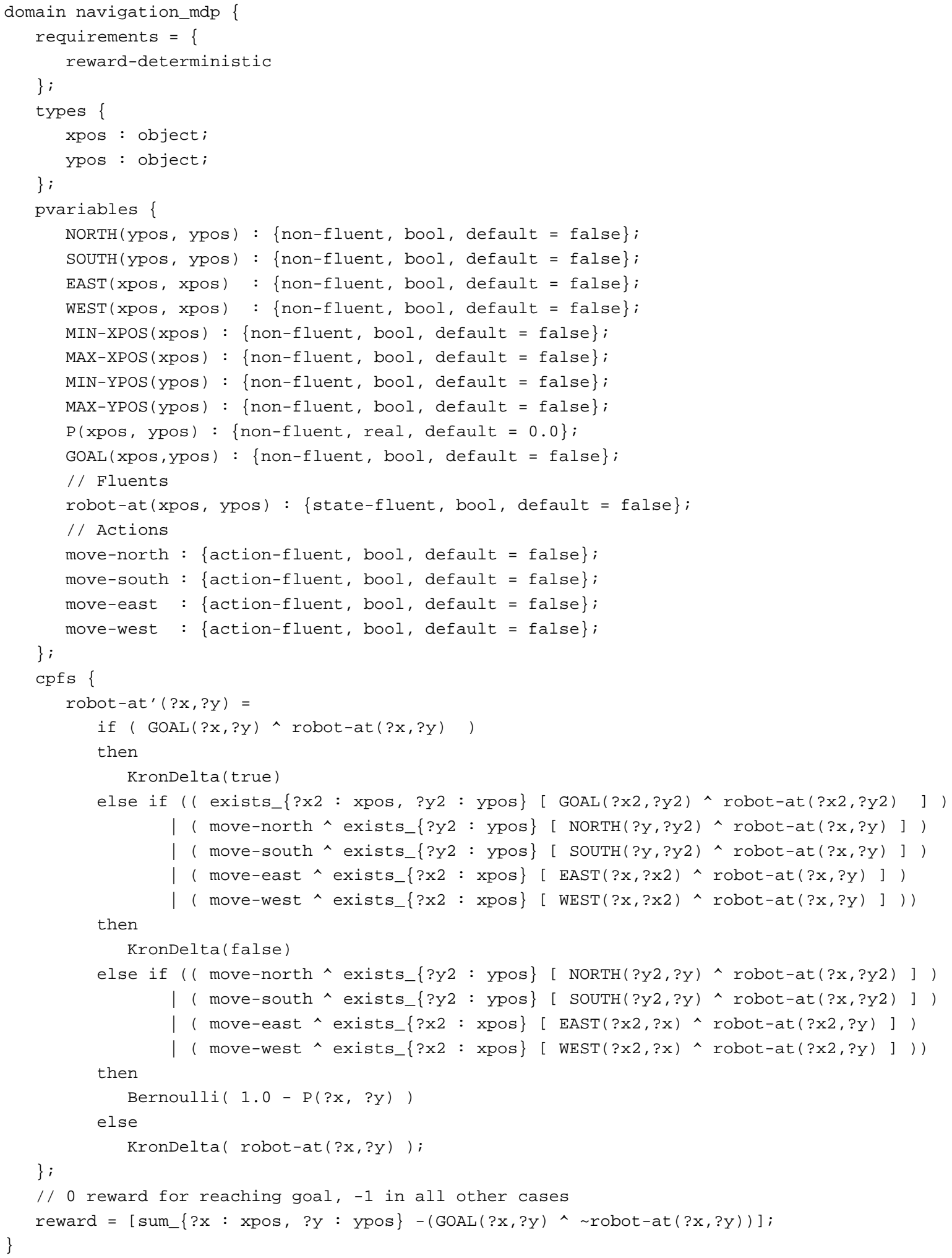




\section{D.5 Descrição do domínio Recon}

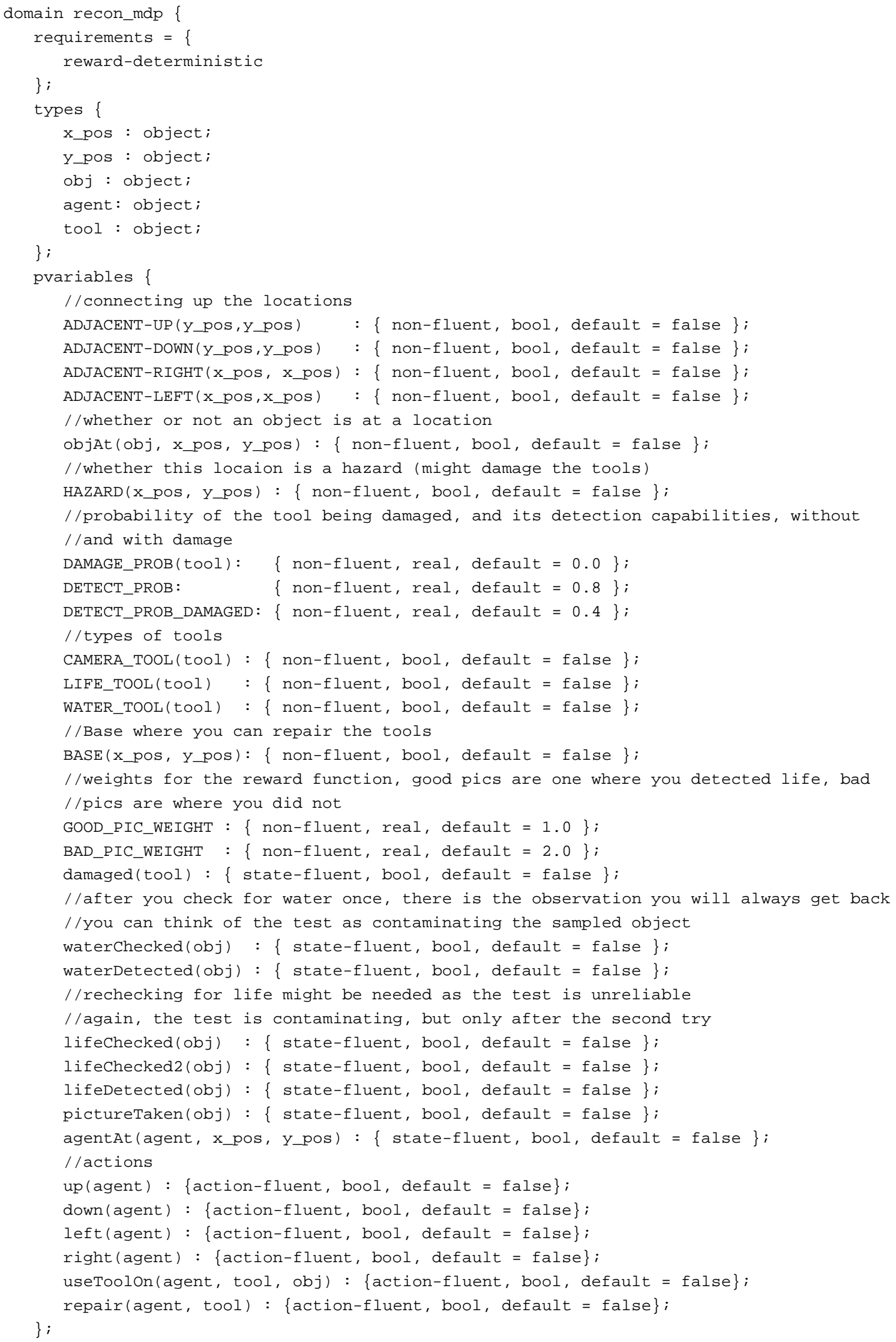


cpfs

//you can fix damage at the base and tools can be damaged by hazards, even if you

//are just adjacent to them

//NOTE: if the hazard is in your cell, you are subject to the full damage probability,

// if the hazard is only in an adjacent cell, you are subject to half the full

// damage probability,

// however, the chance is not cumulative (you are subject to one of

// \{full,half, zero\} damage probability)

damaged' (?t) =

if (damaged(?t) ^ $\sim$ (exists_\{?x : x_pos, ?y : y_pos, ?a: agent\} [agentAt (?a, ?x, ?y)

$\wedge \operatorname{BASE}(? \mathrm{x}$, ?y) repair(?a, ?t)]))

then KronDelta ( true)

else if (exists_\{?x : x_pos, ?y : y_pos, ?a: agent\} [agentAt (?a, ?x, ?y)

$\wedge \sim \operatorname{BASE}(? \mathrm{x}$, ?y) ^ $\operatorname{HAZARD}(? \mathrm{x}$, ?y) ])

then Bernoulli( DAMAGE_PROB (?t) )

else if (exists_\{?x : x_pos, ?y : y_pos, ?a: agent, ?x2 :x_pos\} [agentAt (?a, ?x, ?y)

$\wedge \sim \operatorname{BASE}(? \mathrm{x}$, ?y) ^ $\operatorname{HAZARD}(? \mathrm{x} 2, ? \mathrm{y})$

^ (ADJACENT-LEFT(?x, ?x2) | ADJACENT-RIGHT(?x, ?x2)) ])

then Bernoulli( DAMAGE_PROB (?t) / 2.0)

else if (exists_\{?x : x_pos, ?y : y_pos, ?a: agent, ?y2 :y_pos\} [agentAt (?a, ?x, ?y)

$\wedge$ BASE (?x, ?y) $\wedge \operatorname{HAZARD}(? \mathrm{x}$, ?y2)

$\wedge$ (ADJACENT-UP (?y, ?y2) | ADJACENT-DOWN(?y, ?y2)) ])

then Bernoulli(DAMAGE_PROB (?t) / 2.0 )

else //silly else structure needed because of the way adjacency is encoded

KronDelta( false);

//keeps track of whether you checked for water (which fixes the value, even if you

//used the damaged tool).

waterChecked' (?०) =

KronDelta( waterchecked(?o)

| exists_\{?x : x_pos, ?y : y_pos, ?a: agent, ?t: tool\} [agentAt (?a, ?x, ?y)

^ objAt (?o, ?x, ?y) ^ useToolon(?a, ?t, ?o) ^ WATER_TOOL(?t)]);

//first 2 cases are if you have found water and whether it has been checked, the next

//two are based on the tool being damaged or not

waterDetected' (?०) =

if (waterDetected(?o))

then KronDelta ( true)

else if (waterchecked(?o)) // Only one chance to detect water

then KronDelta( false)

else if (exists_\{?t : tool, ?x : x_pos, ?y : y_pos, ?a: agent\} [WATER_TOOL(?t)

$\wedge$ damaged (?t) ^ agentAt (?a, ?x, ?y) ^ objAt (?०, ?x, ?y)

^ useToolon (?a, ?t, ?o)])

then Bernoulli (DETECT_PROB_DAMAGED)

else if (exists_\{?t : tool, ?x : x_pos, ?y : y_pos, ?a: agent\} [WATER_TOOL (?t) agentAt (?a, ?x, ?y) ^ objAt (?o, ?x, ?y) ^ useToolon(?a, ?t, ?o) ]) then Bernoulli (DETECT_PROB)

else

KronDelta ( false)

//two lifechecked variables, only after the second check is the value fixed

lifeChecked' (?o) =

KronDelta (

lifeChecked (?o)

| exists_\{?x : x_pos, ?y : y_pos, ?a: agent, ?t: tool\} [agentAt (?a, ?x, ?y)

^ objAt (?o, ?x, ?y) ^ useToolon(?a, ?t, ?o) ^ LIFE_TOOL(?t)]);

lifeChecked2' (?०) =

KronDelta (

lifechecked2 (?०)

| lifechecked(?o)

^ exists_\{?x : x_pos, ?y : y_pos, ?a: agent, ?t: tool\} [agentAt(?a, ?x, ?y) 
//similar to waterDetected

^ objAt(?o, ?x, ?y) ^ useToolon(?a, ?t, ?o) ^ LIFE_TOOL(?t)]);

lifeDetected' (?०) =

if (lifeDetected(?०))

then KronDelta( true)

else // Never detect life after 2nd try or if no water

if (lifechecked2(?०) | waterDetected(?०))

then KronDelta ( false)

else if (exists_\{?t : tool, ?x : x_pos, ?y : y_pos, ?a: agent\} [ LIFE_TOOL(?t)

$\wedge$ damaged(?t) ^ agentAt (?a, ?x, ?y) ^ objAt (?o, ?x, ?y)

$\wedge$ usetoolon (?a, ?t, ?o) ])

then Bernoulli (DETECT_PROB_DAMAGED)

else if (exists_\{?t : tool, ?x : x_pos, ?y : y_pos, ?a: agent\} [ LIFE_TOOL(?t)

$\wedge$ agentAt (?a, ?x, ?y) ^ objAt (?o, ?x, ?y)

^ useToolon (?a, ?t, ?o) ])

then Bernoulli(DETECT_PROB)

else

KronDelta( false);

//inhibits reward for future pictures of this object

pictureTaken' (?o) =

KronDelta( exists_\{?x : x_pos, ?y : y_pos, ?a: agent, ?t: tool\} [CAMERA_TOOL(?t)

^ agentAt (?a, ?x, ?y) ^ objAt(?o, ?x, ?y) ^ useToolon(?a, ?t, ?o)

$\wedge$ damaged (?t) ] );

agentAt' $(? \mathrm{a}, ? \mathrm{x}, \mathrm{?y})=$

KronDelta(

[agentAt(?a, ?x, ?y) ^ (up(?a) | down(?a) | right(?a)| left(?a))] |

[left(?a)^exists_\{?x2 : x_pos\}[agentAt (?a, ?x2, ?y)^ADJACENT-LEFT (?x2, ?x)]]

[right (?a)^exists_\{?x2: x_pos\}[agentAt (?a, ?x2, ?y)^ADJACENT-RIGHT(?x2, ?x)]]|

[up (?a)^exists_\{?y2 : y_pos\}[agentAt (?a, ?x, ?y2)^ADJACENT-UP (?y2, ?y)] ]

[down (?a)^exists_\{?y2 : y_pos\}[agentAt (?a, ?x, ?y2)^ADJACENT-DOWN(?y2, ?y)]]);

\}

//we may want to change the way lifeDetected works because right now the same domain has // different possible rewards

// Only get rewarded for a good or bad picture the first time the action is *taken*

reward $=[$ sum_ $\{0:$ : obj $\}$

(GOOD_PIC_WEIGHT *

[ pictureTaken(?०) ^ lifeDetected(?०)

^ exists_\{?x : x_pos, ?y : y_pos, ?a: agent, ?t: tool\} [agentAt (?a, ?x, ?y)

$\wedge$ objAt (?o, ?x, ?y) ^ useToolon(?a, ?t, ?o) ^ CAMERA_TOOL (?t)

$\wedge$ damaged (?t) ] ])

] +

[sum_\{?o: obj\}

-(BAD_PIC_WEIGHT *

[ lifeDetected (?०)

^ exists_\{?x : x_pos, ?y : y_pos, ?a: agent, ?t: tool\} [agentAt (?a, ?x, ?y)

$\wedge$ objAt (?o, ?x, ?y) ^ useToolon(?a, ?t, ?o) ^ CAMERA_TOOL(?t)]])

]

\section{D.6 Descrição do domínio Skill Teaching}

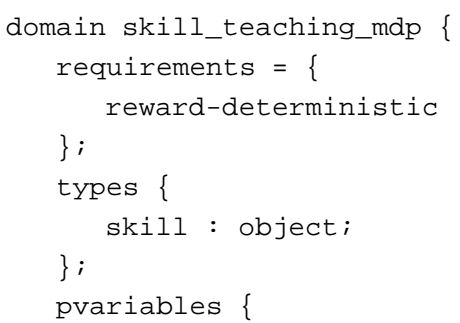


//how valuable is this skill?

SKILL_WEIGHT(skill): \{ non-fluent, real, default $=1.0\}$;

//some skills are pre-reqs for others. Your ability to achiev a higher level skill

//is dependent on how

//many of the pre-reqs you have mastered

PRE_REQ(skill, skill) : \{ non-fluent, bool, default = false $\}$;

//probability of getting a question right if you have all the pre-reqs

PROB_ALL_PRE (skill) : \{ non-fluent, real, default $=0.8$;

//if you don't have all the pre-cons, probaility mass is summed using these

//individual pieces

PROB_PER_PRE (skill) : \{ non-fluent, real, default $=0.1\}$;

PROB_ALL_PRE_MED (skill) : \{ non-fluent, real, default $=1.0\}$;

//if you don't have all the pre-cons, probaility mass is summed using these

//individual pieces

PROB_PER_PRE_MED (skill) : \{ non-fluent, real, default $=0.3\}$;

PROB_HIGH (skill) : \{ non-fluent, real, default $=0.9\}$;

LOSE_PROB (skill): \{ non-fluent, real, default $=0.02\}$;

proficiencyMed(skill) : \{ state-fluent, bool, default = false \};

proficiencyHigh(skill) : \{ state-fluent, bool, default = false \};

updateTurn(skill) : \{state-fluent, bool, default = false\};

answeredRight (skill): \{state-fluent, bool, default = false\};

hintedRight (skill): \{state-fluent, bool, default = false\};

hintDelayVar(skill) : \{state-fluent, bool, default = false\};

askProb(skill) : \{action-fluent, bool, default = false ;

giveHint(skill) : \{action-fluent, bool, default = false ;

\} ;

cpfs \{

updateTurn' (?s) =

KronDelta( [forall_\{?s2: skill\} updateTurn(?s2)] ^ (askProb(?s) | giveHint(?s))); answeredRight' (?s) =

if ([forall_\{?s2: skill\} updateTurn(?s2)] ^askProb(?s) ^ proficiencyHigh(?s)) then Bernoulli(PROB_HIGH (?s))

else if ([forall_\{?s2: skill\} updateTurn(?s2)] ^ askProb(?s) ^ proficiencyMed(?s)

^forall_\{?s3: skill\}[PRE_REQ(?s3, ?s) => proficiencyHigh(?s3)])

then Bernoulli(PROB_ALL_PRE_MED(?s))

else if ([forall_\{?s2: skill\} updateTurn(?s2)] ^ askProb(?s) ^proficiencyMed(?s)

$\wedge$ askProb(?s))

then Bernoulli(sum_\{?s2: skill\}[PRE_REQ(?s2, ?s) * PROB_PER_PRE_MED(?s)])

else if ([forall_\{?s3: skill\} updateTurn(?s3)] ^ askProb(?s)

^forall_\{?s2: skill\}[PRE_REQ(?s2, ?s) => proficiencyHigh(?s2)])

then Bernoulli(PROB_ALL_PRE (?s))

else if ([forall_\{?s2: skill\} updateTurn(?s2)] ^ askProb(?s) ^ askProb(?s))

then Bernoulli(sum_\{?s2: skill\}[PRE_REQ(?s2, ?s) * PROB_PER_PRE(?s)]) else

KronDelta( false);

hintedRight' (?s) =

KronDelta( [forall_\{?s3: skill\} updateTurn(?s3)] ^ giveHint(?s)

^forall_\{?s2: skill\}[PRE_REQ(?s2, ?s) => proficiencyHigh(?s2)] );

hintDelayVar' (?s) =

KronDelta( [forall_\{?s2: skill\} updateTurn(?s2)] ^ giveHint(?s) );

//proficiencyMed can be reached through a hint if all preconditions are known or by a //problem answered correctly

proficiencyMed' (?s) =

if ( updateTurn(?s) ^ proficiencyMed(?s))

then KronDelta ( true )

else if (updateTurn(?s) ^ hintedRight(?s))

then Krondelta ( true)

else if (updateTurn(?s) ^ answeredRight(?s)) 


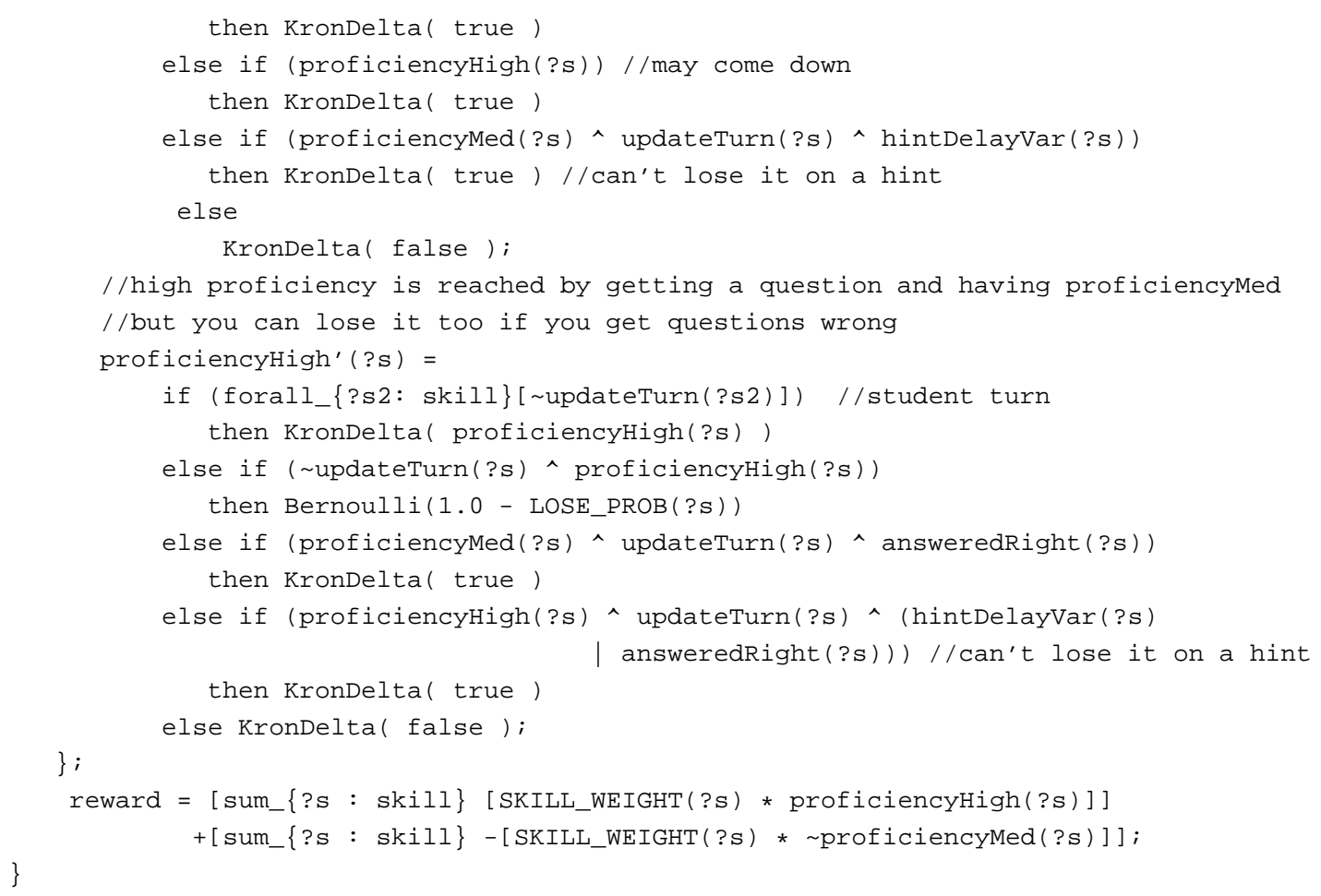

\section{D.7 Descrição do domínio SysAdmin}

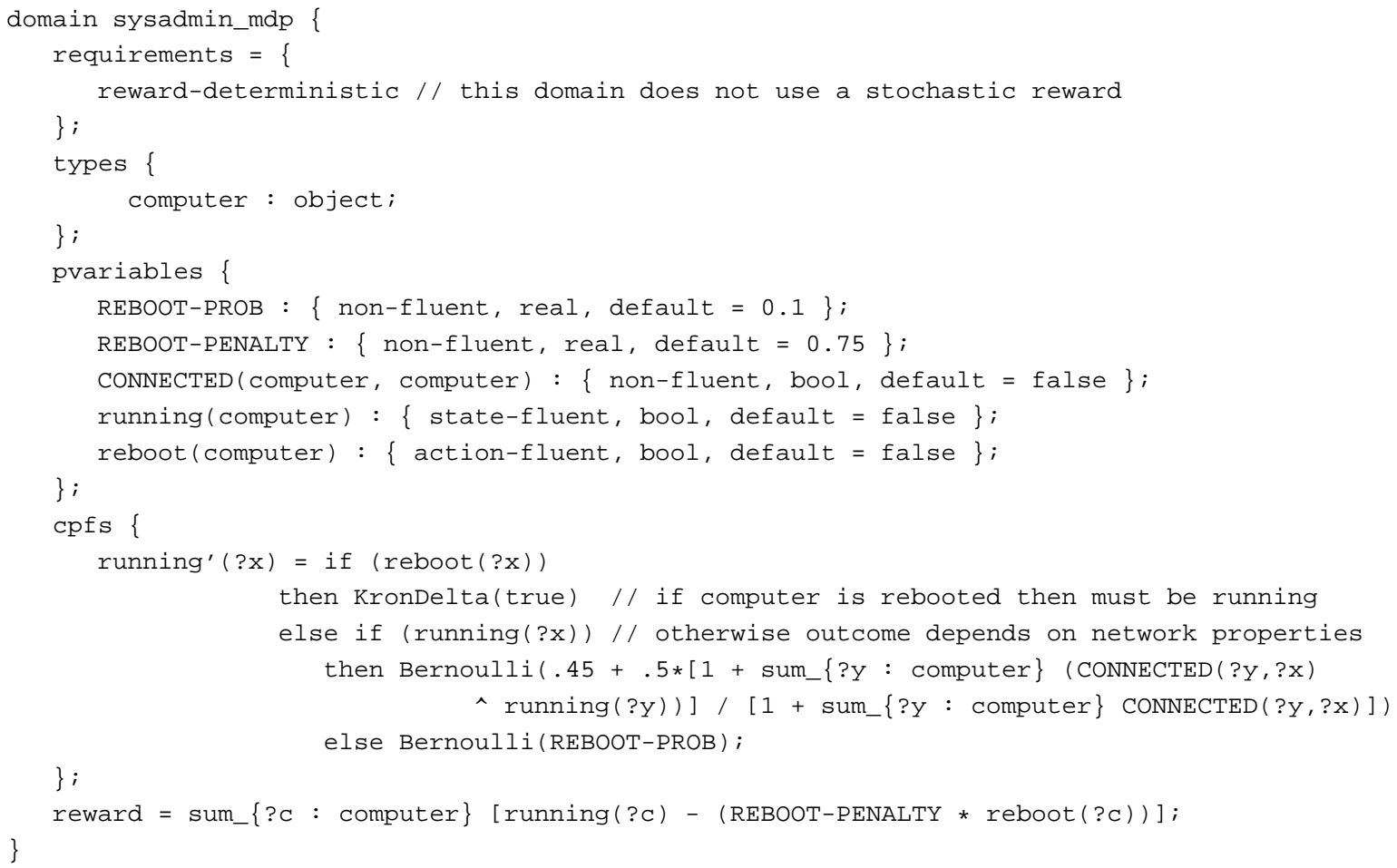

\section{D.8 Descrição do domínio Traffic}

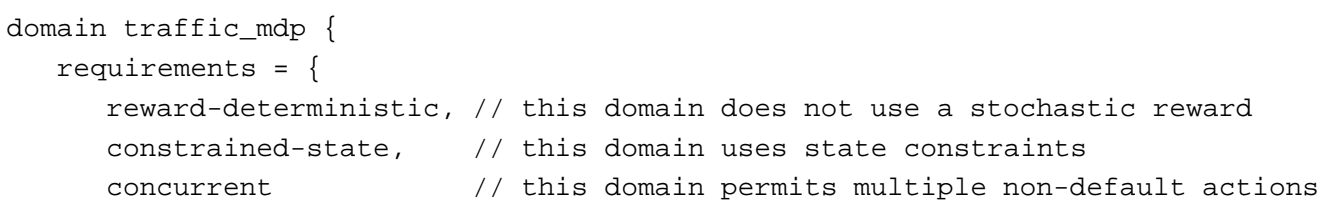




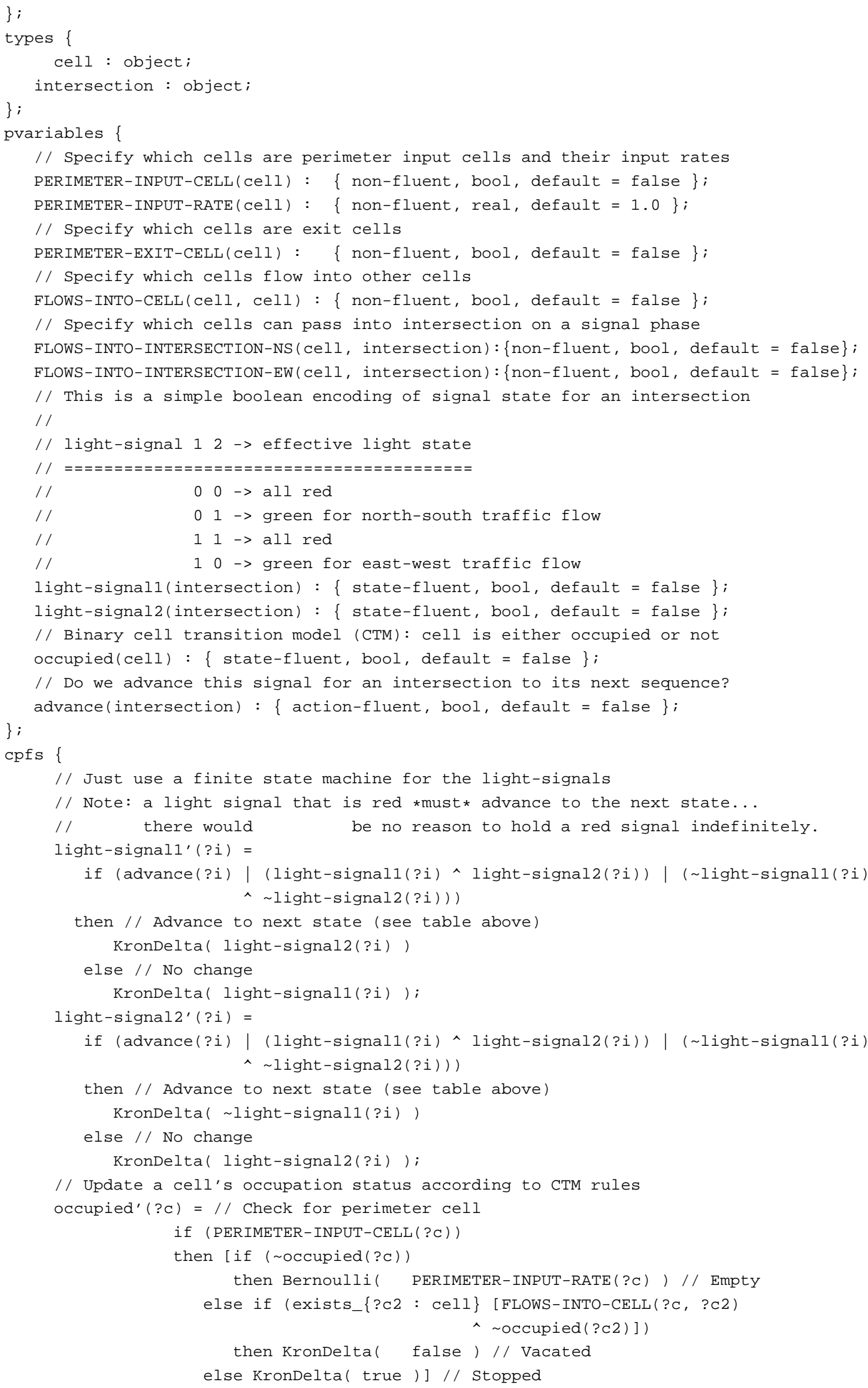




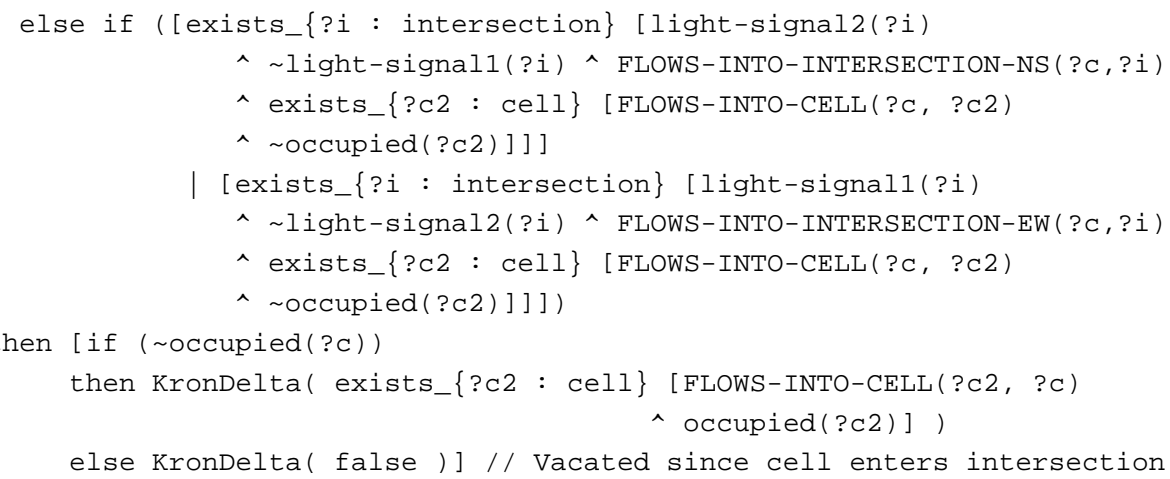
// Check for occupied cell entering intersection (if get here, must be red) else if (exists_\{?i : intersection\} ((FLOWS-INTO-INTERSECTION-NS (?c,?i) | FLOWS-INTO-INTERSECTION-EW(?c, ?i)) ^ occupied(?c)))

then KronDelta( true ) // car stuck at red light // Check cells ?c that take traffic exiting an intersection else if ( exists_\{?i : intersection, ?c2 : cell\} (FLOWS-INTO-INTERSECTION-NS (?c2, ?i) 
APÊNDICE D 


\section{Referências Bibliográficas}

Andersen(1997) Henrik Reif Andersen. An introduction to binary decision diagrams. Course Notes on the $W W W$. Citado na pág. 30

Auer et al.(2002) P. Auer, N. Cesa-Bianchi e P. Fischer. Finite-time analysis of the multiarmed bandit problem. Machine learning, 47(2):235-256. Citado na pág. 89

Bacchus(2000) Fahiem Bacchus. Artificial intelligence planning competition 2000, 2000. URL http://www.cs.toronto.edu/aips2000/. Citado na pág. 61

Bahar et al.(1993) R. Bahar, E.A. Frohm, C.M. Gaona, G.D. Hachtel, E. Macii, A. Pardo e F. Somenzi. Algebraic decision diagrams and their applications. Em Proceedings of the 1993 IEEE/ACM international conference on Computer-aided design, páginas 188-191. IEEE Computer Society Press. Citado na pág. 29

Barto et al.(1995) A.G. Barto, S.J. Bradtke e S.P. Singh. Learning to act using real-time dynamic programming. Artificial Intelligence, 72(1-2):81-138. Citado na pág. xix, 4, 11, 14, 15

Bellman(1957) R. E. Bellman. Dynamic Programming. Princeton University Press. Citado na pág. xix, $3,10,11,12,13$

Bertsekas e Tsitsiklis(1991) D.P. Bertsekas e J.N. Tsitsiklis. An analysis of stochastic shortest path problems. Mathematics of Operations Research, páginas 580-595. Citado na pág. 8

Bonet e Geffner(2003) B. Bonet e H. Geffner. Labeled RTDP: Improving the convergence of real-time dynamic programming. Em Proc. ICAPS, volume 3. Citado na pág. xix, 4, 16, 17, 18

Bonet e Geffner(2001) Blai Bonet e Hector Geffner. Planning and control in Artificial Intelligence: A unifying perspective. Applied Intelligence, 14(3):237-252. Citado na pág. 16

Boutilier et al.(1996) C. Boutilier, N. Friedman, M. Goldszmidt e D. Koller. Context-specific independence in bayesian networks. Em Proceedings of the Twelfth Conference on Uncertainty in Artificial Intelligence, páginas 115-123. Citeseer. Citado na pág. 29

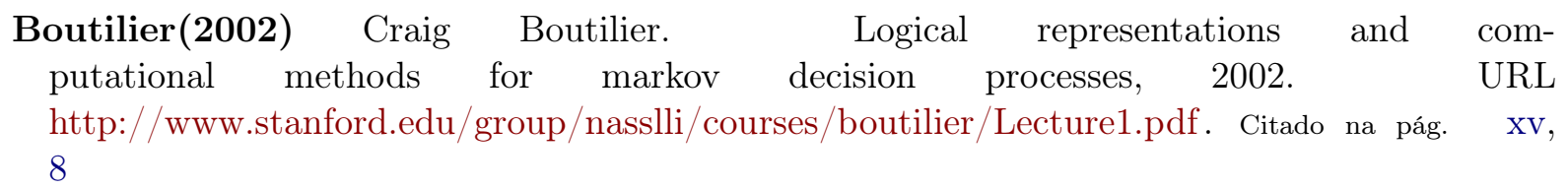

Boutilier et al.(1995) Craig Boutilier, Richard Dearden, Moises Goldszmidt et al. Exploiting structure in policy construction. Em International Joint Conference on Artificial Intelligence, volume 14, páginas 1104-1113. LAWRENCE ERLBAUM ASSOCIATES LTD. Citado na pág. 25

Boutilier et al.(1999) Craig Boutilier, Thomas Dean e Steve Hanks. Decision-Theoretic Planning: Structural Assumptions and Computational Leverage. J. Artificial Intelligence Research, 11:1-94. Citado na pág. 2, 23 
Bryant(1992) R.E. Bryant. Symbolic boolean manipulation with ordered binary-decision diagrams. ACM Computing Surveys (CSUR), 24(3):293-318. Citado na pág. 27

Dean e Kanazawa(1989) T. Dean e K. Kanazawa. A model for reasoning about persistence and causation. Computational intelligence, 5(2):142-150. Citado na pág. 24

Dearden e Boutilier(1997) Richard Dearden e Craig Boutilier. Abstraction and approximate decision-theoretic planning. Artificial Intelligence, 89(12):219 - 283. ISSN 0004-3702. doi: 10.1016/S0004-3702(96)00023-9. URL http://www.sciencedirect.com/science/article/pii/S0004370296000239. Citado na pág. 63

Delgado et al.(2010) K. Delgado, C. Fang, S. Sanner e L. de Barros. Symbolic bounded realtime dynamic programming. Advances in Artificial Intelligence-SBIA 2010, páginas 193-202. Citado na pág. xv, 4, 42, 43

Delgado et al.(2011) Karina Valdivia Delgado, Scott Sanner e Leliane Nunes De Barros. Efficient solutions to factored mdps with imprecise transition probabilities. Artificial Intelligence, 175(9):1498-1527. Citado na pág. 81

Edelkamp e Hoffmann(2004) S. Edelkamp e J. Hoffmann. PDDL2. 2: The language for the classical part of the 4th international planning competition. Fachbereich Informatik, University of Dortmund, Tech. Rep, 195. Citado na pág. 61

Feng et al.(2003) Z. Feng, E.A. Hansen e S. Zilberstein. Symbolic generalization for on-line planning. Em Proceedings of Uncertainty in Artificial Intelligence, volume 19, páginas 209216. Citeseer. Citado na pág. xix, 4, 39, 40

Fikes e Nilsson(1971) Richard E. Fikes e Nils J. Nilsson. Strips: A new approach to the application of theorem proving to problem solving. Artificial Intelligence, 2(3-4):189-208. doi: 10.1016/0004-3702(71)90010-5. URL http://dx.doi.org/10.1016/0004-3702(71)90010-5. Citado na pág. 57

Fox e Long(2003) M. Fox e D. Long. PDDL2.1: An Extension to PDDL for Expressing Temporal Planning Domains. J. Artif. Intell. Res. (JAIR), 20:61-124. Citado na pág. 61

Gardner(1970) M. Gardner. Mathematical games. Scientific American, 223(4):120-123. Citado na pág. 70,76

Gerevini et al.(2009) A.E. Gerevini, P. Haslum, D. Long, A. Saetti e Y. Dimopoulos. Deterministic planning in the fifth international planning competition: PDDL3 and experimental evaluation of the planners. Artificial Intelligence, 173(5-6):619-668. Citado na pág. 62

Ghallab et al.(1998) M. Ghallab, A. Howe, C. Knoblock, D. McDermott, A. Ram, M. Veloso, D. Weld e D. Wilkins. PDDL-the planning domain definition language. AIPS-98 planning committee. Citado na pág. 57, 58

Guestrin et al.(2003) C. Guestrin, D. Koller, R. Parr e S. Venktaraman. Efficient solution methods for factored MDPs. JAIR, 19:399-468. Citado na pág. 2, 11

Hoey et al.(1999) J. Hoey, R. St-Aubin, A. Hu e C. Boutilier. SPUDD: Stochastic planning using decision diagrams. Em Proceedings of the Fifteenth Conference on Uncertainty in Artificial Intelligence, páginas 279-288. Citeseer. Citado na pág. 4, 37, 38, 64

Howard(1960) R. Howard. Dynamic programming and markov decision processes. Cambridge, MA: MIT Press. Citado na pág. xix, 4, 11, 13, 14 
Howard e Matheson(1984) Ronald A. Howard e James E. Matheson. Influence diagrams. Readings on the Principles and Applications of Decision Analysis, 2(3):127-143. Citado na pág. 64

Kaelbling et al.(1998) L.P. Kaelbling, M.L. Littman e A.R. Cassandra. Planning and acting in partially observable stochastic domains. Artificial Intelligence, 101(1-2):99-134. Citado na pág. 64

Keller e Eyerich(2012) Thomas Keller e Patrick Eyerich. PROST: Probabilistic Planning Based on UCT. ICAPS-12. Citado na pág. 85, 89

Kocsis e Szepesvári(2006) L. Kocsis e C. Szepesvári. Bandit based monte-carlo planning. Machine Learning: ECML 2006, páginas 282-293. Citado na pág. 89

Kolobov et al.(2012) Andrey Kolobov, Peng Dai, Mausam e Daniel Weld. Reverse iterative deepening for finite-horizon mdps with large branching factors. ICAPS-12. Citado na pág. 85, 88

McCarthy(1963) John McCarthy. Situations, actions, and causal laws. Relatório Técnico Memo 2, Stanford Artificial Intelligence Project, Stanford University. Citado na pág. 1

McDermott(2000) Drew M McDermott. The 1998 ai planning systems competition. AI magazine, 21(2):35. Citado na pág. 61

McMahan et al.(2005) H. Brendan McMahan, Maxim Likhachev e Geoffrey J. Gordon. Bounded real-time dynamic programming: RTDP with monotone upper bounds and performance guarantees. Em Proceedings of the 22nd international conference on Machine learning, ICML '05, páginas 569-576, New York, NY, USA. ACM. ISBN 1-59593-180-5. doi: http: //doi.acm.org/10.1145/1102351.1102423. URL http://doi.acm.org/10.1145/1102351.1102423. Citado na pág. xix, 20, 21

Nau et al.(2004) Dana Nau, Malik Ghallab e Paolo Traverso. Automated Planning: Theory E Practice. Morgan Kaufmann Publishers Inc., San Francisco, CA, USA. ISBN 1558608567. Citado na pág. 14

Newell e Simon(1963) A. Newell e H.A. Simon. GPS, a program that simulates human thought. Computers and thought, páginas 279-293. Citado na pág. 1

Pednault(1989) E.P.D. Pednault. ADL: Exploring the middle ground between STRIPS and the situation calculus. Em Proceedings of the first international conference on Principles of knowledge representation and reasoning, páginas 324-332. Morgan Kaufmann Publishers Inc. Citado na pág. 57

Pereira(2003) S. L. Pereira. Planejamento em Inteligência Artificial. URL http://www.ime.usp.br/ ${ }^{\text {slago/slago-plan.pdf. Citado na pág. } 1}$

Puterman(1994) Martin L. Puterman. Markov Decision Processes: Discrete Stochastic Dynamic Programming. Wiley-Interscience. ISBN 0471619779. Citado na pág. 7, 12

Russell e Norvig(2010) S.J. Russell e P. Norvig. Artificial intelligence: a modern approach. Prentice hall. Citado na pág. 1

Sanner e Kersting(2010) S. Sanner e K. Kersting. Symbolic dynamic programming for firstorder POMDPs. Em In Proceedings of the 24th AAAI Conference on Artificial Intelligence (AAAI-10), Atlanta, Georgia. Citado na pág. 64 
Sanner(2011) Scott Sanner. International probabilistic planning competition, 2011. URL http://users.cecs.anu.edu.au/ ssanner/IPPC_2011/. Citado na pág. 64, 73, 95

Sanner(2010) Scott Sanner. Relational Dynamic Influence Diagram Language (RDDL): Language Description. Citado na pág. 6, 64, 73

Sanner e Yoon(2010) Scott Sanner e Sungwook Yoon. rddl.sim RDDL simulator, 2010. URL http://code.google.com/p/rddlsim/. Citado na pág. 85

Sanner(2008) S.P. Sanner. First-order decision-theoretic planning in structured relational environments. Tese de Doutorado, University of Toronto. Citado na pág. xv, xix, 30, 31, 33, 34, 105

St-Aubin et al.(2001) R. St-Aubin, J. Hoey e C. Boutilier. APRICODD: Approximate policy construction using decision diagrams. Advances in Neural Information Processing Systems, páginas 1089-1096. Citado na pág. 38, 39, 52

Younes e Littman(2003) H.L.S. Younes e M.L. Littman. PPDDL1. 0: An extension to PDDL for expressing planning domains with probabilistic effects. Em In Proceedings of the 14th International Conference on Automated Planning and Scheduling. Citeseer. Citado na pág. 6, 57, 62,64 